\title{
Social assistance and remittances and their role in the fight against poverty
}

Citation for published version (APA):

Waidler, J. (2018). Social assistance and remittances and their role in the fight against poverty. [Doctoral Thesis, Maastricht University]. Datawyse / Universitaire Pers Maastricht. https://doi.org/10.26481/dis.20181004jw

Document status and date:

Published: 01/01/2018

DOI:

10.26481/dis.20181004jw

Document Version:

Publisher's PDF, also known as Version of record

\section{Please check the document version of this publication:}

- A submitted manuscript is the version of the article upon submission and before peer-review. There can be important differences between the submitted version and the official published version of record.

People interested in the research are advised to contact the author for the final version of the publication, or visit the DOI to the publisher's website.

- The final author version and the galley proof are versions of the publication after peer review.

- The final published version features the final layout of the paper including the volume, issue and page numbers.

Link to publication

\footnotetext{
General rights rights.

- You may freely distribute the URL identifying the publication in the public portal. please follow below link for the End User Agreement:

www.umlib.nl/taverne-license

Take down policy

If you believe that this document breaches copyright please contact us at:

repository@maastrichtuniversity.nl

providing details and we will investigate your claim.
}

Copyright and moral rights for the publications made accessible in the public portal are retained by the authors and/or other copyright owners and it is a condition of accessing publications that users recognise and abide by the legal requirements associated with these

- Users may download and print one copy of any publication from the public portal for the purpose of private study or research.

- You may not further distribute the material or use it for any profit-making activity or commercial gain

If the publication is distributed under the terms of Article $25 \mathrm{fa}$ of the Dutch Copyright Act, indicated by the "Taverne" license above, 
This page (0) is temporarily added. It is added in Word so you can easily view two pages together on the screen in a "bookview". Showing uneven pages on the right side and even numbered pages on the left side of the screen.

Please don't remove het RED and GREEN text on each chaptertittlepage.

These red and green textlines are connected to the runningtittles on each page.

Of course these coloured textlines will not be printed in your book!

You may alter the text of these coloured textlines to your needs. By editing these lines to your need you change the text of the running tittles form that page on.

In this wordfile you will still see some unneccessay page numbers for example on empty pages. In the final pdf for print all these unnecessary elements will be automatically removed. 
Social Assistance and Remittances and Their Role in the Fight Against Poverty 
C copyright Jennifer Waidler, Maastricht 2018

Illustration cover: Melanie Waidler

Printing: Datawyse | Universitaire Pers Maastricht

ISBN 9789463800013 


\title{
Social Assistance and Remittances and Their Role in the Fight Against Poverty
}

\author{
DISSERTATION \\ to obtain the degree of Doctor at Maastricht University, \\ on the authority of the Rector Magnificus, Prof. Dr. Rianne M. Letschert \\ in accordance with the decision of the Board of Deans, \\ to be defended in public on \\ Thursday 4 October 2018, at 16.00 hours \\ by
}

Jennifer Waidler 


\section{Promoters}

Prof. Dr. Pierre Mohnen

Prof. Dr. Franziska Gassmann

Prof. Dr. Melissa Siegel

\section{Assessment Committee}

Prof. Dr. Valentina Mazzucato (chair)

Prof. Dr. Armando Barrientos (Manchester University)

Dr. Jessica Hagen-Zanker (Overseas Development Institute)

Dr. Zina Nimeh 
To my parents, Alicia and Gustavo, for encouraging me to follow my dreams, for teaching me how to be strong, and for showing me how to never give up.

A mis papás, Alicia y Gustavo, por animarme a perseguir mis sueños, por enseñarme a ser fuerte, y por mostrarme cómo nunca darse por vencido 


\section{Table of contents}

List of figures 9

List of tables 9

$\begin{array}{ll}\text { Chapter } 1 \text { Introduction } & 17\end{array}$

1.1 Introduction 19

1.2 Motivation 20

1.3 Defining and measuring poverty 23

1.4 Contribution 25

1.5 Case studies and datasets used 26

1.6 Thesis outline $\quad 30$

References 33

Chapter 2 On the Fungibility of Public and Private Transfers: A Mental Accounting $\begin{array}{ll}\text { Approach } & 37\end{array}$

2.1 Introduction 39

2.2 Literature review $\quad 40$

2.3 The case of South Africa: migration, remittances and social protection transfers 42

2.4 Demand model and empirical analysis 46

2.5 Data 49

2.6 Results $\quad 54$

2.7 Discussion $\quad 68$

References $\quad 70$

Chapter 3 Social Grants, Remittances, and Food Security: Does the Source of Income

Matter? $\quad 72$

3.1 Introduction 74

$\begin{array}{ll}3.2 \text { Literature review } & 75\end{array}$

3.3 Data and indicators 81

3.4 Empirical strategy 83

3.5 Descriptive Statistics $\quad 85$

3.6 Results 91

3.7 Discussion: why are social grants failing to improve nutrition outcomes in South

Africa, or why is their effect not bigger? $\quad 97$

3.8 Conclusion 99

$\begin{array}{lr}\text { References } & 100\end{array}$

$\begin{array}{ll}\text { Appendix } 3 & 103\end{array}$ 
Chapter 4 From Cradle to Grave? Poverty, Social Assistance, and Subjective Wellbeing in Kyrgyzstan 110

4.1 Introduction 112

4.2 Analytical framework 113

4.3 Social assistance and poverty in Kyrgyzstan 116

4.4 Empirical strategy $\quad 117$

4.5 Data and descriptive statistics $\quad 120$

4.6 Results 123

4.7 Conclusion $\quad 130$

References $\quad 133$

$\begin{array}{ll}\text { Appendix } 4 & 135\end{array}$

Chapter 5 In pursuit of happiness: do remittances improve subjective well-being? 142

5.1 Introduction 144

5.2 Case study: Kyrgyzstan 146

5.3 Data and methodology 147

5.4 Results 150

5.5 Conclusion $\quad 159$

References 161

Appendix 5

$\begin{array}{ll}\text { Chapter } 6 \text { Conclusion } & 168\end{array}$

6.1 Key findings and implications $\quad 170$

6.2 Remittances, social assistance, and poverty $\quad 175$

6.3 Limitations and directions for future research 178

$\begin{array}{ll}\text { 6.4 Concluding remarks } & 179\end{array}$

References 181

$\begin{array}{ll}\text { Valorisation } & 184\end{array}$

$\begin{array}{lr}\text { About the author } & 188\end{array}$

$\begin{array}{ll}\text { Selected publications } & 190\end{array}$ 


\section{List of figures}

Figure 2.1: Percentage of households receiving transfers

Figure 3.1: Per capita income from social grants and remittances by expenditure deciles (whole sample)

Figure A4.1: distribution of the probability of receiving social assistance before

(a) and after (b) applying inverse probability weights

Figure 5.1: Average life satisfaction by remittance recipient status 151

Figure 5.2: Subjective economic well-being by transfer recipient status

\section{List of tables}

Table 2.1: Average value (in Rands) of transfers received and gender of recipients

Table 2.2: Expenditure shares according to recipient status in 2008

Table 2.3: Main descriptive statistics according to recipient status (2008)

Table 2.4: Summary statistics

Table 2.5: Effects of income and transfer amounts on expenditure patterns-

Whole sample

Table 2.6: Effects of income and transfer amounts on expenditure patternsAfrican sample

Table 2.7: Effects of income and transfer amounts on expenditure patternsSocial transfer recipients

Table 2.8: Effects of income and transfer amounts on expenditure patternsKwaZulu-Natal

Table 2.9: Effects of income and transfer amounts on expenditure patternscontrolling for recipient's gender

Table 2.10: Effects of income and transfer amounts on expenditure patternscontrolling for frequency of payments

Table 2.11: Effects of income and transfer amounts on expenditure patternscontrolling for poverty status

Table 3.1: Economic characteristics by transfer recipient status

Table 3.2: Food security outcomes by recipient status

Table 3.3: Fixed Effects regressions - Effect of transfers on Dietary Diversity Index

Table 3.4: Marginal effects of transfers on Dietary Diversity Index- Random Effects Ordered Probit (whole sample)

Table 3.5: Fixed Effects regressions - Effect of transfers on adult BMI 
Table 3.6: Fixed Effects regressions - Effect of transfers on children BMI

Table 3.7: Conditional logits - Odds ratios of being food secure, not underweight, not overweight

Table 3.8: Fixed effects IV estimates of the effects of the Older Person's Grant on DDI and nutrition

Table 3.9: Average treatment effects of the Child Support Grant on DDI and nutrition (pooled sample from 2008 and 2010)

Table A3.1: Descriptive statistics of the variables used in the analysis 103

Table A3.2: Effect of transfers on Dietary Diversity Index 104

Table A3.3: Effect of transfers on adult BMI 105

Table A3.4: Effect of transfers on children BMI 106

Table A3.5: Conditional logits - Odds ratios of being food secure, not $\begin{array}{ll}\text { underweight, not overweight } & 107\end{array}$

Table A3.6: Probit estimates: probability of receiving the Child Support Grant

Table A3.7: Matching quality

Table 4.1: Social assistance characteristics by year

Table 4.2: Subjective well-being by recipient status (pooled sample)

Table 4.3: Differences between recipients and non-recipients before and after matching

Table 4.4: Association between social assistance and subjective well-being with inverse probability weights (pooled data)

Table 4.5: Association between social assistance and subjective well-being with inverse probability weights (cross-sections)

Table 4.6: Difference in difference estimation (years 2011, 2012, and 2013) 129

Table 4.7: Difference in difference estimation with inverse probability weights (years 2011 and 2012)

Table 4.8: Heterogeneity of the effect of social assistance regarding age (pooled sample)

Table A4.1: Probability of receiving social assistance (marginal effects) 135

Table A4.2: Matching quality 135

Table A4.3: Summary statistics $\quad 137$

Table A4.4: Association between social assistance and subjective well-beingcross-sections

Table A4.5: Difference in difference estimation, full model

Table A4.6: Difference in difference estimation with inverse probability weights, full model

Table A4.7: Personality index, factor analysis 
Table A4.8: Asset index, factor analysis

Table 5.1: Transfer incidence by year 150

Table 5.2: Effects of remittances on life satisfaction 155

Table 5.3: Effects of remittances on subjective economic well-being with respect $\begin{array}{ll}\text { to the past } & 156\end{array}$

Table 5.4: Effects of remittances on subjective economic well-being with respect to the future

Table 5.5: Second-stage IV results 158

Table 5.6: Control function estimates 159

Table A5.1: Summary statistics at baseline (2011) 163

Table A5.2: First-stage IV regression 164

Table A5.3: Effects of receiving remittances on life satisfaction 165

Table A5.4: Effects of receiving remittances on subjective economic well-being with respect to the past 166

Table A5.5: Effects of receiving remittances on subjective economic well-being with respect to the future 


\section{Acknowledgements}

As many Master students who come to Maastricht, I thought I would be in this city for only one year. But our future is a function of small decisions we make, specific circumstances we face, and a random component which includes luck and coincidences. Doing a $\mathrm{PhD}$ was not in my head, but life factors ended up pointing towards it, and embarking in the journey of writing this book ended up being the dependent variable.

Like most big projects in life, I would not have been able to write this book without the support of many people I had the pleasure to meet and to work with during these years. First and foremost, I would like to thank my supervisors: Melissa, Franziska, and Pierre. Melissa and Franziska, thanks to you I decided to start the $\mathrm{PhD}$ in the first place. More than supervisors, you are role models to me. Not many young researchers have the pleasure to work with two strong women who do not include impossible in their vocabulary. Thank you for always believing in me, even more than I did sometimes. And thank you for helping me to find my passion. Melissa, thank you for creating a great working environment and team, for encouraging me to run and be more sportive, for the great dinners and parties I had the pleasure to attend, and many other things. Franziska, thanks for being so direct and caring at the same time. I have learnt a lot from you. Pierre, you are the best example that excellence and modesty can go hand in hand. I will always be in debt with you for challenging me in econometrics and making me a better researcher. Although I always left the meetings with you slightly overwhelmed, thank you for always asking me to try more and different estimations. You have made my thesis more robust :).

I also want to thank the members of reading committee, Valentina Mazzucato, Armando Barrientos, Zina Nimeh, and Jessica Hagen-Zanker, for reviewing my thesis and giving me detailed and very helpful feedback. It has been an honour to have you reading this book.

I would like to extend my gratitude to the directors of the $\mathrm{PhD}$ programme, Robin and Tatiana, as well as all the support and administrative staff of UNU-MERIT, who are always available to help us with everything we need. Special thanks go to Eveline (thanks for being always so helpful!), Marc, Susan (thanks for your patience during my multiple visits to your office asking for money :)), Sueli, and Herman (thank you for being interested in our aquarium and giving us the 2 little fishes), and Danny (your football pools are the best). During my time in Maastricht, I also had the pleasure to work, exchange ideas, get feedback, or have fun conversations with professors and researchers other than my supervisors. Thank you, Bruno, Zina, Mindel, Nyasha, Stephan, Nils, and Maty.

Doing a PhD gave me the opportunity to travel to many places to present my work. I am thankful for the useful feedback I received at the conferences I attended in Romania, 
Kyrgyzstan, Washington, Bonn, Maastricht, Brussels, and Buenos Aires. I also had the opportunity to do a research stay at the Economic Policy Research Institute (EPRI) and at the Centre of Excellence in Food Security in South Africa. Thank you for welcoming me there, and especially, thank you Stephen Devereux for your enthusiasm in writing a paper with me. I have learnt a lot from you and I really enjoyed our conversations, not only on social protection, but also on South Africa, nutrition, and politics!

It has also been a pleasure to be part of the migration group, with whom I shared work and many projects, but also nice and fun dinners and Christmas parties! Michaella, I really enjoyed working with you in the Moldova and Georgia project. I certainly learnt a lot and was a good training for the $\mathrm{PhD}$ ! Katrin, it was fun living with you and meeting you in the basement corridors to release the stress. I also thank the multiple office mates I had during these years, especially Danilo, Sheng, Inez, and Giulia.

Maastricht gave me the opportunity to meet so many great people with whom I spent so many amazing moments that I would need another thesis to talk about them. I have been lucky to have a great batch, the 2013 batch, always willing to help and support each other. It has been great to share the stressful and the non-stressful moments with you. I leave Maastricht with real friends, many of which I am sure I will meet again. The Argentineans, or adopted Argentineans, or extended Latin community: Juli, Agus, Alejandro L., Francesca, Juanca, Alejandro G., Simone, Fernando, Carmen, Elisa, and Alison: thank you for the great barbeques and dinners, for introducing me in the Fernet world, and for suffering the World Cup with me (some of you). To my friends from the Wife Lunch Club: Iulia, Paula, Giacomo, Tobias, Mary, Bea, Danilo, Alison, Elisa, Andrea, Michelle, and Emanuele. You are amazing! Eating with you was the most enjoyable part of the day, and I still feel close to you thanks to the chat. Thank you Mary, Elisa, and Alison for organizing so many gatherings and parties at your place! I would also like to thank my former housemates, Clotilde, Eli, and Silvia: I had a great time with you and I have been very happy in that house! I would also like to mention other friends with whom I shared great moments, parties, and football at Peters: Sergio, Gintare, Mueid, Cho, Hugo, Mario, Shivani, Tamara. And I am sure I'm forgetting a lot of people...Special thanks to my Paranymphs, Bea and Julieta, thanks a lot for being with me in this very special moment!

In this 30 years of life, I have been lucky to have the chance to meet people from almost every country in the planet. I have friends from many different nationalities, but I can say that for me the Galician ones are the most loyal friends I could have ever found. XORNADAS, thanks for the great summers and holidays we spent together in Vigo. For all the amazing days in the beach, road trips, dinners, parties, barbeques, festivals, and a long etcetera. You are the best medicine for the stress and for the bad moments. With you I feel time does not pass and we never stop being young. 
Probably, the best years of my life happened in Getafe (Madrid), during my university years. One of the best decisions I made in my life was to study at Carlos III de Madrid and to live in a guesthouse (la residencia "Fernando de los Rios"), with a family of 300 people. Apparently, it is possible to have fun every day and still finish the degree :). Fiestas del novato, de navidad, semanas del ocio, trips to Tarifa, Fuengirola, Paris, Prague, Lugo, Berlin, Barcelona, Fallas, Burgos, Brussels, Cantabria, Turkey, Portugal... Years pass and we still manage to see each other every Christmas and every time we have a chance. Thank you for the great time, the laughs, and the inspiring discussions. I admire you and you encourage me to challenge and give more of myself every day. Not many people are lucky to have friends who lock you in a room and don't let you leave until you do not send you paper to the supervisors:)

I would also like to thank the Spanish State, for giving me access to the best public education and health. Family counts, effort counts, hard work counts, but without a government that supports you when nobody else can, only the lucky ones can succeed. Good institutions and a Welfare State is the best way we have to fight inequality and make sure everybody has a chance.

I also want to send a warm hug to my family in Buenos Aires, who is always there despite the thousand kilometres that separate us.

To the best friends that one can find, "Las Frupis", for knowing me so well and always having the best advices. Thanks to the 200 messages per day on WhatsApp, I never feel I am far away from you. After so many years and despite each one of us having a different personality, we keep being as close as when we were 15 years old. Also, to Olalla and Maria, for always being there, in the most important moments, including my defence! I am sure we will keep sharing amazing times together.

Finally, I would not be who I am and I would not have become the professional I am without the support of my parents and all the efforts and sacrifices they have made for me. You made me value education, gave me the wings to pursue my dreams (no matter where I had to go), and always pushed me to give my best in everything I did. I think that what makes human beings great is not what they achieve or how much they succeed, but how they recover from the bad moments and keep fighting. You are an example of that. I also have the greatest sister I could have wished for! You teach me a lot, even if you are much younger than me. Thanks for the beautiful cover and for being so caring, funny, and a great friend. Los quiero mucho y esta tesis se la dedico a ustedes.

Firenze, 3 September 2018 
Chapter 1

Introduction

\section{1 \\ Chapter 1}

Introduction

Overcoming poverty is not a gesture of charity. It is an act of justice. It is the protection of a fundamental human right: the right to dignity and to a decent life.

(Nelson Mandela)

The test of our progress is not whether we add more to the abundance of those who have much; it is whether we provide enough for those who bave too little.

(Franklin D. Roosevelt) 
Chapter 1 


\subsection{Introduction}

Ending poverty is the first sustainable development goal that the United Nations, supported by governments and other international organisations, has set for 2030. Although poverty rates have decreased by more than half in recent decades, more than 767 million people are still living on less than the international poverty line of US\$1.90 a day (World Bank 2016a). Weak institutions, imperfect financial markets, insufficient redistribution, and a slowdown in the economic growth rates of China and other emerging economies, mean that economic growth will be insufficient to eradicate extreme poverty (World Bank 2016a; Bluhm et al. 2014).

Governments around the world have therefore adopted social protection programmes as one of the key elements of their poverty reductions strategies (Bastagli et al. 2016; Barrientos 2013). Social protection is usually defined as the set of "policies and actions which enhance the capacity of the poor and vulnerable to escape poverty and better manage risks and shocks" (OECD 2009, p.10). Social protection and, in particular, noncontributory transfers or social assistance, is crucial to reduce poverty and increase the resilience of the poor. In fact, the third target of the first Sustainable Development Goal calls for the implementation of "nationally appropriate social protection systems and measures for all, including floors, and by 2030 achieve substantial coverage of the poor and vulnerable".1

In recent decades, investment in social protection programmes has increased significantly in the developing world, and social assistance transfers now reach more than 1.9 billion people in almost all developing countries (Honorati et al. 2015). The expansion in coverage followed the increased spending in social protection, both in absolute as well as in relative terms. On average, developing and transition economies spend 1.6 percent of their GDP on social assistance (World Bank 2017a). ${ }^{2}$ According to estimates from the World Bank based on the ASPIRE database, social assistance lifts 69 million people out of absolute poverty each year (World Bank 2017a).

Although many households rely on social protection to make ends meet, many poor households do not have access to, or are not covered by government interventions. As a result, they depend on informal strategies to achieve better living standards. Migration -through remittances- is one of such strategies, especially when defined as a risk mitigation strategy that reduces financial vulnerability and raises household living standards (Stark and Bloom 1985). Remittances, or money sent back home by emigrants from abroad, can contribute to improving the living conditions of the poor by diversifying the sources of income available to a household and increasing the total value of incoming

\footnotetext{
${ }^{1}$ https://sustainabledevelopment.un.org/sdg1

2 The World Bank refers to social assistance (or non-contributory transfers aimed at reducing poverty) as Social Safety Nets.
} 
monetary flows. Based on this definition, migration can be understood as a form of informal social protection (UNICEF 2012).

Although the poverty reduction potential of remittances is not mentioned in the first Sustainable Goal ("No poverty"), the 2030 Agenda calls for a reduction in the transaction costs of remittances in SDG 10 and explicitly refers to migration in SDGs 8, 16, and 17 (Foresti and Hagen-Zanker 2017). Remittance flows to developing countries have been increasing steadily and were estimated at $\$ 429$ billion in 2016 (World Bank 2017b), as compared to $\$ 81.3$ billion in 2000 (World Bank 2010), and there is broad evidence of positive effects of remittances on well-being outcomes such as income, health, and education (Ratha 2013).

The aim of this dissertation is to look at the effects of both social assistance and remittances on a wide range of outcomes, from expenditure patterns to food insecurity and subjective well-being. By doing so, it explores and compares their role in the fight against poverty, one of the primary goals of both transfers. In recognising that migration (through remittances) can be considered an informal social protection strategy, this thesis adopts a broader approach to social protection that includes private transfers (remittances), and defines social protection as "the set of public and private mechanisms that protect and prevent individuals and households from suffering the worst consequences of shocks and stresses" (Brunori and O'Reilly 2010, p.2). Moreover, in this thesis social assistance is defined as cash or in-kind transfers received by certain groups of the population -generally poor and vulnerable families- and which are independent from the level of contributions made by recipients. This work does not focus, therefore, on other types of social protection benefits such as social insurance.

Social assistance and remittances are both important dimensions in the reduction of poverty and, despite the fact that they share many similarities, there is scant literature comparing the two types of transfers (Hagen-Zanker and Himmelstine 2015). This thesis, therefore, explores whether the effects of social assistance and remittances on poverty reduction differ and, if this is the case, the mechanisms driving these differences. Section 1.2 describes the motivation for this research, whereas Section 1.3 discusses the definition of poverty used in this work. Sections 1.4 describes the academic and societal contributions of this dissertation, whereas Section 1.5 describes the case studies chosen. Finally, Section 1.6 provides the outline of the thesis.

\subsection{Motivation}

Many studies have analysed the effects of social protection transfers or remittances on household well-being. Although the specific impacts of transfers differ across countries depending on the characteristics of the migration process and the type and design of the 
social protection programme in place, social transfers and remittances are, in general, positively related to well-being. A review of all the available studies from 2000 until 2015 measuring the impact of social assistance programmes on well-being finds, with a few exceptions, that cash transfers consistently reduce monetary poverty and improve nonmonetary well-being indicators such as education and health (Bastagli et al. 2016). In addition, a review of studies on the effects of remittances concludes that this source of income improves several measures of well-being including income, consumption, asset accumulation, and educational attainment (Ratha et al. 2011).

The relationship between the two transfers remains understudied, however. Contrary to expectations that remittances and social assistance would have similar effects on wellbeing, there is limited evidence suggesting that remittances and social assistance transfers are substitutes for raising living standards. In addition, some studies argue that they may complement each other (Van den Berg and Viet Cuong 2011; McDade 2010, and Hernandez et al. 2012).

A rigorous, evidence-focused literature review by Hagen-Zanker and Himmelstine (2015) found only 11 relevant studies comparing the impact of social protection transfers and remittances on a number of well-being indicators. In the majority of the studies, both social transfers and remittances led to positive effects on households' wellbeing, but the effects on poverty reduction generally appeared to be larger for remittances than for social transfers (Hernandez et al. 2012; Van den Berg and Viet Cuong 2011; McDade 2010; Maitra and Ray 2003). Hagen-Zanker and Himmelstine (2015) only found one study (Gianetti et al. 2009) in which social protection transfers were found to have a stronger poverty reduction impact than remittances.

There are a number of factors that can explain why remittances have a higher (or lower) impact than social protection transfers, including:

(1) Targeting: The way transfers are distributed across the population affect their poverty reduction impact. One would expect that transfers that reach the poorest will have the greatest impacts on poverty reduction. Hagen-Zanker and Himmelstine (2015) point out that contradicting much of the migration literature, which states that remittances do not reach the poorest of the poor, a number of studies in the review suggest that remittances are more likely to reach the extreme poor or vulnerable than social protection transfers (World Bank 1999; Tesliuc and Lindert 2002; Van den Berg and Cuong 2011). One of the reasons, however, is that social protection transfers that are not directly aimed at reducing poverty, such as contributory transfers, may be regressive (Tesliuc and Lindert 2002). 
(2) Coverage: Transfers with low coverage (that is, received by a small share of the population) are expected to have a low impact on poverty reduction. In the countries included in the review, for instance, the coverage of social protection was low, which also helps explain the higher poverty reduction impact of remittances. This does not mean, however, that the coverage of remittances is always higher than social protection transfers, as migrants do not always send remittances.

(3) Amount of the transfer: It is also expected that the bigger the transfer the larger the impact on poverty reduction. In many of the studies of the review (i.e. World Bank 1999; Tesliuc and Lindert 2002; Van den Berg and Cuong 2011; Hernandez et al. 2012) remittances were larger than social protection transfers. The differences in the value of remittances compared to social protection transfers can partly explain the stronger poverty reduction impact of one transfer against the other.

(4) Predictability of the transfer: While social transfers tend to be regular and predictable (DFID 2011), a number of studies point out that remittances are countercyclical and sensitive to negative shocks (Banga and Sahu 2010; Hernandez et al. 2012). This means that social transfers do not respond to variations in households needs over time, whereas remittances might be less predictable but more responsive to intermittent spikes in household needs for cash (such as an expensive health shock). One can relate the timing of the transfer to the "permanent income hypothesis" (Friedman 1957), which states that different sources of income may be spent differently (either on consumption or investment) depending on whether the household sees them as temporary or permanent income.

(5) Use of the transfer: The literature mentions three reasons why social transfers and remittances may not be spent in the same way. The first has to do with the predictability of the transfer (explained above). The second one relates to who in the household receives the transfer, as there is growing evidence rejecting the pooling of income in the household (Schady and Rosero 2008; Maitra and Ray 2003; Duflo and Udry 2004). The third is related to the transfer conditionality (implicit or explicit), as the purposes for sending these transfers and the responsibility households feel towards the government or the migrant can influence the way transfers are spent.

Evidence on the comparative impact of social protection transfers and remittances is limited and highly specific to the context, as it differs in terms of geographical coverage, type of social transfer, indicator of poverty or well-being considered, and methods used to perform the analyses (Hagen-Zanker and Himmelstine 2015). Moreover, many of these studies are subject to important methodological limitations, such as not taking into account the possible endogeneity bias between the transfer(s) and the dependent variable. 
By analysing two different contexts and datasets and addressing methodological issues that existing studies on the topic have faced so far, this research investigates and compares the effects of remittances and social assistance transfers on different dimensions of poverty.

\subsection{Defining and measuring poverty}

"Poverty is a pronounced deprivation in well-being" (World Bank 2000), yet well-being can be defined in many different ways. The most common approach is to take a monetary definition of well-being based on income or consumption. A broader view is the capabilities approach, which was first articulated by Sen in the early 1980s and challenges traditional unidimensional means of evaluating well-being and deprivation (Sen 1987). According to this theory, individuals -to be well-off- need to achieve a number of capabilities that they consider important to function in society (such as appropriate health, education, freedom of speech, etc.). Lack of capabilities, or the freedom to choose among them, leads to limited realisable functionings — deprivation or poverty (Sen 1993; Robeyns 2005). Organizations like the United Nations and the World Bank recognise that poverty comprises many dimensions, including low income and poor access to basic goods and services, as well as low levels of health and education, poor access to clean water and sanitation, inadequate physical security, lack of voice, and insufficient capacity and opportunity to better one's life (World Bank 2000).

Alongside the capabilities approach, other conceptual frameworks are based on multidimensional understandings of poverty (Roelen 2017). Some of them, in addition to objective measures of well-being such as consumption, educational attainment, or nutrition, include relational and subjective components of well-being in their definition. An example is the framework proposed by White (2010), which defines wellbeing as a social process with material, relational, and subjective dimensions. Subjective well-being is gaining increasing attention among researchers and policy makers (Stiglitz, Sen and Fitoussi 2009), and there is a growing literature stating that several dimensions of subjective wellbeing (lack of stress, happiness, satisfaction with life) have an instrumental value, as they are positively related with outcomes such as productivity, decision-making, and educational and health outcomes (Attah et al. 2016).

This thesis takes a multidimensional approach to poverty, as each chapter looks at a different -non monetary- indicator of well-being. One of the reasons for this is methodological, given that there is a clear problem of reverse causality when studying how remittances and social assistance transfers affect the income levels of recipients, or monetary poverty. The other reason is an interest to look at less studied outcomes, such as food security (including nutrition) and subjective well-being. 
Although all the outcome variables explored in this thesis constitute one dimension of poverty (or well-being) or are related to poverty, ${ }^{3}$ the relationship is not always direct. For instance, expenditure patterns may or may not have an effect on poverty reduction. Similarly increased access to food or to a greater variety of food may or may not translate into somebody becoming "non-poor" in the food security or nutrition dimension. However, all the outcomes analysed in this work are related to individuals or households' standards of living, and therefore poverty is given a broad definition.

Moreover, in order to compare different transfers targeted and received by different household members, this thesis assumes a unitary model of household decision making. Unitary models, as opposed to bargaining or collective models of decision making, ${ }^{4}$ assume decisions are taken by the head of the household and that the preferences of the head become the preferences of the whole household. The household is therefore assumed to act as one (Alderman et al. 1995). For social protection policies, the unitary approach implies that what matters for household well-being is the total amount of money a household receives and not the identity of the individual receiving it.

Many authors have rejected the unitary model arguing that who in a household receives a transfer and the bargaining power of the different members of a household affect how decisions are made and, therefore, the effects of transfers on households' well-being (Schady and Rosero 2008; Maitra and Ray 2003; Duflo and Udry 2004). This thesis adopts a unitary model to simplify the empirical work. Having in mind the limitations of this approach, several parts of the thesis (especially chapters 2 and 3) analyse how factors such as who in the household receives the transfer or who is the intended beneficiary could affect the relationship between transfers and the outcomes studied.

Sending remittances is a decision that an individual or household as a whole take, which makes it a private decision. ${ }^{5}$ Despite the fact that this thesis tries to account as much as possible for this endogeneity (through instrumental variable approaches for instance), there are chapters where remittances had to be assumed exogenous, such as chapter 2. Accounting for this endogeneity is harder in the case of remittances than in the case of social assistance transfers, where eligibility is determined by the government and many times is based on exogenous factors such as age or other individual characteristics.

\footnotetext{
${ }^{3}$ Understood here as having access to a minimum level of resources to enjoy an adequate standard of living

${ }^{4}$ Bargaining or collective models assume household members have different tastes and preferences, and that decisions on how to allocate resources are taken collectively.

${ }^{5}$ This is not the case with social protection transfers, as eligibility is determined by the government and therefore transfers are less likely to be endogenous (or it is easier to correct for potential endogeneity).
} 


\subsection{Contribution}

This dissertation contributes to a better understanding of the role of remittances and non-contributory social protection by answering three sub-questions: (1) Do remittances and social assistance have different effects on expenditure patterns? (2) What are the impacts of remittances on food security and nutrition, as compared to social assistance? (3) How are remittances and social assistance related to subjective indicators of wellbeing, such as life satisfaction and subjective economic standards?

Expenditure behaviour (sub-question 1) is a dimension that has not been sufficiently explored when studying the effects of social assistance or remittances, most likely due to a lack of adequate data. By offering immediate alleviation of spending constraints to poor beneficiaries, both private and public transfers are likely to contribute to poverty reduction. This would be the case if transfers are spent on goods and services that alleviate pressing needs and help reduce recipients' deprivations. The few studies that have looked at expenditure patterns have found evidence on this, as social transfers are often spent on necessities such as food (The Kenya CT-OVC Evaluation Team 2012; Coetzee 2013), health (The Kenya CT-OVC Evaluation Team 2012), and clothing (Kooreman 2000; The Kenya CT-OVC Evaluation Team 2012). In terms of remittances, Adams and Cuecuecha (2010) found that both internal and international remittances increased expenditure on education and housing, whereas Adams (1991; 2002) proved that remittances are likely to be saved and used for investment.

Many arguments among policymakers against the expansion of social protection programmes are based on pressumptions that recipients misuse or make bad decisions on how to spend transfers (Du Toit and Neves 2009). In the migration and development debate, there have also been claims that remittances are used for conspicuous consumption and that, thefore, they do not contribute to development (AmuedoDorantes 2014). Based on the above, it is important to understand how expenditure decisions are made in poor households when studying the welfare impacts of private and public transfers. One chapter of this dissertation, therefore, analyses the expenditure patterns of remittances and social assistance, and whether these transfers are spent differently than other sources of income.

In order to analyse whether increases in expenditure contribute -in fact- to poverty reduction, sub-question 2 explores whether remittances and social assistance reduce food insecurity and malnutrition. While previous studies have found positive effects of remittances or social assistance on food security (access to food or quality of food consumed), in the case of nutritional outcomes the evidence is not consistent, as studies find negative, positive, or no effects of these transfers on different measures of nutrition (Manley, Gitter and Slavchevska 2012; Bastagli et al. 2016). Looking in the same study at the effects of both social assistance and remittances on food security and nutrition can give 
a better idea of the effectiveness of formal and informal social protection strategies in reducing food insecurity, a challenge that many low and middle income countries face.

Transfers may also affect unintended outcomes that are not necessarily linked to social protection programs' objectives or to the main reasons for migration, such as happiness or subjective well-being. Understanding this relationship has an intrinsic and instrumental value in development (Natali et al. 2018). In addition to being an end in itself, subjective well-being has been linked to better educational and health outcomes, increases in productivity, savings, and consumption, and better social relationships (Natali et al. 2018; Attah et al. 2016).

Most of the studies analysing the relationship between social protection transfers and subjective well-being focus on Sub-Saharan Africa, and all of them have found positive effects (Haushofer and Shapiro 2016; Kilburn et al. 2018; Daidone et al. 2015; Natali et al. 2018). On the other hand, most of the evidence on the impacts of migration and remittances on subjective well-being comes from Latin America. Most of these studies have found a negative effect of migration on subjective well-being or happiness, and positive or no effects of remittances. Given the limited evidence on the effects of transfers on subjective well-being and that most of the studies focus on specific regions such as Latin America or Sub-Saharan Africa, this dissertation takes a broader approach to impact evaluation by looking at this well-being dimension in a new context that has not been studied before.

Understanding how remittances and social transfers are related will contribute to the current policy debate regarding the role of migration in development. One view is that migrants do (and should) contribute to improving living standards in the home country through remittances (when social protection schemes or other government policies are not sufficient to tackle poverty). The contrasting view is that remittances cannot substitute social protection schemes and that the task of reducing poverty should be assigned to the public sector (for a discussion on the different views regarding the development role of migration and remittances, see De Haas (2010)).

\subsection{Case studies and datasets used}

This dissertation explores the links between social assistance and remittances in two different contexts, South Africa and Kyrgyzstan. Both countries have representative and longitudinal household surveys from which the four empirical chapters draw. In spite of their differences, social protection and migration are important poverty reduction strategies in both countries. A key difference, however, is that while in South Africa social transfers have replaced or "crowded out" (internal) remittances as a consequence of the significant expansion of its social protection system, among other reasons (Du Toit and 
Neves 2009), in Kyrgyzstan (international) remittances are a much more important source of poverty reduction, as they represent more than 30 percent of the country's GDP (World Bank and KNOMAD 2017). Below I present an introduction to the case studies and datasets used in the dissertation.

\section{South Africa}

South Africa is a middle-income country with one of the highest inequality rates in the world. Since the transition to democracy, the country has made considerable progress in reducing poverty due to, among other reasons, its social protection system (World Bank 2017c). Since the end of Apartheid in 1994, South Africa has seen an extraordinary expansion in the coverage of government transfers. The two main social protection programmes in South Africa are the Old Age Pension (often referred to as the Older Person's Grant) and the Child Support Grant. Both are non-contributory, means-tested, and unconditional, and they are targeted at poor elderly individuals and poor caregivers with children, respectively. ${ }^{6}$ Almost three quarters (3.2 million) of the elderly in South Africa are income eligible and receive the Old Age Pension, and around 60 percent of age eligible children (11.9 million people) receive the Child Support Grant (Sassa 2016). Direct spending on social assistance accounted for 3.5 percent of GDP in 2013 (World Bank 2016b). Over the last few years, however, progress towards poverty reduction has slowed down as a result of structural challenges such as a dual labour market, low quality education, a decline in economic growth and high unemployment (World Bank 2017c).

The majority of South African migrants move within the country. Labour migration from rural to urban areas is mainly temporary and dates back to the Apartheid period. Even though in 1987 racial restrictions on residence were lifted, migration patterns did not alter as expected, and internal migration remains temporary for a large number of individuals and households (Posel 2004). Poor households in South Africa, especially in rural areas, continue to rely on remittances to cover their daily needs (Posel and Casale 2006). However, Posel (2009) points out that many labour migrants are now settling in destination areas, which translates into an important decline in the number of households receiving remittances compared to statistics derived from previous household surveys.

To study how remittances and social assistance transfers in South Africa affect wellbeing, this work relies on three waves (2008, 2010, and 2012) of the National Income Dynamics Study (NIDS), a longitudinal and nationally representative survey covering all

\footnotetext{
${ }^{6}$ Unconditional transfers - as opposed to conditional cash transfers or CCTs-are not conditional upon specific behaviours, such as school attendance or regular medical check-ups. Means-tested means that only individuals meeting some income requirements (e.g. earnings below a certain threshold) can benefit from social assistance.
} 
regions in South Africa. ${ }^{7}$ The first wave was collected in 2008 with a sample of around 28,000 individuals and 7,300 households, and household members were followed over time and interviewed every two years. NIDS provides information on the livelihoods of individuals and households over time, their ability to cope with shocks, poverty and wellbeing, fertility, migration, labour market participation, education, vulnerability, etc. Chapters 2 and 3 draw on this dataset.

Remittances are defined in the NIDS as all contributions from non-resident members as well as non-households members. This implies that in addition to contributions sent back home by internal migrants, remittance income can include other contributions such as child maintenance payments. However, as Posel (2016) points out, given the history of temporary migration in South Africa and the fact many families remain geographically divided, informal contributions in South Africa are often associated with remittances sent by migrant workers. In terms of social assistance transfers, this thesis analyses the two main social protection programmes: the Old Age Pension and the Child Support Grant. Social assistance transfers, or social transfers, are often referred to in South Africa as social grants.

\section{Kyrgyzstan}

The Kyrgyz Republic, or Kyrgyzstan, is a land-locked mountainous country and one of the poorest in Central Asia, with a GNI per capita of \$1,100 in 2016 (World Bank 2017d). After becoming independent from the Soviet Union in 1991, poverty rates increased considerably due to the transition to a market economy and the consequent decline of industrial activity and jobs. Despite economic growth and poverty reduction achieved in the last two decades- mainly due to an increase in real wages and private transfers like remittances- a third of the Kyrgyz population is considered poor based on the national poverty line (World Bank 2017d). Kyrgyzstan's main economic activity is agriculture, and nearly two-thirds of its population lives in rural areas.

As a result of the full employment regime that characterised the Soviet Union, social protection policies were designed to support families and certain groups unable to work. Social protection in countries such as Kyrgyzstan, therefore, gave more weight to social insurance and categorical benefits than to poverty-targeted transfers (Barrientos and Kudebayeva 2015). Social insurance and categorical transfers target certain vulnerable groups and help to enhance their capacity to manage economic and social risks, but do not necessarily reach low-income households. After independence in 1991, some new targeted cash transfer programs were introduced. The most important one is the Monthly Benefit for Poor Families (MBPF), originally the Unified Monthly Benefit

\footnotetext{
${ }^{7}$ For more information, see http://www.nids.uct.ac.za/about/what-is-nids
} 
(UMB), which was established in 1998 in an attempt to unify and simplify cash social assistance policy (Tesliuc 2004). The MBPF is a means-tested non-contributory transfer which assigns a monthly benefit to poor families with children.

Despite numerous attempts in reforming the social protection system to protect individuals who became unemployed and fell into poverty during the transition to the market economy, the social protection system in Kyrgyzstan remains complex and fragmented (Barrientos and Kudebayeva 2015). Non-contributory benefits, or social assistance, consist of categorical state benefits and energy compensations, in addition to the poverty targeted transfer (MBPF). Categorical benefits are independent of household income and are received by specific groups (often vulnerable citizens) such as orphans, people with disabilities, elderly individuals without pension rights, war veterans, or mothers with infants. ${ }^{8}$ The most important benefit is the Monthly Social Benefit, targeted at vulnerable groups with limited income generating opportunities, such as people with disabilities, orphans, and elderly without pension rights. Social assistance transfers also include energy compensations provided to pensioners with a small pension and to households living in high-mountain areas (Gassmann and Zardo Trindade 2015). The impact of social assistance transfers on poverty reduction is limited, however, due to the low coverage of the transfers (which reach between 1 and 10 percent of the population) and the small benefit size. The MBPF, for instance, accounts for only 10 percent of total income of poor beneficiaries (Gassmann and Zardo Trindade 2015).

At present, Kyrgyzstan still suffers from the consequences of the collapse of the Soviet Union, such as high unemployment, widespread corruption and state failure to deliver basic services, strong gender disparities, and inter-ethnic conflict (ICG 2016). Given the lack of livelihood opportunities in Kyrgyzstan, many working-age individuals migrate to Russia and other neighbouring countries on a temporary and regular basis to help their families finance their daily needs. Remittances, therefore, constitute a very important source of income in poor households, in many cases the most important source (Thieme 2014). International remittances represent more than 30 percent of the country's GDP (World Bank and KNOMAD 2017), and are received by approximately 25 percent of the Kyrgyz population, therefore having a determinant role in poverty reduction (Gassmann and Zardo Trindade 2015; Guelfi and Sattar 2015). Nevertheless, the side effects of migration include labour shortages and lack of qualified and well-trained personnel in rural areas, where most migrants come from (Thieme 2014).

\footnotetext{
${ }^{8}$ Despite war veterans are not considered vulnerable, and these compensations are usually defined as benefits based on merit or to the privileged, the percentage of individuals receiving this transfer is very low.
} 
Chapters 4 and 5 draw on three waves (2011, 2012, and 2013) of the Life in Kyrgyzstan $(\mathrm{LiK})$ survey, a panel survey conducted annually that covers a sample of approximately 3,000 households (and 8,000 individuals). The survey was administered in all seven oblasts of Kyrgyzstan and the cities of Bishkek and Osh, and data were collected at the household, individual (administered to all adults aged 18 and above), and community level. LiK provides comprehensive information on income, consumption patterns, remittances, well-being indicators, employment, and socio-demographic characteristics of households (Brück et al. 2014). The survey tracks individuals over time and includes new household members that become part of the households which are re-interviewed. ${ }^{?}$

The LIK survey defines remittances as monthly monetary transfers sent by migrants from outside Kyrgyzstan. In the case of social protection transfers, this analysis includes all social assistance (non-contributory) transfers that are included in the survey, such as the Monthly Benefit for Poor Families, the Monthly Social Benefit, and other categorical state benefits.

\subsection{Thesis outline}

The dissertation is composed of four empirical papers (chapters 2 to 5), and all of them make use of quantitative research methods, more specifically quasi-experimental methods of impact evaluation. Chapters 2 and 3 look at the case of South Africa, whereas Chapters 4 and 5 explore the case of Kyrgyzstan.

Chapter 2 studies the expenditure patterns of remittances and social assistance. A relevant policy question when assessing the effects of remittances or social assistance is whether the increased consumption or poverty reduction experienced by recipient households is only explained by a pure income effect (i.e. having more money) or also by the fact that different income sources affect expenditure patterns in different ways. A common assumption in economics is that money is fungible, which means that spending patterns do not depend on the source of income, only on the total amount. The mental accounting theory (a concept introduced by behavioural economist Richard Thaler (1985)), however, rejects this assumption by arguing that people compartmentalise their income into different mental accounts and decide on their consumption within each of these accounts. This chapter uses mental accounting as a theoretical framework and hypothesises that households associate private transfers coming from a migrant differently to public transfers received from the government, and that this impacts the way transfers are spent.

Chapter 3 looks at the effects of remittances and social assistance on food security. Food security is commonly understood as having access to sufficient food for a healthy and

\footnotetext{
${ }^{9}$ For more information on the study and project, see https://lifeinkyrgyzstan.org/.
} 
active life. It is a basic human need, and the right to food is enshrined in South Africa's Constitution. Nutrition status, notably undernutrition, is an objective measure of food insecurity and hunger. Although several studies have looked at whether social assistance or remittances improve food security and/or nutritional outcomes, few of them have looked at a comprehensive set of indicators of food security and nutrition. South Africa makes an interesting case study due to the fact that levels of food insecurity (including malnutrition) have remained high despite many poor households being recipients of social assistance and/or remittances (Hendriks 2014; Devereux and Waidler 2017). Consequently, Chapter 3 addresses two questions: do social assistance and remittances improve food security and nutritional outcomes? If so, do these impacts differ between public and private transfers?

Although many studies have looked at objective measures of well-being, subjective wellbeing has received less attention in the migration as well as in the social protection literature. Chapters 4 and 5 study the relationship between social assistance and subjective well-being, and remittances and subjective well-being, respectively, in Kyrgyzstan. Subjective well-being is measured through self-reported indicators of life satisfaction and subjective economic well-being. Due to the fact that households receiving remittances and social assistance are highly heterogeneous, the effects of these two transfers on subjective well-being are analysed in separate chapters. ${ }^{10}$

The relationship between social assistance and subjective well-being is explored in Chapter 4 . The mechanisms by which social assistance transfers affect subjective well-being are likely to differ from the ones affecting objective indicators of well-being. If receiving social assistance leads to stigma or shame, subjective well-being could be reduced despite the increase in financial resources, and, hence, objective well-being. On the other hand, one can expect increased levels of subjective well-being if social assistance transfers reduce poverty as well as address the negative mechanisms associated with poverty, such as stress, mental health problems or shame (Haushofer and Fehr 2014; Roelen 2017). Under the Soviet Union, social assistance, understood as transfers targeted to people living in poverty, was highly residual and considered a last resort due to the denial of poverty. As a result, benefits were stigmatised and only targeted 'the deserving poor' (Atkinson and Micklewright 1992). This topic has not been studied in a former Soviet country before and, consequently, findings can be informative for other countries that share a similar history.

\footnotetext{
${ }^{10}$ In the dataset used, the overlap of those individuals living in households receiving both social assistance and remittances is less than 2 percent, and the correlation between the two transfers is almost zero. As a result, in the case of Kyrgyzstan, social assistance and remittances are analysed in different chapters and their effects compared in the conclusion.
} 
Chapter 5 studies how remittances affect subjective well-being in Kyrgyzstan. The specificities of migration in Kyrgyzstan, its history as a member of the Soviet Union, and its family values and traditions, are likely to influence the relationship between remittances and subjective well-being and consequently, lead to different findings from the previous case studies analysed so far. This paper contributes to the existing literature by introducing a new case study and by looking at how money transfers from abroad affect both life satisfaction (often used as a proxy for happiness), and subjective economic wellbeing.

Finally, Chapter 6 summarises the main findings and implications from each Chapter and discusses the role of social assistance and remittances in the fight against poverty. It also provides a brief discussion of the differences and similarities between the two case studies, South Africa and Kyrgyzstan. The dissertation ends with some concluding remarks. 


\section{References}

Adams, R. H. (2002). Precautionary saving from different sources of income: Evidence from rural Pakistan. World Bank Policy Research Working Paper, (2761).

Adams, R. H. (1991). The economic uses and impact of international remittances in rural Egypt. Economic Development and Cultural Change, 39(4):695-722.

Adams, R. H. \& Cuecuecha, A. (2010). Remittances, household expenditure and investment in Guatemala. World Development, 38 (11): 1626-1641.

Alderman, H., Chiappori, P. A., Haddad, L., Hoddinott, J., \& Kanbur, R. (1995). Unitary versus collective models of the household: is it time to shift the burden of proof? The World Bank Research Observer, 10(1), 1-19.

Atkinson, A. B., \& Micklewright, J. (1992). Economic transformation in Eastern Europe and the distribution of income. Cambridge University Press.

Attah, R., Barca, V., Kardan, A., MacAuslan, I., Merttens, F., \& Pellerano, L. (2016). Can social protection affect psychosocial wellbeing and why does this matter? Lessons from cash transfers in sub-Saharan Africa. The Journal of Development Studies, 52(8), 1115-1131.

Banga, R., \& Sahu, P. K. (2010). Impact of remittances on poverty in developing countries. eSocialSciences Working Paper id 3100

Barrientos, A. (2013). Social assistance in developing countries. Cambridge: Cambridge University Press.

Barrientos, A., \& Kudebayeva, A. (2015). Social Transfers and Women's Labour Supply in Kyrgyzstan. BWPI Working Paper 215, The University of Manchester, Manchester, UK.

Bastagli, F., Hagen-Zanker, J., Harman, L., Barca, V., Sturge, G. \& Schmidt, T. (2016) Cash transfers: what does the evidence say? A rigorous review of programme impact and of the role of design and implementation features. London: Overseas Development Institute (ODI).

Bluhm, R., de Crombrugghe, D. P. I., \& Szirmai, A. (2014). Poor trends-The pace of poverty reduction after the Millennium Development Agenda (No. 006). United Nations University-Maastricht Economic and Social Research Institute on Innovation and Technology (MERIT).

Brown, P.C., \& Jimenez, E. (2007). Estimating the net effects of migration and remittances on poverty and inequality. UNU-WIDER Research Paper No. 2007/23. United Nations University, Finland.

Brück, T., Esenaliev, D., Kroeger, A., Kudebayeva, A., Mirkasimov, B., \& Steiner, S. (2014). Household survey data for research on well-being and behavior in Central Asia. Journal of Comparative Economics, 42(3), 819-835.

Brunori, P. \& O’Reilly, M. (2010). Social protection for development: A review of definitions. Paper prepared in the framework of the European Report on Development 2010. Brussels: European Commission.

Coetzee, M. (2013). Finding the benefits: Estimating the impact of the South African child support grant. South African Journal of Economics, 81(3):427-450.

Daidone, S., Handa, S., Davis, B., Park, M., Osei, R. D., \& Osei-Akoto, I. (2015). Social Networks and Risk Management in Ghana's Livelihood Empowerment Against Poverty Programme, Papers inwopa 781, Innocenti Working Papers.

De Haas, H. (2010). Migration and development: A theoretical perspective. International migration review, 44(1), 227264.

Devereux, S. \& Waidler, J. (2017). Why does malnutrition persist in South Africa despite social grants? Food Security SA Working Paper Series No.001. DST-NRF Centre of Excellence in Food Security, South Africa.

Duflo, E., \& Udry, C. (2004). Intra household resource allocation in Cote d'Ivoire: Social norms, separate accounts and consumption choices (No. w10498). National Bureau of Economic Research.

Friedman, M. (1957). The permanent income hypothesis. In A theory of the consumption function (pp. 20-37). Princeton University Press.

Foresti, M. \& Hagen-Zanker, J. (2017). Migration and the 2030 Agenda for Sustainable Development. London: Overseas Development Institute.

Gassmann, F. \& Zardo Trindade, L. (2015). Analysis of Potential Work Disincentive Effects of the Monthly Benefit for Poor Families in the Kyrgyz Republic. Report No. 99776-KG. World Bank Group, Washington DC.

Giannetti, M., Federici, D., \& Raitano, M. (2009). Migrant remittances and inequality in Central and Eastern Europe. International Review of Applied Economics, 23(3), 289-307.

Guelfi, A., \& Sattar, S. (2015). Poverty and Economic Mobility in the Kyrgyz Republic. Some insights from the 'Life in Kyrgyzstan Survey'. Report No. 99775-KG. World Bank Group, Washington DC.

Hagen-Zanker, J. \& Himmelstine, L. (2015). What is known about the differential impacts of cash transfers and remittances on poverty and vulnerability of households? Social Policy and Society, 14(2), pp. 00-14. 


\section{Chapter 1}

Haushofer, J., \& Shapiro, J. (2016). The short-term impact of unconditional cash transfers to the poor: experimental evidence from Kenya. The Quarterly Journal of Economics, 131(4), 1973-2042.

Haushofer, J., \& Fehr, E. (2014). On the psychology of poverty. Science, 344(6186), 862-867.

Hendriks, S. (2014). Food security in South Africa: Status quo and policy imperatives. Agrekon, 53(2): 1-24.

Hernandez, E., Sam, A. G., Gonzalez-Vega, C., \& Chen, J. J. (2012). Does the insurance effect of public and private transfers favour financial deepening? Evidence from rural Nicaragua. Review of Development Finance, 2(1), pp. 921.

Honorati, M., Gentilini, U., \& Yemtsov, R. G. (2015). The state of social safety nets 2015. Washington (DC): World Bank Group.

ICG (2016). Kyrgyzstan: State Fragility and Radicalisation, Crisis Group Europe and Central Asia Briefing $\mathrm{N}^{\circ} 83$

Jongwanich, J. (2007). Workers' remittances, economic growth and poverty in developing Asia and the Pacific countries. UN ESCAP Working Paper WP/07/01: 275-18.

Kilburn, K., Handa, S., Angeles, G., Tsoka, M., \& Mvula, P. (2018). Paying for Happiness: Experimental Results from a Large Cash Transfer Program in Malawi. Journal of Policy Analysis and Management, 37(2), 331-356.

Kooreman, P. (2000). The labeling effect of a child benefit system. The American Economic Review, 90(3):571-583.

Maitra, P., \& Ray, R. (2003). The effect of transfers on household expenditure patterns and poverty in South Africa. Journal of Development Economics, 71(1), pp. 23-49.

Manley, J., Gitter, S. \& Slavchevska, V. (2012). How effective are cash transfer programmes at improving nutritional status? A rapid evidence assessment of programmes' effects on anthropometric outcomes. London: EPPICentre, Social Science Research Unit, Institute of Education, University of London.

Mansuri, G. (2006). Migration, school attainment, and child labor: evidence from rural Pakistan. World Bank Policy Research Working Paper, (3945).

McDade, Z. (2010). Are Conditions on Cash Transfers Necessary to Improve Rural Education Outcomes? Evidence from Nicaragua. Honors Project. Paper 31.

Natali, L., Handa, S., Peterman, A., Seidenfeld, D., \& Tembo, G. (2018). Does money buy happiness? Evidence from an unconditional cash transfer in Zambia. SSM-population health, 4, 225-235

OECD (2009). The role of employment and social protection: making economic growth more pro-poor. Policy Statement, DAC High-level meeting.

Posel, D. (2016). Inter-household transfers in South Africa: Prevalence, patterns and poverty. Technical report, SALDRU Working Paper No. 180/NIDS Discussion paper 2016/7.

Posel, D. (2009). Migration: Analysis of the NIDS wave 1 dataset. Technical report, NIDS Discussion Paper, no.1.

Posel, D. (2004). Have migration patterns in post-apartheid South Africa changed? Journal of Interdisciplinary Economics, $15(3-4): 277-292$

Posel, D. (2001). Intra-family transfers and income-pooling. South African Journal of Economics, 69(3): 501-528

Posel, D. and Casale, D. (2006). Internal labour migration and household poverty in post-apartheid South Africa. HSRC Press Cape Town.

Posel, D. (2004). Have migration patterns in post-apartheid South Africa changed? Journal of Interdisciplinary Economics, $15(3-4): 277-292$.

Ratha, D. (2013). The impact of remittances on economic growth and poverty reduction. Migration Policy Institute, Policy Brief, 8, 1-13.

Ratha, D., Mohapatra, S. and Scheja, E. (2011). Impact of migration on economic and social development. A review of evidence and emerging issues. World Bank Policy Research Working Paper No. 5558, Washington DC.

Robeyns, I. (2005). The capability approach: a theoretical survey. Journal of buman development, 6(1), 93-117.

Roelen, K. (2017). Shame, Poverty and Social Protection. CSP working paper No 489, Institute of Development Studies

SASSA (2016). Factsheet: Issue no 4 of 2016. A statistical summary of social grants in South Africa.

Schady, N., \& Rosero, J. (2008). Are cash transfers made to women spent like other sources of income? Economics Letters, 101(3), 246-248.

Stark, O., \& Bloom, D. E. (1985). The new economics of labor migration. The American Economic Review, 173-178.

Sen, A. (1993). Capability and well-being. In Nussbaum, M. and Sen, A. (eds), The Quality of Life. Clarendon Press, Oxford, 30-53

Sen, A. K. (1987). The Standard of Living. In G. Hawthorn (ed.), The Standard of Living (pp. 1-38). Cambridge: Cambridge University Press.

Stiglitz, J., Sen, A., \& Fitoussi, J. P. (2009). The measurement of economic performance and social progress revisited. Reflections and overview. Commission on the Measurement of Economic Performance and Social Progress, Paris. 
Tesliuc, E. D. (2004). Mitigating Social Risks in Kyrgyz Republic. Social Protection discussion paper series; no. 408. Washington, DC: World Bank.

Tesliuc, E., \& Lindert, K. (2002). Social protection, private transfers and poverty, Technical paper No. 3, Guatemala Poverty Assessment program, Washington DC: The World Bank.

Thaler, R. (1985). Mental accounting and consumer choice. Marketing science, 4(3):199-214.

The Kenya CT-OVC Evaluation Team. (2012). The impact of the Kenya Cash Transfer Program for Orphans and Vulnerable Children on household spending. Journal of Development Effectiveness, 4(1), 9-37.

Thieme, S. (2014). Coming home? Patterns and characteristics of return migration in Kyrgyzstan. International Migration, 52(5), 127-143.

du Toit, A. \& Neves, D. (2009). Trading on a Grant: Integrating Formal and Informal Social Protection in PostApartheid Migrant Networks. BWPI working paper 75.

UNICEF (2012). Integrated Social Protection Systems: Enhancing Equity for Children, United Nations Children's Fund, New York.

Van den Berg, M., \& Cuong, N. V. (2011). Impact of public and private cash transfers on poverty and inequality: evidence from Vietnam. Development Policy Review, 29(6), pp. 689-728.

White, S. C. (2010). Analysing wellbeing: a framework for development practice. Development in Practice, 20(2), 158172.

World Bank (2017a). Closing the Gap: The State of Social Safety Nets 2017 "Safety Nets where Needs are Greatest". Washington, DC: World Bank

World Bank (2017b). Migration and remittances. Recent developments and outlook. Migration and development policy brief 2017. Washington, DC: World Bank

World Bank (2017c). The World Bank in South Africa, Overview. http://www.worldbank.org/en/country/southafrica/overview [accessed 10 March 2018].

World Bank (2017d). World Bank Data, Kyrgyz Republic. https://data.worldbank.org/country/kyrgyz-republic [accessed 10 November 2017]

World Bank and KNOMAD (2017). Migration and Development Brief 27: Migration and Remittances-Recent Developments and Outlook. World Bank Publications, Washington DC.

World Bank (2016a). Poverty and Shared Prosperity 2016: Taking on Inequality. Washington DC: World Bank. doi:10.1596/978-1-4648-0958-3.

World Bank (2016b). ASPIRE: The Atlas of Social Protection Indicators of Resilience and Equity. http://datatopics.worldbank.org/aspire/ [accessed 15 January 2018].

World Bank (2010). Migration and Remittances Factbook 2011. Washington DC: The World Bank.

World Bank (2000). World Development Report 2000/2001: Attacking Poverty. Washington DC: The World Bank.

World Bank. (1999). Poverty and social development in Peru, 1994-1997. Washington DC:

The World Bank. 
Chapter 1 
Chapter 2

On the Fungibility of Public and Private Transfers: A Mental Accounting Approach

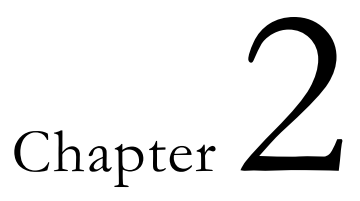

\section{On the Fungibility of Public and Private Transfers: A Mental Accounting Approach ${ }^{11}$}

"It is time to stop making excuses. We need an

enriched approach to doing economic research, one that acknowledges the existence and relevance of Humans."

"If you want to encourage someone to do something, make it easy."

(Richard H. Thaler, Misbehaving)

${ }_{11}$ This Chapter is based on: Waidler, J. (2016). On the fungibility of public and private transfers: a mental accounting approach, UNU-MERIT Working Paper 2016-060. 
Chapter 2 


\subsection{Introduction}

A common assumption in economic theory is that money is fungible. In other words, spending patterns do not depend on the source of income, only on the total amount. A number of theories like the permanent income hypothesis (PIH) developed by Friedman (1957) or the mental accounting theory initiated by behavioural economicsts like Thaler $(1985,1990)$ have challenged this assumption, however. According to the permanent income hypothesis, consumption is determined by the permanent/anticipated income and should not react to transitory changes in income. The second argues that people compartmentalise their income into different mental accounts and decide on their consumption within each of these accounts. Based on this theory, spending behaviour is associated with the income source and therefore money cannot be treated as fungible.

There are a number of examples why individuals would allocate income transfers into different mental accounts. One is self-control, which stresses that people keep different accounts as means of self-control (e.g. to resist overspending) by allocating usually large windfalls into a separate assets or savings account that is not expected to be used for consumption in the immediate future (Shefrin and Thaler 1988). Another example of why people would allocate income into different mental accounts is the "flypaper or labelling effect", where current consumption is associated with a desire to comply with externally imposed labels, which has received particular attention. Kooreman (2000), for example, finds that government provided child grants in the Netherlands are more likely to be spent on child clothing than on other goods. Private transfers such as remittances (money sent by migrants living abroad) can also be analysed in the mental accounting framework. Several studies have shown that households do not use remittances in the same way as income from other sources (Adams 1991; Adams 2002; Adams and Cuecuecha 2010).

Despite the growing literature on mental accounting, and that a few studies have investigated whether government-provided social transfers or remittances are spent differently than income from other sources, the question on whether social transfers are spent differently than remittances remains under researched. To the knowledge of the author, only two studies have tested whether social transfers from the government are spent differently than remittances received from migrants who live abroad, and none of them have explicitly tested the mental accounting theory in this context. ${ }^{12}$ Comparing public and private transfers can give additional and important insights into policy making as the welfare impacts of transfers not only depend on their value, but also on how they are perceived and therefore, spent.

\footnotetext{
12 The other studies comparing how social transfers and remittances are spent are (Maitra and Ray 2003) and (Waidler et al. 2016)
} 
This paper hypothesises that individuals or households perceive a private transfer coming from a family member differently than a public transfer received from the government, and that this impacts the way transfers are spent. To test this hypothesis, the first nationally representative longitudinal survey conducted in South Africa (the National Income Dynamics Survey), covering the years 2008, 2010, and 2012, is used. South Africa provides an excellent case study to answer the question at hand, as both remittances and social transfers constitute an important source of income in poor households. For more than 35 percent of rural black households (which are more likely to live in poverty) remittances are the main source of income (Posel and Casale 2003, 2006). At the same time, the two main social protection programmes aimed at reducing poverty and vulnerability of the most deprived -the child support grant and the old age pension- reach almost 60 percent of children and more than 80 percent of the non-white elderly population (Sassa 2016).

The next section reviews the literature on the mental accounting theory. Section 2.3 describes the case of South Africa and the hypothesis on how remittances and social transfers are likely to be spent. Section 2.4 introduces the demand model and the econometric estimation used to analyse the relationship between the different income sources and expenditure patterns. Section 2.5 describes the data and section 2.6 presents the findings and the different robustness tests. Finally, section 2.7 concludes.

\subsection{Literature review}

Social protection transfers provided by the government or remittances sent by migrants working in a different locality or country facilitate consumption smoothing of households and offer immediate alleviation of spending constraints to poor beneficiaries. A relevant policy question when assessing the effects of these transfers is whether the increased consumption or poverty reduction experienced by recipient households is only explained by a pure income effect (i.e. having more money) or also by the fact that different income sources affect expenditure patterns in different ways. The latter would reject standard microeconomic theory as it implies that the composition of income matters and that certain sources of income may have higher welfare effects than others.

Mental accounting theory supports the idea that money is not fungible, but that the source of income influences spending decisions. Behavioural economists such as Thaler (1985, 1990), and Shefrin and Thaler (1988) argue that people have different mental accounts for different sources of income. There are different reasons why people would compartmentalise different income transfers into different mental accounts. Shefrin and 
Thaler (1988) show that some people create mental accounts as a self-control device to resist overspending by, for example, allocating large windfalls into a separate -assets or savings- account where money is less likely to be spent. Christiaensen and Pan (2012) explore the notion of emotional accounting (Levav and McGraw 2009), which argues that people categorise their incomes based on the feelings they evoke by suggesting that the coding of income is based on the effort involved in obtaining it. The authors test the hypothesis that people are more likely to spend hard earned money on necessities, and unearned money on hedonic (pleasure) goods. In line with their predictions, they find that the marginal propensity to consume from unearned income is higher for clothing, alcohol and tobacco, transportation and communication, and gifts, while earned income is more likely to be spent on staple food and education.

An example of mental accounting that has been recently debated is the "flypaper or labeling effect", which is the desire to comply with externally imposed labels. Kooreman (2000) tests this theory in the context of child benefits in the Netherlands and finds that these benefits are more likely to be spent on child clothing than other sources of income. In the same way Jacoby (2002) and Islam and Hoddinott (2009) prove that benefits from the school feeding and supplementary nutrition programs benefit the child directly. As these studies look at in-kind transfers, the authors test the mental accounting theory by looking at whether there is intra-household reallocation of calories in response to the program. Coetzee (2013), studying the Child Support Grant in South Africa, finds that child grants have a positive impact on children as they are more often spent on goods that benefit children (for example, food) as opposed to adult goods. Benhassine et al. (2013) show that an unconditional cash transfer program in Morocco to fathers of school-age children, which is labelled as an educational support program, increases school participation. Moreover, Beatty et al. (2014) find a robust labelling effect in the case of the winter fuel transfers in the UK: on average, households spend 41 percent of this unconditional transfer on fuel, as compared to 3 percent that would be spent on fuel if the transfer was treated as normal cash.

Remittances can also be analysed in the mental accounting framework. Several studies have shown that households do not use remittances in the same way as income from other sources (Adams 1991; Adams 2002; Adams and Cuecuecha 2010). Adams (1991) proves that remittances are also invested and not only spent on consumption. Adams (2002) states that the marginal propensity to save from those sources of income that are more variable and uncertain -like external remittances- is much higher than from those sources of income that are more predictable. The author finds evidence of the permanent income hypothesis as the marginal propensity to save out of remittances is found to be higher than for any other source of income and suggests that this is due to income volatility and risk aversion, noting that income sources with greater variability 
exhibit greater marginal propensities to save. Adams and Cuecuecha (2010) show that households receiving either internal or international remittances spend more on education and housing than households not receiving remittances, keeping total income constant.

Davies et al. (2009) argue that remittance income is likely to be allocated to its own mental account for several reasons: remittances may come with specific conditions attached (the remitter may require the receiving household to use their income for specific purposes such as education). Moreover, households may attach specific emotional tags to remittances based on how they perceive the migrant (or the migration experience) and/or the motivation behind the remittances. The authors state that "remittances may be considered as either manna from heaven or else the product of someone else's hard work" (p. 324). This will determine in which mental account these transfers are allocated to and, as a result, how they are spent. In the first case, remittances are more likely to be spent on consumption, whereas in the second they will be used for productive purposes such as investment in human and physical capital.

Based on the literature described above, there are reasons to believe that social transfers will have different expenditure patterns than remittances. Social transfers can bring a label attached and influence the types of goods recipient households buy based on the aims of the programme and the intended outcomes. In the case of remittances, recipients may feel conditioned to spend the money in a certain way, plus, the feelings associated with the migration experience of the relative abroad may influence their spending behaviour. However, the decision to allocate different transfers into different mental accounts is context specific and will depend on the type of social protection program and on the migration patterns in the country studied. For instance, whether migration is temporary or long-term, internal or international, low-skilled or highly-skilled, etc. can influence the remittance sender's behaviour and/or the spending behaviour of the recipient households. The next section describes the case of South Africa and proposes a model where remittances and social transfers are allowed to differ from other income sources in the way they are spent.

\subsection{The case of South Africa: migration, remittances and social protection transfers}

\subsubsection{The social protection system}

The social protection system in South Africa is well-established, with one of the largest non-contributory pension programs in the world and one of the largest social cash 
transfer programmes (the Child Support Grant) in terms of the number of participants (World Bank 2015). Both programs are means-tested and targeted at poor elderly individuals and poor households with children, respectively. Under apartheid, the system was designed and developed to target the white population. In 1992, the Social Assistance Act eliminated all discriminatory provisions and the system expanded to cover all other groups. Nowadays, the majority of the beneficiaries are Black ${ }^{13}$ (many of them living in rural areas). Almost three quarters (3.2 million) of the elderly in South Africa are income eligible and receive the Old Age Pension, and around 60 percent of eligible age children (11.9 million people) receive the Child Support Grant (Sassa 2016). Direct spending on social assistance accounted for 3.5 percent of GDP in 2013 (World Bank 2016).

Many studies have assessed the impact of the two main social protection programs in South Africa on different indicators of well-being. Lund (1993), and Ardington and Lund (1995) identify poverty reduction effects of the social pensions as they reach individuals in the lower deciles of income and provide food security and household security. Barrientos (2005) concludes that benefits associated with non-contributory pension programs like the South African one include poverty reduction among the elderly and their households, facilitation of investment in human and physical capital, strengthening of intergenerational solidarity, and insurance against the adverse effects of agricultural reform. More recent papers (Duflo 2000, Niño-Zarazúa et al. 2012, Case and Menendez 2007) confirm previous findings and stress that elderly pool their income to other members of the households, which translates into significant improvements in well being of the whole households, especially children. The Child Support Grant (CSG) has also played a significant role in reducing the number of poor people (Woolard and Leibbrandt 2010). Aguero et al. (2006) find a positive impact of the CSG on child nutrition. A recent impact assessment by DSD, SASSA and UNICEF (2012) finds a positive developmental impact of the Child Support Grant in promoting nutritional, educational and health outcomes.

Analysing how social transfers are spent, Cross and Luckins (1993) document the role of social pensions in enabling recipient households to acquire farming inputs, hire tractors, and hire labour for household tasks such as working the land. Social grants also directly support nutrition, access to transportation services, and other short run productivity enhancing expenditures. Case and Deaton (1998) find that pension income is spent as other income, although money received by women is more likely to be spent on children. Case (2001) looks at the impacts of pension on health and conclude that

13 This paper uses the official classification of racial groups defined by Statistics South Africa, which is used by policy makers and researchers to measure inequality, identify the most vulnerable groups, design and evaluate social protection interventions, etc. There are four main ethnic groups in South Africa: Black Africans, Coloured, Indian/Asian, and White, and the first three altogether are denominated more generally as Black. 
income is pooled in 84 percent of the households, which means that transfers are more likely to benefit the household as a whole and not only the elderly recipients. Maitra and Ray (2003), by analysing whether remittances, pensions, and other income have different expenditure patterns, also find that pensions do not have much of an impact on household expenditure patterns.

Regarding the Child Support Grant, there does seems to be a direct effect on child expenditure: Lund (2002) finds an impact of child transfers on increased school expenses and trips to health services, while Coetzee (2013) concludes that the CSG has a higher marginal propensity to be spent on food than on adult goods, and a higher expenditure on food is expected to have a higher beneficial impact on children than on other household members. Moreover, a qualitative evaluation done by DSD, SASSA and UNICEF (2011) shows that the most frequent uses of the grant are school related expenses (including school fees, transportation, clothing and uniforms) and food (mainly general household food but sometimes child specific). Other uses include clothing and beauty. However, households that were struggling to meet their food needs would first use the grant to buy food and only buy child specific goods once basic needs were satisfied.

Based on previous studies as well as on the labelling effect hypothesis described in the previous section, it seems likely that child transfers will benefit the child directly. Moreover, in the case of South Africa there are information campaigns stressing that the grant is child specific and intended for educational support and nutritional improvement (DSD, SASSA and UNICEF 2011). This paper therefore hypothesises that the Child Support Grant will have a positive impact on the share spent on food and on human capital goods such as education, which are more likely to benefit children. In the case of the Old Age Pension and in line with the studies mentioned above, no significant change in expenditure behaviour is expected due to the fact that pension income is essentially income replacement. Despite the fact that elderly individuals usually pool their income to help the whole household, no major expenditure differences are expected between pension income and the income elderly individuals were earning before becoming eligible for the Old Age Pension.

\subsubsection{Migration and remittances}

South Africa has a history of internal migrants in its labuor force. Under apartheid, there were racial restrictions to urban areas and the permanent settlement of migrants was highly restricted (Posel 2001). As a result, labor migrants (usually black) were moving from rural to urban areas on a temporary basis and living in "homelands" (labor reserves built by the government for migrants). Based on South Africa's history, there are good 
reasons why migrants would remit and retain strong ties with their household of origin: in addition to altruistic motivations, migrants faced insecure employment opportunities and would remit as insurance against unemployment, or for their retirement (as permanent settlement in places of employment was not permitted) (Posel 2004).

In 1987 racial restrictions on movement and residence were lifted; however, migration patterns did not alter after apartheid as expected and internal migration from rural to urban areas remains temporary for a large number of individuals and households (Posel 2004). Poor households in South Africa, especially in rural areas, continue to rely on remittances to cover their daily needs (Posel and Casale 2006). However, analysing the National Income Dynamics Survey of 2008, Posel (2009) points out that many labour migrants are now settling in destination areas and that ties between migrants and households of origin are weakening. This translates into an important decline in the number of households receiving remittances compared to statistics derived from previous household surveys.

There are a limited number of studies analysing the effects of remittances in postapartheid South Africa, mainly due to a lack of nationally representative surveys that can explore patterns and trends in migration. However, it is evident that poor households highly rely on these transfers as they are a significant source of income, especially for rural black households (Posel and Casale 2003, 2006). Lund (1999) points out their income smoothing effects and, while for this author remittances are seen as a wage income that is earned in the market, Haddad and Zeller (1997) treat remittances as an exogenous transfer coming from outside the household. Maitra and Ray (2003) provide evidence supporting the second hypothesis, as they find that remittances are spent differently than the income earned by the household. Remittances are found to have a significant impact on several expenditure shares and, in the case of food and other goods (covering mainly luxury goods), remittances are spent differently than other sources of income: remittances increase the share spent on food, whereas income reduces it, and the opposite occurs in the case of luxury goods.

Studies on other countries have found that given the particularities of this income transfer, remittances are sometimes spent differently than other sources of income (Adams 1991; Adams 2002; Adams and Cuecuecha 2010; Davies et al. 2009; De and Ratha 2012). Given the temporary nature of migration in South Africa, where migrants retain strong ties with the household of origin and remit frequently, one can expect migrants to have an influence on how transfers are spent. As labor migration is generally low skilled, and that sending money represents a big effort to remittance senders, this paper hipothesises that remittance transfers are expected to be spent on basic household needs such as food, health, or household goods. 


\subsection{Demand model and empirical analysis}

\subsubsection{The model}

The relationship between expenditure shares and income is analysed by estimating Engel curves, which linearly relate expenditure shares to the logarithm of income. The demand model chosen for this analysis is the Almost Ideal Demand System (AIDS) from Deaton and Muellbauer (1980) given that it satisfies several useful properties: it gives a first order approximation to any demand system, it satisfies the axioms of choice exactly, it aggregates perfectly over consumers, it has a functional form consistent with previous household budget data, and it is simple to estimate in its linear approximation choice (Blanciforti et al. 1983). In other words, the AIDS model provides a good statistical fit to the different goods (including luxuries, necessities and inferior goods) (Adams and Cuecuecha 2010), allowing the same commodity to be a necessity for the rich and a luxury for the poor. It also satisfies the adding-up condition (that the sum of all total expenditure elasticities weighted by budget shares must add up to one) and represents consumer behaviour closely. Finally, AIDS is directly non-additive, meaning that consumption of one good can affect the marginal utility of another good. This model, therefore, does not impose severe substitution limitations implied by other demand models (Blanciforti et al. 1983).

At the household level, the AIDS model can be written as:

$$
w_{i h t}=\alpha_{i}+\sum_{j=1}^{N} \gamma_{i j} \log p_{j t}+\beta_{i} \log \left(\frac{x_{h t} / k_{h t}}{P_{t}}\right)
$$

where $i=1, \ldots, \mathrm{N}$ represent the $\mathrm{N}$ commodities, $h=1, \ldots, \mathrm{H}$ index households, $t=1, \ldots$, and $T_{h}$ represent time periods for households $h$. Here, $w_{i h t}$ denotes the budget share on good $i$ for household $h$ at time $t, x_{h t}$ denotes total income for household $h$ at time $t$, $p_{j t}$ denotes the price of commodity $j$ at time $t$, and $k_{h t}$ are characteristics of household h. $\mathrm{P}$ is the Stone's price index, which is chosen to make the system linear in parameters. ${ }^{14}$ The price index is defined as:

$$
\log P_{t}=\sum_{i=1}^{N} \bar{w}_{i t}+\log p_{i t}
$$

where $\bar{w}_{i t}$ is the mean of the budget shares across households. The AIDS model satisfies the following properties of demand functions:

$$
\text { Adding up: } \sum_{i} \alpha_{i}=1, \sum_{i} \gamma_{i j}=0, \sum_{i} \beta_{i}=0
$$

\footnotetext{
${ }^{14}$ Also used in Deaton and Muellbauer (1980), Moschini (1995), and Ghalwash (2007)
} 


$$
\begin{gathered}
\text { Homogeneity: } \sum_{j} \gamma_{i j}=0 \\
\text { Symmetry: } \gamma_{i j}=\gamma_{j i}
\end{gathered}
$$

The budget share equations have the properties of demand functions, namely that the sum of budget shares add up to one and ensures that total expenditure is equal to the sum of individual expenditure on different commodities and goods (equation 3); that the demand functions are homogoeneous of degree 0 in prices and total expenditure (equation 4); and that they satisfy the symmetry of the Slutsky matrix (equation 5), necessary for the integrability of the demand system to well-defined preferences.

\subsubsection{Empirical estimation}

The demand model is estimated equation by equation using OLS, and include household fixed effects to control for unobserved variation that can be correlated with the explanatory variables. To test whether remittances and social transfers have an effect on expenditure behaviour other than its effects through total income, I include three variables that express the share of each transfer (Child Support grant, Old Age Pension, and remittances) out of total income. In this way I test for behavioural changes that can occur after a specific transfer represents a higher proportion of total income (besides their effect through total income). The econometric estimation is expressed as:

$$
w_{i h t}=\beta_{i} \log \left(Y_{h t}\right)+\gamma_{1}\left(S T_{h t}\right)+\gamma_{2}\left(R_{h t}\right)+\gamma_{3}\left(H H_{h t}\right)+\gamma_{4}\left(t_{t}\right)+\alpha_{i h}+\varepsilon_{i h t}
$$

where $w_{i h t}$ is the share of total household expenditure on good $i$ at time $t, Y_{h t}$ denotes total household income of household $b$ at time $t . \mathrm{R}$ and ST are the ratios of remittances and social transfers to total income. In this case coefficients will capture a slope effect, that is the percentage point change in expenditure shares when the ratio of the respective transfer to total income increases by 1 percentage point. HH corresponds to the various household characteristics that influence the spending behaviour of the household and that can have an effect on how income is spent the different expenditure categories. These are number of children and number of adults in the household (which controls for the effect of a potential change in household composition induced by the receipt of the transfer), province of residence, whether the household lives in a rural, urban, or tribal area, maximum level of education, etc. $t_{t}$ are year dummies which control for macroeconomic changes and seasonal variation that can affect expenditure. Finally, $\alpha_{i}$ is the household fixed effect and $\varepsilon_{i t}$ the error term.

Note that prices are not included in this equation. Assuming that prices in each region are the same for all households, regional and year dummies are collinear with prices, 
which means prices can be excluded from the equations. Region fixed effects had to be dropped from the model as there was not enough within variation, meaning that there were only a few households who changed provinces during these years. Moreover, in this case I do not impose cross-equation restriction as it is not possible to estimate the system of equation with panel data and individual effects. Note, however, that there is no loss in efficiency due to the fact that all equations have identical explanatory variables; in this cases, the FGLS estimation of the full system is identical to the equation by equation OLS estimation (Zellner 1962).

Fixed effects are used for two reasons. The first is to control for unobserved variation that can be correlated with the explanatory variables included in the model. As long as the unobserved variation is constant over time for a household, then one should not expect to have a problem of endogeneity. For instance, one may expect households to select into migration (and thus to send remittances) based on both observed and unobserved characteristics. If these unobserved characteristics are time invariant (such as ability, motivation, etc.), then the error term will not be correlated with the independent variables and will therefore not generate any bias in the estimation. The second reason to use fixed effects is to analyse how changes in income affect expenditures over time: for instance, one can see if there is a change in expenditure behaviour caused by a change in recipient status or in the amount received.

There can still be systematic differences between recipients and non-recipients that are not accounted for in fixed effects estimation, however. If there are time varying unobserved characteristics that affect both the outcome and whether a household receives transfers, then results may be biased and not representative. In the absence of a proper instrument for remittances, the Child Support Grant, and the Old Age Pension, estimations are done for different sub-samples in order to compare more homogeneous population groups and see whether results from the main estimation hold. I therefore repeat the estimations restricting the sample to the African population (who are more likely to be poor and receiving transfers), and to households that receive either the Old Age Pension or the Child Support Grant (and can or cannot receive remittances). I restrict the sample to only social grant recipients in order to account for possible selection bias. The reason for this is that only households with certain characteristics are eligible for these grants, while everybody is eligible to receive remittances. In this way we obtain a better comparison between the effects of private and public transfers on expenditure. Finally, I also restrict the sample to households living in KwaZulu-Natal, a poor province with a high percentage of households receiving both social transfers and remittances. This allows for a better comparison of the different transfers on expenditure patterns. 
Due to the fact that there are other factors that can influence the spending behaviour of the household, like the gender of the recipient and how regular or unpredictable transfers are, I perform extended models as a robustness check. To capture the effect of who receives the transfer on expenditure shares, binary variables indicating the recipient of the respective transfer (i.e. men or women) are added to the model. To assess whether the regularity/unpredictability of the transfers has an effect on expenditure shares, a variable indicating how many times per year the transfer is received is also tested in the model. This will probably be relevant only for remittances, as social transfers are always received monthly. In addition, I explore other potential mechanisms that can influence the relationship between transfer receipt and expenditure behaviour of beneficiaries.

\subsection{Data}

The data used for this study is the National Income Dynamic Survey (NIDS), South Africa's first nationally representative panel survey that consists of three waves (2008, $2010,2012)$. In the first wave 28,247 individuals (7,296 households) were interviewed, in 2010 28,641 individuals (9,134 households), and in 2012 32,633 individuals (living in 10,236 households). 18,864 individuals were successfully interviewed in all three waves.

Detailed data on expenditure was collected at the household level by asking about the amount of money the household spent in the last month on each particular item for each category of expenditure. Expenditure is classified into nine categories: food and beverages, alcohol and tobacco, clothing, health, transport, education, leisure, housing, utilities and insurance, and miscellaneous. Household income was collected at an individual level, by asking each adult household member how much they received per month from different income sources (labor wage, agricultural income, government transfers, loan interest, remittances, etc.).

As this paper looks at how social transfers (specifically the Old Age Pension and the Child Support Grant) and remittances affect expenditure patterns, a variable for each of these income sources was created at the household level. All income variables were defined in per adult equivalent terms to account for the composition of the household and economies of scale within the household. Finally, the data was deflated to January 2012 as the base period. Deflators were computed from CPI data taken from the South African statistical office (Stats SA).

Figure 2.1 shows the percentage of households receiving remittances, the Old Age Pension, and the Child Support Grant in each wave. In 2008, slightly less than 12 percent of the households were receiving remittances. In 2010, the percentage of remittance recipient households declined by more than 6 percentage points, and increased again in 


\section{Chapter 2}

2012 to approximately 11 percent. The low percentage of households receiving remittances confirms the findings from Posel and Casale (2006) and Posel (2009), who state that remittances in South Africa have been decreasing over the last few decades. The percentage of households receiving the Old Age Pension, on the other hand, increased between 2008 and 2010 (from 20.1 percent to 25.7 percent) and slightly decreased in 2012. The decline in remittances after the year 2008 and the increase in the Old Age Pension reflects the effects of the economic crisis, where migrants had more difficulties to remit and the government needed to reach a higher percentage of the population due to increased poverty rates. The Child Support Grant has the highest coverage, with 31 percent of the households in the year 2008 and 37.7 percent in the year 2012 receiving the grant. This increase is due to changes in age eligibility, which increased from 14 years old in 2008, to 16 years old in 2010, and finally to 18 years old in 2012. The percentage of households receiving both remittances and the Child Support Grant, remittances and the Old Age Pension, and remittances and either the Old Age Pension or the Child Support Grant does not exceed 6.2. This means that these transfers reach different population targets, mainly due to the fact that remittances have a lower coverage than social transfers.

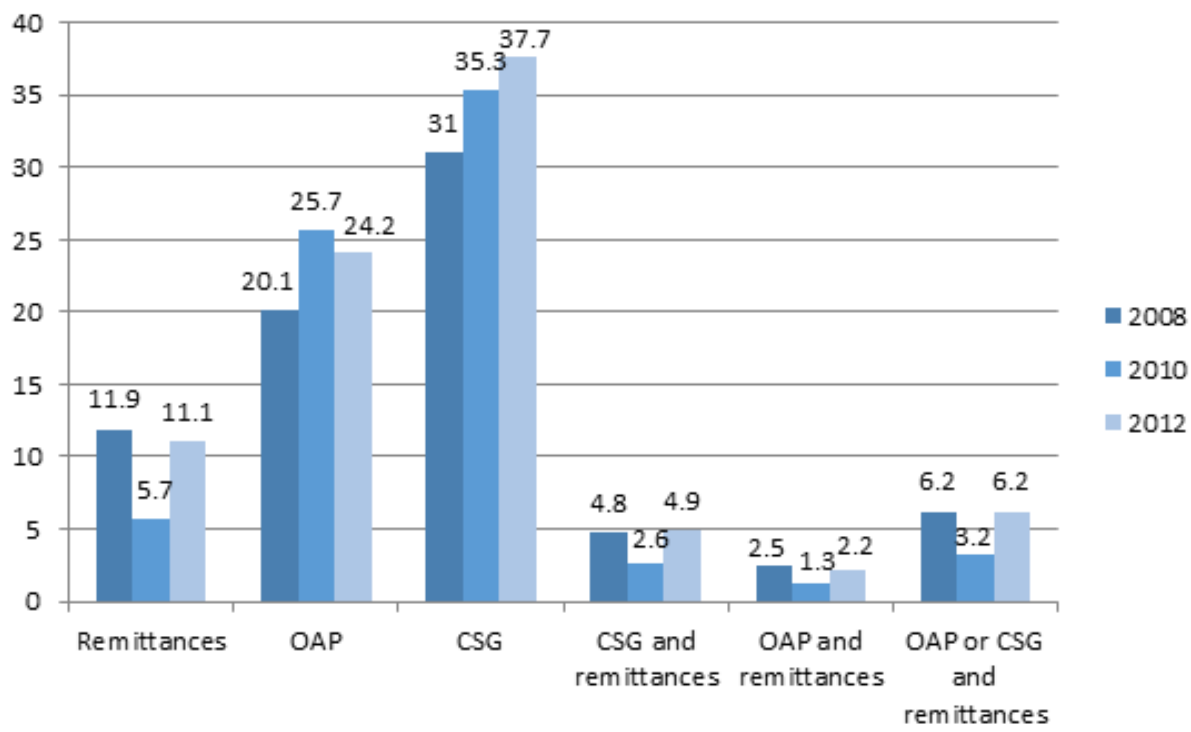

Figure 2.1: Percentage of households receiving transfers

Source: NIDS 2008, 2010, 2012.

While the Old Age Pension is quite generous in comparison to other social transfers (R940 in 2008, R1080 in 2010, and R1200 in 2012), the Child Support Grant is the least generous, despite its large coverage (R100 in 2008, R250 in 2010, and R280 in 2012 per eligible person). Table 2.1 shows the average amount of transfers received in recipient 
households. The average amount received from the Child Support Grant is around half the amount received from the Old Age Pension; this is due to the fact that, on average, there are more children than elderly living in a household. The average amount of remittances lies in between the two social protection transfers in the years 2008 and 2010. However, in 2012 the average amount of remittances increased significantly and reached 1319 rands on average. When accounting for the size of the household and looking at the value of the transfers per capita, one can see that the maximum average amount of the Child Support Grant does not exceed 128 rands, while remittances are, on average, similar in value to the Old Age Pension (and even higher in the year 2012). Finally, in this dataset, it is possible to get information on who in the households receives the transfers. The table shows that both the Child Support Grant and remittances are usually received by women, although to a larger extent in the case of the Child Support Grant, where more than 94 percent of recipients were women in 2008 and 2010 (in 2012 this percentage decreased to 88 percent). In the case of remittances, around 80 percent of remittance recipients are female.

Table 2.1: Average value (in Rands) of transfers received and gender of recipients

\begin{tabular}{lccc}
\hline & 2008 & 2010 & 2012 \\
\hline Mean remittances (per hh) & 739 & 915 & 1319 \\
Mean Child Support Grant (per hh) & 409 & 548 & 630 \\
Mean Old Age Pension (per hh) & 1018 & 1259 & 1411 \\
Mean remittances (per capita) & 215 & 283 & 507 \\
Mean Child Support Grant (per capita) & 77 & 101 & 128 \\
Mean Old Age Pension (per capita) & 263 & 330 & 404 \\
Percentage of females receiving Child grant & 97.4 & 94.9 & 88.0 \\
Percentage of females receiving remittances & 78.2 & 80.6 & 80.0 \\
\hline
\end{tabular}

Source: Author's calculations; NIDS 2008, 2010, and 2012.

Table 2.2 shows the distribution of household expenditure according to recipient status. Transfer recipients have a higher share of expenditure on food, as compared to nonrecipients. Non-recipients, which are more likely to be richer, spend a slightly larger share of their total budget on housing and utilities, leisure and transport. Recipients of the Child Support Grant spend a slightly larger share of their expenditure on education (0.06), as compared to the other groups (0.05). However, one needs to keep in mind that for richer households, expenditure on education in absolute terms is very high, mainly as a result of high school fees for those children who attend private schools. 
Table 2.2: Expenditure shares according to recipient status in 2008

\begin{tabular}{lcccc}
\hline Variable & Receives CSG & Receives OAP & Receives remittances & Non recipients \\
\hline Share food & 0.56 & 0.58 & 0.54 & 0.46 \\
Share alcohol and & 0.03 & 0.03 & 0.02 & 0.04 \\
tobacco & & & & 0.03 \\
Share clothes & 0.03 & 0.02 & 0.03 & 0.05 \\
Share health & 0.03 & 0.03 & 0.03 & 0.17 \\
Share housing and & 0.15 & 0.16 & 0.16 & 0.05 \\
utilities & 0.06 & 0.05 & 0.05 & 0.08 \\
Share education & 0.04 & 0.03 & 0.05 & 0.1 \\
Share transport & 0.08 & 0.08 & 0.09 & 0.05 \\
Share leisure & 0.05 & 0.05 & 0.05 & \\
Other & & &
\end{tabular}

Source: Author's calculations; NIDS 2008.

Table 2.3 shows some basic household characteristics according to recipient status. Households receiving social transfers are, on average, larger in size (5.6/4.8) compared to households receiving remittances (4.6) and no transfers (3.0). Regarding the province where the household lives, both remittances and social transfers go disproportionately to households in KwaZulu-Natal. Gauteng and Limpopo are two other provinces receiving a high percentage of total remittances, whereas households living in provinces like Western Cape or Northern Cape receive a smaller share of remittances on average. The fact that transfers target poor households can be seen by looking at the average income and expenditure per adult equivalent in the different households: households receiving no transfers are by far the richest, followed by households receiving remittances, the Old Age Pension and the Child Support Grant. These transfers also go disproportionately to the Africans who are also more likely to live in poverty. Finally, table 2.4 shows the summary statistics of all the variables used in the regression analysis. 
On the Fungibility of Public and Private Transfers: A Mental Accounting Approach

Table 2.3: Main descriptive statistics according to recipient status (2008)

\begin{tabular}{|c|c|c|c|c|c|}
\hline Variable & $\begin{array}{c}\text { Receive } \\
\text { remittances }\end{array}$ & Receive CSG & Receive OAP & Non recipients & Total \\
\hline Household size & 4.6 & 5.6 & 4.8 & 3.0 & 3.9 \\
\hline \multicolumn{6}{|l|}{ Province } \\
\hline Western Cape & 8.7 & 7.1 & 8.5 & 19.2 & 13.8 \\
\hline Eastern Cape & 13.8 & 14.0 & 17.5 & 10.7 & 12.7 \\
\hline Northern Cape & 6.4 & 7.2 & 7.0 & 8.5 & 7.8 \\
\hline Free State & 5.3 & 5.7 & 5.6 & 6.2 & 6.1 \\
\hline KwaZulu-Natal & 29.3 & 34.1 & 31.6 & 17.7 & 24.3 \\
\hline North West & 6.0 & 7.1 & 7.6 & 6.4 & 6.7 \\
\hline Gauteng & 8.1 & 7.7 & 4.7 & 17.7 & 12.8 \\
\hline Mpumalanga & 7.1 & 8.0 & 6.2 & 8.0 & 7.6 \\
\hline Limpopo & 15.4 & 9.3 & 11.3 & 5.9 & 8.3 \\
\hline \multicolumn{6}{|l|}{ Race } \\
\hline African & 85.7 & 88.4 & 84.7 & 68.6 & 77.1 \\
\hline Coloured & 10.2 & 10.8 & 11.9 & 15.7 & 13.8 \\
\hline Asian/Indian & 0.9 & 0.4 & 1.5 & 2.1 & 1.5 \\
\hline White & 3.2 & 0.4 & 1.9 & 13.6 & 7.6 \\
\hline Income per capita & 842.5 & 385.8 & 552.9 & 2175.9 & 1269.3 \\
\hline $\begin{array}{l}\text { Expenditure per } \\
\text { capita }\end{array}$ & 912.4 & 456.4 & 578.1 & 2230.8 & 1438.0 \\
\hline
\end{tabular}

Source: Author's calculations; NIDS 2008. 
Table 2.4: Summary statistics

\begin{tabular}{llllc}
\hline Variable & Mean & SD & Minimum & Maximum \\
\hline Share food & 0.53 & 0.24 & 0.001 & 0.99 \\
Share alcohol and tobacco & 0.03 & 0.07 & 0 & 0.68 \\
Share clothes & 0.02 & 0.07 & 0 & 0.76 \\
Share health & .05 & 0.10 & 0 & 0.97 \\
Share housing and utilities & 0.16 & 0.14 & 0 & 0.98 \\
Share education & 0.07 & 0.15 & 0 & 0.96 \\
Share transport & 0.05 & 0.11 & 0 & 0.86 \\
Share leisure & 0.07 & 0.09 & 0 & 0.94 \\
Share other & 0.05 & 0.05 & 0 & 0.72 \\
Logarithm of total income (pae) & 6.5 & 1.2 & 0 & 11.2 \\
Share of OAP out of total income & 0.16 & 0.31 & 0 & 1 \\
Share of CSG out of total income & 0.18 & 0.30 & 0 & 1 \\
Share of remittances out of total income & 0.07 & 0.20 & 0 & 1 \\
Number of adults & 3.1 & 1.7 & 0 & 16 \\
Number of children & 1.8 & 1.7 & 0 & 12 \\
Urban formal & 0.39 & 0.49 & 0 & 1 \\
Urban informal & 0.07 & 0.25 & 0 & 1 \\
Rural & 0.54 & 0.50 & 0 & 1 \\
\hline
\end{tabular}

Source: Author's calculations; NIDS 2008.

\subsection{Results}

Table 2.5 shows the results of the fixed effects model for the nine budget shares. The model shows how the share of remittances, the Child Support Grant, and the Old Age Pension to total income affect expenditure shares (controlling for household and residential characteristics). The table shows that an increase in ratio of remittances to total income is associated with an increase in the share spent on food. This means that the more important this transfer becomes as a source of income, the higher is the share of total expenditure on food, which is in line with the findings from Maitra and Ray (2003). An increase in the ratio of remittances to total income is also associated with a decrease in expenditure on alcohol and tobacco, clothing, and transport, and with an increased expenditure on education (although in the latter case the coefficient is only significant at a 10 percent level). This is an interesting finding, as it shows that remittances are not spent on conspicuous consumption and that they are spent differently than other sources of income. These results also support the hypothesis that remittances are likely to be spent on basic household needs.

When the share of income from the Old Age Pension out of total income increases by one percentage point, expenditure on food increases by 0.03 percentage points. Expenditure on education and on housing and utilities both increase by 0.01 percentage 
points, although coefficients are only significant at a 10 percent level. The positive relationship between income from the Old Age Pension and certain expenditure categories contradicts the hypothesis that pension income will not affect expenditure behaviour as these transfers are essentially income replacement. Households seem to be changing their consumption patterns by increasing the share spent on goods that benefit the household as a whole (like food and utilities) as well as goods that benefit children in particular (education and food). At the same time, increased income from the Old Age Pension is associated with a decrease in expenditure on transportation, clothing, leisure, and alcohol and tobacco.

With regards to the Child Support Grant, a one percentage point increase in the share of this source of income is associated with a 0.02 percentage points increase in the share spent on education, and a decrease in 0.02 and 0.01 in the shares spent on alcohol and tobacco and leisure, respectively. This finding supports the hypothesis that child grants are likely be spent on goods that benefit the children (like education), and this could be due to a labelling effect. The findings also support the theory of change hypothesis which says that caregivers (grant recipients) will spend the grant on goods that benefits the beneficiary, in this case children.

This analysis shows that social transfers and remittances are not always spent in the same way as other sources of income, and some difference between them are observed. There is a positive effect of the Child Support Grant, remittances and the Old Age Pension on education, although in the case of the Child Support Grant the relationship is stronger as the coefficient is significant at a 5 percent level (as compared to 10 percent in the other cases) and larger in magnitude. This can be due to the fact that the Child Support Grant is explicitly targeted at children and it is the aim of the programme to improve children's educational outcomes and school attendance. At the same time, both remittances and the Old Age Pension increase the share spent on food, but this is not the case for the Child Support Grant. While remittances and the Old Age Pension are both negatively associated with clothing and transportation, all three grants are negatively associated with expenditure on alcohol and tobacco. In addition, both the Child Support Grant and the Old Age Pension are associated with a decreased expenditure on leisure, but this does not apply to remittances. Finally, an increase in the share of the Old Age Pension to total income increases the share spent on utilities and household goods, while in the case of remittances and child grants no significant results are found. This can be due to the high value of the Old Age Pension in comparison to the other two transfers, as child grants are worth approximately four times less than the Old Age Pension and are less likely to be pooled, and remittances received by poor households are very low in value. 
Table 2.5: Effects of income and transfer amounts on expenditure patterns- Whole sample

\begin{tabular}{|c|c|c|c|c|c|c|c|c|c|}
\hline & Share food & Share clothes & Share health & $\begin{array}{l}\text { Share alcohol } \\
\text { and tobacco }\end{array}$ & Share transport & Share education & Share leisure & Share utilities & Share other \\
\hline \multirow[t]{2}{*}{ Log of total income } & $-0.02^{* *}$ & $0.00^{* *}$ & $0.00^{+}$ & 0.00 & $0.01^{* *}$ & $-0.00^{+}$ & $0.01^{* *}$ & 0.00 & -0.00 \\
\hline & $(0.00)$ & $(0.00)$ & $(0.00)$ & $(0.00)$ & $(0.00)$ & $(0.00)$ & $(0.00)$ & $(0.00)$ & $(0.00)$ \\
\hline \multirow{2}{*}{$\begin{array}{l}\text { Share of OPG out of } \\
\text { total income }\end{array}$} & $0.03^{* *}$ & $-0.01^{*}$ & 0.00 & $-0.01^{* *}$ & $-0.02^{* *}$ & $0.01^{+}$ & $-0.02^{* *}$ & $0.01^{+}$ & -0.00 \\
\hline & $(0.01)$ & $(0.00)$ & $(0.00)$ & $(0.00)$ & $(0.00)$ & $(0.01)$ & $(0.01)$ & $(0.01)$ & $(0.00)$ \\
\hline \multirow{2}{*}{$\begin{array}{l}\text { Share of CSG out of } \\
\text { total income }\end{array}$} & 0.02 & -0.01 & 0.00 & $-0.02^{* *}$ & -0.01 & $0.02^{*}$ & $-0.01^{*}$ & 0.01 & -0.00 \\
\hline & $(0.01)$ & $(0.00)$ & $(0.00)$ & $(0.00)$ & $(0.01)$ & $(0.01)$ & $(0.01)$ & $(0.01)$ & $(0.00)$ \\
\hline Share of remittances & $0.05^{* *}$ & $-0.01^{*}$ & -0.01 & $-0.02^{* *}$ & $-0.02^{* *}$ & $0.02^{+}$ & 0.01 & -0.01 & -0.00 \\
\hline Out of total income & $(0.02)$ & $(0.01)$ & $(0.01)$ & $(0.00)$ & $(0.01)$ & $(0.01)$ & $(0.01)$ & $(0.01)$ & $(0.00)$ \\
\hline \multirow[t]{2}{*}{ Number of adults } & $-0.01^{* *}$ & -0.00 & 0.00 & $-0.00^{* *}$ & $0.00^{* *}$ & $0.00^{*}$ & -0.00 & $0.00^{* *}$ & $0.00^{*}$ \\
\hline & $(0.00)$ & $(0.00)$ & $(0.00)$ & $(0.00)$ & $(0.00)$ & $(0.00)$ & $(0.00)$ & $(0.00)$ & $(0.00)$ \\
\hline \multirow[t]{2}{*}{ Number of children } & -0.00 & 0.00 & $0.00^{*}$ & 0.00 & -0.00 & $0.01^{* *}$ & -0.00 & $-0.00^{*}$ & $-0.00^{*}$ \\
\hline & $(0.00)$ & $(0.00)$ & $(0.00)$ & $(0.00)$ & $(0.00)$ & $(0.00)$ & $(0.00)$ & $(0.00)$ & $(0.00)$ \\
\hline \multirow[t]{2}{*}{ Urban formal } & $-0.07^{* *}$ & 0.01 & $0.01^{+}$ & 0.00 & $0.02^{* *}$ & $0.01^{*}$ & $0.02^{* *}$ & $0.02^{*}$ & -0.00 \\
\hline & $(0.01)$ & $(0.00)$ & $(0.01)$ & $(0.00)$ & $(0.01)$ & $(0.01)$ & $(0.01)$ & $(0.01)$ & $(0.00)$ \\
\hline \multirow[t]{2}{*}{ Urban informal } & $-0.07^{* *}$ & 0.00 & 0.00 & $-0.01^{+}$ & $0.05^{* *}$ & 0.01 & 0.01 & 0.01 & -0.00 \\
\hline & $(0.02)$ & $(0.01)$ & $(0.01)$ & $(0.01)$ & $(0.01)$ & $(0.01)$ & $(0.01)$ & $(0.01)$ & $(0.01)$ \\
\hline \multirow[t]{2}{*}{ Year 2008} & $0.04^{* *}$ & $-0.00^{*}$ & $0.01^{* *}$ & $-0.01^{* *}$ & $0.01^{*}$ & $0.03^{* *}$ & $-0.04^{* *}$ & $-0.02^{* *}$ & $-0.01^{* *}$ \\
\hline & $(0.01)$ & $(0.00)$ & $(0.00)$ & $(0.00)$ & $(0.00)$ & $(0.00)$ & $(0.00)$ & $(0.00)$ & $(0.00)$ \\
\hline \multirow[t]{2}{*}{ Year 2010} & $0.09^{* *}$ & $-0.00^{*}$ & $-0.01^{* *}$ & $-0.01^{* *}$ & $-0.02^{* *}$ & $0.01^{* *}$ & $-0.01^{* *}$ & $-0.04^{* *}$ & $-0.02^{* *}$ \\
\hline & $(0.00)$ & $(0.00)$ & $(0.00)$ & $(0.00)$ & $(0.00)$ & $(0.00)$ & $(0.00)$ & $(0.00)$ & $(0.00)$ \\
\hline \multirow[t]{2}{*}{ Constant } & $0.70^{* *}$ & -0.00 & 0.00 & $0.05^{* *}$ & $-0.04^{* *}$ & 0.02 & $0.06^{* *}$ & $0.15^{* *}$ & $0.06^{* *}$ \\
\hline & $(0.02)$ & $(0.01)$ & $(0.01)$ & $(0.01)$ & $(0.01)$ & $(0.01)$ & $(0.01)$ & $(0.02)$ & $(0.01)$ \\
\hline Observations & 18940 & 18940 & 18940 & 18940 & 18940 & 18940 & 18940 & 18940 & 18940 \\
\hline
\end{tabular}

Standard errors in parentheses; ${ }^{+} p<0.1,{ }^{*} p<0.05,{ }^{* *} p<0.01$ 
Given that there are systematic differences between social transfers recipients and remittance recipients, the model can still suffer from endogeneity if there are omitted variables that are time variant and affect both the treatment and the outcome. For instance, if there is a shock in the household (or in the community) that causes a change in expenditure and, at the same time, generates a response in the person sending remittances or the government by increasing or decreasing transfers sent, our coefficients may be subject to bias. In absence of a proper instrument for the Child Support Grant, the Old Age Pension, and remittances, the estimations are performed separately for different population groups to test for heterogeneity in effects. I reestimate the model in three ways: (1) restricting the sample to the African population in order to compare public and private transfers within a more homogeneous group, (2) restricting the sample to households that receive social transfers (and that can or cannot receive remittances), and (3) restricting the sample to households living in KwaZuluNatal, a province with a high share of households receiving both social transfers and remittances.

When the sample is restricted to the African population -households who are likely to be poor and receive transfers- (Table 2.6) results from the previous estimation hold, although a small positive impact of the Child Support Grant on food are now observed.

By excluding other population groups who are less likely to receive grants and therefore have little or no variation in the amount of transfers received (like the white or Asian population), one can see that the Child Support Grant is, in fact, increasing recipients' expenditure on food more than on other goods. This is also in line with the labelling effect hypothesis that the Child Support Grant is meant to be spent on goods that benefit the child (in this case increased food consumption is expected to lead to better nutritional outcomes).

In table 2.7 the sample is restricted to households receiving the Old Age Pension or the Child Support Grant. In this case the relationship between transfers and expenditure shares is slightly different. Remittances do not longer increase expenditure on food. The reason for this is that the number of households receiving both social transfers and remittances is not very high, and households that receive both social transfers and remittances are very poor, which means remittances received are usually low in value as well as lower in value compared to social transfers. In the case of educational expenditure, we no longer observe significant effects of transfers on this category. One reason could be that there is not much variation in educational expenditure among social transfer recipients across the 3 waves. Results may also imply that the relationship between the Child Support Grant and educational expenditure is not very robust because of data limitations regarding educational expenditure, among other reasons, which will be discussed in the limitations section. 


\section{Chapter 2}

Finally, table 2.8 reports the regressions when the sample is restricted to households living in KwaZulu-Natal. This province is characterised by high levels of poverty and a big percentage of households that are recipients of both social transfers and remittances. What one can see now is a positive and strong impact of the three transfers on food expenditure: a 1 percent increase in the ratio of the Old Age Pension, the Child Support Grant, and remittances to total income increases the share spent on food by $0.08,0.03$, and 0.07 percentage points, respectively. This means that when one compares more homogeneous groups and allows for a better comparison between social transfers and remittances by taking a sub-sample of households that are likely to receive all three transfers, one can see that both social transfers and remittances have a positive and significant effect on the share spent on food. The positive effects of social transfers on education are not significant in this specification though. 
On the Fungibility of Public and Private Transfers: A Mental Accounting Approach

Table 2.6: Effects of income and transfer amounts on expenditure patterns- African sample

\begin{tabular}{|c|c|c|c|c|c|c|c|c|c|}
\hline & Share food & Share clothes & Share health & $\begin{array}{l}\text { Share alcohol } \\
\text { and tobacco }\end{array}$ & Share transport & Share education & Share leisure & Share utilities & Share other \\
\hline \multirow[t]{2}{*}{ Log of total income } & $-0.02^{* *}$ & $0.01^{* *}$ & $0.00^{*}$ & 0.00 & $0.01^{* *}$ & -0.00 & $0.01^{* *}$ & 0.00 & -0.00 \\
\hline & $(0.00)$ & $(0.00)$ & $(0.00)$ & $(0.00)$ & $(0.00)$ & $(0.00)$ & $(0.00)$ & $(0.00)$ & $(0.00)$ \\
\hline \multirow{2}{*}{$\begin{array}{l}\text { Share of OPG out of } \\
\text { total income }\end{array}$} & $0.03^{*}$ & $-0.01^{+}$ & 0.00 & $-0.01^{* *}$ & $-0.02^{* *}$ & $0.01^{+}$ & $-0.01^{*}$ & 0.01 & -0.00 \\
\hline & $(0.01)$ & $(0.00)$ & $(0.00)$ & $(0.00)$ & $(0.00)$ & $(0.01)$ & $(0.01)$ & $(0.01)$ & $(0.00)$ \\
\hline \multirow{2}{*}{$\begin{array}{l}\text { Share of CSG out of } \\
\text { total income }\end{array}$} & $0.02^{+}$ & -0.01 & 0.00 & $-0.02^{* *}$ & -0.00 & $0.02^{*}$ & $-0.01^{*}$ & 0.00 & -0.00 \\
\hline & $(0.01)$ & $(0.01)$ & $(0.01)$ & $(0.00)$ & $(0.01)$ & $(0.01)$ & $(0.01)$ & $(0.01)$ & $(0.00)$ \\
\hline Share of remittances & $0.05^{* *}$ & $-0.02^{*}$ & -0.00 & $-0.02^{* *}$ & $-0.03^{* *}$ & $0.02^{+}$ & 0.01 & -0.01 & -0.00 \\
\hline Out of total income & $(0.02)$ & $(0.01)$ & $(0.01)$ & $(0.00)$ & $(0.01)$ & $(0.01)$ & $(0.01)$ & $(0.01)$ & $(0.00)$ \\
\hline \multirow[t]{2}{*}{ Number of adults } & $-0.00^{*}$ & -0.00 & 0.00 & $-0.00^{* *}$ & $0.00^{* *}$ & $0.00^{*}$ & $-0.00^{+}$ & $0.00^{+}$ & $0.00^{* *}$ \\
\hline & $(0.00)$ & $(0.00)$ & $(0.00)$ & $(0.00)$ & $(0.00)$ & $(0.00)$ & $(0.00)$ & $(0.00)$ & $(0.00)$ \\
\hline \multirow[t]{2}{*}{ Number of children } & $-0.01^{+}$ & 0.00 & $0.00^{*}$ & 0.00 & -0.00 & $0.01^{* *}$ & -0.00 & $-0.00^{*}$ & $-0.00^{*}$ \\
\hline & $(0.00)$ & $(0.00)$ & $(0.00)$ & $(0.00)$ & $(0.00)$ & $(0.00)$ & $(0.00)$ & $(0.00)$ & $(0.00)$ \\
\hline \multirow[t]{2}{*}{ Urban formal } & $-0.07^{* *}$ & 0.01 & $0.01^{+}$ & 0.00 & $0.02^{* *}$ & $0.02^{*}$ & $0.02^{* *}$ & 0.01 & -0.01 \\
\hline & $(0.01)$ & $(0.01)$ & $(0.01)$ & $(0.00)$ & $(0.01)$ & $(0.01)$ & $(0.01)$ & $(0.01)$ & $(0.00)$ \\
\hline \multirow[t]{2}{*}{ Urban informal } & $-0.07^{* *}$ & 0.00 & 0.00 & -0.01 & $0.06^{* *}$ & 0.01 & 0.01 & 0.01 & -0.01 \\
\hline & $(0.02)$ & $(0.01)$ & $(0.01)$ & $(0.01)$ & $(0.01)$ & $(0.01)$ & $(0.01)$ & $(0.01)$ & $(0.01)$ \\
\hline \multirow[t]{2}{*}{ Year 2008} & $0.03^{* *}$ & $-0.00^{+}$ & $0.02^{* *}$ & $-0.01^{* *}$ & $0.01^{* *}$ & $0.03^{* *}$ & $-0.04^{* *}$ & $-0.02^{* *}$ & $-0.01^{* *}$ \\
\hline & $(0.01)$ & $(0.00)$ & $(0.00)$ & $(0.00)$ & $(0.00)$ & $(0.00)$ & $(0.00)$ & $(0.00)$ & $(0.00)$ \\
\hline \multirow[t]{2}{*}{ Year 2010} & $0.09^{* *}$ & $-0.00^{+}$ & $-0.00^{*}$ & $-0.00^{* *}$ & $-0.02^{* *}$ & $0.01^{* *}$ & $-0.01^{* *}$ & $-0.04^{* *}$ & $-0.02^{* *}$ \\
\hline & $(0.01)$ & $(0.00)$ & $(0.00)$ & $(0.00)$ & $(0.00)$ & $(0.00)$ & $(0.00)$ & $(0.00)$ & $(0.00)$ \\
\hline \multirow[t]{2}{*}{ Constant } & $0.70^{* *}$ & -0.00 & -0.00 & $0.04^{* *}$ & $-0.04^{* *}$ & 0.02 & $0.06^{* *}$ & $0.16^{* *}$ & $0.06^{* *}$ \\
\hline & $(0.03)$ & $(0.01)$ & $(0.01)$ & $(0.01)$ & $(0.01)$ & $(0.02)$ & $(0.01)$ & $(0.02)$ & $(0.01)$ \\
\hline Observations & 15767 & 15767 & 15767 & 15767 & 15767 & 15767 & 15767 & 15767 & 15767 \\
\hline
\end{tabular}

Standard errors in parentheses; ${ }^{+} p<0.1,{ }^{*} p<0.05,{ }^{* *} p<0.01$ 
Table 2.7: Effects of income and transfer amounts on expenditure patterns- Social transfer recipients

\begin{tabular}{|c|c|c|c|c|c|c|c|c|c|}
\hline & Share food & Share clothes & Share health & $\begin{array}{l}\text { Share alcohol } \\
\text { and tobacco }\end{array}$ & Share transport & Share education & Share leisure & Share utilities & Share other \\
\hline \multirow[t]{2}{*}{ Log of total income } & -0.01 & $0.01^{*}$ & $-0.01^{*}$ & 0.00 & 0.00 & $-0.02^{* *}$ & 0.00 & $0.01^{+}$ & 0.00 \\
\hline & $(0.01)$ & $(0.00)$ & $(0.00)$ & $(0.00)$ & $(0.00)$ & $(0.01)$ & $(0.00)$ & $(0.01)$ & $(0.00)$ \\
\hline \multirow{2}{*}{$\begin{array}{l}\text { Share of OPG out of } \\
\text { total income }\end{array}$} & $0.06^{* *}$ & -0.00 & -0.01 & -0.01 & $-0.03^{* *}$ & -0.01 & $-0.02^{*}$ & 0.01 & -0.01 \\
\hline & $(0.02)$ & $(0.01)$ & $(0.01)$ & $(0.01)$ & $(0.01)$ & $(0.01)$ & $(0.01)$ & $(0.01)$ & $(0.01)$ \\
\hline \multirow{2}{*}{$\begin{array}{l}\text { Share of CSG out of } \\
\text { total income }\end{array}$} & $0.07^{* *}$ & -0.00 & $-0.02^{*}$ & $-0.02^{*}$ & $-0.03^{* *}$ & -0.02 & $-0.02^{+}$ & 0.01 & 0.01 \\
\hline & $(0.03)$ & $(0.01)$ & $(0.01)$ & $(0.01)$ & $(0.01)$ & $(0.02)$ & $(0.01)$ & $(0.02)$ & $(0.01)$ \\
\hline Share of remittances & 0.04 & -0.02 & -0.02 & $-0.03^{* *}$ & $-0.04^{* *}$ & 0.03 & 0.01 & 0.02 & -0.01 \\
\hline Out of total income & $(0.04)$ & $(0.01)$ & $(0.01)$ & $(0.01)$ & $(0.01)$ & $(0.03)$ & $(0.02)$ & $(0.02)$ & $(0.01)$ \\
\hline \multirow[t]{2}{*}{ Number of adults } & -0.00 & 0.00 & $-0.00^{*}$ & $0.00^{* *}$ & 0.00 & 0.00 & -0.00 & -0.00 & $0.00^{+}$ \\
\hline & $(0.00)$ & $(0.00)$ & $(0.00)$ & $(0.00)$ & $(0.00)$ & $(0.00)$ & $(0.00)$ & $(0.00)$ & $(0.00)$ \\
\hline \multirow[t]{2}{*}{ Number of children } & -0.01 & 0.00 & $0.00^{* *}$ & $0.00^{* *}$ & $-0.00^{*}$ & $0.01^{* *}$ & -0.00 & $-0.01^{*}$ & $-0.00^{+}$ \\
\hline & $(0.00)$ & $(0.00)$ & $(0.00)$ & $(0.00)$ & $(0.00)$ & $(0.00)$ & $(0.00)$ & $(0.00)$ & $(0.00)$ \\
\hline \multirow[t]{2}{*}{ Urban formal } & $-0.07^{* *}$ & 0.02 & 0.00 & -0.00 & -0.01 & $0.04^{* *}$ & $0.04^{* *}$ & -0.01 & 0.00 \\
\hline & $(0.03)$ & $(0.01)$ & $(0.01)$ & $(0.01)$ & $(0.01)$ & $(0.01)$ & $(0.01)$ & $(0.02)$ & $(0.01)$ \\
\hline \multirow[t]{2}{*}{ Urban informal } & -0.10 & 0.02 & 0.03 & 0.00 & 0.05 & $0.06^{* *}$ & 0.04 & $-0.06^{+}$ & -0.02 \\
\hline & $(0.06)$ & $(0.01)$ & $(0.02)$ & $(0.01)$ & $(0.04)$ & $(0.02)$ & $(0.03)$ & $(0.04)$ & $(0.01)$ \\
\hline \multirow[t]{2}{*}{ Year 2008} & $0.05^{* *}$ & $-0.01^{*}$ & $0.01^{*}$ & -0.00 & $0.01^{*}$ & $0.03^{* *}$ & $-0.04^{* *}$ & $-0.03^{* *}$ & $-0.01^{* *}$ \\
\hline & $(0.01)$ & $(0.00)$ & $(0.00)$ & $(0.00)$ & $(0.00)$ & $(0.01)$ & $(0.00)$ & $(0.01)$ & $(0.00)$ \\
\hline \multirow[t]{2}{*}{ Year 2010} & $0.11^{* *}$ & $-0.01^{*}$ & $-0.01^{* *}$ & $-0.01^{* *}$ & $-0.01^{* *}$ & $0.01^{* *}$ & $-0.02^{* *}$ & $-0.04^{* *}$ & $-0.03^{* *}$ \\
\hline & $(0.01)$ & $(0.00)$ & $(0.00)$ & $(0.00)$ & $(0.00)$ & $(0.00)$ & $(0.00)$ & $(0.01)$ & $(0.00)$ \\
\hline \multirow[t]{2}{*}{ Constant } & $0.59^{* *}$ & -0.03 & $0.08^{* *}$ & 0.01 & $0.05^{+}$ & $0.11^{*}$ & $0.08^{*}$ & $0.14^{* *}$ & $0.05^{*}$ \\
\hline & $(0.07)$ & $(0.03)$ & $(0.03)$ & $(0.02)$ & $(0.03)$ & $(0.05)$ & $(0.03)$ & $(0.05)$ & $(0.02)$ \\
\hline Observations & 10632 & 10632 & 10632 & 10632 & 10632 & 10632 & 10632 & 10632 & 10632 \\
\hline
\end{tabular}

Standard errors in parentheses; ${ }^{+} p<0.1,{ }^{*} p<0.05,{ }^{* *} p<0.01$ 
On the Fungibility of Public and Private Transfers: A Mental Accounting Approach

Table 2.8: Effects of income and transfer amounts on expenditure patterns- KwaZulu-Natal

\begin{tabular}{|c|c|c|c|c|c|c|c|c|c|}
\hline & Share food & Share clothes & Share health & $\begin{array}{l}\text { Share alcohol } \\
\text { and tobacco }\end{array}$ & Share transport & Share education & Share leisure & Share utilities & Share other \\
\hline \multirow[t]{2}{*}{ Log of total income } & $-0.05^{* *}$ & $0.01^{* *}$ & $0.01^{* *}$ & -0.00 & $0.01^{* *}$ & -0.00 & $0.01^{* *}$ & $0.01^{* *}$ & $0.00^{* *}$ \\
\hline & $(0.00)$ & $(0.00)$ & $(0.00)$ & $(0.00)$ & $(0.00)$ & $(0.00)$ & $(0.00)$ & $(0.00)$ & $(0.00)$ \\
\hline \multirow{2}{*}{$\begin{array}{l}\text { Share of OPG out of } \\
\text { total income }\end{array}$} & $0.08^{* *}$ & $-0.01^{* *}$ & $-0.01^{*}$ & $-0.02^{* *}$ & $-0.03^{* *}$ & -0.00 & $-0.03^{* *}$ & 0.01 & 0.00 \\
\hline & $(0.01)$ & $(0.00)$ & $(0.00)$ & $(0.00)$ & $(0.00)$ & $(0.01)$ & $(0.00)$ & $(0.01)$ & $(0.00)$ \\
\hline \multirow{2}{*}{$\begin{array}{l}\text { Share of CSG out of } \\
\text { total income }\end{array}$} & $0.03^{* *}$ & 0.01 & -0.00 & $-0.02^{* *}$ & -0.00 & 0.01 & $-0.01^{*}$ & $-0.01^{+}$ & 0.00 \\
\hline & $(0.01)$ & $(0.00)$ & $(0.00)$ & $(0.00)$ & $(0.01)$ & $(0.01)$ & $(0.01)$ & $(0.01)$ & $(0.00)$ \\
\hline Share of remittances & $0.07^{* *}$ & -0.01 & -0.01 & $-0.03^{* *}$ & $-0.02^{*}$ & -0.01 & -0.00 & -0.01 & 0.01 \\
\hline Out of total income & $(0.02)$ & $(0.01)$ & $(0.01)$ & $(0.01)$ & $(0.01)$ & $(0.01)$ & $(0.01)$ & $(0.01)$ & $(0.00)$ \\
\hline \multirow[t]{2}{*}{ Number of adults } & $-0.00^{* *}$ & -0.00 & $0.00^{*}$ & $-0.00^{+}$ & $0.00^{* *}$ & $0.00^{* *}$ & 0.00 & -0.00 & 0.00 \\
\hline & $(0.00)$ & $(0.00)$ & $(0.00)$ & $(0.00)$ & $(0.00)$ & $(0.00)$ & $(0.00)$ & $(0.00)$ & $(0.00)$ \\
\hline \multirow[t]{2}{*}{ Number of children } & $-0.01^{* *}$ & $0.00^{* *}$ & $0.00^{* *}$ & $-0.00^{* *}$ & -0.00 & $0.01^{* *}$ & -0.00 & $-0.00^{+}$ & 0.00 \\
\hline & $(0.00)$ & $(0.00)$ & $(0.00)$ & $(0.00)$ & $(0.00)$ & $(0.00)$ & $(0.00)$ & $(0.00)$ & $(0.00)$ \\
\hline \multirow[t]{2}{*}{ Urban formal } & $-0.13^{* *}$ & 0.00 & $0.03^{* *}$ & $-0.01^{*}$ & $0.02^{* *}$ & $0.02^{* *}$ & $0.01^{* *}$ & $0.06^{* *}$ & $0.01^{* *}$ \\
\hline & $(0.01)$ & $(0.00)$ & $(0.00)$ & $(0.00)$ & $(0.00)$ & $(0.00)$ & $(0.00)$ & $(0.00)$ & $(0.00)$ \\
\hline \multirow[t]{2}{*}{ Urban informal } & $-0.06^{* *}$ & -0.00 & $0.02^{* *}$ & $-0.01^{+}$ & $0.02^{* *}$ & $0.04^{* *}$ & 0.00 & $0.02^{* *}$ & -0.00 \\
\hline & $(0.01)$ & $(0.00)$ & $(0.00)$ & $(0.00)$ & $(0.01)$ & $(0.01)$ & $(0.01)$ & $(0.01)$ & $(0.00)$ \\
\hline \multirow[t]{2}{*}{ Year 2008} & $0.03^{* *}$ & $-0.01^{* *}$ & $0.02^{* *}$ & 0.00 & $0.02^{* *}$ & $0.02^{* *}$ & $-0.02^{* *}$ & $-0.03^{* *}$ & $-0.02^{* *}$ \\
\hline & $(0.01)$ & $(0.00)$ & $(0.00)$ & $(0.00)$ & $(0.00)$ & $(0.00)$ & $(0.00)$ & $(0.00)$ & $(0.00)$ \\
\hline \multirow[t]{2}{*}{ Year 2010} & $0.06^{* *}$ & $0.00^{*}$ & -0.00 & -0.00 & $-0.02^{* *}$ & $0.03^{* *}$ & $-0.01^{* *}$ & $-0.04^{* *}$ & $-0.02^{* *}$ \\
\hline & $(0.01)$ & $(0.00)$ & $(0.00)$ & $(0.00)$ & $(0.00)$ & $(0.00)$ & $(0.00)$ & $(0.00)$ & $(0.00)$ \\
\hline \multirow[t]{2}{*}{ Constant } & $0.91^{* *}$ & $-0.02^{* *}$ & $-0.06^{* *}$ & $0.05^{* *}$ & $-0.05^{* *}$ & 0.01 & $0.05^{* *}$ & $0.09^{* *}$ & $0.02^{* *}$ \\
\hline & $(0.02)$ & $(0.01)$ & $(0.01)$ & $(0.01)$ & $(0.01)$ & $(0.01)$ & $(0.01)$ & $(0.01)$ & $(0.01)$ \\
\hline Observations & 5000 & 5000 & 5000 & 5000 & 5000 & 5000 & 5000 & 5000 & 5000 \\
\hline
\end{tabular}

Standard errors in parentheses; ${ }^{+} p<0.1,{ }^{*} p<0.05,{ }^{* *} p<0.01$ 


\subsubsection{Potential mechanisms}

This paper explores whether remittances and social transfers have different expenditure patterns, as well as whether these transfers are spent differently than other sources of income. One explanation why transfers may not be fungible is the mental accounting theory, according to which different sources of income are allocated to different mental accounts for different consumption purposes. The mental accounting framework could explain the findings that social transfers and remittances are spent differently than other sources of income. However, there are other potential explanations for these findings that are explored in this section.

Several studies have pointed out that who in the household receives the transfer (e.g. a male or a female) has an effect on how transfers are spent. For instance, in South Africa, Duflo (2003) showed that transfers received by women had a higher poverty reduction impact as they were more likely to be spent on basic needs like food. As in the data there is information on who receives the transfer, two binary variables (one for remittances, one for the Child Support Grant) were added to the model to test whether the effect of the transfers on expenditure patterns is influenced by the sex of the recipient (table 2.9). None of these variables were significant in the regressions, meaning that the change in expenditure patterns is not driven by the recipient of the transfer, but by the transfer itself. In this case, however, there is not much variation in recipient status, as both remittances and child grants are mainly received by women, although to a larger extent in the latter than in the former. Moreover, in absence of baseline data (collected before migration or social protection programmes were in place), it is not possible to assess whether there was a change in household expenditure behaviour after a change in recipient status (due to factors such an increase in women's bargaining power).

Another factor that can influence the effect of social transfers and remittances on expenditure patterns is the volatility of the transfer, which has to do with how often households receive the specific transfer. In the case of the Old Age Pension and the Child Support Grant, these transfers are regular as they are received every month. Remittances, however, can vary in their volatility, as certain households receive them almost every month, whereas others receive them only a few times per year. To test that this difference in regularity does not affect the way remittances are spent, the variable "number of times per year the household receives remittances" was added to the regression (table 2.10). This variable does not turn out to be significant, which implies that the effect of remittances on expenditure is due to the transfer itself, and not to the fact that remittances are more irregular and unperdicatable than social protection benefits. In the case of social transfers, however, it is difficult to dissentangle whether 
the frequency of payments affect expenditure behaviour, as transfers have always been regular.

Another potential explanation of the expenditure behaviour of beneficiaries of social transfers is the fact that regular and predictable transfers can lead to a change in preferences, as households can afford to be more forward-looking and therefore willing to spend more money on non-necessities such as education (The Kenya CT-OVC Evaluation Team 2012). Moroever, as mentioned in the literature review, unearned income is expected to be spent differently that earned income (Christiaensen and Pan 2012). If this is the case, the different spending patterns of social transfers and remittances as compared to sources of 'earned' income would be simply explained by the fact that social transfers and remittances are 'unearned' income. However, this would not explain the differences in expenditure patterns between remittances and social transfers observed in this paper. In addition, the findings from this study contradict previous evidence that unearned income is likely to be spent on pleasure goods, as I find that both social transfers and remittances are spent either on necessities or on human capital goods.

Finally, another explanation for why transfers increase expenditure on certain goods is that expenditure elasticities can differ at different levels of expenditure (The Kenya CTOVC Evaluation Team 2012). In this case, controlling for total income would not be enough as the relationship between expenditure shares and income would be non-linear, and households below a certain threshold of income would make different expenditure decisions than households above that threshold. To check for this, I include in the regressions a binary variable which indicates if the household is poor based on the national per capital poverty line. Results stay very similar, however, and the variable indicating poverty status is not significant in any of the regressions (see table 2.11).

Based on the above, there are reasons to conclude that transfers are spent differently than other sources of income due to the fact that income is not fungible and differences sources of income are perceived -and therefore spent- differently. Nevertheless, there are other explanations that cannot be ruled out in absence of baseline data or a random allocation of transfer beneficiaries. One is the fact that the regularity of social transfers can impact how transfers are spent through a change in preferences. Another explanation is that women spend income differently than men, and both social transfers and remittances are received mainly by women. There is recent evidence, however, that the impacts of social assistance are not determined by who in the household receives the transfer (see Hagen-Zanker et al. (2017) for a review of studies in this topic). 
Table 2.9: Effects of income and transfer amounts on expenditure patterns- controlling for recipient's gender

\begin{tabular}{|c|c|c|c|c|c|c|c|c|c|}
\hline & Share food & Share clothes & Share health & $\begin{array}{l}\text { Share alcohol } \\
\text { and tobacco }\end{array}$ & Share transport & Share education & Share leisure & Share utilities & Share other \\
\hline \multirow[t]{2}{*}{ Log of total income } & $-0.02^{* *}$ & $0.00^{* *}$ & $0.00^{+}$ & 0.00 & $0.01^{* *}$ & $-0.00^{+}$ & $0.01^{* *}$ & 0.00 & -0.00 \\
\hline & $(0.00)$ & $(0.00)$ & $(0.00)$ & $(0.00)$ & $(0.00)$ & $(0.00)$ & $(0.00)$ & $(0.00)$ & $(0.00)$ \\
\hline \multirow{2}{*}{$\begin{array}{l}\text { Share of OPG out of } \\
\text { total income }\end{array}$} & $0.03^{* *}$ & $-0.01^{*}$ & 0.00 & $-0.01^{* *}$ & $-0.02^{* *}$ & $0.01^{+}$ & $-0.02^{* *}$ & $0.01^{+}$ & -0.00 \\
\hline & $(0.01)$ & $(0.00)$ & $(0.00)$ & $(0.00)$ & $(0.00)$ & $(0.01)$ & $(0.01)$ & $(0.01)$ & $(0.00)$ \\
\hline \multirow{2}{*}{$\begin{array}{l}\text { Share of CSG out of } \\
\text { total income }\end{array}$} & 0.02 & -0.01 & 0.00 & $-0.02^{* *}$ & -0.01 & $0.02^{*}$ & $-0.01^{*}$ & 0.01 & -0.00 \\
\hline & $(0.01)$ & $(0.00)$ & $(0.00)$ & $(0.00)$ & $(0.01)$ & $(0.01)$ & $(0.01)$ & $(0.01)$ & $(0.00)$ \\
\hline \multirow{2}{*}{$\begin{array}{l}\text { Share of remittances } \\
\text { out of total income }\end{array}$} & $0.05^{* *}$ & $-0.01^{*}$ & -0.01 & $-0.02^{* *}$ & $-0.02^{* *}$ & 0.02 & 0.01 & -0.00 & -0.00 \\
\hline & $(0.02)$ & $(0.01)$ & $(0.01)$ & $(0.00)$ & $(0.01)$ & $(0.01)$ & $(0.01)$ & $(0.01)$ & $(0.00)$ \\
\hline \multirow{2}{*}{$\begin{array}{l}\text { Remittance recipient- } \\
\text { female }\end{array}$} & 0.00 & 0.00 & 0.00 & 0.00 & 0.00 & -0.00 & 0.00 & -0.01 & 0.00 \\
\hline & $(0.02)$ & $(0.01)$ & $(0.01)$ & $(0.01)$ & $(0.01)$ & $(0.01)$ & $(0.01)$ & $(0.01)$ & $(0.00)$ \\
\hline \multirow{2}{*}{$\begin{array}{l}\text { CSG recipient- } \\
\text { female }\end{array}$} & 0.00 & 0.00 & -0.00 & 0.00 & 0.00 & -0.00 & 0.00 & -0.00 & 0.00 \\
\hline & $(0.02)$ & $(0.01)$ & $(0.01)$ & $(0.01)$ & $(0.01)$ & $(0.01)$ & $(0.01)$ & $(0.01)$ & $(0.01)$ \\
\hline \multirow[t]{2}{*}{ Number of adults } & $-0.01^{* *}$ & -0.00 & 0.00 & $-0.00^{* *}$ & $0.00^{* *}$ & $0.00^{*}$ & -0.00 & $0.00^{* *}$ & $0.00^{*}$ \\
\hline & $(0.00)$ & $(0.00)$ & $(0.00)$ & $(0.00)$ & $(0.00)$ & $(0.00)$ & $(0.00)$ & $(0.00)$ & $(0.00)$ \\
\hline \multirow[t]{2}{*}{ Number of children } & -0.00 & 0.00 & $0.00^{*}$ & 0.00 & -0.00 & $0.01^{* *}$ & -0.00 & $-0.00^{*}$ & $-0.00^{*}$ \\
\hline & $(0.00)$ & $(0.00)$ & $(0.00)$ & $(0.00)$ & $(0.00)$ & $(0.00)$ & $(0.00)$ & $(0.00)$ & $(0.00)$ \\
\hline \multirow[t]{2}{*}{ Urban formal } & $-0.07^{* *}$ & 0.01 & $0.01^{+}$ & 0.00 & $0.02^{* *}$ & $0.01^{*}$ & $0.02^{* *}$ & $0.02^{*}$ & -0.00 \\
\hline & $(0.01)$ & $(0.00)$ & $(0.01)$ & $(0.00)$ & $(0.01)$ & $(0.01)$ & $(0.01)$ & $(0.01)$ & $(0.00)$ \\
\hline \multirow[t]{2}{*}{ Urban informal } & $-0.07^{* *}$ & 0.00 & 0.00 & $-0.01^{+}$ & $0.05^{* *}$ & 0.01 & 0.01 & 0.01 & -0.00 \\
\hline & $(0.02)$ & $(0.01)$ & $(0.01)$ & $(0.01)$ & $(0.01)$ & $(0.01)$ & $(0.01)$ & $(0.01)$ & $(0.01)$ \\
\hline \multirow[t]{2}{*}{ Year 2008} & $0.04^{* *}$ & $-0.00^{*}$ & $0.01^{* *}$ & $-0.01^{* *}$ & $0.01^{*}$ & $0.03^{* *}$ & $-0.04^{* *}$ & $-0.02^{* *}$ & $-0.01^{* *}$ \\
\hline & $(0.01)$ & $(0.00)$ & $(0.00)$ & $(0.00)$ & $(0.00)$ & $(0.00)$ & $(0.00)$ & $(0.00)$ & $(0.00)$ \\
\hline \multirow[t]{2}{*}{ Year 2010} & $0.09^{* *}$ & $-0.00^{*}$ & $-0.01^{* *}$ & $-0.01^{* *}$ & $-0.02^{* *}$ & $0.01^{* *}$ & $-0.01^{* *}$ & $-0.04^{* *}$ & $-0.02^{* *}$ \\
\hline & $(0.00)$ & $(0.00)$ & $(0.00)$ & $(0.00)$ & $(0.00)$ & $(0.00)$ & $(0.00)$ & $(0.00)$ & $(0.00)$ \\
\hline \multirow[t]{2}{*}{ Constant } & $0.70^{* *}$ & -0.00 & 0.01 & $0.05^{* *}$ & $-0.03^{* *}$ & 0.02 & $0.06^{* *}$ & $0.15^{* *}$ & $0.06^{* *}$ \\
\hline & $(0.02)$ & $(0.01)$ & $(0.01)$ & $(0.01)$ & $(0.01)$ & $(0.01)$ & $(0.01)$ & $(0.02)$ & $(0.01)$ \\
\hline Observations & 18940 & 18940 & 18940 & 18940 & 18940 & 18940 & 18940 & 18940 & 18940 \\
\hline
\end{tabular}

Standard errors in parentheses ${ }^{+} p<0.1,{ }^{*} p<0.05,{ }^{* *} p<0.01$ 
On the Fungibility of Public and Private Transfers: A Mental Accounting Approach

Table 2.10: Effects of income and transfer amounts on expenditure patterns- controlling for frequency of payments

\begin{tabular}{|c|c|c|c|c|c|c|c|c|c|}
\hline & Share food & Share clothes & Share health & $\begin{array}{l}\text { Share alcohol } \\
\text { and tobacco }\end{array}$ & Share transport & Share education & Share leisure & Share utilities & Share other \\
\hline \multirow[t]{2}{*}{ Log of total income } & $-0.02^{* *}$ & $0.00^{* *}$ & $0.00^{+}$ & 0.00 & $0.01^{* *}$ & $-0.00^{+}$ & $0.01^{* *}$ & 0.00 & -0.00 \\
\hline & $(0.00)$ & $(0.00)$ & $(0.00)$ & $(0.00)$ & $(0.00)$ & $(0.00)$ & $(0.00)$ & $(0.00)$ & $(0.00)$ \\
\hline \multirow{2}{*}{$\begin{array}{l}\text { Share of OPG out of } \\
\text { total income }\end{array}$} & $0.03^{* *}$ & $-0.01^{*}$ & 0.00 & $-0.01^{* *}$ & $-0.02^{* *}$ & $0.01^{+}$ & $-0.02^{* *}$ & $0.01^{+}$ & -0.00 \\
\hline & $(0.01)$ & $(0.00)$ & $(0.00)$ & $(0.00)$ & $(0.00)$ & $(0.01)$ & $(0.01)$ & $(0.01)$ & $(0.00)$ \\
\hline \multirow{2}{*}{$\begin{array}{l}\text { Share of CSG out of } \\
\text { total income }\end{array}$} & 0.02 & -0.01 & 0.00 & $-0.02^{* *}$ & -0.01 & $0.02^{*}$ & $-0.01^{*}$ & 0.01 & -0.00 \\
\hline & $(0.01)$ & $(0.00)$ & $(0.00)$ & $(0.00)$ & $(0.01)$ & $(0.01)$ & $(0.01)$ & $(0.01)$ & $(0.00)$ \\
\hline \multirow{2}{*}{$\begin{array}{l}\text { Share of remittances } \\
\text { out of total income }\end{array}$} & $0.05^{* *}$ & $-0.01^{*}$ & -0.01 & $-0.02^{* *}$ & $-0.02^{* *}$ & 0.02 & 0.01 & -0.01 & -0.00 \\
\hline & $(0.02)$ & $(0.01)$ & $(0.01)$ & $(0.00)$ & $(0.01)$ & $(0.01)$ & $(0.01)$ & $(0.01)$ & $(0.00)$ \\
\hline \multirow{2}{*}{$\begin{array}{l}\text { Frequency of } \\
\text { remittances }\end{array}$} & -0.00 & -0.00 & 0.00 & 0.00 & 0.00 & 0.00 & -0.00 & -0.00 & 0.00 \\
\hline & $(0.00)$ & $(0.00)$ & $(0.00)$ & $(0.00)$ & $(0.00)$ & $(0.00)$ & $(0.00)$ & $(0.00)$ & $(0.00)$ \\
\hline \multirow[t]{2}{*}{ Number of adults } & $-0.01^{* *}$ & -0.00 & 0.00 & $-0.00^{* *}$ & $0.00^{* *}$ & $0.00^{*}$ & -0.00 & $0.00^{* *}$ & $0.00^{*}$ \\
\hline & $(0.00)$ & $(0.00)$ & $(0.00)$ & $(0.00)$ & $(0.00)$ & $(0.00)$ & $(0.00)$ & $(0.00)$ & $(0.00)$ \\
\hline \multirow[t]{2}{*}{ Number of children } & -0.00 & 0.00 & $0.00^{*}$ & 0.00 & -0.00 & $0.01^{* *}$ & -0.00 & $-0.00^{*}$ & $-0.00^{*}$ \\
\hline & $(0.00)$ & $(0.00)$ & $(0.00)$ & $(0.00)$ & $(0.00)$ & $(0.00)$ & $(0.00)$ & $(0.00)$ & $(0.00)$ \\
\hline \multirow[t]{2}{*}{ Urban formal } & $-0.07^{* *}$ & 0.01 & $0.01^{+}$ & 0.00 & $0.02^{* *}$ & $0.01^{*}$ & $0.02^{* *}$ & $0.02^{*}$ & -0.00 \\
\hline & $(0.01)$ & $(0.00)$ & $(0.01)$ & $(0.00)$ & $(0.01)$ & $(0.01)$ & $(0.01)$ & $(0.01)$ & $(0.00)$ \\
\hline \multirow[t]{2}{*}{ Urban informal } & $-0.07^{* *}$ & 0.00 & 0.00 & $-0.01^{+}$ & $0.05^{* *}$ & 0.01 & 0.01 & 0.01 & -0.00 \\
\hline & $(0.02)$ & $(0.01)$ & $(0.01)$ & $(0.01)$ & $(0.01)$ & $(0.01)$ & $(0.01)$ & $(0.01)$ & $(0.01)$ \\
\hline \multirow[t]{2}{*}{ Year 2008} & $0.04^{* *}$ & $-0.00^{*}$ & $0.01^{* *}$ & $-0.01^{* *}$ & $0.01^{*}$ & $0.03^{* *}$ & $-0.04^{* *}$ & $-0.02^{* *}$ & $-0.01^{* *}$ \\
\hline & $(0.01)$ & $(0.00)$ & $(0.00)$ & $(0.00)$ & $(0.00)$ & $(0.00)$ & $(0.00)$ & $(0.00)$ & $(0.00)$ \\
\hline \multirow[t]{2}{*}{ Year 2010} & $0.09^{* *}$ & $-0.00^{*}$ & $-0.01^{* *}$ & $-0.01^{* *}$ & $-0.02^{* *}$ & $0.01^{* *}$ & $-0.01^{* *}$ & $-0.04^{* *}$ & $-0.02^{* *}$ \\
\hline & $(0.00)$ & $(0.00)$ & $(0.00)$ & $(0.00)$ & $(0.00)$ & $(0.00)$ & $(0.00)$ & $(0.00)$ & $(0.00)$ \\
\hline \multirow[t]{2}{*}{ Constant } & $0.70^{* *}$ & -0.00 & 0.00 & $0.05^{* *}$ & $-0.04^{* *}$ & 0.02 & $0.06^{* *}$ & $0.15^{* *}$ & $0.06^{* *}$ \\
\hline & $(0.02)$ & $(0.01)$ & $(0.01)$ & $(0.01)$ & $(0.01)$ & $(0.01)$ & $(0.01)$ & $(0.02)$ & $(0.01)$ \\
\hline Observations & 18940 & 18940 & 18940 & 18940 & 18940 & 18940 & 18940 & 18940 & 18940 \\
\hline
\end{tabular}

Standard errors in parentheses; ${ }^{+} p<0.1,{ }^{*} p<0.05,{ }^{* *} p<0.01$ 
Table 2.11: Effects of income and transfer amounts on expenditure patterns- controlling for poverty status

\begin{tabular}{|c|c|c|c|c|c|c|c|c|c|}
\hline & Share food & Share clothes & Share health & $\begin{array}{l}\text { Share alcohol } \\
\text { and tobacco }\end{array}$ & Share transport & Share education & Share leisure & Share utilities & Share other \\
\hline Log of total & $-0.02^{* *}$ & $0.01^{* *}$ & 0.00 & 0.00 & $0.01^{* *}$ & $-0.00^{+}$ & $0.01^{* *}$ & 0.00 & -0.00 \\
\hline income & $(0.00)$ & $(0.00)$ & $(0.00)$ & $(0.00)$ & $(0.00)$ & $(0.00)$ & $(0.00)$ & $(0.00)$ & $(0.00)$ \\
\hline Share of OAP & $0.03^{*}$ & $-0.01^{*}$ & 0.00 & $-0.01^{*}$ & $-0.02^{* *}$ & $0.01^{*}$ & $-0.02^{* *}$ & $0.02^{*}$ & -0.00 \\
\hline out of total income & $(0.01)$ & $(0.00)$ & $(0.00)$ & $(0.00)$ & $(0.00)$ & $(0.01)$ & $(0.01)$ & $(0.01)$ & $(0.00)$ \\
\hline Share of CSG out & 0.02 & -0.01 & 0.00 & $-0.02^{* *}$ & -0.01 & $0.02^{*}$ & $-0.01^{*}$ & 0.01 & -0.00 \\
\hline of total income & $(0.01)$ & $(0.00)$ & $(0.00)$ & $(0.00)$ & $(0.01)$ & $(0.01)$ & $(0.01)$ & $(0.01)$ & $(0.00)$ \\
\hline Share of remittances & $0.05^{* *}$ & $-0.01^{*}$ & -0.00 & $-0.02^{* *}$ & $-0.02^{* *}$ & $0.02^{+}$ & 0.01 & -0.01 & -0.00 \\
\hline out of total income & $(0.02)$ & $(0.01)$ & $(0.01)$ & $(0.00)$ & $(0.01)$ & $(0.01)$ & $(0.01)$ & $(0.01)$ & $(0.00)$ \\
\hline \multirow[t]{2}{*}{ Number of adults } & $-0.00^{* *}$ & 0.00 & 0.00 & $-0.00^{* *}$ & $0.00^{* *}$ & $0.00^{+}$ & -0.00 & $0.00^{*}$ & $0.00^{*}$ \\
\hline & $(0.00)$ & $(0.00)$ & $(0.00)$ & $(0.00)$ & $(0.00)$ & $(0.00)$ & $(0.00)$ & $(0.00)$ & $(0.00)$ \\
\hline \multirow[t]{2}{*}{ Number of children } & -0.00 & 0.00 & $0.00^{*}$ & 0.00 & -0.00 & $0.01^{* *}$ & -0.00 & $-0.00^{*}$ & $-0.00^{*}$ \\
\hline & $(0.00)$ & $(0.00)$ & $(0.00)$ & $(0.00)$ & $(0.00)$ & $(0.00)$ & $(0.00)$ & $(0.00)$ & $(0.00)$ \\
\hline \multirow[t]{2}{*}{ Urban formal } & $-0.07^{* *}$ & 0.01 & $0.01^{+}$ & 0.00 & $0.02^{* *}$ & $0.01^{*}$ & $0.02^{* *}$ & $0.02^{*}$ & -0.00 \\
\hline & $(0.01)$ & $(0.00)$ & $(0.01)$ & $(0.00)$ & $(0.01)$ & $(0.01)$ & $(0.01)$ & $(0.01)$ & $(0.00)$ \\
\hline \multirow[t]{2}{*}{ Urban informal } & $-0.07^{* *}$ & 0.00 & 0.00 & $-0.01^{+}$ & $0.05^{* *}$ & 0.01 & 0.01 & 0.01 & -0.00 \\
\hline & $(0.02)$ & $(0.01)$ & $(0.01)$ & $(0.01)$ & $(0.01)$ & $(0.01)$ & $(0.01)$ & $(0.01)$ & $(0.01)$ \\
\hline \multirow[t]{2}{*}{ Year 1} & $0.03^{* *}$ & $-0.00^{*}$ & $0.02^{* *}$ & $-0.01^{* *}$ & $0.01^{* *}$ & $0.03^{* *}$ & $-0.04^{* *}$ & $-0.02^{* *}$ & $-0.01^{* *}$ \\
\hline & $(0.01)$ & $(0.00)$ & $(0.00)$ & $(0.00)$ & $(0.00)$ & $(0.00)$ & $(0.00)$ & $(0.00)$ & $(0.00)$ \\
\hline \multirow[t]{2}{*}{ Year 2} & $0.09^{* *}$ & $-0.00^{*}$ & $-0.01^{* *}$ & $-0.01^{* *}$ & $-0.02^{* *}$ & $0.01^{* *}$ & $-0.01^{* *}$ & $-0.04^{* *}$ & $-0.02^{* *}$ \\
\hline & $(0.00)$ & $(0.00)$ & $(0.00)$ & $(0.00)$ & $(0.00)$ & $(0.00)$ & $(0.00)$ & $(0.00)$ & $(0.00)$ \\
\hline \multirow[t]{2}{*}{ Poor } & 0.01 & 0.00 & -0.00 & -0.00 & -0.00 & -0.00 & 0.00 & -0.01 & 0.00 \\
\hline & $(0.01)$ & $(0.00)$ & $(0.00)$ & $(0.00)$ & $(0.00)$ & $(0.00)$ & $(0.00)$ & $(0.00)$ & $(0.00)$ \\
\hline \multirow[t]{2}{*}{ Constant } & $0.68^{* *}$ & -0.01 & 0.01 & $0.05^{* *}$ & $-0.03^{*}$ & 0.03 & $0.06^{* *}$ & $0.17^{* *}$ & $0.06^{* *}$ \\
\hline & $(0.03)$ & $(0.01)$ & $(0.01)$ & $(0.01)$ & $(0.01)$ & $(0.02)$ & $(0.02)$ & $(0.02)$ & $(0.01)$ \\
\hline Observations & 18940 & 18940 & 18940 & 18940 & 18940 & 18940 & 18940 & 18940 & 18940 \\
\hline
\end{tabular}

Standard errors in parentheses; ${ }^{+} p<0.1,{ }^{*} p<0.05,{ }^{* *} p<0.01$ 


\subsubsection{Limitations}

Despite the richness of the National Income Dynamics Survey, some data limitations are present in this study. The NIDS dataset is a longitudinal survey that follows individuals -and not households- over time. For this reason, even if each individual interviewed in the survey has a unique identifier for the three years, households have different identifiers in each wave because individuals can move and change households from one year to the other. As this paper looks at expenditure patterns (which are defined at a household level), this study has been conducted at the household level, which means a unique household identifier had to be created based on the individuals who had the same household identifier in all three waves. The drawback of defining a household level unique identifier is that, due to the fact that this is a panel study, individuals who moved from one household to another in any of the years studied were assigned a new household identifier. This implies that for a specific year, one household may appear in the data as 2 different households when they are actually the same. The fact that this analysis has to be done at the household level also implies that weights can not be used, as panel weights are defined at the individual level and there are no household panel weights available.

It is also important to point out that in this survey remittances are defined as any contribution from non-resident members or non-household members. This means that, even though these transfers are associated typically with remittances sent by migrant workers (Posel 2016), this definition can include other contributions such as child maintenance payments. Given the history of temporary migration in South Africa, however, and the fact that migration has continued in the post-apartheid period and many families remain geographically divided (Posel 2016), one can expect a big percentage of these remittances to come from migrant workers.

Another limitation that is present in most studies that look at expenditure is the possible measurement error. I try to account for this by excluding potential outliers and unreliable information (i.e. households who spend less than 1 percent of their budget on food, or more than 90 percent of their budget on leisure). After re-running the regressions, results from the main estimation hold.

Finally, an additional reason why one should be careful with drawing strong conclusions regarding expenditure on education is that data on education was collected at the household level and households were asked about the amount spent on different educational categories during the month preceding the interview. This is problematic as educational expenditure is seasonal and not smooth over the calendar year, and the months in which interviews took place differ by wave (Branson, Kekana, and Lam 2013). This means that, for some households, part of the increase or decrease in educational 
expenditure could be a result of having been interviewed in different months. Moreover, there is a big difference in educational expenditure by income quintiles, not only in terms of the total amount spent but also in terms of allocation of expenditure across different categories. While the richest households spend most of their educational budget on school fees, for poor households the highest burden are uniforms, as poor households are exempted from paying school fees. Furthermore, in the year 2006 the government announced the abolition of compulsory school fees based on the National Norms and Standards for School Funding (NNSSF) (Branson, Kekana, and Lam 2013). Considering that education has become more accessible for poor households, there could have been an improvement in educational outcomes even if households did not increase their expenditure on education.

\subsection{Discussion}

A common assumption in economics is that money is fungible. In other words, spending patterns are determined by the total amount of income, and not by its source. In line with the mental accounting theory, this paper hypothesised that households associate private transfers coming from a migrant differently than a public transfer received from the government, and that this can influence the way transfers are spent. By analysing the first nationally representative longitudinal survey in South Africa- covering the years 2008, 2010 and 2012- some evidence is found that supports the mental accounting theory, as public and private transfers are not spent in the same way.

Following the labelling effect hypothesis, it was anticipated that the Child Support Grant would benefit the child directly through an increase in household expenditure on child goods relative to other expenditure categories. Results show, with some caveats, that an increase in the Child Support Grant increases the share of expenditure on education, which means the Government is effectively targeting and delivering the message that the child support grant is meant to be spent on children and especially on child's education. Moreover, after restricting the sample to certain population groups or regions in South Africa where both remittances and social transfers have higher coverage, I also find that the Child Support Grant increases the share of expenditure on food, which is also expected to translate into nutritional benefits for the beneficiaries. This finding is important to highlight, as it demonstrates the programme is achieving its intended outcomes even if the grant is unconditional.

In the case of the Old Age Pension, it was hypothesised that pensions would not cause significant behavioural changes as pensions are mainly income replacement. Results seem to contradict expectations, as an increase in pension income leads to an increase 
in the share spent on food, education, and utility bills, therefore improving child wellbeing as well as the well-being of the household as a whole. In South Africa there is a structural unemployment problem as well as high wage inequality, and in many poor households the Old Age Pension is the main source of income. This may be the reason the hypothesis of this paper does not hold, as pensions may not be an income replacement but a new source of income when the pensioner reaches the retirement age.

Regarding the expenditure behaviour of remittances and given the nature of migration in South Africa (mainly internal, low skilled, and temporary), it was expected that remittances would be used to cover basic households needs. Results support this hypothesis, as remittances increase expenditure on food and decrease the share of expenditure on other non-basic goods such as alcohol and tobacco and clothing.

To conclude, this paper has shown that expenditure behaviour can depend on the source of income, and not only on the total income a household earns. This finding has important implications for public policy design, as the expected welfare impacts in a specific country may not only depend on the type of program or amount of a transfer, but also on the potential behavioural effect that this transfer can generate. As a result, it seems important to take into consideration how people perceive different sources of income as well as the explicit or implicit conditions attached to them when estimating the effects of private and public transfers on well-being. 


\section{References}

Adams, R. H. (1991). The economic uses and impact of international remittances in rural Egypt. Economic Development and Cultural Change, 39(4):695-722.

Adams, R. H. (2002). Precautionary saving from different sources of income: Evidence from rural Pakistan. World Bank Policy Research Working Paper, (2761).

Adams, R. H. \& Cuecuecha, A. (2010). Remittances, household expenditure and investment in Guatemala. World Development, 38 (11): 1626-1641.

Aguero, J., Carter, M., \& Woolard, I. (2006). The impact of unconditional cash transfers on nutrition: The South African Child Support Grant.

Ardington, E. \& Lund, F. (1995). Pensions and development: Social security as complementary to programmes of reconstruction and development. Development Southern Africa, 12(4):557-577.

Barrientos, A. (2005). Non-contributory pensions and poverty reduction in Brazil and South Africa. IDPM, University of Manchester.

Beatty, T. K., Blow, L., Crossley, T. F., \& O’Dea, C. (2014). Cash by any other name? Evidence on labeling from the UK winter fuel payment. Journal of Public Economics, 118:86-96.

Benhassine, N., Devoto, F., Duflo, E., Dupas, P., \& Pouliquen, V. (2013). Turning a shove into a nudge? A "labeled cash transfer" for education. Technical report, National Bureau of Economic Research.

Blanciforti, L., Green, R., et al. (1983). The almost ideal demand system: a comparison and application to food groups. Agricultural Economics Research, 35(3):1-10.

Branson, N., Kekana, D., \& Lam, D. (2013). Educational expenditure in South Africa: Evidence from the national income dynamics study. Technical report, SALDRU Working Paper No.124.

Case, A. (2001). Does money protect health status? Evidence from South Africa. Economic Development and Cultural Change, 57(2):215-37.

Case, A. \& Deaton, A. (1998). Large cash transfers to the elderly in South Africa. The Economic Journal, 108 (450):1330-1361

Case, A. \& Menendez, A. (2007). Does money empower the elderly? Evidence from the Agincourt Demographic Surveillance Site. South Africal. Scand.J. Public Health.

Christiaensen, L. \& Pan, L. (2012). On the fungibility of spending and earnings-evidence from rural China and Tanzania. World Bank Policy Research Working Paper, (6298).

Coetzee, M. (2013). Finding the benefits: Estimating the impact of the South African child support grant. South African Journal of Economics, 81(3):427-450.

Davies, S., Easaw, J., \& Ghoshray, A. (2009). Mental accounting and remittances: A study of rural Malawian households. Journal of Economic Psychology, 30(3):321-334.

De, P. K. \& Ratha, D. (2012). Impact of remittances on household income, asset and human capital: evidence from Sri Lanka. Migration and Development, 1(1):163-179.

Deaton, A. \& Muellbauer, J. (1980). An almost ideal demand system. The American economic review, 70(3): 312-326.

DSD, SASSA, \& UNICEF (2011). Child support grant evaluation 2010: Qualitative research report.

DSD, SASSA, \& UNICEF (2012). The South African child support grant impact assessment: Evidence from a survey of children, adolescents and their households.

Duflo, E. (2003). Grandmothers and granddaughters: Old-age pensions and intra-household allocation in South Africa, World Bank Economic Review, 17 (1): 1-25.

Duflo, E. (2000). Child health and household resources in South Africa: Evidence from the old age pension program. The American Economic Review, 90(2):393-398.

Friedman, M. (1957). The permanent income hypothesis. In $A$ theory of the consumption function, pages 20-37. Princeton University Press.

Ghalwash, T. (2007). Energy taxes as a signaling device: An empirical analysis of consumer preferences. Energy Policy, 35(1): 29-38.

Haddad, L. \& Zeller, M. (1997). Can social security programmes do more with less? General issues and the challenges for Southern Africa. Development Southern Africa, 14(2):125-153

Hagen-Zanker, J., Pellerano, L., Bastagli, F., Harman, L., Barca, V., Sturge, G., Schmidt, T. \& Laing, C. (2017). The impact of cash transfers on women and girls. ODI Briefing, London, UK: Overseas Development Institute.

Islam, M. \& Hoddinott, J. (2009). Evidence of intrahousehold flypaper effects from a nutrition intervention in rural Guatemala. Economic development and cultural change, 57(2):215-238. 
Jacoby, H. G. (2002). Is there an intra household flypaper effect? Evidence from a school feeding programme. The Economic Journal, 112(476):196-221.

Kooreman, P. (2000). The labeling effect of a child benefit system. The American Economic Review, 90(3):571-583.

Levav, J. \& McGraw, A.P. (2009). Emotional accounting: How feelings about money influence consumer choice. Journal of Marketing Research, 46(1):66-80.

Lund, F. (1993). State social benefits in South Africa. International Social Security Review, 46(1): 5-25

Lund, F. (1999). Understanding South African social security through recent household surveys: new opportunities and continuing gaps. Development Southern Africa, 16(1):55-67.

Lund, F. (2002). Crowding in care, security and micro-enterprise formation: revisiting the role of the state in poverty reduction and development. Journal of International Development, 14(6): 681-694.

Maitra, P. \& Ray, R. (2003). The effect of transfers on household expenditure patterns and poverty in South Africa. Journal of development Economics, 71(1):23-49.

Moschini, G. (1995). Units of measurement and the stone index in demand system estimation. American journal of agricultural economics, 77(1):63-68.

Niño-Zarazúa, M., Barrientos, A., Hickey, S., \& Hulme, D. (2012). Social protection in Sub-Saharan Africa: Getting the politics right. World development, 40(1): 163-176.

Posel, D. (2004). Have migration patterns in post-apartheid South Africa changed? Journal of Interdisciplinary Economics, 15 (3-4): 277-292.

Posel, D. (2009). Migration: Analysis of the NIDS wave 1 dataset. Technical report, NIDS Discussion Paper, no.1.

Posel, D. (2016). Inter-household transfers in South Africa: Prevalence, patterns and poverty. Technical report, SALDRU Working Paper No. 180/NIDS Discussion paper 2016/7.

Posel, D. \& Casale, D. (2003). What has been happening to internal labour migration in South Africa, 1993-1999? South African Journal of Economics, 71(3):455-479.

Posel, D. \& Casale, D. (2006). Internal labour migration and household poverty in post-apartheid South Africa. HSRC Press Cape Town.

Posel, D. R. (2001). Intra-family transfers and income-pooling. South African Journal of Economics, 69(3): 501-528

SASSA (2016). Factsheet: Issue no 4 of 2016. a statistical summary of social grants in South Africa.

Shefrin, H. M. \& Thaler, R.H. (1988). The behavioral life-cycle hypothesis. Economic inquiry, 26(4): 609-643

Thaler, R. (1985). Mental accounting and consumer choice. Marketing science, 4(3):199-214.

Thaler, R. H. (1990). Anomalies: Saving, fungibility, and mental accounts. The Journal of Economic Perspectives, 4(1):193205.

The Kenya CT-OVC Evaluation Team. (2012). The impact of the Kenya Cash Transfer Program for Orphans and Vulnerable Children on household spending. Journal of Development Effectiveness, 4(1), 9-37.

Waidler, J., Hagen-Zanker, J., Gassmann, F., \& Siegel, M. (2017). Do remittances and social assistance have different impacts on expenditure patterns of recipient households? The Moldovan Case. Migration and Development, 6(3), 355-375.

Woolard, L. \& Leibbrandt, M. (2010). The evolution and impact of unconditional cash transfers in South Africa . A Southern Africa Labour and Development Research Unit Working Paper Number 51. Cape Town: SALDRU, University of Cape Town

World Bank (2015). The state of social safety nets 2015. Technical report, The World Bank: Washington DC.

World Bank (2016). ASPIRE: The Atlas of Social Protection Indicators of Resilience and Equity. http://datatopics.worldbank.org/aspire/ [accessed 15 January 2018].

Zellner, A. (1962). An efficient method of estimating seemingly unrelated regressions and tests for aggregation bias. Journal of the American Statistical Association, 57 (298): 348-36 
Chapter 3

Chapter 3

Social Grants, Remittances, and Food Security: Does the Source of Income Matter?

Chapter

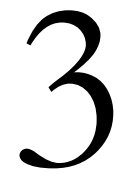

\section{Social Grants, Remittances, and Food Security: Does the Source of Income Matter? ${ }^{15}$}

"He thinks about the amount of the grant, trying to ascertain its actual worth to a family of four. If people lived only by eating, this money would still be small."

'Hunger Eats a Man' - Nkosinathi Sithole

"In a world of plenty, no one, not a single person, should go hungry. But almost 1 billion still do not have enough to eat. I want to see an end to hunger everywhere within my lifetime."

Ban Ki-moon, United Nations SecretaryGeneral

15 This chapter is based on a paper co-authored with Stephen Devereux, currently under review in a journal. 
Social Grants, Remittances, and Food Security: Does the Source of Income Matter? 


\subsection{Introduction}

Social protection is a set of instruments that aim to alleviate poverty and assist vulnerable people to manage risk (Barrientos 2013; World Bank 2012). Narrow approaches restrict the definition to public policy interventions, and frame social protection as a government responsibility towards citizens, who have a right to claim social assistance or social security from the state (ILO 2012). In this paper we favour a broader approach that includes private as well as public sources, following Brunori and O’Reilly (2010: 2): “social protection is generally described as the set of public and private mechanisms that protect and prevent individuals and households from suffering the worst consequences of shocks and stresses". Specifically, we focus on publicly provided social grants (government-to-person (G2P) transfers) and on privately provided remittances (transfers within extended families).

In this paper, we examine and compare the impacts of social grants and remittances on one set of wellbeing outcomes, namely food security and nutrition, using South Africa as a case study. Food security is commonly understood as having access to sufficient food for a healthy, active life. It is a basic human need, and the right to food is enshrined in South Africa's Constitution. Nutrition status, notably under nutrition, is an objective measure of food insecurity and hunger.

Although several studies have looked at whether social grants or remittances improve food security and/or nutritional outcomes, few of them have looked in the same study at a comprehensive set of indicators of food security and nutrition. Moreover, to date and to the knowledge of the authors, there is no evaluation that considers the effects of both social grants and remittances on nutrition and food security. There are several factors that differ across transfers and may influence whether public transfers are more effective than private ones (or vice versa) in reducing food insecurity, such as the frequency and regularity of the payments, the size of the transfers, and the use of the transfers (how transfers are spent). Comparing public and private transfers can give us a better idea of the effectiveness of social protection programmes, as compared to private strategies such as sending informal transfers (remittances) to a family member living in a different location.

South Africa makes an excellent case study for several reasons: its history of internal migration and the fact that many families have relied and still rely on remittances; its comprehensive social protection system which has become more extensive post-Apartheid; and the fact that levels of food insecurity (including malnutrition) have remained high despite many poor households being recipients of social grants and/or remittances (Hendriks 2014; Devereux and Waidler 2017). 
The paper is organised as follows: the next section reviews the literature on the impacts of social grants as well as of remittances on food security and nutrition, both in South Africa and in other countries. The paper continues with a description of the data and indicators used in our analysis, followed by the empirical strategy used to estimate the impacts of remittances and social grants on food security and nutrition. Afterwards, we present the descriptive statistics and the findings, before explaining and discussing the results and, finally, concluding.

\subsection{Literature review}

Public income transfers (social grants) and private income transfers (remittances) are both expected to improve the food security of recipients, through direct as well as indirect channels. The theory of change is that an increase in income will increase expenditure on food, which translates into increases in food intake and dietary diversity. This effect will be larger in poor households, who tend to allocate most of any incremental income to food purchases, because of 'Engel's law' - poorer people spend higher proportions of their total income on food. Increased quantity and quality of food consumption should improve the nutritional status of transfer recipients directly. Indirectly, if some incremental income is allocated to health care this can also positively affect nutrition, because healthier people absorb and utilise nutrients more effectively (DFID 2011; Bailey and Hedlund 2012).

Several factors, however, will influence the extent to which social grants and remittances improve food security outcomes, as well as whether different transfers affect the outcomes differently. These factors include the frequency and regularity of the payments, the size of the transfers, and the use of the transfers (how transfers are spent) (HagenZanker and Himmelstine 2015). One may expect that the bigger the size of the transfer, the higher the poverty reduction effect - or, for our purposes, the higher the improvement in food security. Moreover, regular and predictable transfers are expected to lead to better outcomes, as compared to infrequent or irregular payments (Daidone et al. 2015). While social grants are usually regular and predictable, the frequency of remittances depends highly on the economic situation of the sender. When remittances come mainly from poor households, "family members may not be in a position to provide assistance at the time it is required and payments may not always be received on time" (Thomson and Posel 2002).

Regarding the use of the transfers, different transfers may be spent differently, and this will ultimately affect their poverty reduction impact. How recipients use the transfer can depend on the purposes for sending the transfers (or the aim of the social protection 
programme in place); who is the intended beneficiary of the transfer (i.e. if the transfer targets children or other family members); and who is the recipient of the transfer (e.g. women compared to men). For example, a few studies have shown that transfers received by women tend to have a higher poverty reduction impact as they have a higher propensity to be spent on basic needs like food (Duflo 2003). These factors (size of the transfer, regularity, sex of recipient, and intended use of the transfer) are context-specific, given that the characteristics of social protection transfers and remittances depend on the country studied.

\subsubsection{Effects of social grants on food security}

Numerous evaluations of public cash transfer programmes (CTPs) analyse their impact on self-reported food security indicators, while a smaller number of studies measure their impact on nutritional status (see Manley, Gitter and Slavchevska 2012; Bastagli et al. 2016), usually of children in grant receiving households.

There is widespread evidence that cash transfers increase access to food and food consumption, and reduce food insecurity. A review of the impacts of conditional cash transfers on household food security in Mexico and Nicaragua found significant increases in per capita caloric availability, diet quality (consumption of vegetables, fruit and animal products) and dietary diversity (Hoddinott and Wiesmann 2010). An evaluation of the Productive Safety Net Programme (PSNP) in Ethiopia found that food insecure households that received free cash or food transfers as unconditional 'direct support' for at least two years improved their food security - measured by the number of months that the household self-reports that it can meet its food needs - by 0.4 months a year. This effect was larger for households receiving larger transfers, reaching 2.5 months in some cases (Berhane et al. 2011: 82).

Empirical evidence on nutritional impacts is more limited, more variable and more ambiguous than data on self-reported food security indicators. The Mchinji Social Cash Transfer Scheme in Malawi recorded a substantial fall in the proportion of children with stunted growth, from $55 \%$ to $46 \%$ in just one year, while the prevalence of stunting in control group households remained unchanged - a significant attributable impact (Miller et al. 2011). On the other hand, a randomised controlled trial in Zambia found that households receiving regular cash transfers from the Child Grant Programme increased their food expenditure, food consumption (meals per day) and dietary diversity, relative to a control group, but these positive food security impacts did not translate into improvements in children's nutritional status for the full sample. However, stunting was significantly reduced for children with educated mothers and for children with access to clean water (Seidenfeld et al. 2014: 41). 
A systematic review covering 15 cash transfer programmes in 10 countries found no consistent relationship between receiving cash transfers and child nutritional status. "Half of the programmes showed positive effects and half negative effects on weight for age, and the same is roughly true for weight for height z-scores" (Manley, Gitter and Slavchevska 2012: 43). ${ }^{16}$ Interestingly, that review finds no difference in nutritional outcomes between conditional and unconditional cash transfers, no effect of larger payment sizes, and a positive but statistically insignificant effect of longer programme duration. The authors conclude by noting that: "almost every programme was associated with increased food consumption and/or food diversity, a positive development. However, we see no effects on nutritional status. Clearly improved access to food alone is not sufficient to improve nutritional status" (Manley, Gitter and Slavchevska 2012: 65). A more recent systematic review found that seven of 12 studies recorded a statistically significant increase in dietary diversity, and five of 13 studies found statistically significant reductions in child stunting (an indicator of long-term deprivation), but only one study of five and one study of eight found reductions in child wasting (an indicator of short-term hunger) and underweight respectively (Bastagli et al. 2016). This is interesting as it suggests that regular cash transfers can reverse the effects of long-term nutritional deficits.

Recently, holistic package approaches that deliver cash transfers together with other forms of support, such as health insurance, access to microfinance and behaviour change communication (BCC) - have demonstrated more powerful impacts than cash transfers alone (Roelen et al. 2017). One pilot project in Bangladesh found that a combination of 'cash + BCC', where cash was complemented by nutrition training, performed significantly better than when cash only, food only, cash + food or food + BCC was delivered. In households that received cash+BCC, child stunting rates fell by 7.3 percentage points, but no other modality registered a significant impact on child undernutrition (Ahmed et al. 2016: 158).

\subsubsection{Effects of remittances on food security}

Studies looking at the effects of remittances on food security focus mainly on nutritional outcomes, especially of children, and the evidence so far is inconclusive as studies find positive, negative, as well as no effects of remittances on nutrition. Looking at international remittances (sent by migrants living abroad) and nutritional outcomes in Ecuador, Antón (2010) finds a positive impact on short-term and medium-term child nutritional

\footnotetext{
${ }^{16}$ Stunting, measured by height-for-age z-scores (HAZ), is an indicator of long-term or chronic undernutrition. A child has stunted growth if her or his height is less than 2 standard deviations below the height of a child the same age in a reference population. Wasting, measured by weight-for-height z-scores (WHZ), is an indicator of shortterm weight loss and hunger.
} 
outcomes, but no significant impact of remittances on long-run anthropometric indicators. On the other hand, Ponce et al. (2011) - also in Ecuador and using a different instrumental variable technique - find no effect of remittances on nutrition. In Guatemala, Davis and Brazil (2016) show that international remittances have no influence on the nutritional status of children left behind (aged 3 or less), which could indicate that fathers are not able to improve their economic situation soon enough to make an impact on their children's nutrition. Finally, a panel study in Mexico shows that migration (including remittances) has a detrimental effect on children's height-for-age (Nobles 2007).

Outside Latin America, Babatunde and Martinetti (2011) find that remittance income contributes to improved calorie supply at the household level in Nigeria, but has no significant impact on diet quality, micronutrients supply, and child nutritional status, while a recent study in Tanzania using an instrumental variable approach (Isotto and Kraybill 2017) show that remittances increase the intake of nutrients such as proteins, vitamin A, vitamin C and calcium. In Ethiopia, Abadi et al. (2013) find that migration and remittances improve food security by allowing households to consume better quality food, a higher quantity of food, as well as reducing the frequency and severity of harmful coping strategies such as limiting the quantity or quality of food consumed. In China, however, Brauw and $\mathrm{Mu}$ (2010) find no significant association between internal migration and the prevalence of underweight children.

From the review of these studies we conclude that remittances, like social grants, are likely to improve food security (in terms of food consumption and the quality of food consumed). However, the impact of remittances on nutrition - which is a measure of long-term well-being- is more inconclusive, as positive effects of remittances on nutrition are not always observed. Moreover, the discussion on internal remittances remains "virtually non-existent" (McKay and Deshingkar 2014: 5), with the exception of some studies which have shown that internal remittances usually flow to a large number of poor and rural households (Castalso et al. 2012; Housen et al. 2013) and have the potential to reduce poverty and build human capital (Adams 2007; Adams 2005; Lokshin et al. 2010; Taylor et al. 2005). Studies on internal remittances in middle income countries have shown that, while international remittances are more effective in decreasing poverty, internal remittances have a more equalising effect as they are better targeted at poor households (Taylor et al. 2005). The reason for this is that costs of international migration are higher, and therefore international migrants do not originate from the poorest households, whereas internal migration is often more concentrated among poor families. 


\subsubsection{Comparing the effects of social grants and remittances}

To date and to the knowledge of the authors, there are no empirical studies that compare the effects of remittances and social grants on food security (including nutrition). There are, however, a few studies that look at the effects of social grants and remittances on other well-being indicators, such as health, income poverty and education. HagenZanker and Himmelstine (2015) summarises these studies, and conclude that in most of them both types of transfers have a positive impact on household wellbeing. When looking at the magnitude of the impact, however, remittances appear to have a larger poverty reduction effect, most likely due to a higher level of the transfer and the fact that in these specific case studies remittances are better targeted at poor households. In addition, Waidler et al (2016) compare the effects of remittances and social grants on expenditure patterns in Moldova and conclude that public and private transfers are not spent in the same way.

\subsubsection{Social grants and remittances in South Africa}

\section{Social Grants}

South Africa's Department of Social Development (DSD) administers seven social grants, which target poor individuals from vulnerable demographic groups. The largest is the Child Support Grant (11.9 million beneficiaries), followed by the Older Person's Grant (3.2 million) ${ }^{17}$ and the Disability Grant (1.7 million). The CSG is the least generous, paying R350 per child per month as of April 2016, while the OPG and DG pay R1,505/month (SASSA 2016). Between the years 2008 and 2012, eligibility for the CSG was increased from 14 years old in 2008, to 16 years old in 2010, and finally 18 years old in 2012. Almost one in three South Africans (30\%) is currently a recipient of a social grant.

There is evidence from several household surveys and impact evaluations that the nutrition status of children in households receiving social grants has improved. A 1999 survey found that children living with Older Person's Grant (OPG) recipients were significantly taller, by approximately one standard deviation in height-for-age (Case 2001). Analysis of a 1993 survey found an increase in height-for-age z-scores (HAZ) of 1.16 standard deviations for girls living with a female OPG recipient (usually the child's grandmother), but a much smaller increase for boys, and no significant impact on HAZ for either boys or girls living with a male OAG recipient (Duflo 2003). ${ }^{18}$

\footnotetext{
17 Older Person's Grant and Old Age Pension are often used interchangeably.

18 The Old Age Grant has subsequently been renamed the Older Person's Grant.
} 
An analysis of a sub-national panel dataset, the KwaZulu-Natal Income Dynamics Study (KIDS), found a significant positive impact of the CSG on child stunting. Boys who started receiving the CSG in their first year gained 0.40 in HAZ by three years of age, compared to boys in the control group (Agüero, Carter and Woolard 2007). An impact evaluation of the CSG conducted in 2011 found no impact of the CSG on stunting across the full sample. "However, it improves anthropometric measures for two subsamples, girls and children whose mothers have eight or more grades of schooling" (DSD, SASSA and UNICEF 2012).

Finally, an analysis of the first wave of NIDS panel dataset by Coetzee (2013) found a significant but small impact of the Child Support Grant on child HAZ, amounting to just 0.04 of a standard deviation. "These effect sizes are much smaller than expected, given the relative size of the transfer in relation to the mean per capita household expenditure of households in the sample" (Coetzee 2013: 429).

These empirical findings suggest that the positive nutritional impacts on children of the Older Person's Grant, which is intended to be spent on the basic needs of older persons, are consistently larger than the impacts of the Child Support Grant, which is 'labelled' as a transfer intended for children. One factor might be the fact that the OPG pays substantially more than the CSG, and large numbers of older persons in South Africa are caring for grandchildren, either orphaned or living with them while the child's parents are working or looking for work elsewhere - so the OAG becomes a main source of income and food security for both older persons and children.

\section{Remittances}

The most common form of human mobility in South Africa has been rural to urban migration (Crush et al. 2005), as rural areas are characterised by high levels of poverty and limited economic activity. During apartheid, movements of labour were mainly temporary, due to the fact that the permanent settlement of migrants was highly restricted (Posel 2001). Following the democratic transition in 1994, this trend was not altered as expected, and migration remains cyclical, although the proportion of female temporary migrants has increased (Collinson 2010). Rural poverty in South Africa remains high at around 70 percent (Stats SA 2014) and, due to the fact that productive land has been highly concentrated among the white population, poor households in South Africa continue to rely on remittances to cover their daily needs (Posel and Casale 2006). Nevertheless, analysing the National Income Dynamics Survey of 2008, Posel (2009) points out that many labour migrants are settling in destination areas where they move, as well as ties between migrants and households of origin are weakening. This translates into a sharp decline in the number of households receiving remittances compared to statistics derived from previous household surveys. 
There are no studies - to the knowledge of the authors - looking at the effects of remittances on nutrition or food security in South Africa. There are some studies, however, that analyse the effects of remittances on poverty in post-apartheid South Africa. ${ }^{19}$ Woolard and Klasen (2004) found in a study covering the years 1993 to 1998 that remittances were associated with a decrease in poverty in KwaZulu-Natal, while Maitra and Ray (2003) showed that remittances have a significant positive impact on the share spent on food. According to Collinson (2010), temporary migration improves the socio-economic status of the households, mainly through remittances.

In households where remittances decrease poverty and expenditure on food increases, food security indicators are expected to improve.

\subsection{Data and indicators}

For this analysis, we use the National Income Dynamic Survey (NIDS), South Africa's first nationally representative panel survey that follows more than 28,000 individuals over time. The first round was conducted in 2008 and subsequent rounds were carried out in 2010, 2012 and 2014. NIDS captures data on the livelihoods of individuals and households and therefore collects information on a range of socio-economic variables, such as income, employment, expenditure, migration, shocks, education, and health. In this study, we use only rounds 1 and 2, as some of the indicators used in our analysis had a large number of missing values in round 3, and round 4 was not available at the time of the study. Data also suffer from attrition due to non-response and refusal. To account for household and individual level attrition we use post-stratification calibrated weights when reporting cross-section analysis and panel weights when reporting on the balanced panel.

Income data in NIDS was collected individually by asking every adult from the household the amount they received per month from each income source (such as wage income, bonus payments, income from self-employment, as well as social grants and remittances). In the case of child grants (such as the Child Support Grant), adults were asked whether they received the specific grant on behalf of a child. Remittances are defined in the NIDS survey as all contributions from non-resident members as well as non-household members. We define all income variables in per capita terms. Finally, income and expenditure variables were deflated to 2008 as the base period. Deflators were computed from CPI data taken from the South African statistical office (Stats SA).

\footnotetext{
${ }^{19}$ Due to lack of nationally representative survey that can explore trends in migration, studies on migration and remittances in South Africa are limited.
} 
Our outcome variables consist of three indicators of food security: total expenditure on food, dietary diversity, and body mass index. All three indicators are objective, as subjective indicators were only available for the first round.

\section{Dietary Diversity Index}

Dietary diversity is considered one of the best performing measures of food security (Hoddinott and Yohannes 2002) and nutritional adequacy, including in South Africa (Steyn et al., 2006). The Household Dietary Diversity Score indicator guide identifies twelve food groups based on the United Nations Food and Agriculture Organisation's Food Composition Table for Use in Africa (Ryan and Leibbrandt 2015). ${ }^{20}$ Following this reasoning, the food items listed in the NIDS dataset were grouped into 12 food groups, based on the FAO's table: cereals, white tubers and roots, vegetables, fruits, meat, eggs, fish and other seafood, legumes, nuts and seeds, milk and milk products, oils and fats, sweets, and spices, condiments and beverages.

Detailed data on expenditure was collected at the household level by asking the amount of money the household spent in the last month on each particular food item (as well as whether the household has consumed it or not). The period of food consumption in NIDS is the previous 30 days. While an increase in the number of food categories consumed gives a good indication of improved food access and food security, there is no established threshold of the number of categories a household needs to consume to be defined as "food secure". While the HDDS guide suggests taking the average diversity of the upper tercile, we follow Ryan and Leibbrandt (2015) using the same dataset and take average dietary diversity as a cut-off point (so that households below the average are considered food insecure). The main reason for this is that the average dietary diversity index (DDI) score is as high as 9 in NIDS, probably due to the long recall period for consumption (which is one month, compared to the 24 hours recall period recommended by the HDDS guide).

\section{Food expenditure}

Food expenditure is a common indicator of food security. The rationale is that households that spend a high proportion of their total expenditure on food are more vulnerable than households that spend a lower proportion (Maxwell 1999; Johnson and Toole 1991). This is because households that spend a large share of their income on food are more vulnerable to changes in food prices, as well as to changes in income.

Despite the fact that food expenditure does not perfectly capture the quality or quantity of food consumed (as this depends on availability and prices, and it also does not capture

${ }^{20}$ For more information on the food composition table, see: www.fao.org/docrep/003/X6877E00.htm. 
food produced for own consumption), ${ }^{21}$ food expenditure is still a useful measure to add to the analysis. The variable is defined as the household share of monthly food expenditure out of total expenditure. As suggested by Maxwell et al. (1999), a high food expenditure proportion is regarded as $60 \%$ and above, and these households are classified as food insecure. In this case, we only analyse the binary variable as the continuous one is difficult to interpret.

\section{Anthropometrics}

We calculate the BMI for children aged 6 to 14 years, as well as for adults (above 14 years old). We analyse these two samples separately, as the BMI of adults is more likely to remain relatively constant over time. BMI is calculated as weight divided by height squared and it is derived from the anthropometric data collected in the adult and child individual surveys. Children who have a BMI less than 2 standard deviations below the median BMI for the reference group are classified as undernourished (Dinsdale et al. 2011). The classification of adults is less complex, with one threshold applied to all individuals over the age of 14. A BMI below 18.5 is identified as underweight and a BMI above 24.9 is identified as overweight.

Although anthropometric data was available for children under 5 and we were able to create the indicators for stunted and wasted (based on the z-scores for height-for-age and weight-for-height respectively), in the second round of the survey many children had missing values for these variables and therefore it was not possible to analyse nutrition with panel estimators for this age group.

\subsection{Empirical strategy}

We take advantage of the longitudinal nature of the data and estimate the relationship between transfers and food security via fixed effects regression. We also perform random effects and Mundlak estimations for robustness, given that some variables do not change considerably over time. ${ }^{22}$ The Hausman test, however, always recommends the use of fixed effects regressions. In the case of the dietary diversity index, we estimate

\footnotetext{
${ }^{21}$ Data on food consumption from own production in South Africa is inadequate and not credible. The assumption we would have to make, therefore, is that the vast majority of those involved in agriculture fail to consume anything from their farming (approximately 16 to 20 percent of the households based on the Labour Force Survey). This is unlikely given that, of those households who report to the LFS that they practice agriculture, most do so for the main purpose of food production for own consumption." (Aliber, 2009: 399). Not including food for own production in the analysis is, therefore, a limitation.

22 The Mundlak approach allows correlation between the unobserved individual effects and the regressors by adding group means of the time varying explanatory variables in the model. The advantage of this method, as opposed to fixed effects estimation, is that one can estimate the coefficients of the time invariant variables.
} 
random effects ordered probit regression (in addition to the linear fixed effects regression) as it is an interval variable and can only take 12 values, from 1 to 12 .

Fixed effects regressions allow us to remove unobserved time invariant heterogeneity, which is very likely to be present in this study. Personal or household characteristics that are unobserved, like for example eating habits, are likely to affect food security outcomes and at the same time be correlated with the independent variables, therefore causing estimation bias. However, as it seems plausible to assume these variables stay constant over time, we can remove this bias by introducing individual fixed effects. The model can be expressed as follows:

$$
\begin{aligned}
& F S_{i t}=\beta_{1} \log \left(C S G_{i t}\right)+\beta_{2} \log \left(\text { remittances }_{i t}\right)+\beta_{3} \log \left(O P G_{i t}\right)+\beta_{4} H H_{i t}+ \\
& \beta_{4} Y_{i t}+\alpha_{i}+\epsilon_{i t}(1)
\end{aligned}
$$

where FS are the different food security outcome indicators. The coefficients of interest are the CSG, OPG, and remittances which denote per capita monthly income (in Rands) from the Child Support Grant, Older Person's Grant and remittances, respectively. ${ }^{23}$ The $\mathrm{HH}$ term refers to various household characteristics that can change over time, such as number of adults and children living in the household, maximum level of education attained in the household, and whether the household is located in a rural, urban formal, or informal area. ${ }^{24} \mathrm{Y}$ denotes the year fixed effects (in this case 2008) and $\alpha_{i}+\epsilon_{i t}$ refers to the error term which in this case is divided into two terms: $\alpha_{i}$ is the time invariant error (the individual fixed effect) and $\epsilon_{i t}$ is the time variant error, which is assumed to be random and uncorrelated with the independent variables.

As we are not only interested in analysing how transfers affect the continuous outcomes (values of BMI and DDI), but also how transfers affect the probability of being food secure (being neither underweight nor overweight in the case of adults, and having an above average DDI in the case of the whole household), we estimate fixed effects (conditional) logits to see how an increase in the Older Person's Grant, remittances, and Child Support Grant changes the odds of being food secure. ${ }^{25}$ In this case equation (1) remains the same with the only difference being that the dependent variable is replaced by the binary measures of food security.

Given that both social transfers and remittances are not randomly assigned to recipients, the model can still suffer from endogeneity if there are omitted variables that are time variant and affect both the treatment and the outcome. For instance, if there is a shock

\footnotetext{
${ }^{23}$ In order to have non-negative logarithms of income from the different transfers, we add 1 Rand (local currency) to the whole income distribution.

${ }^{24}$ Due to the fact that NIDS follows individuals and not households, some individuals can move to another households (and therefore change location) from one wave to the other.

${ }^{25}$ We could not look at BMI for children (probability of being nourished) as there were not enough individuals who changed their outcome (from being under-nourished to nourished or vice versa) from one year to the other.
} 
that causes a change in food security outcomes and, at the same time, generates a response in the remitter or the government by increasing or decreasing transfers, our coefficients may be biased. In the absence of a proper instrument for the three transfers (Child Support Grant, Older Person's Grant and remittances), we perform the estimations separately for different population groups to test for heterogeneity in effects. We re-estimate the model by: (1) restricting the sample to the African population in order to compare public and private transfer within a more homogenous group; and (2) restricting the sample to households that receive social transfers (and that can or cannot receive remittances).

As an additional robustness check and to better correct for potential endogeneity, we implement some standard tools of policy evaluation and look at the effects of each transfer separately. The reason why we do not analyse all three transfers in the same model is that, in order to implement quasi-experimental techniques such as propensity score matching or instrumental variable estimation (in cases where an instrument is available), we can only analyse one treatment at a time.

\subsection{Descriptive Statistics}

Table 3.1 shows descriptive information on the percentage of individuals living in households receiving the Older Person's Grant (OPG), the Child Support Grant (CSG), and remittances - as well as combinations of these - and no transfers. Almost 50 percent of the South African population receives either a poverty-related government transfer (CSG or OPG) or private transfers (remittances). The CSG is the transfer with the highest coverage, reaching more than 40 percent of individuals (30 percent of which do not receive either of the other two transfers). Of those individuals living in households receiving the OPG, more than half also receive the CSG, which is consistent with evidence of a high number of multi-generational households in South Africa and with elderly individuals pooling their income and living with children. The number of households relying only on remittances is low and has been decreasing over time (Posel and Casale, 2006; Posel 2009), and this can be seen in table 3.1 with only 1.8 percent of individuals living in households receiving remittances in 2010 (compared with 5.7 in 2008). 
Table 3.1: Economic characteristics by transfer recipient status

\begin{tabular}{|c|c|c|c|c|c|c|c|c|c|c|c|c|c|c|c|c|}
\hline & \multicolumn{2}{|c|}{ Only OPG } & \multicolumn{2}{|c|}{ Only CSG } & \multicolumn{2}{|c|}{ Only Remittances } & \multicolumn{2}{|c|}{ Remit \& CSG } & \multicolumn{2}{|c|}{ Remit \& OPG } & \multicolumn{2}{|c|}{ OPG \& CSG } & \multicolumn{2}{|c|}{$\begin{array}{c}\text { Remit \& OPG \& } \\
\text { CSG }\end{array}$} & \multicolumn{2}{|c|}{ No transfers } \\
\hline & 2008 & 2010 & 2008 & 2010 & 2008 & 2010 & 2008 & 2010 & 2008 & 2010 & 2008 & 2010 & 2008 & 2010 & 2008 & 2010 \\
\hline $\begin{array}{l}\text { \% individuals in } \\
\text { households receiving } \\
\text { transfers }\end{array}$ & 6.5 & 9.8 & 26.3 & 28.9 & 5.7 & 1.8 & 5.3 & 2.1 & 1.2 & 0.4 & 7.1 & 10.4 & 1.2 & 0.6 & 46.8 & 46.1 \\
\hline $\begin{array}{l}\text { Average amount } \\
\text { received (hh level) (real } \\
2008 \text { prices) }\end{array}$ & 1041 & 1154 & 431 & 510 & 2377 & 653 & 1005 & 1523 & 1103 & 1649 & 1555 & 1697 & 2086 & 2202 & - & - \\
\hline $\begin{array}{l}\text { Average pc income } \\
\text { before transfers (real) }\end{array}$ & 400 & 446 & 277 & 463 & 1570 & 1073 & 312 & 435 & 351 & 245 & 136 & 296 & 105 & 315 & - & - \\
\hline $\begin{array}{l}\text { Average pc income } \\
\text { after transfers (real) }\end{array}$ & 678 & 731 & 355 & 553 & 2359 & 1336 & 489 & 699 & 676 & 553 & 342 & 504 & 371 & 609 & 2552 & 3008 \\
\hline $\begin{array}{l}\% \text { of total hh income } \\
\text { the grant represents }\end{array}$ & $73 \%$ & $59 \%$ & $49 \%$ & $41 \%$ & $52 \%$ & $12 \%$ & $56 \%$ & $52 \%$ & $70 \%$ & $68 \%$ & $71 \%$ & $62 \%$ & $78 \%$ & $49 \%$ & - & - \\
\hline $\mathrm{N}$ & 2508 & 3027 & 7506 & 6892 & 1396 & 404 & 1684 & 540 & 399 & 170 & 2547 & 3068 & 560 & 221 & 10262 & 12540 \\
\hline
\end{tabular}

Source: Authors' calculations, NIDS 2008 and NIDS 2010. Post-stratification calibrated weights are applied. 
In terms of the average amount received in recipient households, in 2008 remittances were much higher in magnitude than government transfers. However, remittances do not only reach poor families (this is consistent with the findings from Collinson (2010)), and the high average is mainly the result of high-income households receiving large amounts of remittances (see figure 3.1 below). It is also important to point out that in this survey remittances are defined as "any contribution from non-resident members or non-household members", which means that not only transfers from migrants are included, but also other contributions such as child maintenance payments, payments to an elderly person living in another households or to a child studying in another city. The average amount received from the OPG is more than doubles the amount received from the CSG: the value of the OPG is actually almost four times the value of the CSG, but there are many households with more than one child receiving the CSG.

When looking at the average per capita income before transfers, one can see that in the year 2008, households that rely on all three transfers are by far the poorest and households that only receive remittances are the richest (in the latter case average income is similar to households receiving no transfers). In 2010 remittance recipient households are also the richest but those that receive remittances and the OPG, or both the OPG and CSG and no remittances are slightly poorer that those receiving the three transfers. This can be due to the fact that those receiving all three transfers decreased by half in 2010 due to a big decrease in the number of households receiving remittances. It is curious to see that remittances reach both rich and poor households, but when it reaches poor households they often complement or are complemented by government transfers. One explanation could be that social transfers enable household members to go to the city and look for a job in order to send money back home (Sienaert 2008; Ardington et al. 2009). Finally, the last row shows the percentage of income that each grant represents, on average, in recipient households. Households that receive transfers rely highly on them, as generally more than 50 percent of per capita income comes from transfers, reaching 78 percent in households receiving all three transfers (the CSG, the OPG, and remittances).

Figure 3.1 shows the distribution of (a) the CSG, (b) remittances, and (c) the OPG by expenditure decile. It shows that the CSG is relatively effective in targeting poor households. It is evident that households in the lower deciles of expenditure are more likely to receive - as well as to receive larger amounts of - the CSG. The lowest expenditure decile does not reflect this trend, which could be due to the fact that there are fewer children in this decile, or that very poor households do not apply for the grant due to lack of information or resources. ${ }^{26}$ The opposite occurs with remittances, as richer

\footnotetext{
${ }^{26}$ Very poor households may be discouraged to apply if they lack the necessary documents, have to travel far away to apply for the grant or as a result of less motivated caregivers.
} 
households receive larger amounts on average. One explanation for this could be that richer households are in a better position to send remittances, but one could also speculate that there is a (positive) displacement effect, where remittances between poor people are being crowded out by public transfers, as some qualitative evidence points out (Du Toit and Neves 2009).

The way transfers are targeted will determine their poverty reduction impact. As remittances have been decreasing in size, and a relatively large proportion of them go to wealthier households, we do not expect to see a big impact of remittances on food security. At the same time, the amount of the CSG is too small to have a sizeable impact, even on basic needs. The OPG lies in between (figure 3.1c) - despite being weakly targeted, it is big enough to have an effect on food security. The drawback is that only households with elderly individuals benefit from this transfer.

In terms of frequency, social transfers are received monthly, whereas remittances are also received relatively frequently, with a median of 10 times per year in recipient households. Therefore, both private and public transfers are received regularly. However, remittances can decrease considerably during a crisis or with an idiosyncratic shock to the sender, thereby reducing the poverty reduction impact of remittances. Regarding the sex of the recipient, child grants are mainly received by women ( 97 percent in 2008 and 95 percent in 2010), whereas in the case of remittances the proportion of female recipients is lower but still very high (78 and 80 percent in 2008 and 2010, respectively). The decision on how money is spent may not only depend on who receives the transfer, though, but on who is the head of the household (which is self-defined in the survey). In this regard, 67.7 percent of remittance recipient households, 63.3 percent of CSG recipient households, and 67.5 percent of OPG recipient households are headed by a female. Given that there are no big differences between public and private transfer recipients in terms of who the head of the household is or who the recipient of grants is, we do not expect differences in impacts between public and private transfers to be driven by this factor.

Finally, the way households spend each specific grant and who benefits from them will depend on whether transfers are sent with a specific purpose and on the population group the transfer is targeting. The CSG is targeted at children and there is a clear message from the government that the grant is intended to improve children's well-being, including nutrition and access to education. ${ }^{27}$ In the case of the OPG, even though the grant is targeted at elderly individuals, there is evidence that older persons usually live in households with children and pool their income to help all members of the household, in particular children (Case 2001; Lloyd-Sherlock 2012; Menendez 2007). Consequently,

${ }^{27}$ In fact the CSG has school attendance conditionality but in practice this is not enforced. 
we expect a positive effect of the CSG on children's food security, and of the OPG on children as well as on adults' food security (also due to the fact that the OPG is larger in size as compared to other transfers). In the case of remittances, we only expect to see improvements in food security in poor households, as richer ones are expected to be food secure. For poor households, remittances are a household level transfer which is expected to be poverty reducing, as evidence from internal remittances points out (Castalso et al. 2012; Housen et al. 2013). However, the extent of the improvement will depend on how the money is distributed among household members, and whether transfers are big enough to cover basic needs.

a) Per capita CSG

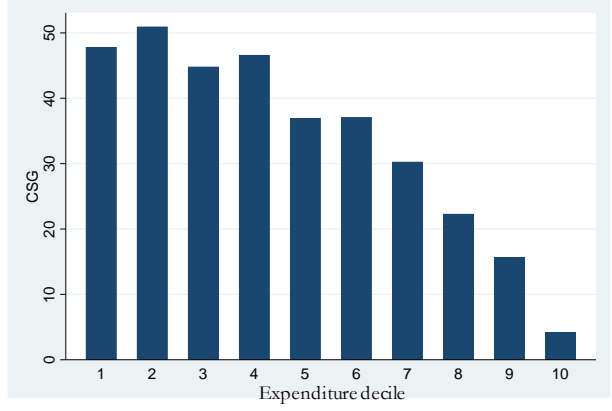

b) Per capita remittances

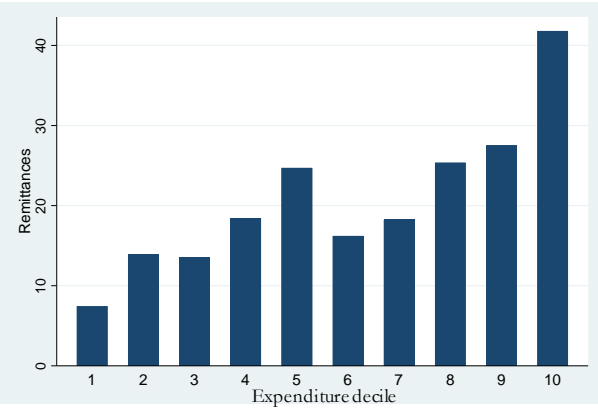

c) Per capita OPG

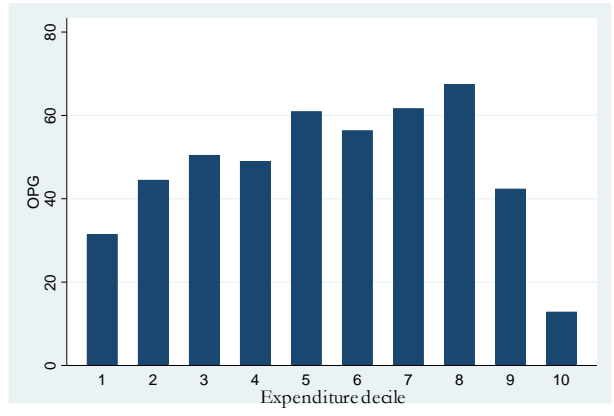

Figure 3.1: Per capita income from social grants and remittances by expenditure deciles (whole sample) Source: NIDS 2008

Table 3.2 shows food security outcomes across the different transfer recipient groups. Results are generally consistent across groups, meaning that when we compare the different food security indicators the ranking holds: households that receive no transfers or only remittances are better off, followed by those receiving remittances and either the CSG or the OPG. This group is followed by households receiving only the OPG, only the CSG, both the OPG and the Child Support Grant and finally by households receiving all three grants, which are in general the most food insecure. 
Table 3.2: Food security outcomes by recipient status

\begin{tabular}{|c|c|c|c|c|c|c|c|c|c|c|c|c|c|c|c|c|}
\hline & \multicolumn{2}{|c|}{ Only OPG } & \multicolumn{2}{|c|}{ Only CSG } & \multicolumn{2}{|c|}{$\begin{array}{c}\text { Only } \\
\text { remittances }\end{array}$} & \multicolumn{2}{|c|}{ Remit \& CSG } & \multicolumn{2}{|c|}{ Remit \& OPG } & \multicolumn{2}{|c|}{ OPG \& CSG } & \multicolumn{2}{|c|}{$\begin{array}{c}\text { Remit \& OPG \& } \\
\text { CSG }\end{array}$} & \multicolumn{2}{|c|}{ No transfers } \\
\hline & 2008 & 2010 & 2008 & 2010 & 2008 & 2010 & 2008 & 2010 & 2008 & 2010 & 2008 & 2010 & 2008 & 2010 & 2008 & 2010 \\
\hline \multicolumn{17}{|l|}{ Food adequacy } \\
\hline DDI $(>8)($ in $\%)$ & 64.1 & 72.1 & 61.8 & 66.8 & 77.6 & 69.0 & 74.1 & 81.7 & 65.8 & 77.8 & 59.5 & 71.2 & 60.8 & 77.5 & 78.4 & 77.6 \\
\hline Average DDI & 9.16 & 9.48 & 8.94 & 9.26 & 9.94 & 9.61 & 9.71 & 10.2 & 9.19 & 9.92 & 8.98 & 9.45 & 9.04 & 9.82 & 10.0 & 9.96 \\
\hline $\begin{array}{l}\text { Average share spent } \\
\text { on food }\end{array}$ & 0.41 & 0.43 & 0.40 & 0.43 & 0.33 & 0.36 & 0.43 & 0.44 & 0.40 & 0.49 & 0.44 & 0.48 & 0.51 & 0.45 & 0.31 & 0.31 \\
\hline $\begin{array}{l}\text { Expenditure on } \\
\text { food }>60 \% \text { (in } \% \text { ) }\end{array}$ & 16.2 & 19.5 & 16.3 & 19.5 & 7.7 & 15.0 & 15.5 & 16.0 & 16.0 & 35.0 & 19.5 & 27.1 & 24.0 & 20.0 & 9.4 & 8.8 \\
\hline \multicolumn{17}{|l|}{ Nutrition (in \%) } \\
\hline $\begin{array}{l}\text { Underweight (BMI } \\
\text { adults) }\end{array}$ & 8.7 & 8.2 & 8.2 & 7.5 & 7.9 & 9.7 & 9.3 & 9.6 & 7.2 & 3.4 & 9.1 & 5.1 & 12.6 & 2.1 & 6.2 & 6.8 \\
\hline $\begin{array}{l}\text { Overweight (BMI } \\
\text { adults) }\end{array}$ & 46.9 & 52.1 & 44.7 & 51.1 & 43.5 & 41.2 & 46.5 & 40.4 & 45.2 & 53.8 & 46.7 & 53.1 & 41.5 & 51.2 & 49.9 & 51.0 \\
\hline Obese (BMI adults) & 26.7 & 27.8 & 24.6 & 28.7 & 18.3 & 19.5 & 23.5 & 32.8 & 27.3 & 22.9 & 25.3 & 30.1 & 20.8 & 23.3 & 24.7 & 28.1 \\
\hline $\begin{array}{l}\text { Nourished (Children } \\
5-14)\end{array}$ & 95.3 & 98.2 & 92.8 & 95.1 & 94.8 & 97.2 & 92 & 95.5 & 100 & 93.7 & 95.1 & 95.2 & 86.4 & 100 & 94.5 & 96.5 \\
\hline \multicolumn{17}{|c|}{ Subjective indicators (in \%) } \\
\hline Child hungry & 28.4 & - & 23.8 & - & 12.8 & - & 13.8 & - & 26.4 & - & 25.6 & - & 27.0 & - & 12.2 & - \\
\hline Adult hungry & 31.6 & - & 30.7 & - & 19.5 & - & 19.9 & - & 28.5 & - & 32.7 & - & 30.5 & - & 15.2 & - \\
\hline $\begin{array}{l}\text { Food adequate for } \\
\text { hh needs }\end{array}$ & 57.2 & - & 54.2 & - & 71.1 & - & 55.3 & - & 54.4 & - & 49.7 & - & 46.1 & - & 69.9 & - \\
\hline
\end{tabular}

Source: Authors' calculations, NIDS 2008 and NIDS 2010. Post-stratification calibrated weights are applied. 


\subsection{Results}

For the econometric analysis, we look at three continuous indicators of food security (dietary diversity and body mass index for adults and for children), and four binary indicators, expressed as the odds of being food secure in terms of dietary diversity (DDI higher than 8) and food expenditure (spending less than 60 percent of total expenditure on food); being not underweight (BMI>18.5); and being not overweight (BMI<24.9) (in both cases for adults older than 14 years old). ${ }^{28}$ We do not estimate the regressions using the share of food expenditure as a continuous variable given that results are hard to interpret, as an increase in the share spent on food can be considered a positive outcome if the household is poor but richer households spend a lower share of their income on food. Table 3.3 shows the fixed effects and the random effects ordered probit results when the dietary diversity index is the dependent variable. Looking at table 3.3, while we do not see significant impacts of the Child Support Grant, the Older Person's Grant is positive and significant in all specifications. Remittances are also positive and significant; although lower in magnitude as compared to the OPG. To have a clearer idea of the magnitude of the coefficients, we can look at the results of the random effects ordered probit regressions (expressed in average marginal effects in table 3.4). For this we have re-classified the DDI in 9 categories (from 4 to 12), as very few individuals have a DDI lower than 4. The regression shows that recipients of the Older Person's Grant as well as remittances have higher probabilities of having a higher DDI. For example, an increase of $10 \%$ in both per capita remittances and the OPG increases the probability of having a DDI of 12 by 0.1 percent (or is associated with being $0.1 \%$ more likely to have a DDI of 12).

There are several explanations for why we see a positive impact of the OPG but not of the CSG. First, as mentioned earlier, the OPG is approximately four times the size of the CSG, so it is to be expected that this grant will have a larger impact on household food security. Another reason is that the DDI identifies well-being at a household level, and we expect a higher effect from the OPG given that this grant is usually pooled and benefits the whole household. In addition, as discussed in Devereux and Waidler (2017), there is evidence that the CSG is being "diluted" in terms of what it is spent on, as poor households have needs other than food as well as recipients of the transfer -caregivers of children, many of whom are teenagers- may be spending the grant on goods that do not benefit their children directly. Finally, remittance income is also a household level transfer which is often spent on food (as shown in Chapter 2), so these results are consistent with previous evidence from South Africa (Maitra and Ray 2003).

\footnotetext{
${ }^{28}$ We could not estimate conditional logits for child bmi (probability of being nourished) as the sample was very small (very few individuals had changed from being nourished to unnourished and vice versa.
} 
With regard to the effects of transfers on BMI (tables 3.5 and 3.6), we do not observe any significant impact of either public or private transfers on nutrition. Although the random effects models show a negative effect of the OPG on adults BMI, this significant effect disappears when we estimate Mundlak regression. This is likely caused by a negative selection into social protection transfers, where individuals with worse nutritional outcomes are more likely to receive transfers from the government. Once we account for this by removing the correlation between the error term and time invariant variables -through Mundlak or fixed effects models-, coefficients are no longer significant.

Finally, table 3.7 shows the conditional logit expressed in odds ratios when food security indicators are expressed as binary variables. Results are consistent with the fixed effects regression, as we only see significant impacts in the case of DDI: an increase in one rand of per capita OPG and remittances increases the odds of being food secure by 0.05 percent. We do not see significant effects when we analyse the odds of being not overweight, not underweight, and food secure in terms of share of expenditure on food.

Table 3.3: Fixed Effects regressions - Effect of transfers on Dietary Diversity Index

\begin{tabular}{lcccc}
\hline & \multicolumn{3}{c}{ Fixed effects } & Random effects ordered probit \\
\cline { 2 - 5 } & $\begin{array}{c}\text { DDI } \\
\text { Whole sample }\end{array}$ & $\begin{array}{c}\text { DDI } \\
\text { African sample }\end{array}$ & $\begin{array}{c}\text { DDI } \\
\text { Grant recipients }\end{array}$ & DDI Whole sample \\
\hline Log of CSG & 0.02 & $0.04^{*}$ & $0.06^{+}$ & $-0.02^{* *}$ \\
& $(0.01)$ & $(0.02)$ & $(0.03)$ & $(0.00)$ \\
Log of OPG & $0.11^{* *}$ & $0.12^{* *}$ & $0.20^{* *}$ & $0.02^{* *}$ \\
Log of remittances & $(0.02)$ & $(0.02)$ & $(0.03)$ & $(0.00)$ \\
& $0.08^{* *}$ & $0.09^{* *}$ & $0.07^{* *}$ & $0.04^{* *}$ \\
Observations & $(0.02)$ & $(0.02)$ & $(0.02)$ & $(0.00)$ \\
Within $R^{2}$ & 38936 & 32312 & 24731 & 38711 \\
\hline
\end{tabular}

Standard errors in parentheses; ${ }^{+} p<0.1,{ }^{*} p<0.05,{ }^{* *} p<0.01$; Panel weights are used and full models are shown in appendix; Control variables include household size and composition, living in rural, urban informal or urban formal areas, year, and maximum level of education attained in the household. The random effects ordered probit also controls for gender of household head, age of the eldest member of the household, race, location (province), housing and living conditions, and number of household members employed. 
Table 3.4: Marginal effects of transfers on Dietary Diversity Index- Random Effects Ordered Probit (whole sample)

\begin{tabular}{lccccccccc}
\hline & $\begin{array}{c}\text { DDI } \\
1-4\end{array}$ & DDI 5 & DDI 6 & DDI 7 & DDI 8 & DDI 9 & DDI 10 & DDI 11 & $\begin{array}{c}\text { DDI } \\
12\end{array}$ \\
\hline Log of CSG & 0.00 & 0.00 & 0.00 & 0.00 & 0.00 & 0.00 & 0.00 & 0.00 & 0.00 \\
& $(0.00)$ & $(0.00)$ & $(0.00)$ & $(0.00)$ & $(0.00)$ & $(0.00)$ & $(0.00)$ & $(0.00)$ & $(0.00)$ \\
Log of OPG & $-0.003^{* *}$ & $-0.002^{* *}$ & $-0.002^{* *}$ & $-0.003^{* *}$ & $-0.003^{* *}$ & $-0.002^{* *}$ & $0.000^{* *}$ & $0.004^{* *}$ & $0.010^{* *}$ \\
& $(0.00)$ & $(0.00)$ & $(0.00)$ & $(0.00)$ & $(0.00)$ & $(0.00)$ & $(0.00)$ & $(0.00)$ & $(0.00)$ \\
Log of & $-0.003^{* *}$ & $-0.002^{* *}$ & $-0.002^{* *}$ & $-0.003^{* *}$ & $-0.003^{* *}$ & $-0.002^{* *}$ & $0.000^{* *}$ & $0.004^{* *}$ & $0.010^{* *}$ \\
Remittances & $(0.00)$ & $(0.00)$ & $(0.00)$ & $(0.00)$ & $(0.00)$ & $(0.00)$ & $(0.00)$ & $(0.00)$ & $(0.00)$ \\
\hline
\end{tabular}

Standard errors in parentheses; ${ }^{+} p<0.1,{ }^{*} p<0.05,{ }^{* *} p<0.01$.

Table 3.5: Fixed Effects regressions - Effect of transfers on adult BMI

\begin{tabular}{lccccc}
\hline & \multicolumn{3}{c}{ Fixed effects } & Random effects & Mundlak \\
\cline { 2 - 6 } & $\begin{array}{c}\text { BMI adults } \\
\text { Whole sample }\end{array}$ & $\begin{array}{c}\text { BMI adults } \\
\text { African sample }\end{array}$ & $\begin{array}{c}\text { BMI adults } \\
\text { Grant recipients }\end{array}$ & $\begin{array}{c}\text { BMI adults } \\
\text { Whole sample }\end{array}$ & $\begin{array}{c}\text { BMI adults } \\
\text { Whole sample }\end{array}$ \\
\hline Log of CSG & -0.03 & -0.04 & $0.21^{* *}$ & 0.00 & 0.02 \\
Log of OPG & $(0.04)$ & $(0.04)$ & $(0.07)$ & $(0.02)$ & $(0.03)$ \\
Log of & 0.02 & 0.01 & $0.20^{* *}$ & $-0.07^{* *}$ & 0.02 \\
Remittances & $(0.04)$ & $(0.04)$ & $(0.06)$ & $(0.03)$ & $(0.03)$ \\
Observations & -0.02 & -0.05 & -0.02 & -0.03 & -0.04 \\
Within $R^{2}$ & $(0.03)$ & $(0.03)$ & $(0.05)$ & $(0.03)$ & $10.03)$ \\
Overall $R^{2}$ & 0.03 & 14233 & 10132 & 16700 & 16700 \\
\hline
\end{tabular}

Standard errors in parentheses; ${ }^{+} p<0.1,{ }^{*} p<0.05,{ }^{* *} p<0.01$; Panel weights are used and full models are shown in appendix; Control variables include household size and composition, living in rural, urban informal or urban formal areas, year, and maximum level of education attained in the household. Random and Mundlak estimations also control for race, location (province), housing and living conditions, number of household members employed, and age of the eldest member of the household.

Table 3.6: Fixed Effects regressions - Effect of transfers on children BMI

\begin{tabular}{lccccc}
\hline & \multicolumn{3}{c}{ Fixed effects } & Random effects & Mundlak \\
\cline { 2 - 6 } & $\begin{array}{c}\text { BMI child } \\
\text { Whole sample }\end{array}$ & $\begin{array}{c}\text { BMI child } \\
\text { African sample }\end{array}$ & $\begin{array}{c}\text { BMI child } \\
\text { Grant recipients }\end{array}$ & $\begin{array}{c}\text { BMI child Whole } \\
\text { sample }\end{array}$ & $\begin{array}{c}\text { BMI child Whole } \\
\text { sample }\end{array}$ \\
\hline Log of CSG & -0.01 & -0.01 & 0.00 & -0.00 & 0.00 \\
Log of OPG & $(0.02)$ & $(0.02)$ & $(0.06)$ & $(0.01)$ & $(0.02)$ \\
& 0.05 & $0.06^{+}$ & 0.06 & 0.01 & 0.03 \\
Log of & $(0.03)$ & $(0.03)$ & $(0.04)$ & $(0.01)$ & $(0.02)$ \\
Remittances & 0.01 & 0.01 & -0.01 & 0.00 & -0.01 \\
\hline Observations & $(0.02)$ & $(0.02)$ & $(0.02)$ & $(0.02)$ & $(0.02)$ \\
WithinR & 3908 & 3475 & 2875 & 3798 & 3798 \\
\hline
\end{tabular}

Standard errors in parentheses; ${ }^{+} p<0.1,{ }^{*} p<0.05,{ }^{* *} p<0.01$; Panel weights are used and full models are shown in appendix; Control variables include household size and composition, living in rural, urban informal or urban formal areas, year, and maximum level of education attained in the household. Random and Mundlak estimations also control for race, location (province), housing and living conditions, number of household members employed, age of the eldest member of the household and characteristics of the child that can influence their nutritional status (whether the mother is alive, and subjective health status). 
Table 3.7: Conditional logits - Odds ratios of being food secure, not underweight, not overweight

\begin{tabular}{lcccc}
\hline & $\begin{array}{c}\text { Food secure } \\
\text { (DDI) }\end{array}$ & $\begin{array}{c}\text { Food secure } \\
\text { (expenditure) }\end{array}$ & Not underweight & Not overweight \\
Log of CSG & 1.02 & 1.00 & 0.97 & 1.01 \\
Log of OPG & $(0.01)$ & $(0.01)$ & $(0.04)$ & $(0.02)$ \\
Log of & $1.05^{* *}$ & 1.02 & 1.03 & 1.02 \\
Remittances & $(0.01)$ & $(0.01)$ & $(0.04)$ & $(0.03)$ \\
Observations & $1.05^{* *}$ & 1.01 & $1.08^{+}$ & 0.98 \\
Pseudo $R^{2}$ & $(0.01)$ & $(0.01)$ & $10.04)$ & $3.03)$ \\
\hline
\end{tabular}

Exponentiated coefficients; Standard errors in parentheses; ${ }^{+} p<0.1,{ }^{*} p<0.05,{ }^{* *} p<0.01$. Full models shown in appendix; Control variables include household size and composition, living in rural, urban informal or urban formal areas, year, and maximum level of education attained in the household.

\subsubsection{Endogeneity concerns: additional estimations}

Given that our data does not cover pre-program outcomes, and that selection into treatment (receiving remittances and social protection transfers) is not random, our study could still suffer from endogeneity bias due to omitted -time varying- variables. ${ }^{29}$ An even more problematic bias could be caused by reverse causality, which would arise if the level of food security and nutrition of individuals determines whether they receive remittances or social assistance transfers. As robustness tests, therefore, and based on data availability and transfers' characteristics, we perform some additional standard methods of policy evaluation, namely propensity score matching and instrumental variable estimation. Given that we cannot apply the same econometric technique to analyse all three transfers, we estimate the effects of each transfer separately. Another reason why we cannot estimate them together is the fact that beneficiaries of remittances, OPG, and CSG have different characteristics, which means their correspondent control groups will also be different.

In the case of the Older Person's Grant, we are able to instrument pension receipt with age eligibility, given that 80 percent of age eligible individuals in South Africa receive the pension. This instrument has been used in other papers studying the impacts of this transfer (see, for example, Standish-White and Finn (2015)). The second-stage instrumental variable (IV) results are shown in the table below, and confirm our findings that pension income improves food security (the dietary diversity index), but has no effect on nutrition. This holds when we analyse the continuous variable (amount received), as well as when estimating the effects of receiving or not receiving the grant (binary variable).

\footnotetext{
${ }^{29}$ Although in the previous section we performed sub-sample analysis to attempt to overcome this limitation, restricting the sample to specific groups threatens the external validity of the study.
} 
Social Grants, Remittances, and Food Security: Does the Source of Income Matter?

Table 3.8: Fixed effects IV estimates of the effects of the Older Person's Grant on DDI and nutrition

\begin{tabular}{lccc}
\hline & DDI & BMI adults & BMI children \\
\hline Receives OPG & $0.63^{* * *}$ & 0.20 & 0.24 \\
& $(0.13)$ & $(0.35)$ & $(0.23)$ \\
Observations & 38936 & 16700 & 3908 \\
F statistic first stage & 583 & 249 & 66 \\
Log of OPG & $0.12^{* * *}$ & 0.04 & 0.05 \\
& $(0.03)$ & $(0.07)$ & $(0.05)$ \\
\hline Observations & 38936 & 16700 & 3908 \\
F statistic first stage & 563 & 243 & 64 \\
\hline
\end{tabular}

Standard errors in parentheses; ${ }^{*} p<0.1,{ }^{* *} p<0.05,{ }^{* * *} p<0.01$; control variables and first-stage regression omitted.

In the case of the Child Support Grant, we rely on matching techniques. In the absence of a good instrument, other studies such as Coetzee (2013) and DSD, SASSA and UNICEF (2012) have used this technique to estimate the effects of the CSG on different well-being indicators. To estimate the treatment, we use variables that influence the probability that an individual lives in a grant recipient household, but are unlikely to be affected by the outcome, such as place of residence, race, housing conditions, and the number of age-eligible children in the household. All the estimations shown below satisfy the balancing property (meaning that differences in covariates between treated and control individuals are not significant after matching), and post-estimation tests indicate that the matching is done correctly. ${ }^{30}$ We perform two different matching techniques: radius matching, and nearest neighbour matching based on the three closest neighbours. $^{31}$

Table 3.9 below shows the average treatment effects of the Child Support Grant on food security and nutrition. Again, we see that the Child Support Grant has no effect on food security (measured through the dietary diversity index), given that the t-statistic is less than 1.96 when performing both radius matching as well as nearest neighbour matching. The effects on adults' BMI are also insignificant. However, when estimating the effects on BMI for children -and as opposed to the estimations shown in the previous subsection- we observe a positive effect of the CSG. Receiving the Child Support Grant leads, on average, to a 0.39 or 0.50 standard deviations increase in the body mass index depending on the matching technique used. The magnitude of this effect is quite considerable given the distribution of this variable (see table A3.1).

\footnotetext{
30 The regression to estimate the propensity score as well as the post-estimation tests are shown in the appendix.

${ }^{31}$ Nearest neighbour matches a treated participant with its closest non-treated participant (or, in our case, with the 3 closest non-participants), whereas radius matching combines nearest neighbour matching with caliper matching. Caliper matching imposes a restriction of a maximum permitted distance between the neighbours (avoiding in this way matching participants whose absolute propensity score difference is high).
} 
Although results should be interpreted with caution given that we cannot use baseline characteristics to estimate the probability of receiving the Child Support Grant ${ }^{32}$, and that propensity score matching only controls for selection on observables, the advantage of this technique is that it allows us to create a proper counterfactual of non-participants and get an unbiased estimation of the effects of this programme, provided all assumptions hold. This may be the reason why findings differ with respect to our previous estimations, and why we now observe positive effects of the CSG. These positive effects on child nutrition are in line with previous evaluations of the Child Support Grant (see, for example, Coetzee (2013) and DSD, SASSA and UNICEF (2012)).

Although some studies have found positive effects of the Child Support Grant on specific nutritional indicators, a review of the literature indicates that the levels of malnutrition in South Africa have not declined, or are declining very slowly, as the proportion of stunted children in South Africa has fluctuated between 20\% and 30\% since the early 1990s (various sources, discussed in Devereux and Waidler 2016). The next section, therefore, discusses why we think this is the case.

With regard to remittances, it was not possible to find a good instrument or to implement propensity score matching, given that covariates that would be expected to influence the probability of receiving remittances did not turn out to be good predictors of treatment status. However, this also means that the estimation of the effects of remittances is less likely to suffer from endogeneity bias, as recipients and non-recipients do not differ, on average, on some main socio-demographic characteristics. One possible explanation for this is that remittances can be received from both household and nonhousehold members, and therefore senders have different characteristics and send remittances for different purposes. In addition, not all remittances are sent by migrant household members, and this lowers the likelihood of reverse causality. Assuming that, in fact, there is reverse causality, we would expect this endogeneity to lead to downward bias, given that migrants are more likely to be negatively selected in terms of income and education, which would imply that remittance recipient households are, in general, less food secure on average (Jacobs and du Plessis 2016). This would also imply that the effects of remittances found in this paper would be under-estimated.

\footnotetext{
${ }^{32}$ For the propensity score matching assumptions to be satisfied, potential outcomes should be independent of treatment assignment. Therefore, in an ideal case, we would use baseline characteristics of individuals (which predate the start of the programme), to estimate the probability of receiving the grant.
} 
Table 3.9: Average treatment effects of the Child Support Grant on DDI and nutrition (pooled sample from 2008 and 2010)

\begin{tabular}{lllll}
\hline & ATT & SE & t-statistic & Observations \\
\hline$D D I$ & & & & \\
\hline Radius matching & 0.24 & 0.29 & 0.82 & 38606 \\
Nearest neighbor (3) & 0.14 & 0.17 & 0.82 & 38606 \\
\hline BMI adults & & & & 16512 \\
\hline Radius matching & 0.59 & 0.82 & 0.71 & 16512 \\
Nearest neighbor (3) & 0.71 & 0.51 & 1.40 & 3861 \\
\hline BMI children & & & & 3861 \\
\hline Radius matching & $\mathbf{0 . 5 0}$ & 0.23 & 2.18 & 2.63 \\
Nearest neighbor (3) & $\mathbf{0 . 3 9}$ & 0.15 & & \\
\hline
\end{tabular}

Source: authors' calculations based on NIDS 2008 and 2010. Coefficients of the average treatment effects on the treated which are significant are highlighted in bold.

\subsection{Discussion: why are social grants failing to improve nutrition outcomes in South Africa, or why is their effect not bigger?}

Empirical evidence points to a paradox in South Africa: self-reported indicators of food insecurity are falling, but indicators of malnutrition are not, or are falling much slower. In the 1990s, responses to the question "In the past year, was there ever a time when you could not afford to feed the children in the household?" in national annual household surveys displayed a steady decline (i.e. improvement), from 41\% in 1994 to 31\% in 1998 (Aliber 2009). In the 2000s, this positive trend continued. Responses in national annual household surveys to a slightly different question - "In the past 12 months, did any child in this household go hungry because there wasn't enough food?" - registered a decline from 24\% in 2002 to $11 \%$ in 2012 (Hendriks 2014).

However, these self-reported indicators are not confirmed when children's nutrition status is measured anthropometrically. The proportion of stunted children in South Africa has fluctuated between $20 \%$ and $30 \%$ since the early 1990 s. The highest rate of $28 \%$ was recorded in 2003 and the lowest rate of $20.9 \%$ was recorded in 2012, but stunting rates were almost identical in 1993 and 2008, at 24.5\% and 24.6\% respectively, and the second lowest rate of $21.6 \%$ was recorded in 1999 (various sources, discussed in Devereux and Waidler, 2016). ${ }^{33}$

Both sets of indicators pre-date the introduction of the Child Support Grant in 1998 and both reveal no clear association between social grants and either food security or nutrition outcomes. Self-reported food security was already improving for children be-

\footnotetext{
${ }^{33}$ These figures are not directly comparable, as different sampling frames and age cohorts were used.
} 
fore the CSG was introduced, and children's nutrition status has not improved significantly since the CSG was introduced. This is surprising for two reasons. Firstly, the number of poor and food insecure children reached by the CSG has increased dramatically since 1998, from just 34,000 children under 7 years old in 1998 to more than 11 million children up to 18 years of age in 2013 (Beukes et al. 2015). In 2012, social grants made the single largest contribution to income in poor households $(42 \%)$, more than wages $(32 \%)$ (Stats SA 2012).

There are several reasons why social grants are failing to significantly reduce malnutrition in South Africa (discussed more in detail in Devereux and Waidler (2017)). First, although social grants in South Africa are relatively generous in comparison with cash transfer programmes in other countries, they are not sufficient to meet nutritional needs, as food prices are rising and social grants are not index-linked (e.g. the annual increment of the Child Support Grant is typically a modest R10 or R20, irrespective of inflation rates). Two other important reasons are dilution among other individuals and other cash needs, and deductions made by service providers, sometimes illegally. Regarding the former, social grants targeted at individuals rather than households face being 'diluted' in two ways: firstly, in terms of who they are spent on, and secondly in terms of what they are spent on. Both forms of dilution can reduce the impacts on the intended beneficiaries. A qualitative evaluation of the CSG confirmed that the CSG cash is used for a diverse range of food and non-food needs by recipients (DSD, SASSA and UNICEF 2011). In terms of the latter, the Department of Social Development (DSD) introduced a payment system for social grants that uses bank accounts and SASSA payment cards - rather than manual disbursement of cash transfers - for several reasons, including: to reduce leakages due to fraud and corruption, and to facilitate financial inclusion of the poor and to reduce their vulnerability to exploitative money-lenders. However, giving bank accounts to beneficiaries also gave opportunities to a range of service providers to make unauthorised deductions from these bank accounts, such as for airtime by cellphone companies and for funeral policies by insurance companies (DSD 2016). Finally, nutrition requires more than food. UNICEF's conceptual framework for the determinants of child malnutrition (UNICEF 1990) identified three 'underlying causes' of child malnutrition: inadequate access to food, inadequate care for children and women, and insufficient health services and unhealthy environment. Only the first of these can be directly attributed to poverty - not enough resources at the individual or household level to acquire adequate food. 


\subsection{Conclusion}

Large numbers of South Africans receive social grants (public transfers) or remittances (private transfers), yet the levels of food insecurity - particularly in terms of nutritional outcomes - are surprisingly high. In this paper we have attempted to estimate the effects of both social grants and remittances on food security and nutrition, as well as to see whether impacts differ between these three transfers (the Child Support Grant, the Older Person's Grant and remittances). While several studies have attempted to estimate the relationship between one of these transfers on nutrition or food security, there is no study comparing all three transfers.

Drawing on the National Income Dynamic Survey (NIDS), South Africa's first nationally representative panel survey, we find significant and positive impacts of the Older Person's Grant and of remittances on the dietary diversity index (DDI), but not of the Child Support Grant. The differences in impacts between the CSG and the OPG respond to differences in the size of the transfers, as well as to the fact that the CSG may be spent not only on children but on needs other than food. Remittances also improve the DDI, which is in line with other findings that remittances in South Africa are spent on food (especially when they are received by poor households).

Regarding nutrition, we find no effect on anthropometry (BMI), by OPG or remittances, which supports other findings - both from South Africa as well as from other countries - that grants and remittances do not have a consistent positive impact on nutrition. On the other hand, however, some estimations point towards a positive effect of the CSG on children' BMI. These positive effects, despite being considerable in magnitude, are not robust to all estimations performed, and therefore we should be cautious in drawing strong conclusions about them. Clearly, the determinants of nutrition status are more complex than food consumption alone, and more attention should be paid to other contributory factors, including child feeding and care practices, hygiene behaviour, sanitation facilities and water quality. Our findings support an emerging consensus that cash transfer programmes "need to be complemented with other nutrition-specific and nutrition-sensitive interventions to maximise effectiveness" (Fenn 2015: 12). 


\section{References}

Abadi, N., Techane, A., Tesfay, G., Maxwell, D., \& Vaitla, B. (2013). The impact of remittances on household food security: A micro perspective from Tigray, Ethiopia. Department of National Resource Economics and Management, Mckelle University, Ethiopia.

Agüero, J., Carter, M. \& Woolard, I. (2007). The impact of unconditional cash transfers on nutrition: the South African Child Support Grant, IPC Working Paper, no. 39. Brasilia: International Poverty Centre.

Ahmed, A., Hoddinott, J., Roy, S., Sraboni, E., Quabili, W. \& Margolies, A. (2016). Which kinds of social safety net transfers work best for the ultra poor in Bangladesh? Operation and impacts of the Transfer Modality Research Initiative. Dhaka: IFPRI and World Food Programme.

Aliber, M. (2009). Exploring Statistics South Africa's national household surveys as sources of information about household-level food security. Agrekon, 48(4): 384-409.

Antón, J. I. (2010). The impact of remittances on nutritional status of children in Ecuador. International Migration Review, 44(2): 269-99.

Ardington, C., Case, A., \& Hosegood, V. (2009). Labor supply responses to large social transfers: Longitudinal evidence from South Africa. American economic journal: Applied economics, 1(1), 22-48.

Babatunde, R.O. \& Martinetti, E.C. (2011). Impact of migrant remittances on food security and nutrition of farming households in Kwara State, Nigeria. Contributed paper for the conference "Shocks in Developing Countries" in Paris, France.

Bailey, S. and Hedlund, K. (2012). The impact of cash transfers on nutrition in emergency and transitional contexts: A review of evidence. London: Overseas Development Institute (ODI).

Barrientos, A. (2013). Social Assistance in Developing Countries. Cambridge: Cambridge University Press.

Bastagli, F., Hagen-Zanker, J., Harman, L., Barca, V., Sturge, G. \& Schmidt, T. (2016). Cash transfers: what does the evidence say? A rigorous review of programme impact and of the role of design and implementation features. London: Overseas Development Institute (ODI).

Berhane, G., Hoddinott, J., Kumar, N. \& Taffesse, A. (2011). The impact of Ethiopia's Productive Safety Nets and Household Asset Building Programme: 2006-2010. Washington DC: International Food Policy Research Institute (IFPRI).

Beukes, R., Jansen, A., Moses, M. \& Yu, D. (2015). Exploring the eligibility criteria of the Child Support Grant and its impact on poverty. Paper presented at the 2015 Biennial Conference of the Economic Society of South Africa. Cape Town: University of Cape Town. 2-4 September.

De Brauw, A. \& Mu, R. (2010). Migration and the overweight and underweight status of children in rural China. Food Policy, 36(1): 88-100.

Brunori, P. \& O'Reilly, M. (2010). Social protection for development: A review of definitions. Paper prepared in the framework of the European Report on Development 2010. Brussels: European Commission.

Case, A. (2001). Does money protect health status? Evidence from South African pensions, NBER Working Paper, No. 8495. Cambridge, MA: National Bureau of Economic Research.

Coetzee, M. (2013). Finding the benefits. Estimating the impacts of the South African Child Support Grant. South African Journal of Economics, 81(3), 427-450.

Collinson, M. A. (2010). Striving against adversity: the dynamics of migration, health and poverty in rural South Africa. Global health action, 3(1), 5080.

Crush, J., William, V., \& Peberdy, S. (2005). Migration in Southern Africa. Global Commission on International Migration.

Davis, J. \& Brazil, N. (2016). Migration, remittances, and nutrition outcomes of left-behind children: a national level quantitative assessment of Guatemala. PLoS One, 11(3): e0152089.

Daidone, S., Pellerano, L., Handa, S. \& Davis, B. (2015). Is graduation from social safety nets possible? Evidence from sub-Saharan Africa, IDS Bulletin, 46(2): 93-102.

Department for International Development (DFID) (2011). Cash Transfers Evidence Paper. London: DFID.

Department of Social Development, South African Social Security Agency and UNICEF (DSD, SASSA and UNICEF) (2012). The South African Child Support Grant Impact Assessment: Evidence from a survey of children, adolescents, and their households. Pretoria: UNICEF South Africa.

Department of Social Development, South African Social Security Agency and UNICEF (DSD, SASSA and UNICEF) (2011). Child Support Grant Evaluation 2010: Qualitative Research Report. Pretoria: UNICEF South Africa. 
Department of Social Development (DSD) (6 May 2016). Statement by the Minister of Social Development, Ms Bathabile Dlamini, on Unauthorised Grant Deductions. www.blacksash.org.za/index.php/media-and-publications/media-statements/1681 [accessed 14 July 2016].

Devereux, S. \& Waidler, J. (2017). Why does malnutrition persist in South Africa despite social grants? Food Security SA Working Paper Series No.001.DST-NRF Centre of Excellence in Food Security, South Africa.

Dinsdale, H., Ridler, C. \& Ells, L. (2011). A simple guide to classifying body mass index in children. Oxford: National Obesity Observatory.

Du Toit, A., \& Neves, D. (2009). Trading on a Grant: Integrating Formal and Informal Social Protection in PostApartheid Migrant Networks. Brooks World Poverty Institute. BWPI Working Paper 75.

Duflo, E. (2003). Grandmothers and granddaughters: Old-age pensions and intra-household allocation in South Africa. World Bank Economic Review, 17 (1): 1-25.

Fenn, B. (2015). Research on Food Assistance for Nutritional Impact (REFANI): Literature Review. London: DFID.

Hagen-Zanker, J. \& Himmelstine, L. (2015). What is known about the differential impacts of cash transfers and remittances on poverty and vulnerability of households? Social Policy and Society, 14(2), pp. 00-14.

Hendriks, S. (2014). Food security in South Africa: Status quo and policy imperatives. Agrekon, 53(2): 1-24.

Hoddinott, J. \& Wiesmann, D. (2010). The impact of conditional cash transfer programs on food consumption, chapter 11 in Adato, M. and Hoddinott, J. (editors) Conditional cash transfers in Latin America. Baltimore: Johns Hopkins University Press.

Hoddinott, J. \& Yohannes, Y. (2002). Dietary diversity as a food security indicator. Washington DC: FANTA.

ILO (2012). Text of the Recommendation Concerning National Floors of Social Protection. Geneva: International Labour Conference.

Isoto, R. E., \& Kraybill, D. S. (2017). Remittances and household nutrition: evidence from rural Kilimanjaro in Tanzania. Food Security, 9(2), 239-253.

Jacobs, W., \& Du Plessis, D. J. (2016). A spatial perspective of the patterns and characteristics of main-and substream migration to the Western Cape, South Africa. Urban Forum, 27(2), 167-185.

Johnson, U. \& Toole, D. (1991). Household food security and nutrition. A conceptual analysis. UNICEF, New York (mimeo).

Maitra, P. \& Ray, R. (2003). The effect of transfers on household expenditure patterns and poverty in South Africa. Journal of Development Economics, 71(1), 23-49.

Manley, J., Gitter, S. \& Slavchevska, V. (2012). How effective are cash transfer programmes at improving nutritional status? A rapid evidence assessment of programmes' effects on anthropometric outcomes. London: EPPICentre, Social Science Research Unit, Institute of Education, University of London.

Maxwell, D., Ahiadeke, C., Levin, C., Armar-Klemesu, M., Zakariah, S. \& Lamptey, G. (1999). Alternative food security indicators: revisiting the frequency and severity of coping strategies. Food Policy, 24(4), 411-429.

Miller, C., Tsoka, M. \& Reichert, K. (2011). Impacts on children of cash transfers in Malawi, chapter 6 in Handa, S., Devereux, S and Webb, D. (editors), Social Protection for Africa's Children. London: Routledge.

Nobles, J. E. (2007). The effects of Mexican migration on sending families. ProQuest.

Ponce, J., Olivie, I. \& Onofa, M. (2011). The role of international remittances in health outcomes in Ecuador: prevention and response to shocks. International Migration Review, 45(3): 727-45.

Posel, D. \& Casale, D. (2006). Internal migration and household poverty in post-apartheid South Africa. In Poverty and Policy in Post-Apartheid South Africa, edited by R. Kanbur and H. Bhorat. Pretoria: Human Sciences Research Council Press, pp. 351-365.

Posel, D. R. (2001). Intra-family transfers and income pooling. South African Journal of Economics, 69(3), 501-528.

Roelen, K., Devereux, S., Abdulai, A., Martorano, B., Palermo, T. \& Ragno, L. (2017). How to make 'cash plus' work: linking cash transfers to services and sectors. Innocenti Working Paper, 2017-10. Florence: UNICEF Office of Research.

Ryan, J. \& Leibbrandt, M. (2015). Multidimensional food insecurity measurement. SALDRU Working Paper Number 160 .

SASSA (South African Social Security Agency) (2016). Fact sheet: Issue no 4 of 2016. A statistical summary of social grants in South Africa.www.sassa.gov.za/index.php/statistical-reports [accessed 16 August 2016].

Seidenfeld, D., Handa, S., Tembo, S., Michelo, S., Harland Scott, C. \& Prencipe, L. (2014). The impact of an unconditional cash transfer on food security and nutrition: The Zambia Child Grant Programme. IDS Special Collection, September: $36-42$. 


\section{Chapter 3}

Sienaert, A. (2008). The labour supply effects of the South African state old age pension: Theory, evidence and implications. A Southern Africa Labour and Development Research Unit. Working Paper Number 20. Cape Town: SALDRU, University of Cape Town

Standish-White, J. \& Finn, A. (2015). Unconditional cash transfers and children's educational outcomes: Evidence from the old age pension program in South Africa. A Southern Africa Labour and Development Research Unit Working Paper Number 147. Cape Town: SALDRU, University of Cape Town

Statistics South Africa (Stats SA) (2012).

Steyn, N.P., Nel, J.H., Nantel, G., Kennedy, G. and Labadarios, D. (2006). Food variety and dietary diversity scores in children: are they good indicators of dietary adequacy? Public Health Nutrition, 9(5): 644-650.

Thomson, R. J. \& Posel, D. B. (2002). The Management of Risk by Burial Societies in South Africa. South African Actuarial Journal, 2: 83-128.UNICEF (1990). Strategy for Improved Nutrition of Children and Women in Developing Countries. Policy Review Paper, E/ICEF/1990/1.6. New York: UNICEF.

UNICEF (1990). Strategy for Improved Nutrition of Children and Women in Developing Countries. Policy Review Paper, E/ICEF/1990/1.6. New York: UNICEF.

Waidler, J. (2016). On the fungibility of public and private transfers: a mental accounting approach. UNU-MERIT Working Paper 2016-60.

Waidler, J., Hagen-Zanker, J., Gassmann, F., \& Siegel, M. (2017). Do remittances and social assistance have different impacts on expenditure patterns of recipient households? The Moldovan Case. Migration and Development, 6(3), 355-375.

World Bank (2012). Social Protection and Labor Strategy 2012-2022: Resilience, Equity, and Opportunity. Washington DC: World Bank.

Woolard, I. \& Klasen, S. (2004). Determinants of Income Mobility and Household Poverty Dynamics in South Africa. Bonn: IZA Discussion Paper. 
Social Grants, Remittances, and Food Security: Does the Source of Income Matter?

\section{Appendix 3}

Table A3.1: Descriptive statistics of the variables used in the analysis

\begin{tabular}{|c|c|c|c|c|}
\hline Variable & Mean & Standard deviation & Minimum & Maximum \\
\hline Dietary diversity index & 9.41 & 2.34 & 1 & 12 \\
\hline BMI adults & 26.19 & 6.55 & 15.1 & 50 \\
\hline BMI children (zbmi) & 0.03 & 1.4 & -4.97 & 4.99 \\
\hline $\log$ of CSG & 2.01 & 2.15 & 0 & 7.22 \\
\hline Log of OPG & 1.34 & 2.29 & 0 & 7.09 \\
\hline Log of remittances & 0.48 & 1.42 & 0 & 10.68 \\
\hline Number of adults & 3.75 & 2.24 & 0 & 37 \\
\hline Number of children & 2.01 & 1.80 & 0 & 12 \\
\hline Urban formal & 0.39 & 0.49 & 0 & 1 \\
\hline Rural & 0.55 & 0.50 & 0 & 1 \\
\hline Urban informal & 0.06 & 0.25 & 0 & 1 \\
\hline No education & 0.23 & 0.42 & 0 & 1 \\
\hline Years 1-4 & 0.17 & 0.37 & 0 & 1 \\
\hline Years 5-7 & 0.17 & 0.38 & 0 & 1 \\
\hline Years 7-12 & 0.27 & 0.44 & 0 & 1 \\
\hline Metrics & 0.16 & 0.37 & 0 & 1 \\
\hline
\end{tabular}

Source: authors' calculations; NIDS 2008 and 2010. 
Chapter 3

Table A3.2: Effect of transfers on Dietary Diversity Index

\begin{tabular}{|c|c|c|c|c|}
\hline & \multicolumn{3}{|c|}{ Fixed effects } & \multirow{3}{*}{$\begin{array}{c}\text { Ordered probit } \\
\text { DDI } \\
\text { Whole sample }\end{array}$} \\
\hline & DDI & DDI & DDI & \\
\hline & Whole sample & African sample & Recipients & \\
\hline \multirow[t]{2}{*}{ Log of pc CSG } & 0.02 & $0.04^{*}$ & $0.06^{+}$ & $-0.02^{* *}$ \\
\hline & $(0.01)$ & $(0.02)$ & $(0.03)$ & $(0.00)$ \\
\hline \multirow[t]{2}{*}{ Log of pc OAP } & $0.11^{* *}$ & $0.12^{* *}$ & $0.20^{* *}$ & $0.02^{* *}$ \\
\hline & $(0.02)$ & $(0.02)$ & $(0.03)$ & $(0.00)$ \\
\hline \multirow[t]{2}{*}{ Log of remittances } & $0.08^{* *}$ & $0.09^{* *}$ & $0.07^{* *}$ & $0.04^{* *}$ \\
\hline & $(0.02)$ & $(0.02)$ & $(0.02)$ & $(0.00)$ \\
\hline \multirow[t]{2}{*}{ Number of adults } & $0.08^{* *}$ & $0.07^{* *}$ & $0.04^{+}$ & $0.02^{* *}$ \\
\hline & $(0.02)$ & $(0.02)$ & $(0.02)$ & $(0.00)$ \\
\hline \multirow[t]{2}{*}{ Number of children } & $-0.07^{*}$ & $-0.08^{*}$ & $-0.12^{* *}$ & $0.01^{* *}$ \\
\hline & $(0.03)$ & $(0.03)$ & $(0.05)$ & $(0.00)$ \\
\hline \multirow[t]{2}{*}{ Urban formal } & $1.07^{* *}$ & $1.34^{* *}$ & $2.69^{* *}$ & $0.39^{* *}$ \\
\hline & $(0.23)$ & $(0.22)$ & $(0.41)$ & $(0.02)$ \\
\hline \multirow[t]{2}{*}{ Urban informal } & $1.24^{* *}$ & $1.42^{* *}$ & 0.99 & $0.26^{* *}$ \\
\hline & $(0.30)$ & $(0.30)$ & $(0.71)$ & $(0.03)$ \\
\hline \multicolumn{5}{|c|}{ Maximum level of education in the household } \\
\hline \multirow[t]{2}{*}{ Years 1-4 } & 0.12 & 0.12 & -0.08 & 0.03 \\
\hline & $(0.13)$ & $(0.14)$ & $(0.18)$ & $(0.02)$ \\
\hline \multirow[t]{2}{*}{ Years 5-7 } & 0.17 & 0.18 & -0.22 & 0.02 \\
\hline & $(0.17)$ & $(0.19)$ & $(0.24)$ & $(0.02)$ \\
\hline \multirow[t]{2}{*}{ Years 7-12 } & 0.22 & 0.26 & -0.14 & $0.08^{* *}$ \\
\hline & $(0.22)$ & $(0.24)$ & $(0.30)$ & $(0.02)$ \\
\hline \multirow[t]{2}{*}{ Metrics } & 0.18 & 0.14 & -0.14 & $0.29^{* *}$ \\
\hline & $(0.26)$ & $(0.29)$ & $(0.37)$ & $(0.02)$ \\
\hline \multirow[t]{2}{*}{ Year 2008} & -0.05 & $-0.10^{*}$ & $-0.20^{* *}$ & $-0.13^{* *}$ \\
\hline & $(0.04)$ & $(0.05)$ & $(0.06)$ & $(0.01)$ \\
\hline \multirow[t]{2}{*}{ Constant } & $8.45^{* *}$ & $8.03^{* *}$ & $7.89^{* *}$ & \\
\hline & $(0.23)$ & $(0.23)$ & $(0.35)$ & \\
\hline Observations & 38936 & 32312 & 24731 & 38711 \\
\hline Within $R^{2}$ & 0.01 & 0.02 & 0.04 & \\
\hline
\end{tabular}

Standard errors in parentheses; ${ }^{+} p<0.1,{ }^{*} p<0.05,{ }^{* *} p<0.01$. Panel weights are used, except in the case of the last specification as weights are not allowed for random effects models.

Random effects ordered probit also controls for race, location (province), housing and living conditions, number of household members employed, and age of the eldest household member. 
Social Grants, Remittances, and Food Security: Does the Source of Income Matter?

Table A3.3: Effect of transfers on adult BMI

\begin{tabular}{|c|c|c|c|c|c|}
\hline & \multicolumn{3}{|c|}{ Fixed effects } & \multirow{2}{*}{$\begin{array}{c}\text { Random effects } \\
\text { Whole sample }\end{array}$} & \multirow{2}{*}{$\begin{array}{c}\text { Mundlak } \\
\text { Whole sample }\end{array}$} \\
\hline & Whole sample & African sample & Recipients & & \\
\hline \multirow[t]{2}{*}{ Log of pc CSG } & -0.03 & -0.04 & $0.21^{* *}$ & 0.00 & 0.02 \\
\hline & $(0.04)$ & $(0.04)$ & $(0.07)$ & $(0.02)$ & $(0.03)$ \\
\hline \multirow[t]{2}{*}{ Log of pc OAP } & 0.02 & 0.01 & $0.20^{* *}$ & $-0.07^{* *}$ & 0.02 \\
\hline & $(0.04)$ & $(0.04)$ & $(0.06)$ & $(0.03)$ & $(0.03)$ \\
\hline \multirow[t]{2}{*}{ Log of remittances } & -0.02 & -0.05 & -0.02 & -0.03 & -0.04 \\
\hline & $(0.03)$ & $(0.03)$ & $(0.05)$ & $(0.03)$ & $(0.03)$ \\
\hline \multirow[t]{2}{*}{ Number of adults } & -0.05 & -0.03 & $0.08^{+}$ & $-0.09^{* *}$ & -0.01 \\
\hline & $(0.04)$ & $(0.04)$ & $(0.05)$ & $(0.02)$ & $(0.03)$ \\
\hline \multirow[t]{2}{*}{ Number of children } & $-0.15^{*}$ & $-0.16^{*}$ & $-0.25^{*}$ & $-0.10^{* *}$ & $-0.25^{* *}$ \\
\hline & $(0.08)$ & $(0.08)$ & $(0.10)$ & $(0.04)$ & $(0.04)$ \\
\hline \multirow[t]{2}{*}{ Urban formal } & -0.42 & -0.32 & 1.17 & $1.07^{* *}$ & 0.54 \\
\hline & $(0.49)$ & $(0.53)$ & $(1.00)$ & $(0.15)$ & $(0.45)$ \\
\hline \multirow[t]{2}{*}{ Urban informal } & 0.39 & 0.44 & 0.01 & $0.71^{* *}$ & 0.95 \\
\hline & $(0.69)$ & $(0.70)$ & $(1.54)$ & $(0.25)$ & $(0.66)$ \\
\hline \multicolumn{6}{|c|}{ Maximum level of education in the bousehold } \\
\hline \multirow[t]{2}{*}{ Years 1-4 } & $-1.37^{*}$ & -0.94 & -1.50 & 0.33 & $-1.24^{*}$ \\
\hline & $(0.70)$ & $(0.77)$ & $(0.99)$ & $(0.25)$ & $(0.58)$ \\
\hline \multirow[t]{2}{*}{ Years 5-7 } & -0.38 & -0.20 & -0.47 & -0.29 & 0.14 \\
\hline & $(0.72)$ & $(0.76)$ & $(0.76)$ & $(0.21)$ & $(0.69)$ \\
\hline \multirow[t]{2}{*}{ Years 7-12 } & 0.94 & 1.02 & -0.01 & $-1.07^{* *}$ & 1.06 \\
\hline & $(0.75)$ & $(0.79)$ & $(0.80)$ & $(0.19)$ & $(0.71)$ \\
\hline \multirow[t]{2}{*}{ Metrics } & $1.54^{*}$ & $1.53^{+}$ & 0.86 & -0.20 & $1.87^{*}$ \\
\hline & $(0.78)$ & $(0.83)$ & $(0.85)$ & $(0.21)$ & $(0.75)$ \\
\hline \multirow[t]{2}{*}{ Year 2008} & $-0.76^{* *}$ & $-0.78^{* *}$ & $-0.75^{* *}$ & $-0.88^{* *}$ & $-0.65^{* *}$ \\
\hline & $(0.11)$ & $(0.11)$ & $(0.16)$ & $(0.06)$ & $(0.07)$ \\
\hline \multirow[t]{2}{*}{ Constant } & $26.71^{* *}$ & $26.43^{* *}$ & $25.65^{* *}$ & $29.09^{* *}$ & $28.90^{* *}$ \\
\hline & $(0.69)$ & $(0.72)$ & $(0.86)$ & $(0.31)$ & $(0.88)$ \\
\hline Observations & 16700 & 14233 & 10132 & 16700 & 16700 \\
\hline Within $R^{2}$ & 0.03 & 0.04 & 0.06 & & \\
\hline Overall $R^{2}$ & & & & 0.16 & 0.17 \\
\hline
\end{tabular}

Standard errors in parentheses; ${ }^{+} p<0.1,{ }^{*} p<0.05,{ }^{* *} p<0.01$; Panel weights are used, except in the case of the last two specifications as weights are not allowed in random effects or Mundlak models. Random and Mundlak estimations also control for race, location (province), housing and living conditions, number of household members employed, and age of the eldest household member. 
Chapter 3

Table A3.4: Effect of transfers on children BMI

\begin{tabular}{|c|c|c|c|c|c|}
\hline & \multicolumn{3}{|c|}{ Fixed effects } & \multirow{2}{*}{$\begin{array}{c}\text { Random effects } \\
\text { Whole sample }\end{array}$} & \multirow{2}{*}{$\begin{array}{c}\text { Mundlak } \\
\text { Whole sample }\end{array}$} \\
\hline & Whole sample & African sample & Recipients & & \\
\hline \multirow[t]{2}{*}{ Log of pc CSG } & -0.01 & -0.01 & 0.00 & -0.00 & 0.00 \\
\hline & $(0.02)$ & $(0.02)$ & $(0.06)$ & $(0.01)$ & $(0.02)$ \\
\hline \multirow[t]{2}{*}{ Log of pc OAP } & 0.05 & $0.06^{+}$ & 0.06 & 0.01 & 0.03 \\
\hline & $(0.03)$ & $(0.03)$ & $(0.04)$ & $(0.01)$ & $(0.02)$ \\
\hline Log of remittances & $\begin{array}{c}0.01 \\
(0.02)\end{array}$ & $\begin{array}{c}0.01 \\
(0.02)\end{array}$ & $\begin{array}{l}-0.01 \\
(0.02)\end{array}$ & $\begin{array}{c}0.00 \\
(0.02)\end{array}$ & $\begin{array}{l}-0.01 \\
(0.02)\end{array}$ \\
\hline \multirow[t]{2}{*}{ Number of adults } & 0.02 & 0.01 & 0.03 & 0.01 & 0.02 \\
\hline & & & & & \\
\hline \multirow[t]{2}{*}{ Number of children } & 0.03 & 0.01 & 0.01 & $-0.05^{* *}$ & -0.05 \\
\hline & $(0.04)$ & $(0.04)$ & $(0.05)$ & $(0.02)$ & $(0.04)$ \\
\hline \multirow[t]{2}{*}{ Urban formal } & $0.83^{+}$ & $0.91^{+}$ & 0.36 & $0.20^{*}$ & 0.55 \\
\hline & $(0.50)$ & $(0.51)$ & $(0.40)$ & $(0.08)$ & $(0.54)$ \\
\hline \multirow[t]{2}{*}{ Urban informal } & -0.76 & -0.69 & $-0.62^{+}$ & 0.18 & -0.07 \\
\hline & $(0.48)$ & $(0.48)$ & $(0.36)$ & $(0.12)$ & $(0.56)$ \\
\hline \multicolumn{6}{|c|}{ Maximum level of education in the bousehold } \\
\hline \multirow[t]{2}{*}{ Years 1-4 } & 0.03 & 0.03 & -0.02 & 0.07 & 0.10 \\
\hline & $(0.12)$ & $(0.13)$ & $(0.15)$ & $(0.08)$ & $(0.11)$ \\
\hline \multirow[t]{2}{*}{ Years 5-7 } & 0.11 & 0.13 & 0.05 & 0.13 & 0.19 \\
\hline & $(0.17)$ & $(0.19)$ & $(0.23)$ & $(0.09)$ & $(0.16)$ \\
\hline \multirow[t]{2}{*}{ Years 7-12 } & 0.30 & 0.44 & 0.35 & 0.25 & $0.47^{+}$ \\
\hline & $(0.26)$ & $(0.28)$ & $(0.31)$ & $(0.18)$ & $(0.27)$ \\
\hline \multirow[t]{2}{*}{ Metrics } & 0.02 & 0.04 & $0.43^{*}$ & 0.27 & 0.23 \\
\hline & $(0.23)$ & $(0.23)$ & $(0.21)$ & $(0.92)$ & $(1.14)$ \\
\hline \multirow[t]{2}{*}{ Year 2008} & -0.06 & -0.03 & -0.09 & -0.02 & 0.04 \\
\hline & $(0.06)$ & $(0.07)$ & $(0.07)$ & $(0.05)$ & $(0.06)$ \\
\hline \multirow[t]{2}{*}{ Constant } & -0.39 & -0.25 & -0.25 & $0.27^{+}$ & 0.35 \\
\hline & $(0.28)$ & $(0.27)$ & $(0.36)$ & $(0.16)$ & $(0.23)$ \\
\hline Observations & 3908 & 3475 & 2857 & 3798 & 3798 \\
\hline Within $R^{2}$ & 0.02 & 0.02 & 0.02 & & \\
\hline Overall & & & & 0.08 & 0.06 \\
\hline
\end{tabular}

Standard errors in parentheses; ${ }^{+} p<0.1,{ }^{*} p<0.05,{ }^{* *} p<0.01$; Panel weights are used, except in the case of the last two specifications as weights are not allowed for random effects and Mundlak models. Random and Mundlak estimations also control for race, location (province), housing and living conditions, number of household members employed, age of the eldest household member and characteristics of the child that can influence their nutritional status (whether the mother is alive, and health status); all these variables have the expected sign and most of them are statistically significant. 
Social Grants, Remittances, and Food Security: Does the Source of Income Matter?

Table A3.5: Conditional logits - Odds ratios of being food secure, not underweight, not overweight

\begin{tabular}{|c|c|c|c|c|}
\hline & Food secure (DDI) & $\begin{array}{l}\text { Food secure } \\
\text { (expenditure) }\end{array}$ & Not underweight & Not overweight \\
\hline \multirow[t]{2}{*}{ Log of pc CSG } & 1.02 & 1.00 & 0.97 & 1.01 \\
\hline & $(0.01)$ & $(0.01)$ & $(0.04)$ & $(0.02)$ \\
\hline \multirow[t]{2}{*}{ Log of pc OAP } & $1.05^{* *}$ & 1.02 & 1.03 & 1.02 \\
\hline & $(0.01)$ & $(0.01)$ & $(0.04)$ & $(0.03)$ \\
\hline \multirow[t]{2}{*}{ Log of remittances } & $1.05^{* *}$ & 1.01 & $1.08^{+}$ & 0.98 \\
\hline & $(0.01)$ & $(0.01)$ & $(0.05)$ & $(0.03)$ \\
\hline \multirow[t]{2}{*}{ Number of adults } & $1.04^{* *}$ & $1.03^{*}$ & $0.92^{*}$ & 0.99 \\
\hline & $(0.01)$ & $(0.01)$ & $(0.04)$ & $(0.03)$ \\
\hline \multirow[t]{2}{*}{ Number of children } & $0.90^{* *}$ & $1.11^{* *}$ & 1.05 & $0.86^{*}$ \\
\hline & $(0.02)$ & $(0.03)$ & $(0.08)$ & $(0.05)$ \\
\hline \multirow[t]{2}{*}{ Urban formal } & $1.95^{* *}$ & $1.91^{* *}$ & $0.44^{+}$ & 0.80 \\
\hline & $(0.31)$ & $(0.33)$ & $(0.22)$ & $(0.25)$ \\
\hline \multirow[t]{2}{*}{ Urban informal } & 1.40 & $1.69^{+}$ & 1.02 & 0.92 \\
\hline & $(0.36)$ & $(0.46)$ & $(1.10)$ & $(0.44)$ \\
\hline \multicolumn{5}{|c|}{ Maximum level of education in the household } \\
\hline \multirow[t]{2}{*}{ Years 1-4 } & 1.01 & 1.06 & 0.98 & 0.68 \\
\hline & $(0.09)$ & $(0.11)$ & $(1.25)$ & $(0.36)$ \\
\hline \multirow[t]{2}{*}{ Years 5-7 } & 1.12 & $1.31^{+}$ & 0.14 & 1.54 \\
\hline & $(0.14)$ & $(0.19)$ & $(0.20)$ & $(0.99)$ \\
\hline \multirow[t]{2}{*}{ Years 7-12 } & 1.08 & $1.51^{*}$ & $0.05^{+}$ & 2.45 \\
\hline & $(0.17)$ & $(0.28)$ & $(0.08)$ & $(1.60)$ \\
\hline \multirow[t]{2}{*}{ Metrics } & 0.90 & 1.29 & $0.04^{*}$ & $4.07^{*}$ \\
\hline & $(0.19)$ & $(0.32)$ & $(0.06)$ & $(2.81)$ \\
\hline \multirow[t]{2}{*}{ Year 2008} & 1.03 & $1.32^{* *}$ & $1.35^{* *}$ & $0.63^{* *}$ \\
\hline & $(0.03)$ & $(0.05)$ & $(0.13)$ & $(0.04)$ \\
\hline Observations & 15480 & 11734 & 1652 & 3842 \\
\hline Pseudo $R^{2}$ & 0.007 & 0.019 & 0.067 & 0.064 \\
\hline
\end{tabular}

Exponentiated coefficients; Standard errors in parentheses; ${ }^{+} p<0.1,{ }^{*} p<0.05,{ }^{* *} p<0.01$ 


\section{Chapter 3}

Table A3.6: Probit estimates: probability of receiving the Child Support Grant

\begin{tabular}{lc}
\hline & Lives in a CSG recipient household \\
\hline Urban formal & $-0.06^{* *}$ \\
Urban informal & $(0.01)$ \\
& -0.00 \\
& $(0.01)$
\end{tabular}

Race (ref category: Black)

Coloured

Other (Asian or White)

Child in the household

age 13-16 years old

Child in the household

age 9-12 years old

$0.14^{* *}$

Child in the household

age $5-8$ years old

$0.18^{* *}$

Child in the household age 1-4 years old

$0.23^{* *}$

(0.00)

Housing

$-0.04^{* *}$

\begin{tabular}{lc} 
& $(0.01)$ \\
\hline Observations & 38612 \\
Pseudo $R^{2}$ & 0.16 \\
\hline
\end{tabular}

Standard errors in parentheses; ${ }^{+} p<0.1,{ }^{*} p<0.05,{ }^{* *} p<0.01$. Coefficients are expressed as average marginal effects.

Table A3.7: Matching quality

\begin{tabular}{lllll}
\hline Sample & Ps R $\mathrm{R}^{2}$ & $\mathrm{p}>$ chi2 & Mean bias & Median bias \\
\hline Unmatched & 0.161 & 0.00 & 34.3 & 33.6 \\
Matched & 0.00 & 0.65 & 0.4 & 0.2 \\
\hline
\end{tabular}

Note: Estimates above show that the matching was done correctly, as the $\mathrm{R}^{2}$ of the model is almost zero and much smaller that the $\mathrm{R}^{2}$ before the matching. Moreover, the P-value of the likelihood-ratio test after matching is higher than 0.1 (i.e. no joint significance of all covariates after matching), as well as the standardised bias is highly reduced after matching and is less than $3 \%$. 
Social Grants, Remittances, and Food Security: Does the Source of Income Matter? 
Chapter 4

Chapter 4

From Cradle to Grave?

Chapter

\section{From Cradle to Grave? Poverty, Social Assistance, and Subjective Well-being in Kyrgyzstan}

"Those who don't feel sorry about the collapse of the Soviet Union have no beart, but those who

think that it may be restored have no brain"

Elderly man in Kyrgyzstan

(Narayan et al. 2000, p.40)

"To be poor is not shameful when we are all poor"

64 years-old man from a Chinese village

(Li et al. 2016, p.7) 
From Cradle to Grave? 


\subsection{Introduction}

Despite a high number of studies looking at objective measures of well-being, subjective well-being has received less attention in the impact evaluation literature when estimating the effects of social assistance. Due to the fact that objective measures of well-being fail to capture fundamental aspects of life such as overall life satisfaction, there is growing consensus on the importance of measuring well-being through subjective indicators (Stiglitz, Sen and Fitoussi 2009). There is also a growing literature stating that several dimensions of subjective wellbeing (lack of stress, happiness, satisfaction with life) have an instrumental value, as they are positively related with outcomes such as productivity, decision-making, and educational and health outcomes (Attah et al. 2016).

The mechanisms by which social assistance transfers affect subjective well-being are likely to differ from the ones affecting objective indicators of well-being. One can expect increased levels of subjective well-being if social assistance transfers reduce poverty as well as address the negative mechanisms associated with poverty, such as stress, mental health problems or shame (Haushofer and Fehr 2014; Roelen 2017). However, if receiving social assistance leads to stigma or shame, subjective well-being could be reduced despite the increase in financial resources, and, hence, objective well-being. Concepts such as poverty and stigma may have different connotations in different contexts and may depend, for instance, on the type of political regime (e.g. communism or capitalist) (Barr 1994), or the extent of inequality in a country (Li et al. 2016).

Drawing on three rounds of the Life in Kyrgyzstan survey (LiK), this paper studies the relationship between social assistance and subjective well-being in Kyrgyzstan. Under the Soviet Union, the state bore the responsibility of providing social benefits in the same way as it controlled the whole economy (Atkinson and Micklewright 1992). Hence the popular say "From Cradle to Grave", an expectation and acceptance that the State will provide support to its citizens throughout their life. At the same time, most of the benefits such as pensions or family benefits were considered income support, meaning that they aimed to complement labour income. Social assistance, understood as transfers targeted to people living in poverty, was highly residual. As Atkinson and Micklewright (1992) describe, "social assistance was rudimentary, a last resort due to the denial of existence of poverty... benefits were stigmatising and handed only to the deserving poor" (pp. 220-221). In the Soviet period, poverty was seen as a pathology and, to a big extent, a responsibility directly attributed to the individual suffering from poverty (Barr 1994).

Despite the large number of studies looking at the effects of social assistance programmes on objective measures of well-being, such as monetary poverty, health, or education (see Bastagli et al. (2016) for a summary of impact evaluations), the relationship between social assistance and subjective well-being remains under-explored. Moreover, 
this topic has not been researched in a former Soviet country before and, consequently, findings could be informative for other countries that share a similar history. Three measures of well-being are studied: overall life satisfaction, individual's perception of the economic situation of the household compared to one year before, and the individual's subjective expectation of the economic situation of the household in the future. This paper contributes to the literature in the following ways: in addition to adding new evidence on the relationship between social assistance and subjective well-being, this paper reduces potential endogeneity by including control variables that are usually unobserved, such as an index for personality traits, and relying on matching and panel data techniques to correct for unobserved heterogeneity.

The rest of the paper is structured as follows: Section 4.2 discusses the theoretical framework and reviews the literature on the impact of social assistance on subjective wellbeing. Section 4.3 introduces the case study, Kyrgyzstan; while Section 4.4 presents the methodology. Section 4.5 explains the data and descriptive statistics of the sample used in the analysis, and Section 4.6 presents the regression results of the relationship between social assistance and subjective well-being. Finally, Section 4.7 concludes.

\subsection{Analytical framework}

Although, historically, happiness has been considered by philosophers the ultimate motivation for human action (Diener 1984), theoretical and empirical work on subjective well-being only started after the $70 \mathrm{~s} .{ }^{34}$ Subjective well-being includes concepts such as life satisfaction, happiness, and positive affect. In the literature, it is usually defined as "people's multidimensional evaluation of their lives, including cognitive judgements of life satisfaction as well as affective evaluations of moods and emotions" (Eid and Diener 2004, 63). There are examples of studies looking at subjective well-being in different fields: The Easterlin's paradox (1974), which argues that an increase in income does not necessarily lead to higher levels of happiness, is well-known in the economic literature. In psychology, Maslow placed happiness and subjective well-being as an ultimate goal in life (Maslow 1970). In the poverty literature, the participatory poverty assessments or "voices of the poor" which emerged at the end of the $20^{\text {th }}$ century also raised the importance of subjective well-being. Participatory poverty assessments confirm the idea that well-being is comprised of many different dimensions aside material well-being, including family, children, livelihood, peace, dignity, and respect (Narayan et al. 2000). Poor people are often caught in several deprivations and the psychological consequences of it are intense and painful (Narayan et al. 2000).

\footnotetext{
${ }^{34}$ Happiness and subjective well-being are often used interchangeably in the psychology, sociology and economic literature (see, for example, Stewart (2014), Bartram (2013), or Diener (1984)).
} 
Happiness has many determinants besides income, such as personality traits, environmental conditions, or social relations (Handa et al. 2014) In fact, a highly-cited paper on the topic suggests that raising the incomes of all does not increase the happiness of all (Easterlin 1995). At the same time, many authors have shown that an improved economic situation can positively affect subjective well-being (Deaton, 2008; Stevenson and Wolfers 2008), and this relationship is expected to be stronger in developing countries (Handa et al. 2014). The reason is that the quality of life of poor people highly depends on the satisfaction of basic needs (Handa et al. 2014).

Moreover, and despite improvements in subjective well-being are not the primary objective of social protection programmes, subjective well-being has an instrumental value, as it has been found to be positively related with outcomes such as productivity, decision-making, and educational and health outcomes (Attah et al. 2016). This means that social protection can impact longer term outcomes through an intermediate effect on subjective well-being.

Despite the importance of measuring the subjective well-being of individuals, the relationship between government (social assistance) transfers and subjective well-being has received little attention in the literature. After all, social transfers aim to increase objective well-being in the first place by increasing the financial resources of households and individuals and reduce monetary poverty. There is a large number of studies that have found positive effects of social transfers on different aspects of objective well-being (see Bastagli et al. 2016 for a summary of impact evaluations), yet the relationship between social transfers and subjective well-being remains understudied. ${ }^{35}$

One can expect increased levels of subjective well-being if social assistance transfers reduce poverty as well as address negative mechanisms associated with poverty. For instance, an increase in material resources often leads to improvements in subjective wellbeing, especially in poor countries (Deaton 2008; Stevenson and Wolfers 2008). One of the reasons is that social assistance, through its effects on poverty reduction, can address some of the negative consequences of poverty, such as stress, mental health problems or shame (Haushofer and Fehr 2014; Roelen 2017). However, if receiving social assistance leads to stigma or shame, subjective well-being could be reduced despite the increase in financial resources, and, hence, objective well-being. ${ }^{36}$ Stigma and shame are

\footnotetext{
35 Objective well-being refers to the satisfaction of certain recognised (and objectively defined) needs or, looked at it the other way around, "poverty is having less than an objectively defined, absolute minimum" (Hagenaars and De Vos 1988).

${ }^{36}$ Shame is an "affect or emotion that occurs in response to social rejection or perceived loss of social attractiveness that threaten one's self-esteem and sense of belonging" (Roelen 2017, p.7, from Van Vliet 2008), whereas stigma is defined as "a strong feeling of disapproval that most people in a society have about something, especially when this is unfair" (Cambridge English dictionary). Therefore, we can think of stigma as a social phenomenon while shame resides in the person. Moreover, public stigma can lead to self-stigma, or the 'potential internalisation of the negative beliefs and feelings associated with the stigmatised condition' (Bos et al. 2013: 2) (in Roelen 2017, p.8).
} 
closely related concepts, as the former can act as a mechanism leading to the latter (Roelen 2017). The psychology literature has identified several negative consequences of shame, such as avoiding responsibilities, self-oriented distress, anger and depression (Tangney, Stuewig and Mashek 2007, in Teroni and Bruun (2011)).

Whether or not social assistance is associated with stigma depends on the type of social assistance, the context, and the targeting method (Li and Walker 2016). Receiving a social pension is socially accepted in most countries, and the same applies to child benefits if they are universal. Many times, however, programs are not supported by the population. For instance, when programs are narrowly targeted to specific groups or use community based targeting, the stigma attached to benefit receipt is likely to be higher. In some occasions, stigmatisation and shame occur as a consequence of how the programme is implemented. For example, the publication of names or having to queue in a public space to receive the transfer can have stigmatising effects (Roelen 2017). The same occurs with community verification processes, where a community leader has to decide if someone deserves the benefit or not, such as China's dibao scheme (Yan 2014). Overall, the level of stigmatisation will highly depend on the extent to which social assistance recipients are perceived as legitimate claimants of entitlements rather than beneficiaries of government generosity (Lister 2004).

There are two studies looking at the effects of social pensions on subjective well-being. Lloyd-Sherlock et al. (2012) find that pensions in Brazil increase overall levels of satisfaction with household well-being. In a similar vein, Moller-Radloff (2012) finds that pensions in South Africa lead to higher elderly well-being and overall satisfaction. The positive relationship between pension receipt and life satisfaction is somehow expected given the fact that pensions are socially accepted and are mainly an income replacement when individuals reach retirement age. With regard to poverty-targeted benefits, however, evidence is mixed. Two different unconditional cash transfer programs in Kenya increase subjective well-being levels (Haushofer and Shapiro 2013; Handa et al. 2014), as they have positive effects on indicators such as positive feelings and satisfaction with life, as well as on future perceptions of quality of life. This is not the case with the conditional cash transfers (CCT) programme in Colombia 'Familias en acción'. Galama, Morgan, and Saavedra (2017), show that the program has positive effects on many aspects of well-being, including the level of satisfaction with income. However, levels of self-reported life satisfaction are not found to improve as a result of the transfers.

The inconclusive evidence regarding poverty targeted transfers can be attributed to the differences between programmes and contexts in which they operate. This paper adds to the limited existing evidence of the effects of social assistance on subjective well-being 
by looking at a new case study, Kyrgyzstan, which differs from previous ones not only in terms of the design of its social protection system but also with respect to its Soviet's past, where poverty and social assistance had different connotations than in other contexts.

\subsection{Social assistance and poverty in Kyrgyzstan}

The Kyrgyz Republic, or Kyrgyzstan, is a land-locked and mountainous country, considered one of the poorest in Central Asia with a Gross National Income (GNI) per capita of $\$ 1100$ (World Bank 2017). After becoming independent in 1991, poverty rates increased considerably due to the transition to the market economy and consequent decline of industrial activity and jobs. Despite poverty decreasing since the beginning of the $21^{\text {st }}$ century, a third of the Kyrgyz population is considered poor based on the national poverty line (World Bank 2017).

During Soviet times, the state controlled the whole economy and was in charge of providing jobs, access to health-care, and education for everyone. In cases where income from the job market was not enough to satisfy household needs, or when individuals were not able to work, the government would provide social benefits, including family and maternity benefits, social pensions, or benefits to certain groups of the population such as war veterans (Atkinson and Micklewright 1992). The popular saying "From Cradle to Grave" reflects a circumstance where individuals were protected by the state throughout their life. As a result of how the economy was designed, poverty was seen as a pathology with high personal responsibility (Barr 1994). Social assistance (here referring to safety nets of last resorts, targeted at poor individuals) was highly residual, and benefits were subject to discretion by local authorities, which resulted in arbitrary decisions and a high level of stigma (Barr 1994; Atkinson and Micklewright 1992).

In spite of the progress made after the difficult years that followed the transition to the market economy, Kyrgyzstan still suffers from the consequences of the collapse of the Soviet Union and the impoverishment that followed, such as high unemployment, widespread corruption, state failure to deliver basic services, strong gender disparities, and inter-ethnic conflict (ICG 2016). As an effort to protect poor individuals during the transition to the market economy and counteract its negative effects, the government implemented several reforms to its social protection system, including the introduction of a poverty targeted transfer (the Monthly Benefit for Poor Families -MBPF-, previously known as the Unified Monthly Benefit) (Tesliuc 2004). However, social assistance programmes in Kyrgyzstan have failed to lift a significant number of individuals out of poverty (Gassmann 2011). One reason is that, as in the Soviet era, a big percentage of 
the social protection budget is spent on categorical benefits, which do not necessarily reach the poorest (Barrientos and Kudebayeva 2015). Categorical benefits focus on vulnerable groups unable to work, such as people with disabilities or sickness, older people, war veterans, or mothers with infants. The most important one is the Monthly Social Benefit (MSF), a cash transfer provided to orphans, people with disabilities and elderly individuals without pension rights (Gassmann and Zardo Trindade 2015).

The only transfer targeted at poor households in Kyrgyzstan is the aforementioned Monthly Benefit for Poor Families (MBPF), a means-tested benefit targeted at families living in extreme poverty. Eligibility for the MBPF is based on an income and asset component, as well as the presence of children in the household. The eligibility threshold is the Guaranteed Minimum Income (GMI), a discretionary threshold set by the government equal to approximately one third to one half of the extreme poverty line (Gassmann and Zardo Trindade 2015). Despite being relatively well-targeted, benefit sizes of the MBPF are too small to have a sizeable effect on poverty reduction, as they account for only 10 percent of total income of poor beneficiaries. Overall, all non-contributory benefits in Kyrgyzstan have low coverage, reaching between 1 and 10 percent of the population, with the exception of energy compensations, which reach a higher percentage of beneficiaries (Gassmann and Zardo Trindade 2015). ${ }^{37}$

Given the legacy of the country as a member of the Soviet Union, poverty, as well as the receipt of poverty targeted benefits such as the $\mathrm{MBPF}$, is likely to be associated with shame and stigma. Qualitative interviews conducted in Kyrgyzstan in the year 2000 reflect this, as it is common among respondents to report that in Soviet times they did not know what poverty was, and that now they feel humiliated (Narayan et al 2000). However, the expectation that the state will provide support would be accepted in the context of 'from cradle to grave' protection offered by the former system, especially in the case of categorical benefits, which do not necessarily reach the poorest. At the same time, given the limited benefit size of most social assistance transfers one would not expect a sizeable increase in subjective well-being, except for the subjective perception that the state cares for its citizens.

\subsection{Empirical strategy}

The aim of this paper is to investigate whether receiving social assistance has a positive or negative effect on subjective well-being. I answer this question through the following specification:

\footnotetext{
${ }^{37}$ Energy compensations are provided to pensioners with a small pension and to households living in high-mountain areas.
} 


$$
S W B_{i h k}=\beta_{0}+\beta_{1} S A_{i h k}+\beta_{2} Y_{i h k}+\beta_{3} X_{h k}+\alpha_{k}+\epsilon_{i h k}
$$

$S W B_{i h k}$ measures subjective well-being of individual $i$ in household $h$ in oblast $k$, and SA is a binary variable indicating whether an individual lives in a household receiving social assistance. The coefficient of interest is therefore $\beta_{1}$, which indicates if social assistance has a positive or negative effect on subjective well-being. $Y_{i h k}$ is a vector of individual level controls, while $X_{h k t}$ is a vector of household level characteristics. $\alpha_{k}$ refers to the oblast fixed effects, and $\epsilon_{i h k}$ is the idiosyncratic error.

Given that recipients of social assistance are not randomly selected from the population, simply comparing recipients with non-recipient will yield biased results, as the two groups have different characteristics which, at the same time, affect subjective well-being. To address the unobserved heterogeneity as well as the lack of an appropriate counterfactual, this analysis relies on matching as well as difference in difference techniques. The matching is done in two steps: I calculate the probability of receiving social assistance (propensity score) based on a number of covariates which are unlikely to change over time, such as oblast and region of residence (urban/rural), housing conditions and possession of assets and livestock, age, gender, ethnicity, and education of the recipient, gender of the head of the household, and whether the household head is engaged in agriculture. As a second step, I regress subjective well-being on social assistance recipient status (and a set of additional control variables) and apply inverse probability weights (IPW) to the specification.

Inverse probability of treatment weighting (IPTW) uses weights based on the propensity score to create a sample where the distribution of covariates is independent of treatment assignment (Austin 2011). ${ }^{38}$ If $\overline{\boldsymbol{p}}$ is the propensity score, which is an estimate of the probability of being in the treatment group given a set of individual and household covariates $\boldsymbol{x}$, individuals who receive social assistance will have a weight $\frac{\mathbf{1}}{\overline{\boldsymbol{p}}}$, and non-recipients a weight $\frac{\mathbf{1}}{\mathbf{1 - \overline { \boldsymbol { p } }}}$. A similar approach was taken by Handa el al. (2014) when estimating the relationship between social assistance and subjective well-being in Kenya. Regressions are estimated for the pooled sample (pooling three years of data), as well as for each year separately.

Subjective well-being is influenced by many factors, from economic conditions to personality traits and environmental conditions (Handa et al. 2014). Therefore, in addition to the observable characteristics used to match treated and control individuals, I include in the regressions other variables which are expected to affect subjective well-being. These include characteristics of respondents that were not included estimation of the propensity score, such as working status and whether the individual practices sports. Moreover, given that the survey includes a section on personality consisting on different questions that

38 This method was first proposed by Rosenbaum (1987). 
measure the extent of extraversion, openness, agreeableness, neuroticism, and conscientiousness of the respondent (the big five personality traits), an index for personality is created through factor analysis and included as an independent variable in the regressions. ${ }^{39}$

Household characteristics include the household size, whether the household has children, whether the household experienced an idiosyncratic shock in last year, and an index of asset holding created through factor analysis which includes media appliances (including television, radio, phone, and computer), and home appliances (including refrigerator, washing machine, and other assets)..$^{40}$ Many authors have proven how an improvement in material conditions can positively affect subjective well-being (Deaton, 2008; Stevenson and Wolfers 2008). This relationship is stronger and more robust in developing countries as the quality of life of poor people highly depends on the satisfaction of basic needs (Handa et al. 2014).

Given that individuals can receive social assistance in any of the years studied and benefits were in place before the survey was collected, it is not possible to use baseline characteristics (pre-treatment) to calculate the probability that an individual receives social assistance. To check for the robustness of the results, I estimate a difference in difference regression with the three years of data, as well as difference in difference combined with matching for the years 2011 and 2012 (and excluding the year 2013). In both cases and in order to compare the situation of beneficiaries with non-beneficiaries before and after receiving social assistance, I drop individuals who receive social assistance in 2011. In the second case, and with the aim of combining difference in difference with matching techniques, I restrict the sample to the years 2011 and 2012 and estimate the propensity score of receiving social assistance in 2012 with variables from $2011 .{ }^{41}$ The difference in difference specification is shown in equation (2).

$$
\begin{aligned}
S W B_{\text {ihk }}= & \beta_{0}+\beta_{1} \text { treat } 2012+\beta_{2} \text { treat } 2013+\beta_{3} \text { treat } 2012 \_2013+ \\
& +\beta_{4} \text { year } 2012+\beta_{5} \text { year } 2013+\beta_{6} \text { treat } 2012 * \text { year } 2012+ \\
& +\beta_{7} \text { treat } 2013 * \text { year } 2013+\beta_{8} \text { treat } 2012 \_2013 * \text { year } 2012+ \\
& +\beta_{9} \text { treat } 2012 \_2013 * \text { year } 2013+\beta_{10} Y_{\text {ihk }}+\beta_{11} X_{h k}+\alpha_{k}+\epsilon_{\text {ihk }}
\end{aligned}
$$

Where $\boldsymbol{\beta}_{\mathbf{1}}$ and $\boldsymbol{\beta}_{\mathbf{2}}$ measure the pre-treatment differences between treated and controls in 2012 and 2013, respectively, and $\boldsymbol{\beta}_{\mathbf{3}}$ measures pre-treatment differences between those receiving social assistance in both years (2012 and 2013), with respect to those who do not receive transfers in any of the three years. Changes in subjective well-being over time

\footnotetext{
${ }^{39}$ More information on how the personality index is created is provided in the appendix.

${ }^{40}$ More detailed explanation of the asset index is provided in the appendix.

41 The reason why I drop the year 2013 in the last specification is that, as mentioned before, the probability of receiving social assistance changes every year, and it is not possible to include two different weights per individual in the difference in difference estimation. Nevertheless, and as it is shown below, it seems reasonable to look at the change in subjective well-being levels from 2011 to 2012, as between these years the number of beneficiaries of social assistance increased, whereas in 2013 the number of beneficiaries decreased with respect to 2012.
} 
for the control groups are given by $\boldsymbol{\beta}_{\mathbf{4}}$ and $\boldsymbol{\beta}_{\mathbf{5}}$. The difference-in-difference estimators (DD) are given by $\boldsymbol{\beta}_{\mathbf{6}}, \boldsymbol{\beta}_{\mathbf{7}}, \boldsymbol{\beta}_{\mathbf{8}}$, and $\boldsymbol{\beta}_{\mathbf{9}} ; \boldsymbol{\beta}_{\mathbf{6}}$ compares changes in well-being levels between 2011 and 2012 among those receiving social assistance only in 2012, to the changes in the same period among the control group (those who do not receive social assistance neither in 2011, nor in 2012). $\boldsymbol{\beta}_{\mathbf{7}}$ captures changes in well-being levels between 2011 and 2013 among those receiving social assistance only in 2013, to the changes in the same period among the control group (those who do not receive social assistance in any of the three years). Finally, $\boldsymbol{\beta}_{\mathbf{8}}$ and $\boldsymbol{\beta}_{\mathbf{9}}$ compare subjective well-being levels between those receiving social assistance in both years -2012 and 2013- and those who do not receive social assistance in any of the three years, for the years 2012 and 2013, respectively. The remaining coefficients to be estimated are the same as in equation (1).

Finally, the difference in difference regression combined with propensity score matching, restricted to the years 2011 and 2012, is denoted as:

$$
\begin{gathered}
S W B_{i h k}=\beta_{0}+\beta_{1} \text { treat } 2012+\beta_{2} \text { year } 2012+\beta_{3} \text { treat } 2012 * \text { year } 2012+ \\
+\beta_{4} Y_{i h k}+\beta_{5} X_{h k}+\alpha_{k}+\epsilon_{i h k}
\end{gathered}
$$

In equation (3), $\beta_{3}$ captures the DD estimator, which measures the changes in subjective well-being between treated and controls before and after the receipt of the transfer. As before, $\beta_{2}$ captures the change in subjective well-being levels between 2011 and 2012 among those who do not receive social assistance, whereas pre-treatment differences between those receiving and those who do not receive social assistance is captured by $\beta_{1}$. The regression includes inverse probability weights, which in this case are used to match treated and non-treated units based on "pre-program" characteristics (Khandker et al. 2010). The advantage of combining difference in difference with matching techniques is that, given that participants are not randomly selected from the population, there can still be time-varying selection bias attributable to differences in initial observable characteristics and which is not accounted for in the difference in difference estimation.

\subsection{Data and descriptive statistics}

This analysis draws on data from the Life in Kyrgyzstan (LiK) study, a panel survey conducted annually that covers a sample of approximately 3,000 households (and 8,000 individuals). The survey was administered in all seven oblasts of Kyrgyzstan and the cities of Bishkek and Osh, and data were collected at the household, individual (administered to all adults aged 18 and above), and community level. LiK provides comprehensive information on income, consumption patterns, remittances, well-being indicators, employment and socio-demographic characteristics of households (Bruck et al. 2014). 
The survey tracks individuals over time, and includes new household members that become part of the households that are re-interviewed. To make the analysis more consistent, individuals who have missing information on the key variables in any of the three years are dropped. The final balanced sample consists of 5,899 individuals per year and only includes adults who are 18 years old or older, given that the subjective well-being questionnaire was only administered to adult household members.

In this paper social assistance is defined as all non-contributory benefits (both categorical and means-tested). The household questionnaire includes a section of income sources which asks the main respondent whether the household received any social assistance transfers in the last 12 months, including the Monthly Benefit for Poor Families (meanstested), the Monthly Social Benefit, Compensatory Payments, and other social payments (categorical), as well as the amount received from each transfer per month. Table 4.1 provides this information and confirms previous evidence in that approximately 10 percent of the population receives social assistance, although this percentage is lower in 2013 (Gassmann and Zardo Trindade 2015). On average, households receive between KGS 1,400 and 1,800 per month, which represents approximately 15 percent of their total income. In 2013, however, the percentage of individuals receiving categorical transfers dropped by almost 4 percentage points. ${ }^{42}$

Table 4.1: Social assistance characteristics by year

\begin{tabular}{llll}
\hline Social assistance & 2011 & 2012 & 2013 \\
\hline \% individuals in recipient hhs & 9.1 & 10.2 & 5.3 \\
$\begin{array}{l}\text { Average amount received (monthly) in } \\
\text { recipient hhs (KGS) }\end{array}$ & 1469 & 1561 & 1721 \\
\% of total income (recipients) & 15.6 & 13.8 & 14.6 \\
\hline
\end{tabular}

Source: authors' calculations, LiK 2011, 2012, 2013

Three measures of subjective well-being are used; the first one relates to the general satisfaction with life, and the other two constitute subjective measures of economic wellbeing. Life satisfaction has been identified by the OECD (2013) as one of the core measures of subjective well-being; it has been widely used across countries and proven to be reliable and valid. Self-reported life satisfaction is measured on an 11-point scale, ranging from 0 ('completely dissatisfied') to 10 ('completely satisfied').

Subjective economic well-being is measured with two questions: (1) "If you look back one year, how has your household's economic situation changed since that date?", and (2) "How do you think the economic situation of your household will be in one year from

\footnotetext{
42 In 2013, social protection benefits were recorded in a separate section (as opposed to previous years), and more disaggregated categories were added. In 2013 categorical benefits non-contributory pensions, social monthly allowance, compensations from local authorities and other allowances. The decline in benefits received in this year could be partly a result of measurement error given the change in the questionnaire and the way of recording the benefits.
} 


\section{Chapter 4}

now?" Respondents can choose between five options: highly increased, moderately increased, stayed the same, moderately decreased, and highly decreased. Based on this information I create a binary variable that takes the value of 1 if the situation has improved or 0 if the situation has worsened or remained the same. The possibility to compare the current economic situation with the situation either in the past or future reduces the noise of subjective economic well-being measures, as subjective answers often depend on how respondents compare themselves to other individuals, as well as their personality or emotional circumstances. As this could imply very different answers even if individuals have a similar economic situation, looking at a relative measure avoids the problem of establishing an absolute standard for what is economic well-being and what is not (Jones 2014).

Table 4.2 shows subjective well-being rates by recipient status. The average life satisfaction score is 6.82, and differences between social assistance recipients and non-recipients are not significant. The same applies to the variable measuring whether the economic situation of the household has improved with respect to the past, as in both groups, on average, 47 percent of respondents consider that the household is better off compared to one year before. When looking at the expectation with regard to the future, however, social assistance recipients have lower well-being levels as compared to non-recipients, as a smaller percentage expects an improvement in the household's economic situation. In addition, this difference is statistically significant. Although these statistics shed some light on the differences in subjective well-being levels between recipients and non-recipients, subjective well-being is driven by many other factors besides social assistance recipient status. Moreover, these two groups are expected to be highly heterogeneous. The next section presents the regression results, which rely on matching and difference in difference techniques to account for this heterogeneity.

Table 4.2: Subjective well-being by recipient status (pooled sample)

\begin{tabular}{lcccc}
\hline Indicator & $\begin{array}{c}\text { Mean } \\
\text { Recipients }\end{array}$ & $\begin{array}{c}\text { Mean } \\
\text { non-recipients }\end{array}$ & T stat & $\begin{array}{c}\text { Mean } \\
\text { Total }\end{array}$ \\
\hline Life satisfaction & 6.88 & 6.82 & -1.10 & 6.82 \\
$\begin{array}{l}\text { Economic situation has improved with respect } \\
\text { to the past }\end{array}$ & 0.47 & 0.47 & -0.04 & 0.47 \\
Economic situation will improve in the future & 0.52 & 0.54 & 1.73 & 0.54 \\
\hline Observations & 1445 & 16252 & 17697 \\
\hline
\end{tabular}

Source: authors' calculations, LiK 2011, 2012, 2013; Subjective well-being rates express averages across the three years 


\subsection{Results}

\subsubsection{Results based on matching}

Table 4.3 provides mean differences for the variables used to calculate the probability of receiving social assistance, for both treated and control individuals before and after matching. Looking at the unmatched sample (panel A), we can see that recipients and non-recipients differ in all characteristic except for the gender of the household head. Recipients of social assistance are more likely to live in the poorer oblasts of Issik-Kul, Jalal-abad and Naryn, and less likely to live in an urban area. A slightly higher percentage of recipients are the spouse of the household head, are married, and have access to good flooring. However, on average, recipients have less household appliances as well as lower levels of education. Moreover, recipients are more likely to live in a household engaged in agriculture, as recipient households own more livestock and have a higher percentage of heads working on agriculture, as compared to non-recipient households. After matching, one can see that no significant differences remain between the variables (panel B). Table A4.1 in the appendix shows the results of the probit regression used to calculate the probability of receiving social assistance and associated weights. Further evidence that the matching is appropriate is provided in table A4.2 and figure A4.1 in the appendix: table A4.2 shows the statistics of the quality of the matching, and figure A4.1 the distribution of the probability scores before and after applying the inverse probability weights. Moreover, table A4.3 gives a summary of all the variables used in the analysis.

The results based on the inverse probability weighted regressions are reported in tables 4.4 and 4.5 below. According to table 4.4 (based on the pooled sample), receiving social assistance leads to a reduction in life satisfaction. Moreover, recipients of social assistance have a 6-percentage point lower likelihood of expecting an improvement in the economic situation of the household in the future. Table 4.5 confirms these results, as the negative relationship between social assistance and life satisfaction holds when performing the regressions for each year separately (2011, 2012, and 2013), whereas the effect of social assistance on subjective economic well-being with regards to the future is again negative and significant in the years 2012 and 2013. On the contrary, the coefficient for social assistance is insignificant when estimating the subjective economic situation of respondents with respect to the past.

Based on these findings, one can conclude that social assistance has no positive effects on subjective well-being. In addition, receiving social benefits is associated with lower levels of satisfaction with life and an expectation that the household's economic situation will not improve in the near future. This can be due to the fact that benefits are not addressing the negative consequences of poverty. It can also imply that poverty and 
social assistance benefits are still stigmatised. The next subsection shows the results based on the difference in difference analysis.

Table 4.3: Differences between recipients and non-recipients before and after matching

\begin{tabular}{|c|c|c|c|c|c|c|}
\hline & \multicolumn{3}{|c|}{$\begin{array}{c}\text { Unmatched sample } \\
\text { (Panel A) }\end{array}$} & \multicolumn{3}{|c|}{$\begin{array}{l}\text { Matched sample } \\
\text { (Panel B) }\end{array}$} \\
\hline & SA Recipients & S SA Non-recipients & $\mathrm{p}$-value & SA Recipients & SA Non-recipients & $\mathrm{p}$-value \\
\hline \multicolumn{7}{|c|}{ 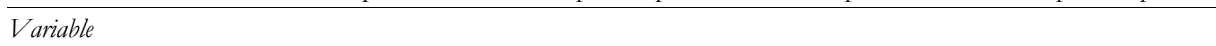 } \\
\hline Rural & 0.79 & 0.62 & 0.00 & 0.79 & 0.80 & 0.46 \\
\hline \multicolumn{7}{|l|}{ Oblast (ref: Bishkeek) } \\
\hline Issyk-Kul & 0.08 & 0.09 & 0.20 & 0.08 & 0.09 & 0.13 \\
\hline Jalal-Abad & 0.24 & 0.15 & 0.00 & 0.24 & 0.25 & 0.63 \\
\hline Naryn & 0.08 & 0.04 & 0.00 & 0.08 & 0.09 & 0.39 \\
\hline Batken & 0.11 & 0.08 & 0.00 & 0.11 & 0.11 & 0.40 \\
\hline Osh & 0.23 & 0.21 & 0.04 & 0.23 & 0.20 & 0.12 \\
\hline Talas & 0.06 & 0.04 & 0.00 & 0.06 & 0.07 & 0.70 \\
\hline Chui & 0.11 & 0.17 & 0.00 & 0.11 & 0.11 & 0.59 \\
\hline Osh city & 0.03 & 0.05 & 0.00 & 0.03 & 0.03 & 0.36 \\
\hline Age & 41.6 & 43.0 & 0.00 & 41.6 & 42.0 & 0.46 \\
\hline Age squared & 1947 & 2097 & 0.00 & 1947 & 1989 & 0.42 \\
\hline \multicolumn{7}{|c|}{ Relationship to household head (ref: head) } \\
\hline Spouse & 0.30 & 0.27 & 0.03 & 0.30 & 0.29 & 0.39 \\
\hline Son/Daughter & 0.21 & 0.25 & 0.00 & 0.21 & 0.20 & 0.58 \\
\hline Other & 0.11 & 0.09 & 0.00 & 0.11 & 0.12 & 0.44 \\
\hline Married & 0.79 & 0.73 & 0.00 & 0.79 & 0.77 & 0.23 \\
\hline Ethnic Kyrgyz & 0.75 & 0.66 & 0.00 & 0.76 & 0.77 & 0.22 \\
\hline \multicolumn{7}{|c|}{ Education (ref: primary/ no education) } \\
\hline Secondary & 0.69 & 0.54 & 0.00 & 0.69 & 0.70 & 0.63 \\
\hline Technical & 0.11 & 0.15 & 0.00 & 0.11 & 0.09 & 0.35 \\
\hline University & 0.06 & 0.18 & 0.00 & 0.06 & 0.08 & 0.08 \\
\hline Head agriculture & 0.31 & 0.19 & 0.00 & 0.31 & 0.31 & 0.90 \\
\hline Male hh head & 0.78 & 0.77 & 0.34 & 0.78 & 0.77 & 0.96 \\
\hline Good flooring & 0.75 & 0.71 & 0.00 & 0.75 & 0.75 & 0.76 \\
\hline Livestock & 2.05 & 1.33 & 0.00 & 2.05 & 2.12 & 0.21 \\
\hline Appliances & 3.09 & 3.40 & 0.00 & 3.09 & 3.09 & 0.94 \\
\hline Observations & 1443 & 16226 & & 1443 & 16226 & \\
\hline
\end{tabular}

Source: authors' calculations, LiK 2011, 2012, 2013 
Table 4.4: Association between social assistance and subjective well-being with inverse probability weights (pooled data)

\begin{tabular}{|c|c|c|c|}
\hline & Life Satisfaction & $\begin{array}{c}\text { Economic situation is better } \\
\text { than in the past }\end{array}$ & $\begin{array}{l}\text { Expects economic } \\
\text { Situation to improve }\end{array}$ \\
\hline \multirow[t]{2}{*}{ Receives SA } & $-0.27^{* *}$ & -0.02 & $-0.06^{* *}$ \\
\hline & $(0.08)$ & $(0.02)$ & $(0.02)$ \\
\hline \multirow[t]{2}{*}{ Male } & $-0.16^{+}$ & 0.00 & 0.00 \\
\hline & $(0.10)$ & $(0.02)$ & $(0.02)$ \\
\hline \multirow[t]{2}{*}{ Age } & -0.04 & -0.00 & -0.00 \\
\hline & $(0.03)$ & $(0.00)$ & $(0.00)$ \\
\hline \multirow[t]{2}{*}{ Age squared } & 0.00 & 0.00 & 0.00 \\
\hline & $(0.00)$ & $(0.00)$ & $(0.00)$ \\
\hline \multirow[t]{2}{*}{ Married } & $0.46^{* *}$ & 0.03 & 0.03 \\
\hline & $(0.14)$ & $(0.02)$ & $(0.02)$ \\
\hline \multirow[t]{2}{*}{ Ethnic Kyrgyz } & $0.22^{+}$ & $0.08^{* *}$ & $0.07^{* *}$ \\
\hline & $(0.11)$ & $(0.02)$ & $(0.02)$ \\
\hline Urban & $-0.60^{* *}$ & $-0.12^{* *}$ & $-0.13^{* *}$ \\
\hline \multirow[t]{2}{*}{$\mathrm{HH}$ size } & $0.05^{*}$ & $0.02^{* *}$ & $0.03^{* *}$ \\
\hline & $(0.02)$ & $(0.00)$ & $(0.00)$ \\
\hline \multirow[t]{2}{*}{$\mathrm{HH}$ has kids } & -0.20 & -0.04 & $-0.05^{*}$ \\
\hline & $(0.14)$ & $(0.03)$ & $(0.03)$ \\
\hline \multicolumn{4}{|c|}{ Education (ref: primary or no education) } \\
\hline \multirow[t]{2}{*}{ Secondary } & -0.22 & 0.03 & -0.04 \\
\hline & $(0.15)$ & $(0.03)$ & $(0.03)$ \\
\hline \multirow[t]{2}{*}{ Technical } & -0.28 & 0.04 & -0.03 \\
\hline & $(0.22)$ & $(0.03)$ & $(0.04)$ \\
\hline \multirow[t]{2}{*}{ University } & -0.17 & $0.10^{*}$ & 0.03 \\
\hline & $(0.25)$ & $(0.05)$ & $(0.04)$ \\
\hline \multirow[t]{2}{*}{ Works } & 0.14 & -0.01 & 0.01 \\
\hline & $(0.11)$ & $(0.02)$ & $(0.02)$ \\
\hline \multirow[t]{2}{*}{ Plays sports } & $0.59^{* *}$ & $0.10^{* *}$ & $0.07^{* *}$ \\
\hline & $(0.10)$ & $(0.02)$ & $(0.02)$ \\
\hline \multirow[t]{2}{*}{ Personality } & $0.55^{* *}$ & $0.04^{* *}$ & $0.06^{* *}$ \\
\hline & $(0.06)$ & $(0.01)$ & $(0.01)$ \\
\hline \multirow[t]{2}{*}{ Asset index } & $0.38^{* *}$ & $0.09^{* *}$ & $0.10^{* *}$ \\
\hline & $(0.08)$ & $(0.02)$ & $(0.01)$ \\
\hline Experienced idiosyncratic & -0.03 & $-0.04^{*}$ & $-0.05^{*}$ \\
\hline Shock & $(0.09)$ & $(0.02)$ & $(0.02)$ \\
\hline \multirow[t]{2}{*}{ Constant } & $7.08^{* *}$ & $0.16^{*}$ & $0.32^{* *}$ \\
\hline & $(0.64)$ & $(0.07)$ & $(0.09)$ \\
\hline Observations & 17589 & 17589 & 17589 \\
\hline$R^{2}$ & 0.18 & 0.13 & 0.17 \\
\hline
\end{tabular}

Linear probability OLS regressions with robust standard errors and inverse probability weights;

${ }^{+} p<0.1,{ }^{*} p<0.05,{ }^{* *} p<0.01$; Regressions also include oblast fixed effects. I originally controlled for the presence of networks, as there is evidence that a rich social life and having a network support improves subjective well-being (Diener and Seligman 2002). However, due to the large number of missing observations, I have excluded this variable from the analysis. Results were not altered, though. 
Table 4.5: Association between social assistance and subjective well-being with inverse probability weights (cross-sections)

\begin{tabular}{|c|c|c|c|c|c|c|c|c|c|}
\hline & \multicolumn{3}{|c|}{2011} & \multicolumn{3}{|c|}{2012} & \multicolumn{3}{|c|}{2013} \\
\hline & $\begin{array}{c}\text { Life } \\
\text { satisfaction }\end{array}$ & $\begin{array}{c}\text { Econ. situation } \\
\text { better than in } \\
\text { the past }\end{array}$ & $\begin{array}{c}\text { Expects } \\
\text { Econ. situation to } \\
\text { improve }\end{array}$ & $\begin{array}{c}\text { Life } \\
\text { satisfaction }\end{array}$ & $\begin{array}{c}\text { Econ. situation is } \\
\text { better than in } \\
\text { the past }\end{array}$ & $\begin{array}{l}\text { Expects } \\
\text { Econ. situation to } \\
\text { improve }\end{array}$ & $\begin{array}{c}\text { Life } \\
\text { satisfaction }\end{array}$ & $\begin{array}{c}\text { Econ. situation is } \\
\text { better than in } \\
\text { the past }\end{array}$ & $\begin{array}{l}\text { Expects } \\
\text { econ. situation to } \\
\text { improve }\end{array}$ \\
\hline Receives SA & $\begin{array}{l}-0.20^{*} \\
(0.10)\end{array}$ & $\begin{array}{l}-0.01 \\
(0.02)\end{array}$ & $\begin{array}{l}-0.03 \\
(0.02)\end{array}$ & $\begin{array}{l}-0.29^{*} \\
(0.12)\end{array}$ & $\begin{array}{l}-0.03 \\
(0.02)\end{array}$ & $\begin{array}{c}-0.06^{* *} \\
(0.02)\end{array}$ & $\begin{array}{l}-0.30^{*} \\
(0.14)\end{array}$ & $\begin{array}{l}-0.01 \\
(0.04)\end{array}$ & $\begin{array}{l}-0.08^{*} \\
(0.03)\end{array}$ \\
\hline Controls & Yes & Yes & Yes & Yes & Yes & Yes & Yes & Yes & Yes \\
\hline Obs & 5873 & 5873 & 5873 & 5874 & 5874 & 5874 & 5842 & 5842 & 5842 \\
\hline $\mathrm{R}^{2}$ & 0.23 & 0.17 & 0.19 & 0.28 & 0.18 & 0.21 & 0.21 & 0.14 & 0.21 \\
\hline
\end{tabular}

Linear probability OLS regressions with robust standard errors and inverse probability weights; ${ }^{+} p<0.1,{ }^{*} p<0.05,{ }^{* *} p<0.01$; full regressions are shown in table A4.4 in the appendix. 


\subsubsection{Results based on difference in difference (DD) estimation}

Table 4.6 shows the results of the difference in difference regression. Compared to the inverse probability weighted regressions from the previous sub-section, receiving social assistance is not associated with changes in life satisfaction. However, receiving social assistance is negatively related with the subjective economic expectations of recipients with respect to the future, as significant coefficients are observed for those who receive social assistance only in 2012 as well as for those receiving social assistance in both years -2012 and 2013-, compared to those who do not receive social assistance in any of the three years. In addition, there is some indication that social assistance reduces subjective economic well-being with respect to the past among those who receive social assistance in both 2012 and 2013.

There are some factors that could explain why significant effects of social assistance on life satisfaction are no longer observed. On the one hand, it is likely that there are unobserved factors which are not accounted for in the inverse probability weighted (IPW) regressions that affect both the probability of receiving social assistance as well as subjective well-being. The reason why matching techniques do not account for unobserved heterogeneity is that the probability of receiving social assistance and resulting inverse probability weights are based on observed covariates. At the same time and as a result of excluding individuals who receive social assistance in 2011, 543 observations were excluded from the difference in difference estimations. Moreover, given that the sample is highly heterogeneous, it is possible that there are time-varying variables that differ between recipients and non-recipients at the baseline (before beneficiaries started receiving social assistance) and, as a result, an appropriate counterfactual is lacking in the difference in difference regression.

As a next step, I combine difference in difference with matching techniques by weighting each observation based on the probability of receiving social assistance in the year 2012 with characteristics at the baseline (2011). To be able to combine the two techniques, observations from the year 2013 are dropped. The reason why changes in subjective well-being between the years 2011 and 2012 (and not 2013) are analysed, is that in 2012 there was an increase in beneficiaries with respect to 2011, while in 2013 the percentage of beneficiaries decreased with respect to 2012.

These estimations are presented in Table 4.7, and show negative and significant effects of receiving social assistance on the three indicators of well-being. Even though there was an overall increase in well-being levels in the year 2012, those receiving social assistance had, on average, 0.47 points lower life satisfaction and were 11 and 17 percentage points less likely to report an improvement in the economic situation with respect to the past or expect an improvement in the economic situation in the future, respectively. 
Based on these findings, one can conclude that receiving social assistance does not contribute to an improvement in well-being. In terms of the life satisfaction indicator, both inverse probability weighted regressions as well as difference-in-difference combined with inverse probability weighting (restricting the sample to the years 2011 and 2012) indicate that receiving social assistance leads to lower levels of life satisfaction. Moreover, all estimations point towards a negative relation between social assistance and the expectations that the economic situation will improve in the future. In this case, however, one should be aware that the negative effects can be a result of reverse causality, which would arise if those who think their economic situation will not improve are less inclined to perform income generation activities and, therefore, need to rely on social assistance. Regarding the perceptions regarding changes in the economic situation with respect to the past, only the difference in difference regressions show a negative effect of social assistance, as coefficients are insignificant when estimating inverse probability weighted regressions (section 4.6.1).

There are different reasons that can explain the non-existent or negative association between receiving social assistance and subjective well-being. One is the small amount of social assistance benefits, which are not sufficient to lift recipients out of poverty and improve their subjective well-being. Another explanation could be that beneficiaries are disappointed by the state, given that the help they expect is only marginal and not enough to cover their basic needs. Finally, an additional explanation is that, based on its past as a member of the Soviet Union, poor individuals who receive social assistance in Kyrgyzstan suffer from stigma and shame, which would result in lower subjective well-being levels. The next sub-section explores whether the effects of social assistance differ with regards to age, by making a distinction between those individuals who were part of the Soviet system, and those who became adults after independence. 
Table 4.6: Difference in difference estimation (years 2011, 2012, and 2013)

\begin{tabular}{|c|c|c|c|}
\hline & $\begin{array}{c}\text { Life } \\
\text { satisfaction }\end{array}$ & $\begin{array}{c}\text { Econ. situation better } \\
\text { than in the past }\end{array}$ & $\begin{array}{c}\text { Expects } \\
\text { econ. situation to } \\
\text { improve }\end{array}$ \\
\hline \multirow[t]{2}{*}{ Treated only in $2012 *$ year 2012} & 0.20 & -0.04 & $-0.09^{* *}$ \\
\hline & $(0.12)$ & $(0.03)$ & $(0.03)$ \\
\hline \multirow[t]{2}{*}{ Treated only in 2013* year 2013} & 0.26 & 0.06 & 0.01 \\
\hline & $(0.19)$ & $(0.05)$ & $(0.05)$ \\
\hline Treated in 2012 and 2013* & -0.18 & $-0.15^{*}$ & $-0.18^{* *}$ \\
\hline Year 2012 & $(0.26)$ & $(0.06)$ & $(0.06)$ \\
\hline Treated in 2012 and $2013 *$ & -0.22 & -0.01 & -0.02 \\
\hline Year 2013 & $(0.25)$ & $(0.06)$ & $(0.06)$ \\
\hline Treated only in & -0.09 & 0.00 & $0.04^{*}$ \\
\hline 2012 & $(0.07)$ & $(0.02)$ & $(0.02)$ \\
\hline Treated only in & $-0.43^{* *}$ & $-0.11^{* *}$ & $-0.11^{* *}$ \\
\hline 2013 & $(0.12)$ & $(0.03)$ & $(0.03)$ \\
\hline Treated in & 0.19 & 0.04 & -0.00 \\
\hline 2012 and 2013 & $(0.21)$ & $(0.05)$ & $(0.05)$ \\
\hline \multirow[t]{2}{*}{ Year 2012} & $0.20^{* *}$ & $0.05^{* *}$ & $0.05^{* *}$ \\
\hline & $(0.04)$ & $(0.01)$ & $(0.01)$ \\
\hline \multirow[t]{2}{*}{ Year 2013} & $0.20^{* *}$ & $0.06^{* *}$ & $0.08^{* *}$ \\
\hline & $(0.04)$ & $(0.01)$ & $(0.01)$ \\
\hline Controls & Yes & Yes & Yes \\
\hline Observations & 17079 & 17079 & 17079 \\
\hline $\mathrm{R}^{2}$ & 0.13 & 0.10 & 0.14 \\
\hline
\end{tabular}

Source: Linear probability OLS regressions with robust standard errors and inverse probability weights; Robust standard errors in parentheses; ${ }^{+} p<0.1,{ }^{*} p<0.05,{ }^{* *} p<0.01$; full regressions are shown in table A4.5 in the appendix.

Table 4.7: Difference in difference estimation with inverse probability weights (years 2011 and 2012)

\begin{tabular}{lccc}
\hline & Life satisfaction & $\begin{array}{c}\text { Econ. situation better than in } \\
\text { the past }\end{array}$ & $\begin{array}{c}\text { Expects econ. situation } \\
\text { to improve }\end{array}$ \\
\hline Treated*Year 2012 & $\mathbf{- 0 . 4 7 ^ { * }}$ & $\mathbf{- 0 . 1 1 ^ { * }}$ & $\mathbf{- 0 . 1 7 ^ { * * }}$ \\
Treated & $\mathbf{( 0 . 2 1 )}$ & $\mathbf{( 0 . 0 4 )}$ & $\mathbf{( 0 . 0 4 )}$ \\
& 0.01 & 0.04 & $0.08^{*}$ \\
Year 2012 & $(0.17)$ & $(0.04)$ & $(0.04)$ \\
Controls & $0.23^{* *}$ & $0.05^{* *}$ & $0.06^{* *}$ \\
Observations & $(0.06)$ & $(0.01)$ & $(0.01)$ \\
$\mathrm{R}^{2}$ & Yes & Yes & Yes \\
\hline
\end{tabular}

Linear probability OLS regressions with robust standard errors and inverse probability weights; Robust standard errors in parentheses; ${ }^{+} p<0.1,{ }^{*} p<0.05,{ }^{* *} p<0.01$; full regressions are shown in table A4.6 in the appendix. 


\subsubsection{Heterogeneity in effects}

In order to shed light on whether perceptions towards poverty and social assistance have changed with respect to the former system and whether effects are heterogeneous with regards to age, I look at whether those individuals who were adults when Kyrgyzstan was still a part of the Soviet Union (currently elderly individuals) assess their situation differently than younger individuals.

The results shown in table 4.8 are an extension of the model presented in table 4.4 and include an interaction term between receiving social assistance and whether the respondent is 60 years old or older as an explanatory variable. The table shows that the negative effects of social assistance remain, but the interaction is not significant. It seems, therefore, that the negative effect of receiving social assistance on subjective well-being applies to the whole population, and not only to those who lived under the Soviet system.

Table 4.8: Heterogeneity of the effect of social assistance regarding age (pooled sample)

\begin{tabular}{lccc}
\hline & Life satisfaction & $\begin{array}{c}\text { Econ. situation better than } \\
\text { in the past }\end{array}$ & $\begin{array}{c}\text { Expects econ. situation to } \\
\text { improve }\end{array}$ \\
\hline Receives SA & $-0.31^{* * *}$ & -0.03 & $-0.05^{* *}$ \\
Receives SA*elderly & $(0.09)$ & $(0.02$ & $(0.02)$ \\
& 0.27 & 0.02 & -0.07 \\
Controls & $(0.24)$ & $(0.06)$ & $(0.05)$ \\
Obs & Yes & Yes & Yes \\
$\mathrm{R}^{2}$ & 17589 & 17589 & 17589 \\
\hline
\end{tabular}

Linear probability OLS regressions with robust standard errors and inverse probability weights; Robust standard errors in parentheses; ${ }^{+} p<0.1,{ }^{*} p<0.05,{ }^{* *} p<0.01$; all the other explanatory variables remain very similar to the previous estimation (Table 4.4).

\subsection{Conclusion}

There is little evidence about the relationship between social assistance and subjective well-being. This is an important question, not only because there is now a consensus on the importance of measuring well-being through subjective indicators (Stiglitz, Sen and Fitoussi 2009), but also because the mechanisms by which social assistance affect subjective well-being differ from the ones affecting objective well-being. Factors such as the design, targeting, and implementation of social protection programmes and, especially, whether transfers are associated with shame and stigma, are likely to influence the effects of social assistance on subjective well-being.

Drawing on three rounds of the Life in Kyrgyzstan survey, this paper has analysed a country where the social protection system in place and the connotations of poverty are, 
to a big extent, influenced by its history as a member of the Soviet Union. Under the Soviet period, poverty was seen as a pathology and a responsibility directly attributed to the poor individual (Barr 1994), and poverty targeted transfers were highly residual and stigmatised. Contrary to previous studies that have found a positive relation between social assistance and subjective well-being (Haushofer and Shapiro 2013; Handa et al. 2014), this paper finds, in most of the estimations performed, a negative effect of social assistance on life satisfaction, as well on the subjective economic expectations with respect to the future. Moreover, to a certain extent, it is also observed that social assistance recipients are less likely to report an improvement in the economic situation with respect to the past. There are several factors that can explain these finding in the Kyrgyz context.

One reason could be that benefits are, in general, not large enough to address the negative mechanisms associated with poverty and, hence, increase satisfaction with life and with the household's economic situation. Another explanation could be that beneficiaries are disappointed by the State, given that the help they expect is only marginal and not even enough to cover their basic needs. Finally, an additional explanation is that, based on its past as a member of the Soviet Union, poor individuals who receive social assistance in Kyrgyzstan suffer from stigma and shame, which would result in lower subjective well-being levels. This stigmatisation could be partly a result of government officials' behaviour. On a recent public opinion survey among residents of Kyrgyzstan, more than 70 percent of the citizens think that corruption is a big problem in the country and that the government is not making a sufficient effort to fight corruption (International Republican Institute 2017). Concerns about corruption apply to different kinds of institutions and organisations, including ministries, universities, the police, etc. This also supports past evidence that there are important complaints among social protection beneficiaries about social service officials, who are accused of engaging in unlawful practices, abusing their power and humiliating clients (Narayan et al. 2000).

Moreover, a robust finding is that receiving social assistance is associated with a lower likelihood of expecting an improvement in the economic situation in the future. An additional explanation for this finding besides the ones mentioned before is that social assistance, as compared to labor income, is unlikely to contribute to social mobility in Kyrgyzstan. In a study about the prospects for Central Asia, Davalos et al (2016) find that citizens in this region believe that new and better jobs, as compared to social assistance and other types of money transfers, are the most important factors to get ahead. However, this finding should be interpreted with caution as it could be the result of reverse causality (where receiving benefits is, to a certain extent, a result of negative hopes about the future).

One mechanism that this paper cannot test, unfortunately, is whether the negative effects of social assistance come from the Monthly Benefit for Poor Families, which is a 
poverty-targeted transfer. As explained before, categorical benefits were not stigmatised during Soviet times given that they were income support provided by the state to complement labour income or meet the needs of individuals who were unable to work. Social assistance targeted at poor families, on the contrary, was highly stigmatized, as poverty was attributed high individual responsibility. One would therefore expect stronger negative effects on subjective well-being from the MBPF than from categorical benefits. The reason why testing this mechanism is not possible is that, when one splits the sample of beneficiaries of social assistance between those receiving categorical benefits and those receiving the MBPF, descriptive statistics look different to official sources based on the Household Integrated Survey, as in the LIK categorical benefits look over reported while the MBPF underreported. An explanation for this is that respondents are not aware of the different types of benefits they receive, as the survey includes many different categories of social assistance. This potentially results in measurement error.

To conclude, this study finds that social assistance leads to lower subjective well-being levels in Kyrgyzstan. Previous studies have shown that social protection in Kyrgyzstan does not lead to big reductions in poverty and, based on these findings, neither does social assistance improve the subjective well-being of beneficiaries. Based on the history of this country as a member of the Soviet Union, there are reasons to suspect that poverty and poverty-targeted benefits are stigmatised. Moreover, even if categorical benefits may not be associated with stigma, individuals seem to have lost the feeling of "from cradle to grave" protection that they used to enjoy in the past. 


\section{References}

Attah, R., Barca, V., Kardan, A., MacAuslan, I., Merttens, F., \& Pellerano, L. (2016). Can social protection affect psychosocial wellbeing and why does this matter? Lessons from cash transfers in sub-Saharan Africa. The Journal of Development Studies, 52(8), 1115-1131.

Atkinson, A. B., \& Micklewright, J. (1992). Economic transformation in Eastern Europe and the distribution of income. Cambridge University Press.

Austin, P. C. (2011). An introduction to propensity score methods for reducing the effects of confounding in observational studies. Multivariate behavioral research, 46(3), 399-424.

Barr, N. A. (Ed.). (1994). Labor markets and social policy in Central and Eastern Europe: The transition and beyond. World Bank Publications.

Barrientos, A., \& Kudebayeva, A. (2015). Social Transfers and Women's Labour Supply in Kyrgyzstan. BWPI Working Paper 215, The University of Manchester, Manchester, UK.

Bartram, D. (2013). Happiness and 'economic migration': A comparison of Eastern European migrants and stayers. Migration Studies, 1(2), 156-175.

Bastagli, F., Hagen-Zanker, J., Harman, L., Barca, V., Sturge, G. \& Schmidt, T. (2016). Cash transfers: what does the evidence say? A rigorous review of programme impact and of the role of design and implementation features. London: Overseas Development Institute (ODI).

Bos, A. E., Pryor, J. B., Reeder, G. D., \& Stutterheim, S. E. (2013). Stigma: Advances in theory and research. Basic and applied social psychology, 35(1), 1-9.

Brück, T., Esenaliev, D., Kroeger, A., Kudebayeva, A., Mirkasimov, B., \& Steiner, S. (2014). Household survey data for research on well-being and behavior in Central Asia. Journal of Comparative Economics, 42(3), 819-835.

Davalos, M. E., Demarchi, G., Kits, B., Oral, I., \& Santos, I. (2016). Voices of Europe and Central Asia: New Insights on Shared Prosperity and Jobs. Washington DC: World Bank.

Deaton, A. (2008). Income, Health, and Well-Being around the World: Evidence from the Gallup World Poll. Journal of Economic Perspectives, 22(2): 53-72.

Diener, E., \& Seligman, M. E. (2002). Very happy people. Psychological science, 13(1), 81-84.

Diener, E. (1984). Subjective well-being. Psychological bulletin, 95 (3), 542-575

Easterlin, R. A. (1995). Will raising the incomes of all increase the happiness of all?. Journal of Economic Behavior \& Organization, 27(1), 35-47.

Easterlin, R. A. (1974). Does economic growth improve the human lot? Some empirical evidence. Nations and housebolds in economic growth, 89, 89-125.

Eid, M., \& Diener, E. (2004). Global judgments of subjective well-being: Situational variability and long-term stability. Social indicators research, 65(3), 245-277.

FAO (2016). Evaluation of FAO's contribution to the Kyrgyz Republic Annexes. Country programme evaluation series. Food and Agriculture organization of the United Nations.

Galama, T.J., Morgan, R. \& Saavedra, J.E. (2017). The Impacts of Social Assistance Programs on Financial and Subjective Wellbeing: Evidence from a Conditional Cash-Transfer Program in Colombia. CESR Working Paper No. 2017

Gassmann, F. \& Zardo Trindade, L. (2015). Analysis of Potential Work Disincentive Effects of the Monthly Benefit for Poor Families in the Kyrgyz Republic. Report No. 99776-KG. Washington DC: World Bank Group.

Gassmann, F. (2011). To What Extent Does the Existing Safety Net Protect the Poor? Washington, D.C: World Bank Group. http://documents.worldbank.org/curated/en/914301486988386789/To-what-extent-doesthe-existing-safety-net-protect-the-poor

Gebreeyesus, M. (2015). Firm adoption of international standards: evidence from the Ethiopian floriculture sector. Agricultural economics 46.S1 (2015): 139-155.

Hagenaars, A., \& De Vos, K. (1988). The definition and measurement of poverty. Journal of Human Resources, 211221.

Handa, S., Martorano, B., Halpern, C., Pettifor, A., \& Thirumurthy, H. (2014). Subjective Well-being, Risk Perceptions and Time Discounting. Evidence from a Large-Scale Cash Transfer Programme. Office of Research Working Paper, UNICEF.

Haushofer, J., \& Fehr, E. (2014). On the psychology of poverty. Science, 344(6186), 862-867.

Haushofer, J., \& Shapiro, J. (2013). Household response to income changes: Evidence from an unconditional cash transfer program in Kenya. Massachusetts Institute of Technology.

ICG (2016). Kyrgyzstan: State Fragility and Radicalisation, Crisis Group Europe and Central Asia Briefing Nº83 


\section{Chapter 4}

Jin, L. (2016). Migration, Relative Deprivation, and Psychological Well-Being in China. American Behavioral Scientist, 60(5-6), 750-770.

Jo, Y. N. (2013). Psycho-social dimensions of poverty: When poverty becomes shameful. Critical Social Policy, 33(3), 514-531.

Jones, R. C. (2014). Migration and Family Happiness in Bolivia: Does Social Disintegration Negate Economic Wellbeing? International Migration, 52(3), 177-193.

Khandker, S. R., Koolwal, G. B., \& Samad, H. A. (2009). Handbook on impact evaluation: quantitative methods and practices. World Bank Publications.

Li, M., \& Walker, R. (2016). Shame, stigma and the take-up of social assistance: Insights from rural China. International Journal of Social Welfare.

Lister, R. (2004). Poverty. Cambridge: Polity Press.

Lloyd-Sherlock, P., Saboia, J., \& Ramírez-Rodríguez, B. (2012). Cash transfers and the well-being of older people in Brazil. Development and Change, 43(5), 1049-1072.

Lukashova, I. \& Makenbaeva, I. (2009). Impact of the global financial crisis on labour migration from Kyrgyzstan to Russia. Qualitative overview and quantitative survey, Report by OSCE, ACTED and European Commission, http://www.osce.org/bishkek/40540.

Maslow, A. (1970). Motivation and Personality. Harper and Row, New York.

Møller, V., \& Radloff, S. (2013). Perceptions of fortune and misfortune in older South African households: Social assistance and the 'good life'. Social indicators research, 111(3), 633-664.

Mundlak, Y. (1978). On the pooling of time series and cross section data. Econometrica: journal of the Econometric Society, 69-85.

Narayan, D., Chambers, R., Shah, M. K., \& Petesch, P. (2000). Voices of the Poor: Crying out for Change. New York: Oxford University Press for the World Bank.

OECD Better Life Initiative (2013). OECD Guidelines on Measuring Subjective Well-Being.

Roelen, K. (2017). Shame, Poverty and Social Protection. CSP working paper No 489, Institute of Development Studies

Rosenbaum, P. R. (1987). Model-based direct adjustment. Journal of the American Statistical Association, 82(398), $387-$ 394.

Saavedra, J. E. (2016). The effects of conditional cash transfer programs on poverty reduction, human capital accumulation and wellbeing. In United Nations Expert Group Meeting.

Stevenson, B., \& Wolfers, J. (2008). Economic growth and subjective well-being: reassessing the Easterlin paradox (No. w14282). National Bureau of Economic Research.

Stewart, F. (2014). Against happiness: A critical appraisal of the use of measures of happiness for evaluating progress in development. Journal of Human Development and Capabilities, 15(4), 293-307.

Stiglitz, J., Sen, A., \& Fitoussi, J. P. (2009). The measurement of economic performance and social progress revisited. Reflections and overview. Commission on the Measurement of Economic Performance and Social Progress, Paris.

Teroni, F., \& Bruun, O. (2011). Shame, guilt and morality. Journal of moral philosophy, 8(2), 223-245.

Tesliuc, E. D. (2004). Mitigating Social Risks in Kyrgyz Republic. Social Protection discussion paper series; no. 408. Washington, DC: World Bank. http://documents.worldbank.org/curated/en/917891468758403442/Mitigating-social-risks-in-Kyrgyz-Republic

Van Vliet, K. J. (2008). Shame and Resilience in Adulthood: A Grounded Theory Study. Journal of Counseling Psychology 55.2: 233-45

World Bank (2017). World Bank Data, Kyrgyz Republic. https://data.worldbank.org/country/kyrgyz-republic [accessed 10 November 2017] 


\section{Appendix 4}

Table A4.1: Probability of receiving social assistance (marginal effects)

\begin{tabular}{|c|c|c|}
\hline \multicolumn{3}{|c|}{ Receives SA } \\
\hline & coef & Se \\
\hline Urban & -0.00 & 0.01 \\
\hline \multicolumn{3}{|c|}{ Oblast (ref category: Bishkeek) } \\
\hline Issik-Kul & 0.01 & 0.01 \\
\hline Jalal- Abad & $0.06^{* *}$ & 0.01 \\
\hline Naryn & $0.06^{* *}$ & 0.01 \\
\hline Batken & $0.05^{* *}$ & 0.01 \\
\hline Osh & $0.03^{* *}$ & 0.01 \\
\hline Talas & $0.05^{* *}$ & 0.01 \\
\hline Chui & $0.02^{+}$ & 0.01 \\
\hline Osh City & $0.03^{*}$ & 0.01 \\
\hline Age & -0.00 & 0.00 \\
\hline Age squared & 0.00 & 0.00 \\
\hline \multicolumn{3}{|c|}{ Relation to hb head (ref: hb head) } \\
\hline Spouse & -0.00 & 0.01 \\
\hline Son or daughter & $-0.04^{* *}$ & 0.01 \\
\hline Other & $-0.02^{+}$ & 0.01 \\
\hline Married & 0.01 & 0.01 \\
\hline Head agriculture & $0.02^{* *}$ & 0.01 \\
\hline Head is male & $-0.03^{* *}$ & 0.01 \\
\hline \multicolumn{3}{|c|}{ Ethnicity (ref category: Kyrgyz) } \\
\hline Uzbek & -0.01 & 0.01 \\
\hline Russian & $-0.03^{* *}$ & 0.01 \\
\hline Other & $-0.01^{*}$ & 0.01 \\
\hline Good flooring & $-0.01^{*}$ & 0.00 \\
\hline \multicolumn{3}{|c|}{ Education (ref: no education or primary) } \\
\hline Secondary & -0.01 & 0.01 \\
\hline Technical & $-0.02^{* *}$ & 0.01 \\
\hline University & $-0.06^{* *}$ & 0.01 \\
\hline Livestock & $0.02^{* *}$ & 0.00 \\
\hline Appliances & $-0.00^{* *}$ & 0.00 \\
\hline Observations & 17669 & \\
\hline$R^{2}$ & 0.06 & \\
\hline
\end{tabular}

Standard errors in parentheses; ${ }^{+} p<0.1,{ }^{*} p<0.05,{ }^{* *} p<0.01$; coefficients are expressed as average marginal effects.

Table A4.2: Matching quality

\begin{tabular}{lcccc}
\hline Sample & $\mathrm{R} 2$ & $\mathrm{p}>$ chi2 & Mean Bias & Median Bias \\
\hline Unmatched & 0.06 & 0.00 & 16.7 & 11.1 \\
Matched & 0.005 & 0.61 & 2.8 & 2.7 \\
\hline
\end{tabular}

Note: Estimates above show that the matching was done correctly, as the $\mathrm{R}^{2}$ of the model is almost zero and much smaller that the $\mathrm{R}^{2}$ before the matching. Moreover, the P-value of the likelihood-ratio test after matching is higher than 0.1 (i.e. no joint significance of all covariates after matching), as well as the standardized bias is highly reduced after matching and is less than $3 \%$. 
a)

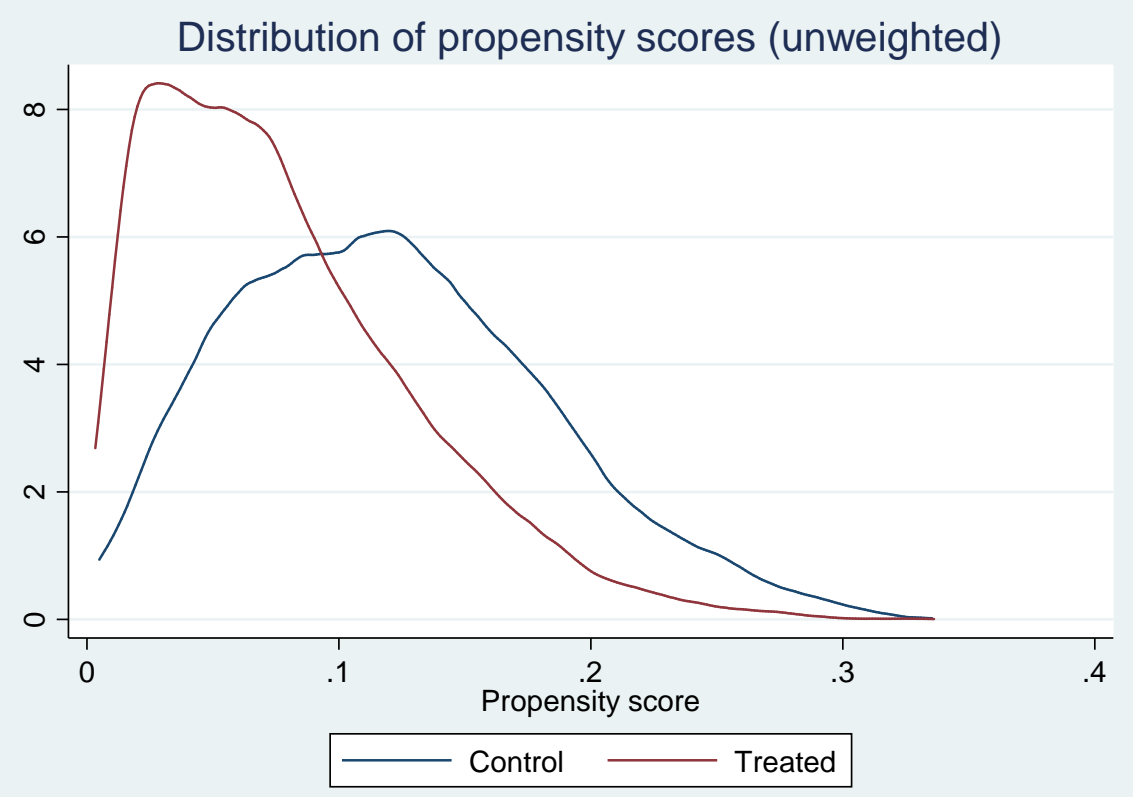

b)

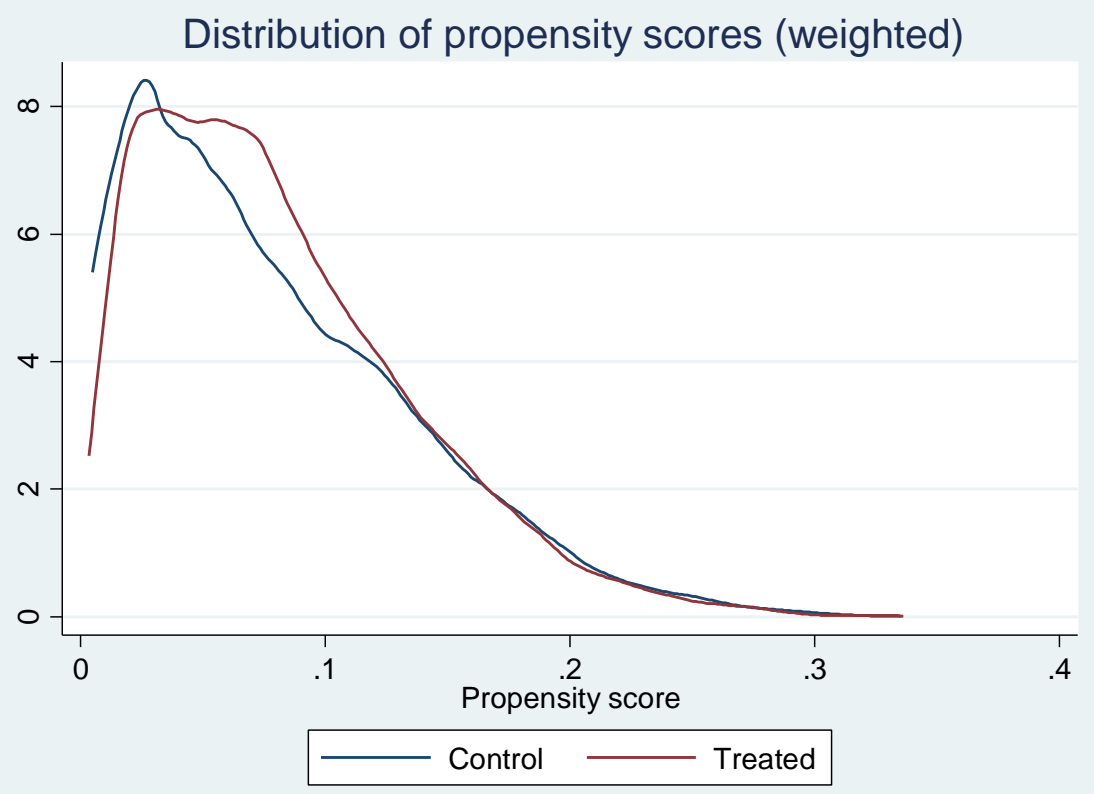

Figure A4.1: distribution of the probability of receiving social assistance before (a) and after (b) applying inverse probability weights 
Table A4.3: Summary statistics

\begin{tabular}{|c|c|c|c|c|c|}
\hline Variable & Obs & Mean & $\mathrm{SD}$ & Min & Max \\
\hline Receives SA & 17697 & 0.08 & 0.27 & 0 & 1 \\
\hline Male & 17697 & 0.46 & 0.50 & 0 & 1 \\
\hline Age & 17697 & 42.8 & 15.80 & 18 & 95 \\
\hline Age squared & 17697 & 2085 & 1489 & 324 & 9025 \\
\hline Married & 17697 & 0.73 & 0.44 & 0 & 1 \\
\hline Ethnic Kyrgyz & 17697 & 0.67 & 0.47 & 0 & 1 \\
\hline Uzbek & 17697 & 0.14 & 0.34 & 0 & 1 \\
\hline Russian & 17697 & 0.09 & 0.28 & 0 & 1 \\
\hline Other & 17697 & 0.11 & 0.31 & 0 & 1 \\
\hline \multicolumn{6}{|l|}{ Oblast } \\
\hline Jalal-Abad & 17697 & 0.15 & 0.36 & 0 & 1 \\
\hline Naryn & 17697 & 0.05 & 0.21 & 0 & 1 \\
\hline Batken & 17697 & 0.08 & 0.28 & 0 & 1 \\
\hline Osh & 17697 & 0.21 & 0.41 & 0 & 1 \\
\hline Talas & 17697 & 0.04 & 0.20 & 0 & 1 \\
\hline Chui & 17697 & 0.16 & 0.37 & 0 & 1 \\
\hline Bishkek & 17697 & 0.17 & 0.37 & 0 & 1 \\
\hline Osh city & 17697 & 0.05 & 0.21 & 0 & 1 \\
\hline Urban & 17697 & 0.37 & 0.48 & 0 & 1 \\
\hline HH size & 17697 & 5.36 & 2.34 & 1 & 15 \\
\hline HH has kids & 17697 & 0.73 & 0.11 & 0 & 1 \\
\hline Secondary & 17693 & 0.55 & 0.50 & 0 & 1 \\
\hline Technical & 17693 & 0.15 & 0.35 & 0 & 1 \\
\hline University & 17693 & 0.17 & 0.37 & 0 & 1 \\
\hline Works & 17674 & 0.27 & 0.45 & 0 & 1 \\
\hline Sports & 17681 & 0.19 & 0.39 & 0 & 1 \\
\hline Networks & 17408 & 0.36 & 0.48 & 0 & 1 \\
\hline Personality & 17650 & 0.00 & 0.82 & -3.29 & 2.19 \\
\hline Good flooring & 17693 & 0.72 & 0.45 & 0 & 1 \\
\hline Idiosyncratic shock & 17697 & 0.38 & 0.49 & 0 & 1 \\
\hline Asset index & 17697 & 0.09 & 0.92 & -1.07 & 3.11 \\
\hline Life satisfaction & 17697 & 6.82 & 2.07 & 0 & 10 \\
\hline Past & 17697 & 0.46 & 0.50 & 0 & 1 \\
\hline Future & 17697 & 0.54 & 0.50 & 0 & 1 \\
\hline Livestock & 17697 & 1.39 & 1.42 & 0 & 6 \\
\hline Appliances & 17697 & 3.38 & 1.44 & 0 & 7 \\
\hline Head agriculture & 17677 & 0.20 & 0.40 & 0 & 1 \\
\hline Head male & 17677 & 0.77 & 0.42 & 0 & 1 \\
\hline Head & 17697 & 0.38 & 0.49 & 0 & 1 \\
\hline Spouse & 17697 & 0.28 & 0.45 & 0 & 1 \\
\hline Son or daughter & 17697 & 0.25 & 0.43 & 0 & 1 \\
\hline Other & 17697 & 0.09 & 0.29 & 0 & 1 \\
\hline
\end{tabular}

Source: authors' calculations, LiK 2011, 2012 and 2013; estimates express averages across the three years 
Table A4.4: Association between social assistance and subjective well-being- cross-sections

\begin{tabular}{|c|c|c|c|c|c|c|c|c|c|}
\hline & \multicolumn{3}{|c|}{2011} & \multicolumn{3}{|c|}{2012} & \multicolumn{3}{|c|}{2013} \\
\hline & $\begin{array}{c}\text { Life } \\
\text { Satisfac- } \\
\text { tion }\end{array}$ & $\begin{array}{c}\text { Econ. } \\
\text { Situation } \\
\text { better than } \\
\text { past }\end{array}$ & $\begin{array}{l}\text { Expects } \\
\text { Econ situ- } \\
\text { ation to } \\
\text { improve }\end{array}$ & $\begin{array}{c}\text { Life } \\
\text { Satisfac- } \\
\text { tion }\end{array}$ & $\begin{array}{c}\text { Econ. } \\
\text { Situation } \\
\text { better than } \\
\text { past }\end{array}$ & $\begin{array}{l}\text { Expects } \\
\text { Econ situ- } \\
\text { ation to } \\
\text { improve }\end{array}$ & $\begin{array}{c}\text { Life } \\
\text { Satisfac- } \\
\text { tion }\end{array}$ & $\begin{array}{c}\text { Econ. } \\
\text { Situation } \\
\text { better than } \\
\text { past }\end{array}$ & $\begin{array}{l}\text { Expects } \\
\text { Econ situ- } \\
\text { ation to } \\
\text { improve }\end{array}$ \\
\hline \multirow[t]{2}{*}{ Receives SA } & $-0.20^{*}$ & -0.01 & -0.03 & $-0.29^{*}$ & -0.03 & $-0.06^{* *}$ & $-0.30^{*}$ & -0.01 & $-0.08^{*}$ \\
\hline & $(0.10)$ & $(0.02)$ & $(0.02)$ & $(0.12)$ & $(0.02)$ & $(0.02)$ & $(0.14)$ & $(0.04)$ & $(0.03)$ \\
\hline \multirow[t]{2}{*}{ Male } & $-0.20^{+}$ & -0.00 & -0.00 & -0.16 & 0.00 & 0.00 & -0.09 & 0.00 & -0.01 \\
\hline & $(0.11)$ & $(0.03)$ & $(0.04)$ & $(0.15)$ & $(0.03)$ & $(0.02)$ & $(0.16)$ & $(0.03)$ & $(0.03)$ \\
\hline \multirow[t]{2}{*}{ Age } & $-0.12^{* *}$ & -0.00 & 0.00 & -0.05 & $-0.01^{*}$ & $-0.01^{*}$ & 0.06 & -0.00 & -0.00 \\
\hline & $(0.03)$ & $(0.01)$ & $(0.01)$ & $(0.03)$ & $(0.00)$ & $(0.00)$ & $(0.05)$ & $(0.01)$ & $(0.01)$ \\
\hline \multirow[t]{2}{*}{ Age squared } & $0.00^{* *}$ & 0.00 & -0.00 & 0.00 & $0.00^{*}$ & $0.00^{*}$ & -0.00 & 0.00 & 0.00 \\
\hline & $(0.00)$ & $(0.00)$ & $(0.00)$ & $(0.00)$ & $(0.00)$ & $(0.00)$ & $(0.00)$ & $(0.00)$ & $(0.00)$ \\
\hline \multirow[t]{2}{*}{ Married } & $0.62^{* *}$ & 0.05 & -0.02 & $0.68^{* *}$ & 0.05 & 0.02 & 0.19 & -0.01 & $0.09^{*}$ \\
\hline & $(0.15)$ & $(0.04)$ & $(0.04)$ & $(0.17)$ & $(0.03)$ & $(0.03)$ & $(0.23)$ & $(0.04)$ & $(0.04)$ \\
\hline \multirow{2}{*}{$\begin{array}{l}\text { Ethnic } \\
\text { Kyrgyz }\end{array}$} & $0.24^{+}$ & $0.06^{+}$ & 0.03 & $0.32^{+}$ & $0.11^{* *}$ & $0.12^{* *}$ & 0.13 & $0.09^{*}$ & $0.09^{* *}$ \\
\hline & $(0.14)$ & $(0.03)$ & $(0.04)$ & $(0.17)$ & $(0.03)$ & $(0.03)$ & $(0.16)$ & $(0.04)$ & $(0.03)$ \\
\hline \multirow[t]{2}{*}{ Urban } & $-0.92^{* *}$ & $-0.15^{* *}$ & $-0.17^{* *}$ & $-0.53^{* *}$ & $-0.06^{+}$ & $-0.06^{+}$ & $-0.44^{* *}$ & $-0.17^{* *}$ & $-0.16^{* *}$ \\
\hline & $(0.15)$ & $(0.03)$ & $(0.04)$ & $(0.20)$ & $(0.03)$ & $(0.03)$ & $(0.10)$ & $(0.03)$ & $(0.03)$ \\
\hline \multirow[t]{2}{*}{$\mathrm{HH}$ size } & 0.03 & $0.02^{* *}$ & $0.03^{* *}$ & $0.07^{*}$ & $0.03^{* *}$ & $0.04^{* *}$ & $0.05^{*}$ & $0.01^{+}$ & $0.01^{+}$ \\
\hline & $(0.03)$ & $(0.01)$ & $(0.01)$ & $(0.03)$ & $(0.01)$ & $(0.01)$ & $(0.02)$ & $(0.01)$ & $(0.01)$ \\
\hline \multirow[t]{2}{*}{ HH has kids } & -0.11 & 0.00 & -0.02 & -0.24 & $-0.15^{* *}$ & $-0.14^{* *}$ & -0.22 & 0.04 & 0.02 \\
\hline & $(0.16)$ & $(0.05)$ & $(0.05)$ & $(0.20)$ & $(0.03)$ & $(0.03)$ & $(0.20)$ & $(0.04)$ & $(0.03)$ \\
\hline \multicolumn{10}{|c|}{ Education (ref category: primary or no education) } \\
\hline \multirow[t]{2}{*}{ Secondary } & 0.04 & -0.02 & -0.07 & -0.11 & $0.07^{+}$ & 0.03 & $-0.75^{* *}$ & 0.00 & $-0.12^{* *}$ \\
\hline & $(0.18)$ & $(0.04)$ & $(0.05)$ & $(0.22)$ & $(0.04)$ & $(0.04)$ & $(0.25)$ & $(0.04)$ & $(0.05)$ \\
\hline \multirow[t]{2}{*}{ Technical } & 0.08 & 0.05 & -0.04 & 0.13 & $0.10^{+}$ & 0.07 & $-1.16^{* *}$ & -0.01 & $-0.12^{+}$ \\
\hline & $(0.23)$ & $(0.05)$ & $(0.06)$ & $(0.28)$ & $(0.05)$ & $(0.05)$ & $(0.43)$ & $(0.05)$ & $(0.07)$ \\
\hline \multirow[t]{2}{*}{ University } & 0.17 & 0.10 & 0.07 & -0.26 & $0.09^{+}$ & 0.07 & $-0.84^{*}$ & 0.07 & -0.11 \\
\hline & $(0.31)$ & $(0.07)$ & $(0.07)$ & $(0.35)$ & $(0.05)$ & $(0.05)$ & $(0.41)$ & $(0.09)$ & $(0.07)$ \\
\hline \multirow[t]{2}{*}{ Works } & 0.08 & -0.03 & 0.03 & 0.21 & 0.02 & 0.03 & $0.26^{+}$ & 0.02 & -0.03 \\
\hline & $(0.16)$ & $(0.04)$ & $(0.04)$ & $(0.17)$ & $(0.03)$ & $(0.03)$ & $(0.14)$ & $(0.04)$ & $(0.03)$ \\
\hline \multirow[t]{2}{*}{ Plays sports } & $0.43^{* *}$ & $0.19^{* *}$ & $0.11^{* *}$ & $0.61^{* *}$ & 0.01 & 0.03 & $0.74^{* *}$ & $0.09^{*}$ & $0.10^{* *}$ \\
\hline & $(0.15)$ & $(0.04)$ & $(0.04)$ & $(0.17)$ & $(0.03)$ & $(0.04)$ & $(0.14)$ & $(0.04)$ & $(0.03)$ \\
\hline \multirow[t]{2}{*}{ Personality } & $0.52^{* *}$ & 0.01 & $0.03^{+}$ & $0.77^{* *}$ & $0.10^{* *}$ & $0.11^{* *}$ & $0.25^{* *}$ & -0.00 & 0.02 \\
\hline & $(0.08)$ & $(0.02)$ & $(0.02)$ & $(0.09)$ & $(0.01)$ & $(0.01)$ & $(0.08)$ & $(0.02)$ & $(0.01)$ \\
\hline \multirow[t]{2}{*}{ Asset index } & $0.81^{* *}$ & $0.12^{* *}$ & $0.15^{* *}$ & $0.24^{*}$ & $0.10^{* *}$ & $0.09^{* *}$ & $0.22^{*}$ & 0.04 & $0.06^{* *}$ \\
\hline & $(0.08)$ & $(0.02)$ & $(0.02)$ & $(0.11)$ & $(0.02)$ & $(0.02)$ & $(0.10)$ & $(0.03)$ & $(0.02)$ \\
\hline Experienced & 0.03 & -0.01 & 0.01 & -0.15 & $-0.10^{* *}$ & $-0.10^{* *}$ & -0.11 & $-0.05^{+}$ & $-0.09^{* *}$ \\
\hline $\begin{array}{l}\text { Idiosyncratic } \\
\text { shock }\end{array}$ & $(0.13)$ & $(0.04)$ & $(0.04)$ & $(0.13)$ & $(0.02)$ & $(0.02)$ & $(0.15)$ & $(0.03)$ & $(0.03)$ \\
\hline \multirow[t]{2}{*}{ Constant } & $8.37^{* *}$ & 0.06 & 0.09 & $6.76^{* *}$ & $0.26^{*}$ & $0.41^{* *}$ & $5.99^{* *}$ & $0.22^{+}$ & $0.50^{* *}$ \\
\hline & $(0.75)$ & $(0.12)$ & $(0.11)$ & $(0.60)$ & $(0.12)$ & $(0.12)$ & (1.04) & $(0.11)$ & $(0.17)$ \\
\hline Observations & 5873 & 5873 & 5873 & 5874 & 5874 & 5874 & 5842 & 5842 & 5842 \\
\hline$R^{2}$ & 0.23 & 0.17 & 0.19 & 0.28 & 0.18 & 0.21 & 0.21 & 0.14 & 0.21 \\
\hline
\end{tabular}

Linear probability OLS regressions with robust standard errors and inverse probability weights; ${ }^{+} p<0.1,{ }^{*} p<0.05,{ }^{* *} p<0.01$; Regressions also include oblast fixed effects. 
Table A4.5: Difference in difference estimation, full model

\begin{tabular}{|c|c|c|c|}
\hline & $\begin{array}{c}\text { Life } \\
\text { Satisfaction }\end{array}$ & $\begin{array}{l}\text { Economic } \\
\text { Situation better than past }\end{array}$ & $\begin{array}{c}\text { Expects } \\
\text { Economic situation to improve }\end{array}$ \\
\hline \multirow[t]{2}{*}{ Treated only in $2012 *$ year2012 } & 0.20 & -0.04 & $-0.09^{* *}$ \\
\hline & $(0.12)$ & $(0.03)$ & $(0.03)$ \\
\hline \multirow[t]{2}{*}{ Treated only in $2013 *$ year 2013} & 0.26 & 0.06 & 0.01 \\
\hline & $(0.19)$ & $(0.05)$ & $(0.05)$ \\
\hline Treated in 2012 and & -0.18 & $-0.15^{*}$ & $-0.18^{* *}$ \\
\hline $2013 *$ year2012 & $(0.26)$ & $(0.06)$ & $(0.06)$ \\
\hline Treated in 2012 and & -0.22 & -0.01 & -0.02 \\
\hline $2013 *$ year2013 & $(0.25)$ & $(0.06)$ & $(0.06)$ \\
\hline \multirow[t]{2}{*}{ Treated only in 2012} & -0.09 & 0.00 & $0.04^{*}$ \\
\hline & $(0.07)$ & $(0.02)$ & $(0.02)$ \\
\hline \multirow[t]{2}{*}{ Treated only in 2013} & $-0.43^{* *}$ & $-0.11^{* *}$ & $-0.11^{* *}$ \\
\hline & $(0.12)$ & $(0.03)$ & $(0.03)$ \\
\hline \multirow[t]{2}{*}{ Treated in 2012 and 2013} & 0.19 & 0.04 & -0.00 \\
\hline & $(0.21)$ & $(0.05)$ & $(0.05)$ \\
\hline \multirow[t]{2}{*}{ Year 2012} & $0.20^{* *}$ & $0.05^{* *}$ & $0.05^{* *}$ \\
\hline & $(0.04)$ & $(0.01)$ & $(0.01)$ \\
\hline \multirow[t]{2}{*}{ Year 2013} & $0.20^{* *}$ & $0.06^{* *}$ & $0.08^{* *}$ \\
\hline & $(0.04)$ & $(0.01)$ & $(0.01)$ \\
\hline \multirow[t]{2}{*}{ Male } & $-0.10^{* *}$ & -0.01 & -0.01 \\
\hline & $(0.03)$ & $(0.01)$ & $(0.01)$ \\
\hline \multirow[t]{2}{*}{ Age } & $-0.05^{* *}$ & $-0.00^{*}$ & -0.00 \\
\hline & $(0.01)$ & $(0.00)$ & $(0.00)$ \\
\hline \multirow[t]{2}{*}{ Age squared } & $0.00^{* *}$ & $0.00^{* *}$ & 0.00 \\
\hline & $(0.00)$ & $(0.00)$ & $(0.00)$ \\
\hline \multirow[t]{2}{*}{ Married } & $0.44^{* *}$ & $0.06^{* *}$ & $0.04^{* *}$ \\
\hline & $(0.04)$ & $(0.01)$ & $(0.01)$ \\
\hline \multirow[t]{2}{*}{ Ethnic kyrgyz } & $0.29^{* *}$ & $0.09^{* *}$ & $0.10^{* *}$ \\
\hline & $(0.04)$ & $(0.01)$ & $(0.01)$ \\
\hline \multirow[t]{2}{*}{ Urban } & $-0.56^{* *}$ & $-0.09^{* *}$ & $-0.07^{* *}$ \\
\hline & $(0.05)$ & $(0.01)$ & $(0.01)$ \\
\hline \multirow[t]{2}{*}{$\mathrm{HH}$ size } & $0.02^{*}$ & $0.01^{* *}$ & $0.01^{* *}$ \\
\hline & $(0.01)$ & $(0.00)$ & $(0.00)$ \\
\hline \multirow[t]{2}{*}{ HH has kids } & $0.10^{*}$ & 0.01 & 0.02 \\
\hline & $(0.04)$ & $(0.01)$ & $(0.01)$ \\
\hline \multirow[t]{2}{*}{ Works } & $0.23^{* *}$ & $0.03^{* *}$ & 0.01 \\
\hline & $(0.04)$ & $(0.01)$ & $(0.01)$ \\
\hline \multirow[t]{2}{*}{ Plays sports } & $0.45^{* *}$ & $0.09^{* *}$ & $0.08^{* *}$ \\
\hline & $(0.04)$ & $(0.01)$ & $(0.01)$ \\
\hline \multirow[t]{2}{*}{ Personality } & $0.43^{* *}$ & $0.05^{* *}$ & $0.08^{* *}$ \\
\hline & $(0.02)$ & $(0.00)$ & $(0.00)$ \\
\hline \multirow[t]{2}{*}{ Asset index } & $0.41^{* *}$ & $0.06^{* *}$ & $0.06^{* *}$ \\
\hline & $(0.02)$ & $(0.01)$ & $(0.00)$ \\
\hline \multirow[t]{2}{*}{ Idiosyncratic shock } & $-0.21^{* *}$ & $-0.04^{* *}$ & $-0.03^{* *}$ \\
\hline & $(0.03)$ & $(0.01)$ & $(0.01)$ \\
\hline \multirow[t]{2}{*}{ Constant } & $7.05^{* *}$ & $0.17^{* *}$ & $0.24^{* *}$ \\
\hline & $(0.14)$ & $(0.03)$ & $(0.03)$ \\
\hline Observations & 17079 & 17079 & 17079 \\
\hline $\mathrm{R}^{2}$ & 0.13 & 0.10 & 0.14 \\
\hline
\end{tabular}

Linear probability OLS regressions; Robust standard errors in parentheses; ${ }^{+} p<0.1,{ }^{*} p<0.05,{ }^{* *} p<0.01$; Regressions include oblast fixed effects and control for the level of education of respondents. 
Chapter 4

Table A4.6: Difference in difference estimation with inverse probability weights, full model

\begin{tabular}{|c|c|c|c|}
\hline & Life & Economic & Expects \\
\hline & Satisfaction & Situation better than past & Economic situation to improve \\
\hline \multirow[t]{2}{*}{ Treated in $2012 *$ year2012 } & $-0.47^{*}$ & $-0.11^{*}$ & $-0.17^{* *}$ \\
\hline & $(0.21)$ & $(0.04)$ & $(0.04)$ \\
\hline \multirow[t]{2}{*}{ Treated in 2012} & 0.01 & 0.04 & $0.08^{*}$ \\
\hline & $(0.17)$ & $(0.04)$ & $(0.04)$ \\
\hline \multirow[t]{2}{*}{ Year 2012} & $0.23^{* *}$ & $0.05^{* *}$ & $0.06^{* *}$ \\
\hline & $(0.06)$ & $(0.01)$ & $(0.01)$ \\
\hline \multirow[t]{2}{*}{ Male } & -0.14 & -0.02 & 0.01 \\
\hline & $(0.19)$ & $(0.02)$ & $(0.02)$ \\
\hline \multirow[t]{2}{*}{ Age } & -0.02 & $-0.01^{* *}$ & $-0.01^{*}$ \\
\hline & $(0.04)$ & $(0.00)$ & $(0.00)$ \\
\hline \multirow[t]{2}{*}{ Age squared } & 0.00 & $0.00^{*}$ & $0.00^{+}$ \\
\hline & $(0.00)$ & $(0.00)$ & $(0.00)$ \\
\hline \multirow[t]{2}{*}{ Married } & $0.90^{* *}$ & $0.10^{* *}$ & $0.11^{* *}$ \\
\hline & $(0.17)$ & $(0.02)$ & $(0.03)$ \\
\hline \multirow[t]{2}{*}{ Ethnic Kyrgyz } & $0.32^{+}$ & $0.14^{* *}$ & $0.13^{* *}$ \\
\hline & $(0.18)$ & $(0.02)$ & $(0.03)$ \\
\hline \multirow[t]{2}{*}{ Urban } & $-0.39^{* *}$ & $-0.09^{* *}$ & $-0.09^{* *}$ \\
\hline & $(0.13)$ & $(0.02)$ & $(0.02)$ \\
\hline \multirow[t]{2}{*}{$\mathrm{HH}$ size } & $0.05^{+}$ & $0.03^{* *}$ & $0.03^{* *}$ \\
\hline & $(0.02)$ & $(0.00)$ & $(0.00)$ \\
\hline \multirow[t]{2}{*}{ HH has kids } & $-0.35^{+}$ & $-0.09^{* *}$ & $-0.08^{* *}$ \\
\hline & $(0.19)$ & $(0.03)$ & $(0.03)$ \\
\hline \multirow[t]{2}{*}{ Secondary } & $-0.39^{+}$ & 0.03 & -0.01 \\
\hline & $(0.23)$ & $(0.03)$ & $(0.03)$ \\
\hline \multirow[t]{2}{*}{ Technical } & -0.17 & 0.02 & 0.05 \\
\hline & $(0.27)$ & $(0.04)$ & $(0.04)$ \\
\hline \multirow[t]{2}{*}{ University } & $-0.87^{*}$ & 0.00 & 0.00 \\
\hline & $(0.42)$ & $(0.05)$ & $(0.05)$ \\
\hline \multirow[t]{2}{*}{ Works } & 0.17 & $0.04^{+}$ & 0.04 \\
\hline & $(0.18)$ & $(0.02)$ & $(0.03)$ \\
\hline \multirow[t]{2}{*}{ Plays sports } & $0.86^{* *}$ & $0.09^{* *}$ & $0.14^{* *}$ \\
\hline & $(0.17)$ & $(0.03)$ & $(0.04)$ \\
\hline \multirow[t]{2}{*}{ Personality } & $0.72^{* *}$ & $0.08^{* *}$ & $0.11^{* *}$ \\
\hline & $(0.07)$ & $(0.01)$ & $(0.01)$ \\
\hline \multirow[t]{2}{*}{ Asset index } & $0.21^{+}$ & $0.07^{* *}$ & $0.05^{* *}$ \\
\hline & $(0.12)$ & $(0.01)$ & $(0.02)$ \\
\hline \multirow[t]{2}{*}{ Idiosyncratic shock } & -0.23 & $-0.04^{+}$ & $-0.06^{* *}$ \\
\hline & $(0.16)$ & $(0.02)$ & $(0.02)$ \\
\hline \multirow[t]{2}{*}{ Constant } & $6.44^{* *}$ & $0.25^{* *}$ & $0.28^{* *}$ \\
\hline & $(0.46)$ & $(0.08)$ & $(0.08)$ \\
\hline Observations & 11107 & 11107 & 11107 \\
\hline$R^{2}$ & 0.29 & 0.17 & 0.22 \\
\hline
\end{tabular}

Linear probability OLS regressions; Robust standard errors in parentheses; ${ }^{+} p<0.1,{ }^{*} p<0.05,{ }^{* *} p<0.01$. Regressions include oblast fixed effects 
Table A4.7: Personality index, factor analysis

\begin{tabular}{lccc}
\hline Variable & Eigenvalue & Factor & Uniqueness \\
\hline Extraversion & 1.49 & -0.37 & 0.86 \\
Openness & 0.29 & 0.53 & 0.72 \\
Agreeableness & -0.01 & 0.49 & 0.76 \\
Neuroticism & -0.20 & 0.62 & 0.61 \\
Conscientiousness & -0.25 & 0.67 & 0.56 \\
\hline
\end{tabular}

Note: only eigenvalues higher than one are retained, although the index is robust to different options.

Table A4.8: Asset index, factor analysis

\begin{tabular}{lccc}
\hline Variable & Eigenvalue & Factor & Uniqueness \\
\hline Refrigerator & 2.16 & 0.32 & 0.90 \\
Gas stove & 0.76 & 0.58 & 0.66 \\
Electric stove & 0.36 & -0.09 & 0.99 \\
Microwave & 0.26 & 0.46 & 0.79 \\
Sewing machine & 0.13 & -0.03 & 0.99 \\
Washing machine & -0.01 & -0.18 & 0.97 \\
Washing machine & -0.05 & 0.68 & 0.54 \\
Mobile phone & -0.07 & 0.12 & 0.99 \\
Landline phone & -0.12 & 0.60 & 0.64 \\
Internet & -0.15 & 0.52 & 0.73 \\
TV & -0.17 & 0.08 & 0.99 \\
Computer & -0.22 & 0.60 & 0.64 \\
Radio & -0.27 & 0.07 & 0.99
\end{tabular}

Note: only eigenvalues higher than one are retained, although the index is robust to different options. 
Chapter 5

Chapter 5

In pursuit of happiness: do remittances improve subjective well-being?

Chapter

In pursuit of happiness: do remittances improve subjective well-being?

"People think about life in terms of changes, not levels. They can be changes from the status quo or changes from what was expected, but whatever form they take, it is changes that make us happy or miserable."

(Richard H. Thaler)

"Happiness is the meaning and purpose in life" (Aristotle) 
In pursuit of happiness: do remittances improve subjective well-being? 


\subsection{Introduction}

Subjective well-being is an important -yet understudied- topic in the migration and remittances literature. The self-assessment by individuals of their own situation with respect to economic, social or political aspects of life is important, as each person is likely able to best assess their own welfare (Anderson 2014). Moreover, there is recent literature stating that different dimensions of subjective well-being, such as lack of stress, happiness, and satisfaction with life are positively related with increased productivity, improved decision making, and better educational and health outcomes (Attah et al. 2016). ${ }^{43}$ While extensive evidence has been found of remittances having a positive effect on objective measures of well-being of the household left behind, such as income, consumption, asset accumulation, or educational attainment (see Ratha and Mohapatra (2011) for a review of studies), the relationship between remittances and subjective wellbeing is more ambiguous.

When analysing indicators such as life satisfaction, circumstances associated with migration such as family separation may imply that remittances do not increase happiness, or that the increased satisfaction due to an improved economic situation cannot offset the decline in happiness due to the migration of a relative and the hard-living conditions he/she has to face abroad (Borraz 2008; Jones 2015). Moreover, if one looks at relative measures of well-being (how individuals compare themselves to others), it is possible that the migration experience of a household member exposed migrant households to other lifestyles and therefore the subjective benchmark may now be a different (richer) reference group. For instance, there is recent evidence that migration does not lead to happiness because, among other reasons, people adjust their reference group (Bartram 2013). On the other hand, individuals could feel that they are better off if migration increases their economic or social status or if the increase in income is highly correlated with improvements in subjective well-being.

While several studies have looked at the effects of migration and remittances on the subjective well-being of migrants, studies looking at the subjective well-being of the household left behind are more limited. Anderson (2014), looking at the effects of remittances on subjective economic well-being in Ethiopia using matching techniques, finds that money transfers from migrants have a significant and positive impact on household subjective economic well-being. Semyonov (2008) combines two measures of subjective economic well-being, the households' self-reported capacity to meet its basic needs and its self-assessed relative position compared to the average Filipino family, and finds a positive effect of remittances on household well-being.

${ }^{43}$ A more extensive definition and discussion of subjective well-being is given in the previous chapter. 
Looking at indicators such as happiness or satisfaction with the economic situation of the household, studies from Latin America find positive or no effects of remittances, but negative effects of migration. This means that remittances cannot compensate for the decrease in happiness associated with the loss of a family member. Borraz et al. (2008) investigate the impact of migration and remittances on household self-reported happiness in Ecuador, and find that households with close family members abroad (parents, children, spouses) are less happy than households without a close migrant, whereas remittances appear to have no effect on happiness. Jones (2015) finds that the perceived economic situation in Mexico improves as a result of remittances received from abroad, but that happiness is lower when compared to non-migrants. The author concludes that social cohesion (family unity and maintenance of values) is an important determinant of happiness, and that the decline in happiness due to lower social cohesion (as a result of migration) is higher than the increase in happiness due to remittances. Similarly, Jones (2013) findings from his research in Bolivia indicate that economic well-being due to migration increases levels of family happiness. However, family disintegration resulting from migration decreases family happiness even more, with the net result that migrant households are considerably less happy than non-migrant households.

Drawing on three rounds of the Life in Kyrgyzstan Survey, this paper studies how remittances affect subjective well-being in Kyrgyzstan. This paper contributes to the existing literature by introducing a new case study and by looking at how money transfers from abroad affect both life satisfaction (often used as a proxy for happiness) as well as subjective economic well-being. High levels of unemployment after the collapse of the Soviet Union, and a lack of livelihood opportunities in rural areas of Kyrgyzstan, resulted in many families choosing migration as the only way out of poverty (ICG 2016). Remittances, therefore, constitute an important poverty reduction strategy and many families rely on them to cover their daily needs (Guelfi and Sattar 2015). The specificities of migration in Kyrgyzstan, its history as a member of the Soviet Union, and its family values and traditions, are likely to influence the relationship between remittances and subjective well-being and, consequently, lead to different findings from the previous case studies analysed so far.

The next section provides a more detailed overview of migration and remittances in Kyrgyzstan, while section 5.3 presents the data and the empirical strategy to study the relationship between remittances and subjective well-being. Section 5.4 discusses the results, while section 5.5 concludes. 


\subsection{Case study: Kyrgyzstan}

Kyrgyzstan is considered one of the poorest countries in Central Asia. The country's main economic activity is agriculture (predominantly farming), and a third of its population is considered poor. Lack of livelihood opportunities in rural areas, where most of the poor live, encourages families to engage in migration to escape poverty (World Bank 2017). As a result, the country is highly dependent on remittances: in 2016, money sent by migrants abroad accounted for 34.5 percent of the country's GDP (World Bank and KNOMAD 2017), which makes Kyrgyzstan first in the world in terms of the relative importance of international remittances to the country's economy.

Following the dissolution of the Soviet Union, limited income generating opportunities due to low industrial production resulted in many working age adults seeking better opportunities abroad. Labour migrants mainly seek temporarily employment in Russia and other neighbouring countries (Lukashova and Makenbaeva 2009). In 2010, the stock of migrants was estimated at 204,382 (UNDP 2017). This is a conservative estimate as it does not take into account long-term migrants that are no longer considered a part of the household, or a large number of the undocumented and irregular migrants (Ruget and Usmanalieva 2008). Other sources (Lukashova and Makenbaeva 2009) give estimates that go up to 1 million migrants.

Migration is part of the everyday people's lives in Kyrgyzstan, and it is mainly a temporary solution for young people that should conclude with return (Thieme 2014). Due to the determinant role of remittances -received by approximately 25 percent of the Kyrgyz population- for poverty reduction (Gassmann and Zardo Trindade 2015; Guelfi and Sattar 2015), migration is regarded as something positive as it has significantly improved the economic situation of households. Nevertheless, the side effects of migration include labor shortages and lack of qualified and well-trained personnel in rural areas, where most migrants come from (Thieme 2014).

While it is clear that the economic situation of migrant households has improved as a result of migration, the subjective assessment of individuals of their own well-being can also include the wider impacts of migration for the family and the community such as labour shortages and changes in care arrangements for children and the elderly (Thieme 2014). As a social worker from the province of Batken explains in an interview: "Our country is saved by migration"... but it has destroyed the family as an institution, and children are left bebind" (ICG 2016, P.4). As a result, and while one would expect migrant families to report an improvement in their economic situation, the effects on life satisfaction will depend on how individuals define well-being and how migration affects the different components of well-being, which not only include material aspects. 


\subsection{Data and methodology}

\subsubsection{Data and indicators}

This analysis draws on data from the Life in Kyrgyzstan (LiK) survey, a longitudinal dataset which covers a sample of approximately 3,000 households (and 8,000 individuals) and is representative at the national level. Three waves (2011, 2012, and 2013) are used and merged into a balanced panel. Regarding the measures of well-being used, the first one relates to the general satisfaction with life, and the other two constitute subjective measures of economic well-being: whether the household's economic situation has improved with respect to the previous year, and whether the household expects to be better-off in the next year.

The main explanatory variable is the amount of remittances received by the respondent's household. This variable is based on the sub-section "material aid" of the household questionnaire, which asks whether the household has received money transfers from persons living abroad and, if this is the case, the average amount received per month. A more detailed explanation of the dataset and subjective well-being indicators analysed are provided in Chapter 4.

The LiK dataset includes many variables which are relevant in determining subjective well-being and can therefore be included in the analysis (see Handa et al. 2014; Deaton 2008; Stevenson and Wolfers 2008). These include basic demographic and socio-economic characteristics of respondents -such as sex, age, education, ethnicity, and whether the individual works-, as well as household characteristics, such as whether the household experienced an idiosyncratic shock in the last year, the household size, assets holding, and place of residence (including the oblast and whether the household lives in an urban or rural area). ${ }^{44}$ Asset holding is an index created through factor analysis, and includes media appliances (such as radio, computer, television, mobile phone) and home appliances (including refrigerator, washing machine, etc.).

Finally, the analysis includes individual characteristics that are expected to affect subjective well-being, such as whether the individual practices sports. Given that the survey includes a section on personality consisting of different questions that measure the extent of extraversion, openness, agreeableness, neuroticism, and conscientiousness of the respondent (the big five personality traits), I create an index for personality and include it as an independent variable in the regressions. ${ }^{45}$

\footnotetext{
44 Other variables such as quality of flooring or the income per capita before transfers were originally included in the analysis, but were finally left out as they were highly correlated with other welfare variables and lacked explanatory power.

45 The asset and personality indices are created in the same way as in the previous chapter (see appendix A4).
} 


\subsubsection{Empirical strategy}

To estimate the relationship between remittances and subjective well-being and using the three years of data available, several versions of the following equation are estimated:

$$
S W B_{\text {ihkt }}=\beta_{0}+\beta_{1} \log \left(\text { rem }_{\text {ihkt }}\right)+\beta_{2} Y_{\text {ihkt }}+\beta_{3} X_{\text {hkt }}+\alpha_{k}+\epsilon_{\text {ihkt }}
$$

Where $i$ indexes individuals, $b$ households, $k$ oblasts, and $t$ time (years). $S W B_{\text {inkt }}$ refers to three different subjective well-being indicators, while rem $_{\text {ihkt }}$ is the main explanatory variable that indicates the monthly per capita amount of remittances received by an individual. As robustness checks, the value of remittances is substituted with a binary variable indicating treatment status (whether or not an individual lives in a household that receives remittances). $Y_{i h k t}$ is a vector of individual level controls, whereas $X_{h k t}$ is a vector of household level controls. $\alpha_{k}$ refers to the oblast fixed effects, and $\epsilon_{i h k t}$ is the idiosyncratic error.

Panel data techniques are useful to address econometric challenges such as unobserved heterogeneity, which arises when the explanatory variables are correlated with individual unobserved effects. In this specific case, one can expect that certain variables which are unobserved and are expected to influence whether an individual receives remittances, such as ability, motivation, specific needs that the individual may have, may also influence his or her level of life satisfaction or subjective economic well-being. When the dependent variable is continuous, this is often solved by estimating a fixed effects regression, exploiting the within individual variation over time. However, this is not possible in nonlinear models (for example, in cases where the dependent variable is dichotomous).

One way to solve this problem is by applying a correlated random effects model (CRE) employing the Mundlak (1978) approach, which allows correlation between the unobserved individual effects and the regressors by adding group means of the time varying explanatory variables in the model (Gebreeyesus 2015). Given that the subjective wellbeing variables analysed in this paper can be either binary (in the case of therelative economic situation with respect to the past and to the future) or ordinal (in the case of the life satisfaction indicator), I estimate correlated random effects probit in the first case, and correlated random effects ordered probit in the second one. A modified version of the model is shown below:

$$
\begin{aligned}
& S W B^{*}{ }_{i h k t}=\beta_{0}+\beta_{1}\left(\text { rem }_{\text {ihkt }}\right)+\beta_{2} Y_{i h k t}+\beta_{3} X_{h k t}+\beta_{4} \bar{Y}_{i h k t}+\beta_{5} \bar{X}_{h k t}+\alpha_{k}+ \\
& \epsilon_{\text {ihkt }}
\end{aligned}
$$

Equation (2) is an extended version of (1), and incorporates a vector of the average time varying variables to control for unobserved heterogeneity. $S W B^{*}$ is the latent variable 
to be estimated. Alternatively, linear probability models are estimated treating the dependent variables as continuous and incorporating the time invariant error or individual fixed effect " $\alpha_{i}$ ".

Although panel data analysis can solve the heterogeneity and self-selection problem ${ }^{46}$ (assuming that the unobserved variables correlated with the variables in the regression are time invariant), in the case of remittances there can also be a problem of reverse causality that cannot be solved with fixed effects estimators. The reason for this is that low levels of life satisfaction or subjective economic well-being can drive members of a household to migrate and therefore to send remittances. To solve the identification problem, an instrumental variable approach is used.

The instrument is an indicator of migrant networks (measured through the percentage of households in the community with a migrant abroad) interacted with a variable indicating the percentage of households in the community where the eldest person speaks Russian as a second language. The first one has been widely used in the migration literature, as networks are shared at the community level and decrease the costs of migration (McKenzie and Rapoport, 2007; Waidler et al. 2016, among others). Regarding the second one, and given that the majority of migrants go to Russia, one can assume that those individuals who grew up in a household where a member spoke Russian are more likely to migrate. A similar instrument has been used by Azzarri and Zezza (2011) for Tajikistan, a country that shares the same past Soviet history and has similar migration patterns to Kyrgyzstan. According to the sample used, only 6 percent of respondents are ethnic Russians and the majority speaks Kyrgyz as a first language, so it is unlikely that living in a household where a household member speaks Russian is correlated with individual subjective well-being, which would violate the exogeneity condition. ${ }^{47}$ Both indicators are defined at a community level, as in this way they are less likely to influence the dependent variable. While this paper acknowledges that the instrument could still violate the exogeneity condition, the aim is to see whether results hold when applying this technique, as this will give more validity to the findings.

The two-stage least squares (2SLS) method of instrumental variable estimation is used. The instrumental variable estimation is denoted as:

$$
S W B_{\text {ihkt }}=\beta_{0}+\beta_{1} \log \left(\text { rem }^{*}{ }_{\text {ihkt }}\right)+\beta_{2} Y_{\text {ihkt }}+\beta_{3} X_{h k t}+\alpha_{k}+\epsilon_{\text {ihkt }}
$$

Where $S W B$ is the outcome variable, $\mathrm{rem}^{*}$ is the instrumented variable indicating the amount of per capita remittances that households receive (measured in logs), and $Y$ and

\footnotetext{
${ }^{46}$ Recipients of remittances are not randomly assigned, and therefore they are likely to have specific characteristics which are different from non-recipients.

${ }^{47}$ To be cautious, however, we also estimate the regressions using only the instrument for networks (and exclude the language one). Results remain qualitatively very similar.
} 
$\mathrm{X}$ are the same exogenous variables included in the models presented above. The estimation is performed in two steps: first, the amount of remittances is estimated based on the instrument (Networks and Russian as a second language interaction variable) and the other exogenous variables. Second, the fitted values of the first regression are used in the main equation to predict subjective well-being.

\subsection{Results}

\subsubsection{Descriptive results}

Given that the subjective well-being questionnaire was only administered to individuals over 17 years old, this analysis only includes adult respondents. After removing from the sample those individuals who did not answer the subjective well-being questionnaire in the three years, the final balanced sample is made of 5,899 individuals. The tables below show some descriptive statistics of the final sample. Table 5.1 shows the percentage of individuals living in households receiving international remittances, as well as the average amount received (per capita), and the percentage of total household income that this transfer represents. More than 15 percent of individuals in the sample live in households receiving remittances. International remittances have been increasing in value and constitute an important source of income in recipient households: in 2013, 56 percent of household income came from international remittances. Table 5.1 also shows that the majority of migrant households (more than 80 percent) receive remittances.

Table 5.1: Transfer incidence by year

\begin{tabular}{|c|c|c|c|}
\hline International remittances & 2011 & 2012 & 2013 \\
\hline$\%$ living in recipient households & 15.7 & 15.2 & 16.3 \\
\hline$\%$ living in recipient -migrant-households & 88.5 & 82.2 & 81.2 \\
\hline Per capita received in recipient hhs $(\mathrm{KGS})^{*}$ & 982 & 1683 & 2672 \\
\hline $\begin{array}{l}\% \text { of remittances out of total income in recipient } \\
\text { households }\end{array}$ & 30.9 & 39.1 & 56.0 \\
\hline
\end{tabular}

Source: authors' calculations; LiK 2011, 2012, 2013. *KGS is the abbreviation of the local currency (Kyrgyz Som).

Figure 5.1 shows the mean levels of life satisfaction by transfer recipient status. In general, differences in average levels of life satisfaction between remittance recipients and non-recipients are small. Remittance recipients are slightly more satisfied than non-recipients in 2011 as well as in 2012 (although in the first case differences are only significant at a 10 percent level). Looking at subjective economic well-being (figure 5.2), remittance recipients have always, on average, higher subjective well-being levels than nonrecipients, and differences are always significant at a 1 percent level. 
At a first glance, it seems that remittance recipients have better economic conditions than non-recipients, yet differences in life satisfaction are smaller or insignificant. These descriptive results only provide a preliminary view of how subjective well-being differs between remittance recipients and non-recipients, however. In order to see the extent to which remittances affect subjective well-being, regression analysis is needed. Table A5.1 in the appendix presents a descriptive summary of all the variables used in the analysis, and the next sub-section shows the results from the econometric estimations.

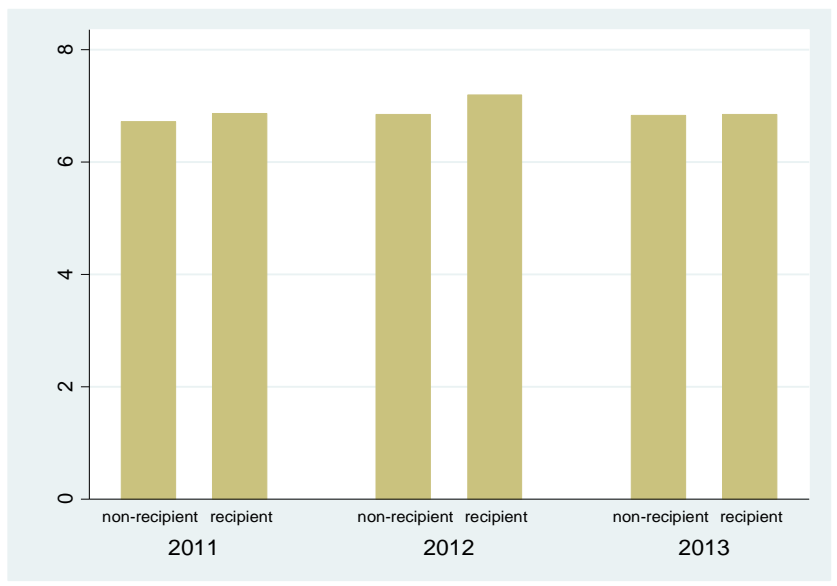

Figure 5.1: Average life satisfaction by remittance recipient status

Source: authors' calculations, LiK 2011, 2012, and 2013.

Differences between recipients and non-recipients are significant in 2011 (at a 10\% level), and in 2012 (at a 1\% level)

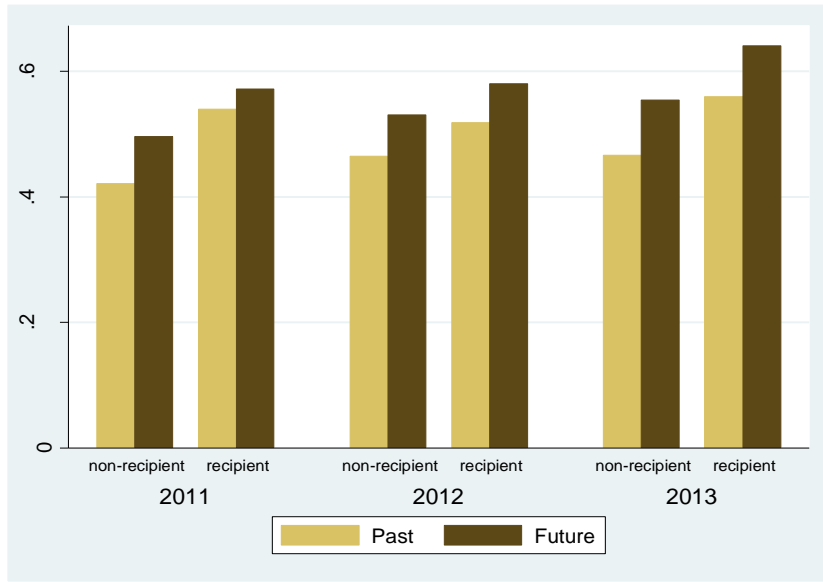

Figure 5.2: Subjective economic well-being by transfer recipient status

Source: authors' calculations, LiK 2011, 2012, and 2013.

Differences between recipients and non-recipients are always significant at a 1\% level 


\subsubsection{Results from regression analysis}

The effects of transfers on life satisfaction are shown in table 5.2, whereas tables 5.3 and 5.4 show the results for the subjective economic wellbeing indicators. The effect of remittances on life satisfaction is insignificant in all specifications, and this also holds when one looks at the continuous variable as well as the binary variable indicating remittance recipient status (table A5.3 in the appendix). This means one cannot conclude that money sent from migrants living abroad corresponds with increases in life satisfaction. It seems that money coming from remittances is not sufficient to change the levels of life satisfaction of households left behind, which could be due to the negative costs associated with migration, such as labor shortages and lack of services in rural areas, adults having to leave their children and parents behind, etc.

When looking at how remittances affect the subjective economic situation of the household with respect to the past, however, findings are more positive (table 5.3). An increase in 100 Kyrgyz Soms (KGS) of per capita remittances received increases the probability of individuals reporting an improvement in the economic situation by 1 percentage point, and this holds in all three specifications (random effects probit, correlated random effects probit, and fixed effects). Moreover, those who receive remittances are 6 to 7 percentage points more likely to report an improvement in the economic situation with respect to the past, as compared to non-recipients (table A5.4). Given the size of remittances in recipient households, results confirm expectations that remittances are likely to contribute to an improvement in subjective economic well-being. Remittances also increase the expectation that the economic situation will improve in the next year; yet, the coefficient for remittances is only significant in the first specification (table 5.4).

Looking at the control variables, most coefficients have the expected sign: individuals who are younger, married or female are more likely to have higher subjective well-being levels. However, the effects of age and gender only hold for the life satisfaction indicator (and not in all specifications), as the coefficients are not significant in the subjective economic well-being regressions. Factors like working, practicing sports, and having good living conditions (such as more assets) are also associated with higher subjective well-being levels. Having been exposed to a shock, on the contrary, is negatively associated with well-being. Belonging to an ethnic minority, as well as living in urban areas, also corresponds to lower well-being levels. The level of education, however, does not seem to affect subjective well-being.

Table 5.5 shows the second stage results of the instrumental variable estimations (both fixed and random effects), and the first stage regression is shown in table A5.2 in the appendix. The instrument used to predict international remittances is positive and significant at a one-percent level. Additional goodness-of-fit tests-the Kleibergen-Paap F 
statistic (Kleibergen and Paap 2006) further confirm the relevance of the instrument. Most of the other variables included in the first stage regression are statistically significant. Not surprisingly, individuals who work, who are male, and who live in urban areas are less likely to live in households receiving large amounts of remittances. Furthermore, all the provinces with the exception of Naryn receive, on average, larger amounts of remittances than the capital Bishkek, which confirms previous evidence from Kyrgyzstan that most remittances go to rural areas (Thieme 2014). The likelihood of receiving larger amounts of remittances increases with household size, with idiosyncratic shocks and with education up to the university level. This means that the amount of remittances received is higher for those with secondary or technical education, but those with a university degree are not necessarily more likely to receive remittances than those with primary education. Given that highly educated people are usually better-off and that the demand for highly skilled personnel in Central Asia is large (Sondergaard et al. 2012), it is expected that those with higher levels of education are less likely to migrate or receive remittances. Household wealth (measured through the asset index) is positively related with the amount of remittances received.

Looking at the coefficient of interest in table 5.5-logarithm of remittances- we see that the effect on life satisfaction is insignificant, whereas the effect on the subjective economic well-being with respect to the past is positive and significant in both the random and the fixed effects models, which confirms the findings presented above. In addition, coefficients are higher in magnitude: an increase in 100 KGS of per capita remittances increases the likelihood of reporting improvements with respect to the past by 6 to 10 percentage points. A possible explanation for this is that individuals who migrate have lower subjective well-being levels to begin with, so not accounting for reverse causality leads to downward bias. This is very likely in Kyrgyzstan, given that migrants leave the country due to a lack of economic and job opportunities. With regard to the subjective economic situation with respect to the future, now coefficients are positive and significant in both the random effects and fixed effects instrumental variable regressions. These results suggest that, after accounting for the fact that remittance recipient households (most of which are migrant households) have lower subjective well-being levels than non-recipients before receiving remittances, an increase in the amount of money received from abroad improves their economic expectations.

Given that the 2SLS regression model is designed for continuous dependent variables and to account for the fact that the dependent variables in this analysis are either binary or ordinal, control functions are estimated. Following Papke and Wooldridge (2008) and Gebreeyesus (2015), I combine the correlated random effects approach (CRE) from before with a control function approach $(\mathrm{CF})$, which produces consistent estimates in nonlinear models with endogenous explanatory variables. Within this method, I estimate the 


\section{Chapter 5}

residuals from the first-stage regression predicting the amount of remittances received and include them as an additional variable in the second stage equation (Waidler et al. 2016). The first stage includes all explanatory variables described before, as well as the means of the time varying variables, and the networks-language instrument.

After applying this technique (see table 5.6), the effects of remittances on life satisfaction remain insignificant, whereas the effects on respondents' economic situation with respect to the past are again positive and significant (in line with previous estimations). In terms of the last specification, however, the coefficient for remittances becomes insignificant, which means that the positive effect of remittances on subjective economic expectations does not hold with respect to the previous instrumental variable estimates. Moreover, a diagnostic test of endogeneity using the Durbin-Wu-Hausman rejects that remittances are exogenous only when analysing the subjective economic situation with respect to the past, as the residuals are only significant in this specification. 
Table 5.2: Effects of remittances on life satisfaction

\begin{tabular}{|c|c|c|c|}
\hline & $\begin{array}{l}\text { Life satisfaction } \\
\text { RE ordered probit }\end{array}$ & $\begin{array}{l}\text { Life satisfaction } \\
\text { Fixed effects }\end{array}$ & $\begin{array}{l}\text { Life satisfaction } \\
\text { CRE ordered probit }\end{array}$ \\
\hline Log of per capita & 0.01 & 0.00 & 0.00 \\
\hline Remittances & $(0.00)$ & $(0.01)$ & $(0.00)$ \\
\hline \multirow[t]{2}{*}{ Male } & $-0.05^{*}$ & & $-0.08^{* *}$ \\
\hline & $(0.02)$ & & $(0.02)$ \\
\hline \multirow[t]{2}{*}{ Age } & $-0.03^{* *}$ & $0.09^{*}$ & $0.04^{+}$ \\
\hline & $(0.00)$ & $(0.04)$ & $(0.02)$ \\
\hline \multirow[t]{2}{*}{ Age squared } & $0.00^{* *}$ & -0.00 & -0.00 \\
\hline & $(0.00)$ & $(0.00)$ & $(0.00)$ \\
\hline \multirow[t]{2}{*}{ Married } & $0.25^{* *}$ & $0.19^{+}$ & $0.12^{+}$ \\
\hline & $(0.03)$ & $(0.11)$ & $(0.07)$ \\
\hline \multirow[t]{2}{*}{ Ethnic Kyrgyz } & $0.17^{* *}$ & & $0.18^{* *}$ \\
\hline & $(0.02)$ & & $(0.02)$ \\
\hline \multirow[t]{2}{*}{ Urban } & $-0.31^{* *}$ & & $-0.34^{* *}$ \\
\hline & $(0.03)$ & & $(0.03)$ \\
\hline \multirow[t]{2}{*}{ Household size } & 0.01 & 0.03 & 0.02 \\
\hline & $(0.01)$ & $(0.03)$ & $(0.02)$ \\
\hline \multirow[t]{2}{*}{ Household has kids } & $0.05^{+}$ & -0.10 & -0.05 \\
\hline & $(0.03)$ & $(0.11)$ & $(0.06)$ \\
\hline \multicolumn{4}{|c|}{ Education (ref category: primary or no education) } \\
\hline \multirow[t]{2}{*}{ Secondary } & 0.00 & 0.09 & 0.04 \\
\hline & $(0.04)$ & $(0.23)$ & $(0.15)$ \\
\hline \multirow[t]{2}{*}{ Technical } & -0.01 & -0.11 & -0.08 \\
\hline & $(0.04)$ & $(0.22)$ & $(0.15)$ \\
\hline \multirow[t]{2}{*}{ University } & $0.07^{+}$ & 0.19 & 0.09 \\
\hline & $(0.04)$ & $(0.28)$ & $(0.18)$ \\
\hline \multirow[t]{2}{*}{ Works } & $0.13^{* *}$ & $0.21^{* *}$ & $0.13^{* *}$ \\
\hline & $(0.02)$ & $(0.06)$ & $(0.03)$ \\
\hline \multirow[t]{2}{*}{ Plays sports } & $0.25^{* *}$ & $0.26^{* *}$ & $0.16^{* *}$ \\
\hline & $(0.03)$ & $(0.05)$ & $(0.03)$ \\
\hline \multirow[t]{2}{*}{ Personality } & $0.27^{* *}$ & & $0.27^{* *}$ \\
\hline & $(0.01)$ & & $(0.01)$ \\
\hline Experienced idiosyncratic & $-0.06^{* *}$ & $-0.08^{*}$ & -0.03 \\
\hline Shock & $(0.02)$ & $(0.04)$ & $(0.02)$ \\
\hline \multirow[t]{2}{*}{ Asset index } & $0.23^{* *}$ & $0.13^{* *}$ & $0.08^{* *}$ \\
\hline & $(0.01)$ & $(0.04)$ & $(0.02)$ \\
\hline \multirow[t]{2}{*}{ Constant } & & $3.60^{* *}$ & \\
\hline & & $(1.07)$ & \\
\hline Observations & 17613 & 17658 & 17613 \\
\hline Sigma2_u & 0.25 & & 0.25 \\
\hline Within $\mathrm{R}^{2}$ & & 0.01 & \\
\hline Means of time-varying variables & No & - & Yes \\
\hline Joint test of time-average variables & - & - & 0.00 \\
\hline
\end{tabular}

Robust standard errors in parentheses; ${ }^{+} p<0.1,{ }^{*} p<0.05,{ }^{* *} p<0.01$. Regressions also include oblast fixed effects. Given that the coefficients of the ordered probit do not have an interpretation, I also calculate marginal effects for each level of the dependent variable, but coefficients are not significant either. Means of average time variables are excluded in the correlated random effects probit, but most of them are significant. The joint test of equality of means is rejected, which means that there is unobserved heterogeneity and the correlated random effects model is the correct specification. 
Table 5.3: Effects of remittances on subjective economic well-being with respect to the past

\begin{tabular}{|c|c|c|c|}
\hline & $\begin{array}{c}\text { SWB-past } \\
\text { RE probit } \\
\text { (marginal effects) }\end{array}$ & $\begin{array}{l}\text { SWB-past } \\
\text { Fixed effects }\end{array}$ & $\begin{array}{c}\text { SWB-past } \\
\text { CRE probit } \\
\text { (marginal effects) }\end{array}$ \\
\hline Log of per capita & $0.01^{* *}$ & $0.01^{* *}$ & $0.01^{* *}$ \\
\hline Remittances & $(0.00)$ & $(0.00)$ & $(0.00)$ \\
\hline \multirow[t]{2}{*}{ Male } & -0.00 & & -0.01 \\
\hline & $(0.01)$ & & $(0.01)$ \\
\hline \multirow[t]{2}{*}{ Age } & $-0.00^{*}$ & $0.02^{*}$ & $0.02^{+}$ \\
\hline & $(0.00)$ & $(0.01)$ & $(0.01)$ \\
\hline \multirow[t]{2}{*}{ Age squared } & $0.00^{* *}$ & -0.00 & -0.00 \\
\hline & $(0.00)$ & $(0.00)$ & $(0.00)$ \\
\hline \multirow[t]{2}{*}{ Married } & $0.06^{* *}$ & $0.12^{* *}$ & $0.13^{* *}$ \\
\hline & $(0.01)$ & $(0.03)$ & $(0.03)$ \\
\hline \multirow[t]{2}{*}{ Ethnic Kyrgyz } & $0.09^{* *}$ & & $0.09^{* *}$ \\
\hline & $(0.01)$ & & $(0.01)$ \\
\hline \multirow[t]{2}{*}{ Urban } & $-0.10^{* *}$ & & $-0.10^{* *}$ \\
\hline & $(0.01)$ & & $(0.01)$ \\
\hline \multirow[t]{2}{*}{ Household size } & $0.01^{* *}$ & $-0.02^{*}$ & $-0.01^{+}$ \\
\hline & $(0.00)$ & $(0.01)$ & $(0.01)$ \\
\hline \multirow[t]{2}{*}{ Household has kids } & 0.00 & -0.01 & -0.00 \\
\hline & $(0.01)$ & $(0.03)$ & $(0.03)$ \\
\hline \multicolumn{4}{|c|}{ Education (ref category: primary or no education) } \\
\hline \multirow[t]{2}{*}{ Secondary } & 0.01 & $0.21^{* *}$ & $0.22^{* *}$ \\
\hline & $(0.01)$ & $(0.07)$ & $(0.07)$ \\
\hline \multirow[t]{2}{*}{ Technical } & 0.01 & $0.13^{*}$ & $0.14^{*}$ \\
\hline & $(0.02)$ & $(0.06)$ & $(0.07)$ \\
\hline \multirow[t]{2}{*}{ University } & $0.05^{* *}$ & $0.27^{* *}$ & $0.28^{* *}$ \\
\hline & $(0.02)$ & $(0.08)$ & $(0.08)$ \\
\hline \multirow[t]{2}{*}{ Works } & $0.03^{* *}$ & $0.05^{* *}$ & $0.05^{* *}$ \\
\hline & $(0.01)$ & $(0.01)$ & $(0.02)$ \\
\hline \multirow[t]{2}{*}{ Plays sports } & $0.08^{* *}$ & $0.04^{* *}$ & $0.05^{* *}$ \\
\hline & $(0.01)$ & $(0.01)$ & $(0.01)$ \\
\hline \multirow[t]{2}{*}{ Personality } & $0.05^{* *}$ & & $0.05^{* *}$ \\
\hline & $(0.01)$ & & $(0.01)$ \\
\hline Experienced idiosyncratic & $-0.03^{* *}$ & $-0.04^{* *}$ & $-0.04^{* *}$ \\
\hline Shocks & $(0.01)$ & $(0.01)$ & $(0.01)$ \\
\hline \multirow[t]{2}{*}{ Asset index } & $0.07^{* *}$ & 0.02 & $0.02^{+}$ \\
\hline & $(0.01)$ & $(0.01)$ & $(0.01)$ \\
\hline \multirow[t]{2}{*}{ Constant } & & $-0.62^{*}$ & \\
\hline & & $(0.26)$ & \\
\hline Observations & 17613 & 17658 & 17613 \\
\hline Sigma_u & 0.44 & & 0.45 \\
\hline Within $\mathrm{R}^{2}$ & & 0.01 & \\
\hline $\begin{array}{l}\text { Includes means of time-varying } \\
\text { variables }\end{array}$ & No & - & Yes \\
\hline $\begin{array}{l}\text { Joint test of time-average variables } \\
(\text { Prob }>\text { chi2) }\end{array}$ & - & - & 0.00 \\
\hline
\end{tabular}

Robust standard errors in parentheses; ${ }^{+} p<0.1,{ }^{*} p<0.05,{ }^{* *} p<0.01$. Regressions also include oblast fixed effects. Means of average time variables are excluded in the correlated random effects probit, but most of them are significant. The joint test of equality of means is rejected, which means that there is unobserved heterogeneity and the correlated random effects model is the correct specification. 
Table 5.4: Effects of remittances on subjective economic well-being with respect to the future

\begin{tabular}{|c|c|c|c|}
\hline & $\begin{array}{c}\text { SWB-future } \\
\text { RE probit } \\
\text { (marginal effects) }\end{array}$ & $\begin{array}{l}\text { SWB-future } \\
\text { Fixed effects }\end{array}$ & $\begin{array}{c}\text { SWB-future } \\
\text { CRE probit } \\
\text { (marginal effects) }\end{array}$ \\
\hline Log of per capita & $0.01^{* *}$ & 0.00 & 0.00 \\
\hline remittances & $(0.00)$ & $(0.00)$ & $(0.00)$ \\
\hline \multirow[t]{2}{*}{ Male } & -0.00 & & $-0.02^{*}$ \\
\hline & $(0.01)$ & & $(0.01)$ \\
\hline \multirow[t]{2}{*}{ Age } & -0.00 & $0.02^{+}$ & 0.01 \\
\hline & $(0.00)$ & $(0.01)$ & $(0.01)$ \\
\hline \multirow[t]{2}{*}{ Age squared } & 0.00 & 0.00 & 0.00 \\
\hline & $(0.00)$ & $(0.00)$ & $(0.00)$ \\
\hline \multirow[t]{2}{*}{ Married } & $0.05^{* *}$ & $0.08^{* *}$ & $0.08^{* *}$ \\
\hline & $(0.01)$ & $(0.03)$ & $(0.03)$ \\
\hline \multirow[t]{2}{*}{ Ethnic Kyrgyz } & $0.10^{* *}$ & & $0.10^{* *}$ \\
\hline & $(0.01)$ & & $(0.01)$ \\
\hline \multirow[t]{2}{*}{ Urban } & $-0.07^{* *}$ & & $-0.08^{* *}$ \\
\hline & $(0.01)$ & & $(0.01)$ \\
\hline \multirow[t]{2}{*}{ Household size } & $0.01^{* *}$ & $-0.02^{* *}$ & $-0.02^{*}$ \\
\hline & $(0.00)$ & $(0.01)$ & $(0.01)$ \\
\hline \multirow[t]{2}{*}{ Household has kids } & 0.01 & 0.01 & 0.02 \\
\hline & $(0.01)$ & $(0.03)$ & $(0.03)$ \\
\hline \multicolumn{4}{|c|}{ Education (ref category: primary or no education) } \\
\hline \multirow[t]{2}{*}{ Secondary } & -0.02 & 0.03 & 0.02 \\
\hline & $(0.01)$ & $(0.07)$ & $(0.07)$ \\
\hline \multirow[t]{2}{*}{ Technical } & $-0.04^{*}$ & -0.01 & -0.01 \\
\hline & $(0.02)$ & $(0.07)$ & $(0.07)$ \\
\hline \multirow[t]{2}{*}{ University } & 0.03 & 0.11 & 0.12 \\
\hline & $(0.02)$ & $(0.08)$ & $(0.08)$ \\
\hline \multirow[t]{2}{*}{ Works } & 0.01 & 0.02 & 0.02 \\
\hline & $(0.01)$ & $(0.01)$ & $(0.01)$ \\
\hline \multirow[t]{2}{*}{ Plays sports } & $0.07^{* *}$ & $0.02^{+}$ & $0.02^{+}$ \\
\hline & $(0.01)$ & $(0.01)$ & $(0.01)$ \\
\hline \multirow[t]{2}{*}{ Personality } & $0.08^{* *}$ & & $0.08^{* *}$ \\
\hline & $(0.01)$ & & $(0.01)$ \\
\hline Experienced idiosyncratic & $-0.02^{*}$ & $-0.02^{*}$ & $-0.02^{*}$ \\
\hline Shocks & $(0.01)$ & $(0.01)$ & $(0.01)$ \\
\hline \multirow[t]{2}{*}{ Asset index } & $0.06^{* *}$ & $0.02^{+}$ & $0.02^{*}$ \\
\hline & $(0.01)$ & $(0.01)$ & $(0.01)$ \\
\hline \multirow[t]{2}{*}{ Constant } & & -0.35 & \\
\hline & & $(0.28)$ & \\
\hline Observations & 17613 & 17658 & 17613 \\
\hline Sigma_u & 0.50 & & 0.50 \\
\hline Within $\mathrm{R}^{2}$ & & 0.01 & \\
\hline $\begin{array}{l}\text { Includes means of time-varying } \\
\text { variables }\end{array}$ & No & - & Yes \\
\hline Joint test of time-average variables & - & - & 0.00 \\
\hline
\end{tabular}

Robust standard errors in parentheses; ${ }^{+} p<0.1,{ }^{*} p<0.05,{ }^{* *} p<0.01$. Regressions also include oblast fixed effects. Means of average time variables are excluded in the correlated random effects probit, but most of them are significant. Moreover, the joint test of equality of means is rejected, which means that there is unobserved heterogeneity and the correlated random effects model is the correct specification. 
Table 5.5: Second-stage IV results

\begin{tabular}{|c|c|c|c|c|c|c|}
\hline & & Life & SWB - Past & SWB - Past & SWB - Future & SWB - Future \\
\hline & $\mathrm{RE}$ & $\mathrm{FE}$ & $\mathrm{RE}$ & $\mathrm{FE}$ & $\mathrm{RE}$ & $\mathrm{FE}$ \\
\hline Log of & 0.04 & 0.06 & $0.06^{* *}$ & $0.10^{* *}$ & $0.02^{+}$ & $0.05^{*}$ \\
\hline Remittances & $(0.04)$ & $(0.06)$ & $(0.01)$ & $(0.02)$ & $(0.01)$ & $(0.02)$ \\
\hline \multirow[t]{2}{*}{ Male } & $-0.08^{*}$ & & 0.00 & & -0.00 & \\
\hline & $(0.04)$ & & $(0.01)$ & & $(0.01)$ & \\
\hline \multirow[t]{2}{*}{ Age } & $-0.05^{* *}$ & $0.09^{*}$ & $-0.01^{* *}$ & $0.02^{+}$ & -0.00 & $0.02^{+}$ \\
\hline & $(0.01)$ & $(0.04)$ & $(0.00)$ & $(0.01)$ & $(0.00)$ & $(0.01)$ \\
\hline \multirow[t]{2}{*}{ Age squared } & $0.00^{* *}$ & -0.00 & $0.00^{* *}$ & -0.00 & 0.00 & 0.00 \\
\hline & $(0.00)$ & $(0.00)$ & $(0.00)$ & $(0.00)$ & $(0.00)$ & $(0.00)$ \\
\hline \multirow[t]{2}{*}{ Married } & $0.44^{* *}$ & $0.20^{+}$ & $0.07^{* *}$ & $0.13^{* *}$ & $0.05^{* *}$ & $0.09^{* *}$ \\
\hline & $(0.05)$ & $(0.12)$ & $(0.01)$ & $(0.03)$ & $(0.01)$ & $(0.03)$ \\
\hline \multirow[t]{2}{*}{ Urban } & $-0.55^{* *}$ & & $-0.09^{* *}$ & & $-0.07^{* *}$ & \\
\hline & $(0.05)$ & & $(0.01)$ & & $(0.01)$ & \\
\hline \multirow[t]{2}{*}{ Household size } & 0.01 & 0.03 & -0.00 & $-0.02^{*}$ & $0.01^{*}$ & $-0.02^{* *}$ \\
\hline & $(0.01)$ & $(0.03)$ & $(0.00)$ & $(0.01)$ & $(0.00)$ & $(0.01)$ \\
\hline Household has & $0.09^{+}$ & -0.07 & $0.04^{*}$ & 0.05 & 0.01 & 0.04 \\
\hline Kids & $(0.05)$ & $(0.10)$ & $(0.01)$ & $(0.04)$ & $(0.01)$ & $(0.03)$ \\
\hline \multicolumn{7}{|c|}{ Education (ref category: primary or no education) } \\
\hline \multirow[t]{2}{*}{ Secondary } & 0.00 & 0.06 & 0.00 & $0.16^{+}$ & -0.02 & 0.00 \\
\hline & $(0.05)$ & $(0.26)$ & $(0.01)$ & $(0.08)$ & $(0.01)$ & $(0.07)$ \\
\hline \multirow[t]{2}{*}{ Technical } & -0.03 & -0.14 & 0.00 & 0.08 & $-0.03^{+}$ & -0.04 \\
\hline & $(0.06)$ & $(0.24)$ & $(0.02)$ & $(0.08)$ & $(0.02)$ & $(0.08)$ \\
\hline \multirow[t]{2}{*}{ University } & 0.12 & 0.15 & $0.04^{* *}$ & $0.21^{*}$ & 0.02 & 0.09 \\
\hline & $(0.08)$ & $(0.31)$ & $(0.02)$ & $(0.10)$ & $(0.02)$ & $(0.07)$ \\
\hline \multirow[t]{3}{*}{ Works } & $0.22^{* *}$ & $0.22^{* *}$ & $0.04^{* *}$ & $0.06^{* *}$ & 0.01 & 0.03 \\
\hline & $(0.04)$ & $(0.06)$ & $(0.01)$ & $(0.02)$ & $(0.01)$ & $(0.02)$ \\
\hline & $(0.05)$ & $(0.06)$ & $(0.01)$ & $(0.01)$ & $(0.01)$ & $(0.01)$ \\
\hline \multirow[t]{2}{*}{ Personality } & $0.44^{* *}$ & & $0.05^{* *}$ & & $0.08^{* *}$ & \\
\hline & $(0.02)$ & & $(0.00)$ & & $(0.00)$ & \\
\hline Experienced & $-0.12^{* *}$ & $-0.08^{+}$ & $-0.04^{* *}$ & $-0.05^{* *}$ & $-0.02^{* *}$ & $-0.03^{*}$ \\
\hline idiosyncratic shocks & $(0.03)$ & $(0.05)$ & $(0.01)$ & $(0.01)$ & $(0.01)$ & $(0.01)$ \\
\hline \multirow[t]{2}{*}{ Asset index } & $0.37^{* *}$ & $0.13^{* *}$ & $0.05^{* *}$ & 0.01 & $0.05^{* *}$ & 0.02 \\
\hline & $(0.03)$ & $(0.04)$ & $(0.01)$ & $(0.01)$ & $(0.01)$ & $(0.01)$ \\
\hline \multirow[t]{2}{*}{ Constant } & $7.24^{* *}$ & $3.68^{* *}$ & $0.31^{* *}$ & $-0.50^{*}$ & $0.30^{* *}$ & -0.29 \\
\hline & $(0.18)$ & $(0.91)$ & $(0.05)$ & $(0.25)$ & $(0.04)$ & $(0.30)$ \\
\hline Observations & 17613 & 17658 & 17613 & 17658 & 17613 & 17658 \\
\hline$R^{2}$ & 0.13 & 0.002 & 0.06 & 0.004 & 0.13 & 0.0001 \\
\hline $\begin{array}{l}\text { Kleibergen-Paap rk } \\
\text { Wald F statistic }\end{array}$ & & 200 & & 200 & & 200 \\
\hline $\begin{array}{l}\text { Davidson-Mackinnon } \\
\text { test of exogeneity }\end{array}$ & & $\begin{array}{l}\text { p-value } \\
=0.33\end{array}$ & & $\begin{array}{l}\text { p-value } \\
=0.00\end{array}$ & & $\begin{array}{l}\mathrm{p} \text {-value } \\
=0.00\end{array}$ \\
\hline
\end{tabular}

Bootstrapped standard errors in parentheses; ${ }^{+} p<0.1,{ }^{*} p<0.05,{ }^{* *} p<0.01$. Regressions also include oblast fixed effects. The test of exogeneity is rejected in the two subjective economic well-being regressions (past and future), which means that in these regressions the coefficient for remittances is endogenous. 
Table 5.6: Control function estimates

\begin{tabular}{lccc}
\hline & Life satisfaction & $\begin{array}{c}\text { SWB- Past } \\
\text { Probit } \\
\text { Marginal effects }\end{array}$ & $\begin{array}{c}\text { SWB- Future } \\
\text { Probit } \\
\text { Marginal effects }\end{array}$ \\
\hline Logarithm of per capita & 0.10 & $0.19^{* *}$ & 0.02 \\
Remittances & $(0.08)$ & $(0.03)$ & $(0.04)$ \\
Residuals & -0.10 & $-0.18^{* *}$ & -0.02 \\
Controls & $(0.08)$ & $(0.03)$ & $(0.04)$ \\
Average time varying & Yes & Yes & Yes \\
Variables & Yes & Yes & Yes \\
Observations & 17613 & 17613 & 17613 \\
Sigma2_u & 0.25 & & 0.50 \\
Sigma_u & & 0.45 & \\
\hline
\end{tabular}

Bootstrapped standard errors in parentheses; ${ }^{+} p<0.1,{ }^{*} p<0.05,{ }^{* *} p<0.01$. Regressions include all the controls variables from the previous regressions as well as the averages time varying variables to account for unobserved heterogeneity.

\subsection{Conclusion}

In the last few decades we have seen an increase in the number of studies looking at the effects of remittances on different indicators of well-being. While there is extensive evidence and general agreement that remittances improve objective indicators of well-being (such as income, educational attainment, consumption, food security, etc.), the relationship between remittances and subjective levels of well-being is more ambiguous. Migration and remittances can increase or decrease subjective well-being based on the reference group of the household left behind, as well as on the emotional consequences of having a member abroad.

This paper has estimated the relationship between remittances and several indicators of subjective well-being through several econometric techniques, such as correlated random effects models and instrumental variable estimations. Moreover, control variables that are usually unobserved, such as an index for personality traits, were included in the analysis. Subjective well-being has mainly been studied in Latin America and, given the specificities of migration in Kyrgyzstan and the country's history as a member of the Soviet Union, providing a new case study is an important contribution to the literature.

Due to the determinant role of remittances for the country's economy, this paper hypothesised that money transfers from migrants would increase the subjective economic well-being of households left behind. This paper finds that remittances are associated with feelings of improvement in the economic situation of the household with respect to the past, and these positive effects hold in all specifications. These findings are also 


\section{Chapter 5}

in line with previous studies looking at the effects of remittances on subjective economic well-being, which all find positive effects. Moreover, in some of the estimations performed, remittances are associated with a higher likelihood of expecting an improvement in the economic situation in the future.

When looking at the indicator for life satisfaction, remittances appear to have neither positive nor negative effects on subjective well-being. In line with previous evidence, other negative factors related to receiving remittances and having a member abroad could counteract the positive feelings of experiencing an improvement in the economic situation. According to a World Bank book about how poor people define well-being in different parts of the world, people in Kyrgyzstan understand well-being as "good life and wealth...however... well-being is impossible without tolerance, peace, family and children". Well-being is also defined as "stability on a household and society level and ability to satisfy one's material and spiritual needs." (Narayan et al. 2000). It seems, therefore, that despite being vital for helping households to satisfy basic needs and improving their living conditions, remittances are not sufficient to increase recipients' satisfaction with life. 


\section{References}

Anderson, L. (2014). Migration, remittances and household welfare in Ethiopia. UNU-MERIT working paper series, ISSN 1871-9872

Attah, R., Barca, V., Kardan, A., MacAuslan, I., Merttens, F., \& Pellerano, L. (2016). Can social protection affect psychosocial wellbeing and why does this matter? Lessons from cash transfers in sub-Saharan Africa. The Journal of Development Studies, 52(8), 1115-1131.

Austin, P. C. (2011). An introduction to propensity score methods for reducing the effects of confounding in observational studies. Multivariate behavioral research, 46(3), 399-424.

Azzarri, C., \& Zezza, A. (2011). International migration and nutritional outcomes in Tajikistan. Food Policy, 36(1), 54-70.

Bartram, D. (2013). Happiness and 'economic migration': A comparison of Eastern European migrants and stayers. Migration Studies 1.2 (2013): 156-175.

Bartram, D. (2010). International migration, open borders debates, and happiness. International Studies Review, 12(3), 339-361.

Borraz, F., Rossi, M., \& Pozo, S. (2008). And What About the Family Back Home? International Migration and Happiness, Working Paper, Universidad de la Republica, Documento No. 03/08.

Cohen, J., Jones, R. \& Conway, D. (2005). Why Remittances Shouldn't Be Blamed for Rural Underdevelopment in Mexico. Critique of Anthropology 25(1): 87-96.

Deaton, A. (2008). Income, Health, and Well-Being around the World: Evidence from the Gallup World Poll. Journal of Economic Perspectives, 22(2): 53-72.

FAO (2016). Evaluation of FAO's contribution to the Kyrgyz Republic Annexes. Country programme evaluation series. Food and Agriculture organization of the United Nations.

Gassmann, F. \& Zardo Trindade, L. (2015). Analysis of Potential Work Disincentive Effects of the Monthly Benefit for Poor Families in the Kyrgyz Republic. Report No. 99776-KG. Washington DC: World Bank Group.

Gebreeyesus, M. (2015). Firm adoption of international standards: evidence from the Ethiopian floriculture sector. Agricultural economics 46.S1 (2015): 139-155.

Guelfi, A., \& Sattar, S. (2015). Poverty and Economic Mobility in the Kyrgyz Republic. Some insights from the 'Life in Kyrgyzstan Survey'. Report No. 99775-KG.World Bank Group, Washington DC.

Handa, S., Martorano, B., Halpern, C., Pettifor, A., \& Thirumurthy, H. (2014). Subjective Well-being, Risk Perceptions and Time Discounting. Evidence from a Large-Scale Cash Transfer Programme. Office of Research Working Paper, UNICEF.

ICG (2016). Kyrgyzstan: State Fragility and Radicalisation, Crisis Group Europe and Central Asia Briefing N83

Jin, L. (2016). Migration, Relative Deprivation, and Psychological Well-Being in China. American Behavioral Scientist, 60(5-6), 750-770.

Jones, R. (2015). Migration Pessimism and the Subjective Well-Being of Migrant Households in Mexico. Bulletin of Latin American Research, 34(3) 305-323.

Jones, R. C. (2014). Migration and Family Happiness in Bolivia: Does Social Disintegration Negate Economic Wellbeing? International Migration, 52(3), 177-193.

Jones, R. C. (2009). Migration permanence and village decline in Zacatecas: when you can't go home again. The Professional Geographer, 61(3), 382-399.

Kleibergen, F., \& Paap, R. (2006). Generalized reduced rank tests using the singular value decomposition. Journal of econometrics, 133(1), 97-126.

Lukashova, I. \& Makenbaeva, I. (2009). Impact of the global financial crisis on labour migration from Kyrgyzstan to Russia. Qualitative overview and quantitative survey, Report by OSCE, ACTED and European Commission, http://www.osce.org/bishkek/40540.

Marchetta, F. (2012). Return migration and the survival of entrepreneurial activities in Egypt. World Development, 40(10), 1999-2013.

McKenzie, D., \& Rapoport, H. (2007). Network effects and the dynamics of migration and inequality: theory and evidence from Mexico. Journal of development Economics 84.1: 1-24.

Mundlak, Y. (1978). On the pooling of time series and cross section data. Econometrica: journal of the Econometric Society, 69-85.

Narayan, D., Chambers, R., Shah, M. K., \& Petesch, P. (2000). Voices of the Poor: Crying out for Change. New York: Oxford University Press for the World Bank. 


\section{Chapter 5}

Papke, L. E., \& Wooldridge, J. M. (2008). Panel data methods for fractional response variables with an application to test pass rates. Journal of Econometrics, 145(1-2), 121-133.

Ratha, D., Mohapatra, S. \& Scheja, E. (2011). Impact of migration on economic and social development. A review of evidence and emerging issues. World Bank Policy Research Working Paper No. 5558, Washington DC.

Ruget, V., \& Usmanalieva, B. (2008). Citizenship, migration and loyalty towards the state: A case study of the Kyrgyzstani migrants working in Russia and Kazakhstan. Central Asian Survey, 27(2), 129-141.

Semyonov, M., \& Gorodzeisky, A. (2008). Labor migration, remittances and economic well-being of households in the Philippines. Population Research and Policy Review, 27(5), 619.

Sondergaard, L., Murthi, M., Abu-Ghaida, D., Bodewig, C. \& J. Rutkowski (2012). Skills, Not Just Diplomas. Managing Education for Results in Eastern Europe and Central Asia. Washington DC: The World Bank.

Stevenson, B., \& Wolfers, J. (2008). Economic growth and subjective well-being: reassessing the Easterlin paradox (No. w14282). National Bureau of Economic Research.

Thieme, S. (2014). Coming home? Patterns and characteristics of return migration in Kyrgyzstan. International Migration, 52(5), 127-143.

UNDP (2017). World population prospects, the 2015 revision. Accessed May 2017: https://esa.un.org/ unpd/wpp/

Waidler, J., Vanore, M., Gassmann, F., \& Siegel, M. (2017). Does it matter where the children are? The wellbeing of elderly people 'left behind' by migrant children in Moldova. Ageing \& Society, 37(3), 607-632.

World Bank (2017). World Bank Data, Kyrgyz Republic. https://data.worldbank.org/country/kyrgyz-republic [accessed 10 November 2017]

World Bank and KNOMAD (2017). Migration and Development Brief 27: Migration and Remittances-Recent Developments and Outlook. World Bank Publications, Washington DC. 


\section{Appendix 5}

Table A5.1: Summary statistics at baseline (2011)

\begin{tabular}{|c|c|c|c|c|c|}
\hline Variable & Observations & Mean & SD & Min & Max \\
\hline Receives remittances & 5899 & 0.16 & 0.37 & 0 & 1 \\
\hline Logarithm of remittances & 5899 & 0.98 & 2.32 & 0 & 8.87 \\
\hline Male & 5899 & 0.46 & 0.50 & 0 & 1 \\
\hline Age & 5899 & 41.7 & 15.8 & 18 & 93 \\
\hline Age squared & 5899 & 1991 & 1454 & 324 & 8649 \\
\hline Married & 5899 & 0.73 & 0.44 & 0 & 1 \\
\hline Ethnic Kyrgyz & 5899 & 0.67 & 0.47 & 0 & 1 \\
\hline \multicolumn{6}{|l|}{ Oblast } \\
\hline Jalal-Abad & 5899 & 0.15 & 0.36 & 0 & 1 \\
\hline Naryn & 5899 & 0.05 & 0.21 & 0 & 1 \\
\hline Batken & 5899 & 0.08 & 0.28 & 0 & 1 \\
\hline Osh & 5899 & 0.21 & 0.41 & 0 & 1 \\
\hline Talas & 5899 & 0.04 & 0.20 & 0 & 1 \\
\hline Chui & 5899 & 0.17 & 0.37 & 0 & 1 \\
\hline Bishkek & 5899 & 0.17 & 0.37 & 0 & 1 \\
\hline Osh City & 5899 & 0.05 & 0.21 & 0 & 1 \\
\hline Urban & 5899 & 0.37 & 0.48 & 0 & 1 \\
\hline Household size & 5899 & 5.5 & 2.4 & 1 & 15 \\
\hline Household has kids & 5899 & 0.77 & 0.42 & 0 & 1 \\
\hline Secondary & 5897 & 0.53 & 0.50 & 0 & 1 \\
\hline Technical & 5897 & 0.18 & 0.38 & 0 & 1 \\
\hline University & 5897 & 0.17 & 0.37 & 0 & 1 \\
\hline Works & 5894 & 0.29 & 0.45 & 0 & 1 \\
\hline Sports & 5897 & 0.22 & 0.42 & 0 & 1 \\
\hline Personality & 5883 & 0.01 & 0.82 & -3.29 & 2.18 \\
\hline Idiosyncratic shock & 5899 & 0.21 & 0.41 & 0 & 1 \\
\hline Asset index & 5899 & 0.09 & 0.89 & -1.07 & 3.11 \\
\hline Life satisfaction & 5899 & 6.74 & 2.21 & 0 & 10 \\
\hline Past & 5899 & 0.44 & 0.50 & 0 & 1 \\
\hline Future & 5899 & 0.51 & 0.50 & 0 & 1 \\
\hline
\end{tabular}




\section{Chapter 5}

Table A5.2: First-stage IV regression

\begin{tabular}{|c|c|c|}
\hline $\begin{array}{l}\text { Logarithm of per capita } \\
\text { Remittances }\end{array}$ & Coefficient & $\begin{array}{c}\text { Standard } \\
\text { error }\end{array}$ \\
\hline Male & $-0.13^{* *}$ & $(0.05)$ \\
\hline Age & $0.05^{* *}$ & $(0.01)$ \\
\hline Age squared & $-0.00^{* *}$ & $(0.00)$ \\
\hline Married & $-0.14^{*}$ & $(0.06)$ \\
\hline Ethnic Kyrgyz & -0.07 & $(0.05)$ \\
\hline Household size & $0.16^{*}$ & $(0.01)$ \\
\hline Household has kids & $-0.63^{* *}$ & $(0.06)$ \\
\hline \multicolumn{3}{|l|}{ Oblast (ref Bishkeek) } \\
\hline Issyk-Kul & $0.22^{*}$ & $(0.11)$ \\
\hline Jalal-Abad & $1.34^{* *}$ & $(0.11)$ \\
\hline Naryn & -0.06 & $(0.14)$ \\
\hline Batken & $1.17^{* *}$ & $(0.12)$ \\
\hline Osh & $0.87^{* *}$ & $(0.11)$ \\
\hline Talas & $0.62^{* *}$ & $(0.14)$ \\
\hline Chui & $0.18^{+}$ & $(0.10)$ \\
\hline Osh city & $0.48^{* *}$ & $(0.13)$ \\
\hline$\underline{\text { Urban }}$ & $-0.17^{*}$ & $(0.07)$ \\
\hline \multicolumn{3}{|c|}{ Education (ref primary or no education) } \\
\hline Secondary & $0.20^{* *}$ & $(0.07)$ \\
\hline Technical & $0.25^{* *}$ & $(0.09)$ \\
\hline University & 0.11 & $(0.09)$ \\
\hline Works & $-0.14^{* *}$ & $(0.05)$ \\
\hline Sports & $0.17^{* *}$ & $(0.05)$ \\
\hline Idiosyncratic shock & 0.00 & $(0.03)$ \\
\hline Personality & $0.14^{* *}$ & $(0.04)$ \\
\hline Asset index & $0.09^{* *}$ & $(0.03)$ \\
\hline Networks*Russian & $4.05^{* *}$ & $(0.19)$ \\
\hline Constant & $-1.41^{* *}$ & $(0.21)$ \\
\hline Observations & 17613 & \\
\hline$R^{2}$ & 0.14 & \\
\hline Wald chi2(25) & 1941 & \\
\hline Prob $>$ chi2 & 0.00 & \\
\hline
\end{tabular}

Standard errors in parentheses; ${ }^{+} p<0.1,{ }^{*} p<0.05,{ }^{* *} p<0.01$ 
Table A5.3: Effects of receiving remittances on life satisfaction

\begin{tabular}{|c|c|c|c|}
\hline & $\begin{array}{l}\text { Life satisfaction } \\
\text { RE ordered probit }\end{array}$ & $\begin{array}{l}\text { Life satisfaction } \\
\text { Fixed effects }\end{array}$ & $\begin{array}{l}\text { Life satisfaction } \\
\text { CRE ordered probit }\end{array}$ \\
\hline Receives & 0.02 & 0.01 & 0.02 \\
\hline remittances & $(0.03)$ & $(0.06)$ & $(0.03)$ \\
\hline \multirow[t]{2}{*}{ Male } & $-0.05^{*}$ & & $-0.09^{* *}$ \\
\hline & $(0.02)$ & & $(0.02)$ \\
\hline \multirow[t]{2}{*}{ Age } & $-0.03^{* *}$ & $0.09^{*}$ & $0.04^{+}$ \\
\hline & $(0.00)$ & $(0.04)$ & $(0.02)$ \\
\hline \multirow[t]{2}{*}{ Age squared } & $0.00^{* *}$ & -0.00 & -0.00 \\
\hline & $(0.00)$ & $(0.00)$ & $(0.00)$ \\
\hline \multirow[t]{2}{*}{ Married } & $0.25^{* *}$ & $0.19^{+}$ & $0.12^{+}$ \\
\hline & $(0.03)$ & $(0.11)$ & $(0.07)$ \\
\hline \multirow[t]{2}{*}{ Ethnic Kyrgyz } & $0.17^{* *}$ & & $0.18^{* *}$ \\
\hline & $(0.02)$ & & $(0.02)$ \\
\hline \multirow[t]{2}{*}{ Urban } & $-0.31^{* *}$ & & $-0.34^{* *}$ \\
\hline & $(0.03)$ & & $(0.03)$ \\
\hline \multirow[t]{2}{*}{ Household size } & 0.01 & 0.03 & 0.02 \\
\hline & $(0.01)$ & $(0.03)$ & $(0.02)$ \\
\hline \multirow[t]{2}{*}{ Household has kids } & 0.05 & -0.10 & -0.05 \\
\hline & $(0.03)$ & $(0.11)$ & $(0.06)$ \\
\hline \multirow[t]{2}{*}{ Secondary } & 0.00 & 0.09 & 0.04 \\
\hline & $(0.04)$ & $(0.23)$ & $(0.15)$ \\
\hline \multirow[t]{2}{*}{ Technical } & -0.01 & -0.11 & -0.08 \\
\hline & $(0.04)$ & $(0.22)$ & $(0.15)$ \\
\hline \multirow[t]{2}{*}{ University } & $0.07^{+}$ & 0.19 & 0.09 \\
\hline & $(0.04)$ & $(0.28)$ & $(0.18)$ \\
\hline \multirow[t]{2}{*}{ Works } & $0.13^{* *}$ & $0.21^{* *}$ & $0.13^{* *}$ \\
\hline & $(0.02)$ & $(0.06)$ & $(0.03)$ \\
\hline \multirow[t]{2}{*}{ Plays sports } & $0.25^{* *}$ & $0.26^{* *}$ & $0.16^{* *}$ \\
\hline & $(0.03)$ & $(0.05)$ & $(0.03)$ \\
\hline \multirow[t]{2}{*}{ Personality } & $0.27^{* *}$ & & $0.27^{* *}$ \\
\hline & $(0.01)$ & & $(0.01)$ \\
\hline Experienced idiosyncratic & $-0.06^{* *}$ & $-0.08^{*}$ & -0.03 \\
\hline shock & $(0.02)$ & $(0.04)$ & $(0.02)$ \\
\hline \multirow[t]{2}{*}{ Asset index } & $0.23^{* *}$ & $0.13^{* *}$ & $0.08^{* *}$ \\
\hline & $(0.01)$ & $(0.04)$ & $(0.02)$ \\
\hline \multirow[t]{2}{*}{ Constant } & & $3.60^{* *}$ & \\
\hline & & $(1.07)$ & \\
\hline Observations & 17613 & 17658 & 17613 \\
\hline Sigma2_u & 0.25 & & 0.25 \\
\hline Within $\mathrm{R}^{2}$ & & 0.01 & \\
\hline Joint test of equality of means & - & & 0.00 \\
\hline
\end{tabular}

Robust standard errors in parentheses; ${ }^{+} p<0.1,{ }^{*} p<0.05,{ }^{* *} p<0.01$. Regressions also include oblast fixed effects. 
Chapter 5

Table A5.4: Effects of receiving remittances on subjective economic well-being with respect to the past

\begin{tabular}{|c|c|c|c|}
\hline & $\begin{array}{c}\text { SWB-past } \\
\text { RE probit } \\
\text { (marginal effects) }\end{array}$ & $\begin{array}{l}\text { SWB-past } \\
\text { Fixed effects }\end{array}$ & $\begin{array}{c}\text { SWB-past } \\
\text { CRE probit } \\
\text { (marginal effects) }\end{array}$ \\
\hline Receives & $0.06^{* *}$ & $0.06^{* *}$ & $0.07^{* *}$ \\
\hline remittances & $(0.01)$ & $(0.02)$ & $(0.02)$ \\
\hline \multirow[t]{2}{*}{ Male } & -0.00 & & -0.01 \\
\hline & $(0.01)$ & & $(0.01)$ \\
\hline \multirow[t]{2}{*}{ Age } & $-0.00^{*}$ & $0.02^{*}$ & $0.02^{+}$ \\
\hline & $(0.00)$ & $(0.01)$ & $(0.01)$ \\
\hline \multirow[t]{2}{*}{ Age squared } & $0.00^{*}$ & -0.00 & -0.00 \\
\hline & $(0.00)$ & $(0.00)$ & $(0.00)$ \\
\hline \multirow[t]{2}{*}{ Married } & $0.06^{* *}$ & $0.12^{* *}$ & $0.13^{* *}$ \\
\hline & $(0.01)$ & $(0.03)$ & $(0.03)$ \\
\hline \multirow[t]{2}{*}{ Ethnic Kyrgyz } & $0.09^{* *}$ & & $0.09^{* *}$ \\
\hline & $(0.01)$ & & $(0.01)$ \\
\hline \multirow[t]{2}{*}{ Urban } & $-0.10^{* *}$ & & $-0.10^{* *}$ \\
\hline & $(0.01)$ & & $(0.01)$ \\
\hline \multirow[t]{2}{*}{ Household size } & $0.01^{* *}$ & $-0.02^{*}$ & $-0.02^{+}$ \\
\hline & $(0.00)$ & $(0.01)$ & $(0.01)$ \\
\hline \multirow[t]{2}{*}{ Household has kids } & 0.00 & -0.01 & -0.00 \\
\hline & $(0.01)$ & $(0.03)$ & $(0.03)$ \\
\hline \multirow[t]{2}{*}{ Secondary } & 0.02 & $0.21^{* *}$ & $0.22^{* *}$ \\
\hline & $(0.01)$ & $(0.07)$ & $(0.07)$ \\
\hline \multirow[t]{2}{*}{ Technical } & 0.01 & $0.13^{*}$ & $0.14^{*}$ \\
\hline & $(0.02)$ & $(0.06)$ & $(0.07)$ \\
\hline \multirow[t]{2}{*}{ University } & $0.05^{* *}$ & $0.27^{* *}$ & $0.28^{* *}$ \\
\hline & $(0.02)$ & $(0.08)$ & $(0.08)$ \\
\hline \multirow[t]{2}{*}{ Works } & $0.03^{* *}$ & $0.05^{* *}$ & $0.05^{* *}$ \\
\hline & $(0.01)$ & $(0.01)$ & $(0.02)$ \\
\hline \multirow[t]{2}{*}{ Plays sports } & $0.08^{* *}$ & $0.04^{* *}$ & $0.05^{* *}$ \\
\hline & $(0.01)$ & $(0.01)$ & $(0.01)$ \\
\hline \multirow[t]{2}{*}{ Personality } & $0.05^{* *}$ & & $0.05^{* *}$ \\
\hline & $(0.01)$ & & $(0.01)$ \\
\hline Experienced idiosyncratic & $-0.03^{* *}$ & $-0.04^{* *}$ & $-0.05^{* *}$ \\
\hline shock & $(0.01)$ & $(0.01)$ & $(0.01)$ \\
\hline \multirow[t]{2}{*}{ Asset index } & $0.07^{* *}$ & 0.02 & $0.02^{+}$ \\
\hline & $(0.01)$ & $(0.01)$ & $(0.01)$ \\
\hline \multirow[t]{2}{*}{ Constant } & & $-0.64^{*}$ & \\
\hline & & $(0.26)$ & \\
\hline Observations & 17613 & 17658 & 17613 \\
\hline Sigma_u & 0.44 & & 0.45 \\
\hline Within $\mathrm{R}^{2}$ & & 0.01 & \\
\hline Joint test of equality of means & - & & 0.00 \\
\hline
\end{tabular}

Robust standard errors in parentheses; ${ }^{+} p<0.1,{ }^{*} p<0.05,{ }^{* *} p<0.01$. Regressions also include oblast fixed effects. 
Table A5.5: Effects of receiving remittances on subjective economic well-being with respect to the future

\begin{tabular}{|c|c|c|c|}
\hline & $\begin{array}{c}\text { SWB-future } \\
\text { RE probit } \\
\text { (marginal effects) }\end{array}$ & $\begin{array}{l}\text { SWB-future } \\
\text { Fixed effects }\end{array}$ & $\begin{array}{c}\text { SWB-future } \\
\text { CRE probit } \\
\text { (marginal effects) }\end{array}$ \\
\hline Receives & $0.03^{* *}$ & 0.02 & 0.02 \\
\hline remittances & $(0.01)$ & $(0.02)$ & $(0.02)$ \\
\hline \multirow[t]{2}{*}{ Male } & -0.00 & & $-0.02^{*}$ \\
\hline & $(0.01)$ & & $(0.01)$ \\
\hline \multirow[t]{2}{*}{ Age } & -0.00 & $0.02^{+}$ & 0.01 \\
\hline & $(0.00)$ & $(0.01)$ & $(0.01)$ \\
\hline \multirow[t]{2}{*}{ Age squared } & 0.00 & 0.00 & 0.00 \\
\hline & $(0.00)$ & $(0.00)$ & $(0.00)$ \\
\hline \multirow[t]{2}{*}{ Married } & $0.05^{* *}$ & $0.08^{* *}$ & $0.08^{* *}$ \\
\hline & $(0.01)$ & $(0.03)$ & $(0.03)$ \\
\hline \multirow[t]{2}{*}{ Ethnic Kyrgyz } & $0.10^{* *}$ & & $0.10^{* *}$ \\
\hline & $(0.01)$ & & $(0.01)$ \\
\hline \multirow[t]{2}{*}{ Urban } & $-0.07^{* *}$ & & $-0.08^{* *}$ \\
\hline & $(0.01)$ & & $(0.01)$ \\
\hline \multirow[t]{2}{*}{ Household size } & $0.01^{* *}$ & $-0.02^{* *}$ & $-0.02^{*}$ \\
\hline & $(0.00)$ & $(0.01)$ & $(0.01)$ \\
\hline \multirow[t]{2}{*}{ Household has kids } & 0.01 & 0.01 & 0.02 \\
\hline & $(0.01)$ & $(0.03)$ & $(0.03)$ \\
\hline \multirow[t]{2}{*}{ Secondary } & -0.02 & 0.03 & 0.02 \\
\hline & $(0.01)$ & $(0.07)$ & $(0.07)$ \\
\hline \multirow[t]{2}{*}{ Technical } & $-0.04^{*}$ & -0.01 & -0.02 \\
\hline & $(0.02)$ & $(0.07)$ & $(0.07)$ \\
\hline \multirow[t]{2}{*}{ University } & 0.03 & 0.11 & 0.12 \\
\hline & $(0.02)$ & $(0.08)$ & $(0.08)$ \\
\hline \multirow[t]{2}{*}{ Works } & 0.01 & 0.02 & 0.02 \\
\hline & $(0.01)$ & $(0.01)$ & $(0.01)$ \\
\hline \multirow[t]{2}{*}{ Plays sports } & $0.07^{* *}$ & $0.02^{+}$ & $0.02^{+}$ \\
\hline & $(0.01)$ & $(0.01)$ & $(0.01)$ \\
\hline \multirow[t]{2}{*}{ Personality } & $0.08^{* *}$ & & $0.08^{* *}$ \\
\hline & $(0.01)$ & & $(0.01)$ \\
\hline Experienced idiosyncratic & $-0.02^{*}$ & $-0.02^{*}$ & $-0.02^{*}$ \\
\hline shock & $(0.01)$ & $(0.01)$ & $(0.01)$ \\
\hline \multirow[t]{2}{*}{ Asset index } & $0.06^{* *}$ & $0.02^{+}$ & $0.02^{*}$ \\
\hline & $(0.01)$ & $(0.01)$ & $(0.01)$ \\
\hline \multirow[t]{2}{*}{ Constant } & & -0.36 & \\
\hline & & $(0.28)$ & \\
\hline Observations & 17613 & 17658 & 17613 \\
\hline Sigma_u & 0.50 & & 0.50 \\
\hline Within $\mathrm{R}^{2}$ & & 0.01 & \\
\hline Joint test of equality of means & - & & 0.00 \\
\hline
\end{tabular}

Robust standard errors in parentheses; ${ }^{+} p<0.1,{ }^{*} p<0.05,{ }^{* *} p<0.01$. Regressions also include oblast fixed effects. 
Chapter 6

Chapter 6

Conclusion

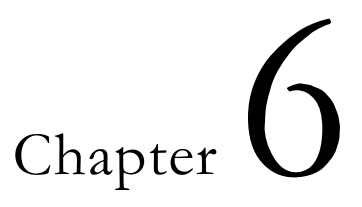

Conclusion 
Conclusion 
This final chapter highlights the key findings derived from this dissertation. Section 6.1 summarises and discusses the main conclusions as well as the implications for policy and research from each chapter. Section 6.2 gives a more general overview of the role of social assistance and remittances in the fight against poverty. Finally, Section 6.3 discusses the main limitations of this study as well as directions for future research, while Section 6.4 concludes.

\subsection{Key findings and implications}

This dissertation has explored the relationship between public (social assistance) and private (remittances) transfers and a wide range of well-being indicators, from food security to subjective well-being and expenditure patterns. In doing so, it has contributed to a better understanding of the links between remittances and social assistance given that both are social protection mechanisms used by households to meet basic needs and build resilience against shocks. They key findings from each chapter are summarised below.

\section{Key finding 1: Social assistance transfers can achieve the desired outcomes even in the absence of conditions tied to certain behaviours}

Key finding 2: Neither remittances nor social assistance transfers are "misused".

Chapter 2 explored the expenditure patterns of remittances and social assistance transfers in South Africa and showed that the two social assistance transfers (Old Age Pension and Child Support Grant) as well as remittances are spent differently than other sources of income. The Child Support Grant increased expenditure on education and, in some cases, on food. This increase was not only due to an income effect, but also due to a substitution effect: households spent more on education from the Child Support Grant than from other sources of income. One possible explanation for this finding is a labelling effect, which would imply that transfers are spent on children because the programme is targeted at them and it is aimed at improving their well-being. Meanwhile, the Old Age Pension was spent disproportionately on goods that improve child wellbeing as well as the well-being of the household as a whole, as an increase in pension income led to an increase in the share spent on food, education, and utility bills. This result was unexpected, as one would not anticipate pension income to alter the patterns of expenditure within a household (as they often replace the income that was previously earned in the market). A possible explanation is that a non-negligible amount of households in South Africa depend on this grant, and in many of them it constitutes the main source of income. Remittance income was also spent differently than other sources of income, as it increased expenditure on food and decreased the share of expenditure 
on other non-basic goods, such as alcohol, tobacco, and clothing by more than other sources of income.

One main implication from these findings is that social assistance transfers can bring the desired outcomes despite not being conditional upon certain behaviours. Provided that the effects from the Child Support Grant are explained by a labelling effect, this would imply that the government is effectively targeting and delivering the message that the grant is meant to be spent on children and, especially, on children's education. This would also imply that the programme is achieving its intended outcomes even if the grant is unconditional.

In addition, this chapter adds to the existing evidence that unconditional cash transfers are spent on necessities like food as well as on human capital goods (Haushofer and Shapiro 2013; The Kenya CT-OVC Evaluation Team 2012). This implies unconditional transfers can lead to positive long-term well-being outcomes and contribute to breaking the inter-generational transmission of poverty despite transfers not being conditional upon certain behaviours (such as attending school). Conditional cash transfers have very high administrative costs and high costs of participation for beneficiaries (Handa et al. 2009). In addition, and although there are political motivations for implementing conditional cash transfers, it is not clear whether the positive impacts of CCTs that have been observed in other contexts like Latin America are due to the conditionalities per se, or as a result of an increase in income that would be spent on these goods and services anyways (Handa et al. 2009).

A key factor when analysing the efficiency of social protection programmes is the way in which recipients spend social assistance transfers. In policy debates, many arguments against the broadening of social protection systems are based on presumptions that recipients misuse or make unwise decisions on how to spend transfers (Du Toit and Neves 2009). As a result, it is important to understand how expenditure decisions are made in poor households. In the migration and development debate, there have also been claims that remittances are used for conspicuous consumption and that, thefore, they do not contribute to development. This chapter has shown that neither social assistance nor remittances are misused, as they are associated with an increase in spending either on basic goods or on human capital goods.

Key finding 3: Food security is more than food. Both public and private transfers increase the quantity and variety of food consumed, but this does not necessarily translate into better nutritional outcomes 
Chapter 3 examined the impact of social grants (social assistance) and remittances on food security and nutritional outcomes. Dietary diversity index (DDI) at the household level and body mass index (BMI) at the individual level (children and adults) were used as the key measures of food security status. This Chapter concluded that the Old Age Pension and remittances improved food security due to an income effect. This was not the case with the Child Support Grant, most likely due to the fact that transfers were very small in size. Neither the Old Age Pension nor remittances improved nutritional outcomes, however. In the case of the Child Support Grant, after performing some additional estimations to create an appropriate counterfactual and reduce the likelihood of endogeneity bias, a positive effect on children's BMI was observed. This is also an important finding and it gives further indication (in line with the findings from Chapter 2) that the Child Support Grant leads to positive nutritional outcomes.

Despite the positive effects found in this Chapter on either food security or nutritional outcomes, a review of the evidence on the state of food security and nutrition in South Africa in the last 20 years shows that food insecurity has been falling, but that undernutrition indicators are falling more slowly, if at all (Devereux and Waidler 2017). Given the high coverage of social protection transfers in South Africa, this raises an obvious question: why are social transfers not making a more substantial contribution towards improving nutrition outcomes in grant-receiving households?

Although social transfers in South Africa are relatively generous compared to other countries, they are not sufficient to meet nutritional needs. The reason is that food prices are rising, and social grants are not index-linked according to inflation. Another important reason why social grants do not significantly reduce malnutrition is that transfers are often diluted among other individuals (and not only the intended beneficiary) and among other needs, such as educational expenditure, clothing, transportation, etc. (several sources, explained in Devereux and Waidler (2017)).

In addition, and despite the positive evidence of cash transfer programmes found to date, there are non-financial or structural barriers that can prevent transfers from achieving their full potential and improving long-term outcomes (Roelen et al. 2017). This is underscored by the extensive literature finding limited effects of social assistance transfers on nutrition (Manley, Gitter and Slavchevska 2012; Bastagli et al. 2016). It has been recognised that malnutrition is a complex phenomenon that has multiple causes (Devereux and Waidler 2017). UNICEF's conceptual framework for the determinants of child malnutrition (UNICEF 1990) identified three 'underlying causes' of child malnutrition: inadequate access to food, inadequate care for children and women, and insufficient health services and unhealthy environment. Only the first of these can be directly attributed to poverty - not enough resources at the individual or household level to acquire adequate food. Nutrition, therefore, needs more than food. 
The implication is that neither social transfers nor remittances are enough to eradicate malnutrition in South Africa. Even if increases in income can raise food expenditure and lead to increased food consumption, indicators of malnutrition could remain unchanged at the aggregate level if the scope and scale of transfers are not enough to affect national nutrition statistics. "Even at the individual level, increased food consumption, largely financed by social grants, might not improve the person's nutrition status if care practices are poor or the sanitation environment is unhygienic" (Devereux and Waidler 2017, p. 23). Social grants and, to a lesser extent, remittances are essential to reduce food insecurity and hunger in poor households, but the determinants of nutrition status are more complex than food consumption. As stated in Devereux and Waidler (2017), "a holistic approach is needed to tackle the persistent and unacceptably high levels of child malnutrition in South Africa” (p. 24).

Key finding 4: The impacts of social assistance on subjective well-being depend on the context where the social protection programme is implemented and can be influenced by factors such as stigma, trust in the government, or poverty

Chapter 4 analysed the relationship between social assistance and subjective well-being in Kyrgyzstan. Under the Soviet period, poverty and poverty-targeted transfers were highly residual and stigmatised (Barr 1994). Contrary to previous studies that have found a positive relationship between social assistance and subjective well-being (all of them in Sub-Saharan Africa), ${ }^{48}$ this Chapter found a negative effect of social assistance on life satisfaction, as well on the subjective economic expectations of respondents with respect to the future. Moreover, to a certain extent, social assistance recipients were less likely to report an improvement in the economic situation with respect to the past.

The findings from Chapter 4 confirm previous evidence from Kyrgyzstan that transfers are inadequate to lift a significant percentage of the population out of poverty (Gassmann and Zardo Trindade 2015). However, the negative effect on the subjective well-being indicators chosen is counterintuitive and different from previous studies on this topic. One reason could be that government benefits in Kyrgyzstan are, in general, not large enough to address the negative mechanisms associated with poverty and, hence, increase satisfaction with life and with the household's economic situation. Another explanation can be that beneficiaries are disappointed by the State, given that the help they expect is only marginal and not enough to cover basic needs. Finally, an additional explanation is that, based on its past as a member of the Soviet Union, poor individuals who receive social assistance in Kyrgyzstan suffer from stigma and shame, which would result in lower subjective well-being levels.

${ }^{48}$ See Haushofer and Shapiro (2016), Kilburn et al. (2018); Daidone et al. (2015); Natali et al. (2018). 
An important implication that arises from the findings of this Chapter is that the impacts of social protection programmes can differ depending on the history and the characteristics of the countries where they take place. A bad implementation (not only in terms of the way the cash is delivered but also in terms of the behaviour of the officials involved in the process of delivering it) can also result in a bad experience of participants towards social assistance and a higher likelihood of feeling stigma or shame. Based on a recent public opinion survey among residents of Kyrgyzstan, more than 70 percent of the citizens think that corruption is a big problem in the country and that the government is not making a sufficient effort to fight corruption (International Republican Institute 2017). Concerns about corruption apply to different kinds of institutions and organisations, including ministries, universities, the police, etc. Moreover, past evidence points out that there are important complaints among social protection beneficiaries about social service officials, who are accused of engaging in unlawful practices, abusing their power and humiliating clients (Narayan et al. 2000).

The conclusions from Chapter 4 can be informative to other Former Soviet or Central Asian countries, where research on subjective well-being is lacking (such as Tajikistan or Kazakhstan). Therefore, collecting qualitative data and extending this research to similar countries would be helpful to confirm these findings and extend the evidence base on this topic.

\section{Key finding 5: Remittances can improve the economic situation of households, but not necessarily their life satisfaction}

Due to the determinant role of remittances for the Kyrgyz economy, Chapter 5 looked at whether remittances improved the subjective well-being of beneficiary households. This Chapter found that remittance income was associated with feelings of improvement in the economic situation of the household with respect to the past, which confirms findings from previous studies that looked at the effects of remittances on subjective economic well-being. Moreover, after controlling for reverse causality through an instrumental variable approach, remittances were associated with a higher likelihood of expecting an improvement in the economic situation in the future. The relationship between remittances and life satisfaction was not significant, though. A potential explanation for this finding is that other negative factors related to receiving remittances and having a member abroad could counteract the positive feelings of experiencing an improvement in the economic situation. For instance, qualitative evidence points out to labour shortages, lack of qualified and well-trained personnel in rural areas, and changes in care arrangements for children and elderly as a result of migration (Thieme 2014). 
The findings from Chapter 5 confirm the existing evidence (mainly from Latin America) that remittances increase the satisfaction with the economic situation of the household, but do not necessarily lead to an increase in recipients' happiness or satisfaction with life

\subsection{Remittances, social assistance, and poverty}

Although complementarity or substitutability between social assistance and remittances is not directly tested in this thesis, ${ }^{49}$ the aim was to investigate how effective public and private transfers are in improving different poverty dimensions. As explained in the introduction, several factors can explain differences in poverty reduction effectiveness, including the targeting, coverage, transfer adequacy, regularity and expenditure patterns of transfers. The first point to highlight from this work is the very small overlap between social assistance and remittance recipients, both in South Africa and in Kyrgyzstan. This has posed methodological challenges, as comparing the effects of remittances and social assistance in the same estimation when groups of recipients are highly heterogeneous can be problematic. However, this is a finding per se, as the fact that remittances and social assistance reach different population groups implies that these two transfers are to a larger extent complements than substitutes. The usual explanation for this phenomenon is that migrants do not necessarily originate from the poorest households, as migration entails certain costs, whereas social assistance often targets the poorest population. In the two case studies analysed, however, this is only true to a certain extent.

In South Africa, both remittances and social assistance transfers are received by the poor (although some remittances do reach wealthier households), as a majority of migrants are low-skilled and negatively selected in terms of income and education (Jacobs and Plessis 2016). On the one hand, the African National Congress (ANC), which has been ruling since the start of democracy in South Africa, has invested in broadening the social protection system and, as a result, expenditure on social grants has been growing in the last two and a half decades. On the other, migration and remittances have become less significant due to a decline in local light manufacturing activity and an overall decline in jobs in the manufacturing and mining sectors, which were a priority under the Apartheid government (du Toit and Neves 2009). This means that while social assistance coverage has been expanding since the end of Apartheid, migration and remittances have declined, which explains the small overlap between social assistance and remittance beneficiaries.

\footnotetext{
${ }^{49}$ First of all, it is different to test complementarity if social assistance and remittances target different parts of the population. Second, since I have neither randomised control nor baseline surveys, I can only indirectly establish a sense of causality.
} 
Moreover, some studies point out that social assistance transfers have crowded out remittances, meaning that an increase in social spending has led to a decline in remittances received by social grant beneficiaries (Jensen 2004; Du Toit and Neves 2009). Many authors argue that this can be perceived as sub-optimal indirect effect of social spending, as there is a reduction in effectiveness of social protection programmes. Chapter 3 argues that this is not necessarily a bad outcome, as this means that senders of remittances, who have in general low levels of well-being, can be better off as they can use the money for other pressing needs. Du Toit and Neves (2009), in line with sociologists and anthropologists, argue that crowding out can be bad only if households are considered in isolation and not in the context of spatially extended reciprocation networks. The authors find qualitative evidence based on detailed case studies that access to social assistance by migrants' relatives allow migrants to have better lives, invest in their human capital, and help other relatives who do not receive social assistance. In these cases, remittances are redirected for purposes other than meeting basic needs or helping close family members. This does not mean, however, that they do not contribute to improvements in wellbeing, as it implies that either migrants are better off than before, or other relatives who were not receiving remittances can benefit from these transfers.

In addition, Chapter 2 has shown that the way transfers are labelled influence the expenditure behaviour of recipient households. This means that governments can contribute to improving specific dimensions of well-being across the population through the design of its social protection programmes. This is not the case with remittances, as expenditure patterns will depend on the situation and expectations of both senders and recipients of remittances, and this may vary across different households and different migratory contexts.

In South Africa, social transfers and remittances also complement each other. Chapter 2 and Chapter 3 show that, among the poorest households and in line with previous evidence, both social assistance and remittances help to cover every day needs. In some cases, as some previous evidence has shown (Sienaert 2008; Ardington et al. 2009), social assistance transfers 'crowd in' remittances, as government transfers are used to finance job searches in urban areas. This would also explain the findings from Chapter 2 that remittances and social transfers are not spent in the same way, although all transfers play a key role in financing basic household needs and human capital investments.

In Kyrgyzstan, the situation is different. After independence and with the end of the planned economy, informal transfers (including remittances, informal networks, and inter-household transfers in general) became a more important source of protection as a result of the loss of transfers from the Soviet Union central budget (Tesliuc 2004). Despite the efforts from the government to reform the social protection system to reduce 
extreme poverty, social assistance transfers have low coverage and therefore many poor households do not benefit from social assistance.

After 1991 and, as opposed to the case of South Africa, remittances have gained importance relative to other sources of income. Remittance income has higher coverage and adequacy than social assistance transfers, as it constitutes a much more important source of income in recipient households. Like in South Africa, migrants also originate from poor households (although, most likely not the extreme poor), although in Kyrgyzstan a higher percentage of the poorest receive remittances than social assistance (Gassmann 2011). These factors can explain the different effects observed between remittances and social assistance on subjective well-being, as remittances improve recipients' perception of their economic situation, whereas social assistance recipients do not feel they are better off than in the past, nor do they perceive that their economic situation will improve in the near future.

In Kyrgyzstan, therefore, informal sources of social protection are a better strategy for poverty reduction. However, this also implies that the country's economy is highly dependent on the financial situation of Russia (which is the main destination country for migrants) and therefore vulnerable to changes in the country's exchange rates, immigration policies, and unemployment rates. Moreover, other potential negative effects of migration in Kyrgyzstan include brain drain, labour shortages, and limitations to achieve economic growth as a result of a reduced motivation to invest in the country (ICG 2016; Thieme 2014). This means that migration and remittances should be complemented with policies that encourage investment in Kyrgyzstan, promote employment, and improve the living conditions of households in sending communities. For example, the government could encourage the productive use of remittances in a way that it leads to better livelihood opportunities in migrant sending areas of Kyrgyzstan. Investing in rural areas is essential for households not being fully dependent on migration, and to avoid labour shortages and lack of basic services in the most deprived areas of the country. Moreover, given that migration to Russia and other neighbouring countries is temporary and migrants plan their permanent return as they reach their retirement age (Thieme 2014), the government could facilitate this transition and provide return migrants with better living conditions through, for example, a pension or saving scheme. This would improve the living conditions of returnees while generating positive outcomes for the economy, such as increased employment and savings accumulation.

As this dissertation has shown, the importance of remittances vis-a-vis social assistance depends, to a large extent, on the history and level of development of a country. Being aware of the importance of different strategies households rely upon to improve their well-being is important and can inform policy making in different ways. Inasmuch as both social assistance and remittances contribute to improvements in well-being in both 
South Africa and Kyrgyzstan, as this thesis has shown, it is important to recognise the limits to what these transfers can achieve. In the case of remittances, putting a heavy burden on recipients on how they should spend these transfers (for example, by encouraging them to invest in productive activities) is unlikely to improve their poverty reduction effectiveness. The reason is that migrant households have many different needs which vary over time, and will use remittances for the purposes that they consider more appropriate in each situation. In the case of social assistance transfers, and even if governments can encourage recipients to spend transfers on specific goods and services which are likely to improve their nutritional or educational outcomes, the positive effects of transfers may not be sufficient to lift a significant proportion of the population out of poverty (as Chapter 3 has shown). This is also why it is important to consider other development strategies to complement social protection programmes.

\subsection{Limitations and directions for future research}

While the studies included in this dissertation have overcome some major methodological barriers from previous work comparing the effects of remittances and social assistance transfers, these studies are not without their limitations. In absence of randomisation in the selection of social assistance or remittance recipients, as well as in absence of baseline data collected before the first migration episode or before the launch of the social protection programmes, all the empirical chapters rely on quasi-experimental techniques of policy evaluation to deal with endogeneity, such as propensity score matching, instrumental variables estimation, and panel data techniques like fixed effects estimation. However, each method has its advantages and disadvantages, and therefore proving causality is always challenging. The availability of longitudinal surveys to analyse changes in well-being and livelihood strategies, such as the two surveys used in this dissertation, is a big step forward in this regard, and more countries in the future should have representative longitudinal household surveys (with information on both informal and formal transfers) available to researchers. The challenge of proving causality is harder when studying the impacts of remittances than of social protection transfers, as the decision to send remittances is taken at the household level and therefore it is inherently endogenous. Although throughout the thesis the word 'effects' is used when describing the findings from each of the chapters, this is done assuming that the conditions from each method hold and that quasi-experimental techniques properly address endogeneity bias. This is unlikely to be always the case, especially in Chapter 2. Therefore, in some cases, the word 'effects' could instead reflect 'associations' between transfers and well-being outcomes. 
In addition, lab or field experiments would be recommended to better test the fungibility of money and analyse how people spend different sources of transfers. Qualitative studies would also be very helpful and should complement quantitative ones in order to get a better understanding of households' dynamics and the way they combine different social protection strategies.

Another feature that has posed methodological challenges is the fact that remittance recipients and social assistance recipients are heterogeneous groups, meaning that if this heterogeneity is not accounted for, it is not possible to know whether the differences in impacts from remittances and social assistance transfers are due to the transfers themselves or to the fact that they are received by different individuals or households. In South Africa, econometric techniques that account for this heterogeneity were used in an attempt to overcome this, such as fixed effects estimation and several sub-sample estimations to compare more homogeneous groups of recipients. In Kyrgyzstan, the overlap was so small that social assistance and remittances had to be analysed separately, acknowledging that they are received by different population groups. This is likely to be the case in many countries, however. This also implies that when studying the linkages between social assistance and remittances (or other sources of informal transfers), one should be aware that these transfers are likely to cover different population groups.

In terms of directions for future work, it would be recommended to study case studies and datasets with a bigger overlap of remittances and social assistance beneficiaries. In addition, other sources of informal transfers - and not only remittances- should be analysed. In developing countries, households engage in many different forms of informal exchanges, such as inter-household transfers, mutual solidarity or rotating saving associations, etc. Consequently, and even though further analysis on the links between remittances and social assistance is needed, future work should focus on the links between social assistance and other kinds of private or informal transfers.

\subsection{Concluding remarks}

This dissertation has shown that both social assistance transfers and remittances are important social protection strategies that households rely upon to achieve better wellbeing outcomes, albeit the extent to which one transfer is more effective than the other is highly dependent on the history and level of development of the country studied. Despite the percentage of household receiving both social assistance and remittances is low, transfers are likely to complement each other in poor households. The reason is that government money can be used to finance migration or cover the costs of searching 
for a job in the city, and this will most likely translate into higher well-being improvements than if only one transfer is received. Moreover, 'Crowding out' -or a decline in remittances resulting from an increase in social spending- is not necessarily a bad outcome, given that the receipt of social assistance can ease the burden on migrants and allow them to allocate their income to different uses or to meet other needs. Households should not be considered in isolation, especially in developing countries, where migrants send remittances not only to the immediate family, but also to extended family living in other households.

Complementarity between social assistance and remittances could be further exploited to maximise the poverty reduction potential of these transfers. For instance, offering social protection to return migrants will improve individuals' well-being and bring at the same time important benefits to rural areas or sending communities if the resources and skills that migrants bring back home can be utilised in an effective way. At the same time, it is important that migrant households who stay behind in sending communities have access to services and to social protection in general. For instance, if there are no health facilities available or if migrant children do not have access to good quality education, remittances cannot contribute to improvements in human capital.

It is important to recognise that despite remittances and social assistance transfers are important poverty reduction instruments, neither of them can be seen as a unique solution to meet the first sustainable development goal 'No Poverty'. Structural and nonfinancial barriers often prevent these transfers from improving long-term well-being outcomes. Moreover, public and private transfers do not always reach the poorest households and therefore their poverty reduction potential is compromised. While the coverage and adequacy of social protection transfers should improve, migration costs as well as the transaction costs of remittances should be reduced to allow the poorest to benefit from migration, so that no one is left behind. All in all, formal and informal strategies of social protection are not isolated from each other, and therefore both should be analysed together when designing policy interventions. 


\section{References}

Ahmed, A., Hoddinott, J., Roy, S., Sraboni, E., Quabili, W. \& Margolies, A. (2016). Which kinds of social safety net transfers work best for the ultra-poor in Bangladesh? Operation and impacts of the Transfer Modality Research Initiative. Dhaka: IFPRI and World Food Programme.

Amuedo-Dorantes, C. (2014). The good and the bad in remittance flows. IZA World of Labor 2014:97

Ardington, C., Case, A., \& Hosegood, V. (2009). Labor supply responses to large social transfers: Longitudinal evidence from South Africa. American economic journal: Applied economics, 1(1), 22-48.

Barr, N. A. (Ed.). (1994). Labor markets and social policy in Central and Eastern Europe: The transition and beyond. World Bank Publications.

Bastagli, F., Hagen-Zanker, J., Harman, L., Barca, V., Sturge, G. \& Schmidt, T. (2016) Cash transfers: what does the evidence say? A rigorous review of programme impact and of the role of design and implementation features. London: Overseas Development Institute (ODI).

Beukes, R., Jansen, A., Moses, M. \& Yu, D. (2015). Exploring the eligibility criteria of the Child Support Grant and its impact on poverty. Paper presented at the 2015 Biennial Conference of the Economic Society of South Africa. Cape Town: University of Cape Town. 2-4 September.

Daidone, S., Handa, S., Davis, B., Park, M., Osei, R. D., \& Osei-Akoto, I. (2015). Social Networks and Risk Management in Ghana's Livelihood Empowerment Against Poverty Programme, Papers inwopa 781, Innocenti Working Papers

Department of Social Development (DSD), South African Social Security Agency (SASSA) and UNICEF (2011). Child Support Grant Evaluation 2010: Qualitative Research Report. Pretoria: UNICEF South Africa.

Department of Social Development (DSD) (11 September 2014). Statement by the Minister of Social Development, Ms Bathabile Dlamini, on the Occasion of the Media Briefing on Unauthorised Deductions. www.dsd.gov.za/index.php?option=com_content\&task=view\&id=625\&Itemid=106 [accessed 14 July 2016].

Department of Agriculture, Forestry and Fisheries (DAFF) (2015). Abstract of Agricultural Statistics 2015. Pretoria: Republic of South Africa.

Devereux, S. \& Waidler, J. (2017). Why does malnutrition persist in South Africa despite social grants? Food Security SA Working Paper Series No.001. DST-NRF Centre of Excellence in Food Security, South Africa.

Gassmann, F. (2011). To What Extent Does the Existing Safety Net Protect the Poor?

Handa, S., Peterman, A., Davis, B., \& Stampini, M. (2009). Opening up Pandora's box: The effect of gender targeting and conditionality on household spending behavior in Mexico's PROGRESA program. World Development, 37(6), 1129-1142.

Haushofer, J., \& Shapiro, J. (2016). The short-term impact of unconditional cash transfers to the poor: experimental evidence from Kenya. The Quarterly Journal of Economics, 131(4), 1973-2042.

Haushofer, J., \& Shapiro, J. (2013). Household response to income changes: Evidence from an unconditional cash transfer program in Kenya. Massachusetts Institute of Technology.

ICG (2016). Kyrgyzstan: State Fragility and Radicalisation, Crisis Group Europe and Central Asia Briefing No83

International Republican Institute (IRI) (2017). Public Opinion Survey Residents of Kyrgyzstan 2017. Center for Insights in Survey Research.

Jacobs, W., \& Du Plessis, D. J. (2016). A spatial perspective of the patterns and characteristics of main-and substream migration to the Western Cape, South Africa. Urban Forum 27 (2), 167-185.

Jensen, R. T. (2004). Do private transfers 'displace' the benefits of public transfers? Evidence from South Africa. Journal of Public Economics, 88(1), 89-112.

Kilburn, K., Handa, S., Angeles, G., Tsoka, M., \& Mvula, P. (2018). Paying for Happiness: Experimental Results from a Large Cash Transfer Program in Malawi. Journal of Policy Analysis and Management, 37(2), 331-356.

Manley, J., Gitter, S. \& Slavchevska, V. (2012). How effective are cash transfer programmes at improving nutritional status? A rapid evidence assessment of programmes' effects on anthropometric outcomes. London: EPPICentre, Social Science Research Unit, Institute of Education, University of London.

Narayan, D., Chambers, R., Shah, M. K., \& Petesch, P. (2000). Voices of the Poor: Crying out for Change. New York: Oxford University Press for the World Bank.

Natali, L., Handa, S., Peterman, A., Seidenfeld, D., \& Tembo, G. (2018). Does money buy happiness? Evidence from an unconditional cash transfer in Zambia. SSM-population bealth, 4, 225-235

Roelen, K., Devereux, S., Abdulai, A. G., Martorano, B., Palermo, T., and Ragno, L. P. (2017). How to Make 'Cash Plus' Work. Office of Research- Innocenti Working Paper, WP-2017-10. 
SASSA (South African Social Security Agency) (2016). Fact sheet: Issue no 4 of 2016 - 30 April 2016, A statistical summary of social grants in South Africa. www.sassa.gov.za/index.php/statistical-reports [accessed 16 August 2016].

Sienaert, A. (2008). The labour supply effects of the South African state old age pension: Theory, evidence and implications. A Southern Africa Labour and Development Research Unit. Working Paper Number 20. Cape Town: SALDRU, University of Cape Town

Taylor, V. \& Chagunda, C. (2015). The gender dimensions of food insecurity: Women's experiences of entitlements and deprivation in South Africa. Chapter 7 in S. Fukuda-Parr and V. Taylor (editors), Food Security in South Africa: Human rights and entitlement perspectives. Cape Town: UCT Press.

Tesliuc, E. D. (2004). Mitigating Social Risks in Kyrgyz Republic. Social Protection discussion paper series; no. 408. Washington, DC: World Bank. http://documents.worldbank.org/curated/en/917891468758403442/Mitigating-social-risks-in-Kyrgyz-Republic

The Kenya CT-OVC Evaluation Team. (2012). The impact of the Kenya Cash Transfer Program for Orphans and Vulnerable Children on household spending. Journal of Development Effectiveness, 4(1), 9-37.

Thieme, S. (2014). Coming home? Patterns and characteristics of return migration in Kyrgyzstan. International Migration, 52(5), 127-143.

du Toit, A. \& Neves, D. (2009). Trading on a Grant: Integrating Formal and Informal Social Protection in PostApartheid Migrant Networks. BWPI working paper 75.

UNICEF (1990). Strategy for Improved Nutrition of Children and Women in Developing Countries. Policy Review Paper, E/ICEF/1990/1.6. New York: UNICEF. 
Conclusion 
Valorisation

Valorisation 
In accordance to Article 23 of the regulation governing the attainment for doctoral degree in the Maastricht University, the following section discusses the valorisation opportunities offered by this PhD thesis. Following the corresponding guidelines, these opportunities are analysed in terms of the social and economic relevance of the thesis, the potential target groups to whom the results can be interesting and the degree of innovativeness of the research methods used.

The main focus of the thesis has been to explore and compare the role of social assistance transfers and remittances in the fight against poverty, an objective that governments around the world pursue and which has culminated in the formulation of 17 global goals for sustainable development. In addition to the academic contribution of looking at two different kinds of transfers and exploring several poverty dimensions, the findings from this dissertation have direct social and economic relevance, as they are valuable for the design of public policies.

Chapter Two looks at how recipients spend the cash received through government transfers (social assistance), as compared to private transfers sent by relatives (remittances). The findings are relevant for policymakers given that the effectiveness of government programmes and the extent to which programme objectives are met are directly linked to how transfers are utilized. Arguments against the expansion of social protection programmes are often based on the presumption that recipients abuse government transfer programmes or that they make bad decisions on how to spend the money. Having a better knowledge of and more evidence on how remittances are used is also relevant for policymakers, given that these transfers have a strong poverty reduction potential. Remittances represent more than 20 percent of the GDP in many developing countries, and they have become more important than official development aid. In the migration and development debate, there have been claims that remittances are used for conspicuous consumption and that, thefore, they do not contribute to development. Chapter Two finds that both remittances and social assistance transfers are used to cover basic needs. Moreover, government transfers are spent according to the programmes' objectives.

Chapter Three explores whether social assistance transfers and remittances are effective in reducing food insecurity and malnutrition. Ending hunger is the second sustainable development goal that the United Nations has set for 2030. Reducing malnutrition is a major concern for governments and international organisations all around the world, given that child malnutrition has detrimental effects on child development in the longrun. Therefore, it is important to understand whether and how cash transfers, private or public, can contribute to improving this poverty indicator. This Chapter finds that both remittances and social assistance are effective in improving the quantity and quality of food consumed (food security). However, they are not sufficient to improve nutritional 
outcomes, such as children and adults' body mass index (BMI). These findings suggest that other interventions are needed to improve nutritional outcomes of the most vulnerable population. This thesis recommends a holistic approach to overcome structural barriers that prevent transfers from achieving their full potential. Structural barriers include, among others, limited knowledge on nutrition, unhygienic environments, and lack of access to safe drinking water.

Chapters Four and Five look at the relationship between transfers and subjective wellbeing. Although improving subjective well-being may not be the primary objective of government transfers or remittances, understanding this relationship has an important value in development, as improvements in subjective well-being have been linked to improved education and health outcomes, increases in productivity and consumption, and better social relationships. Moreover, poverty is not simply a lack of income but can materialise in other dimensions, including subjective well-being. Chapter Four finds that social assistance does not necessarily increase subjective well-being. An important implication for policymaking is that the attitudes of participants towards social protection depend on how these programmes are implemented. Badly designed or implemented programmes can result in negative experiences of participants, in particular if transfer receipt induces feelings of stigma or shame, which then leads to lower subjective wellbeing. Chapter Five finds that remittances have a positive effect on recipients' perceptions of their economic situation. However, receiving remittances does not lead to improvements in life satisfaction. Other negative factors related to receiving remittances and having a member abroad could counteract the positive feelings of experiencing an improvement in the economic situation.

This dissertation uses novel longitudinal surveys to answer the research questions at hand, and combines different econometric techniques in each Chapter. In terms of the diffusion of the results of the research, the main outcomes of the thesis have been published or are in the process of being published as working papers or peer-reviewed journal articles. Moreover, results have been presented at several international conferences. Specifically, Chapter Two has been presented at the IAREP-SABE Conference on Behavioural Economics in Sibiu, Romania (2015); Chapter Three has been presented at a seminar at the University of Western Cape, in South Africa (2016), the Social Protection Conference in Bonn, Germany (Tying the knots) (2016), and at the APPAM International Conference in Brussels, Belgium (2017). Chapters Four and Five have been presented at the $3^{\text {rd }}$ Life in Kyrgyzstan Conference in Bishkek, Kyrgyzstan (2017). Chapter Four has also been presented at the HDCA Conference in Buenos Aires, Argentina (2018). 
Valorisation 


\section{About the author}

Jennifer Waidler was born in Buenos Aires, Argentina. She holds a Master's in Public Policy with a specialization in Social Policy Design from Maastricht University, and a Degree in Business Administration from the University Carlos III de Madrid. During her time as a PhD fellow at UNU-MERIT, Jennifer has worked as a researcher on a variety of migration and social protection related projects for several institutions including the World Bank, The European Commission, the Overseas Development Institute, and the Centre of Excellence in Food Security in South Africa. Her dissertation focuses on the effects of public and private transfers on different well-being indicators in developing countries, and her main areas of interest/ expertise include multidimensional poverty measurement, effects of migration and remittances, and impacts of cash transfer programs on outcomes such as food security, subjective well-being, and expenditure behavior.

Jennifer is currently working at the UNICEF Office of Research - Innocenti (based in Florence, Italy), where she evaluates the effects of Cash Transfers and 'Cash PLUS' programs in Ethiopia and Tanzania as part of The Transfer Project. 


\section{Selected publications}

Vanore, M., Siegel, M., Gassmann, F., \& Waidler, J. (2017). Adult Child Migration and Elderly Multidimensional Well-Being: Comparative Analysis Between Moldova and Georgia, Research on Aging: 1-24

Gassmann, F., Siegel, M., Vanore, M., \& Waidler, J. (2017). Unpacking the Relationship between Parental Migration and Child Well-Being: Evidence from Moldova and Georgia, Child Indicators Research, 1-18.

Waidler, J., Vanore, M., Gassmann, F., \& Siegel, M. (2017). Migration and the MultiDimensional Well-Being of Elderly Persons in Georgia, Journal of Population Ageing, 122.

Devereux, S. \& Waidler, J. (2017). Why does malnutrition persist in South Africa despite social grants? Food Security SA Working Paper Series No.001. DST-NRF Centre of Excellence in Food Security, South Africa

Waidler, J., Vanore, M., Gassmann, F., \& Siegel, M. (2016). Does it matter where the children are? The wellbeing of elderly people 'left behind' by migrant children in Moldova, Ageing and Society, 1-26.

Waidler, J., Hagen-Zanker, J., Gassmann, F., \& Siegel, M. (2016). Do remittances and social assistance have different impacts on expenditure patterns of recipient households? The Moldovan Case, Migration and Development, 1-21.

Siegel, M., \& Waidler, J. (2012). Migration and multi-dimensional poverty in Moldovan communities, Eastern Journal of European Studies, 3:2, 105-119 